NTP TECHNICAL REPORT ON

THE TOXICOLOGY AND

CARCINOgENESIS Studies OF

Di-N-BUtYl Phthalate

(CASRN 84-74-2)

ADMINISTERED IN FEED tO

SpRague DaWley

(HSD:SPRAGUE DAWLEY ${ }^{\circledR} \mathrm{SD}^{\circledR}$ )

RATS AND B6C3Fl/N MICE

NTP TR 600

NOVEMBER 2021 


\title{
NTP Technical Report on the Toxicology and Carcinogenesis Studies of Di-n-butyl Phthalate (CASRN 84-74-2) Administered in Feed to Sprague Dawley (Hsd:Sprague Dawley ${ }^{\circledR}$ SD $^{\circledR}$ ) Rats and B6C3F1/N Mice
}

Technical Report 600

November 2021

\author{
National Toxicology Program \\ Public Health Service \\ U.S. Department of Health and Human Services
}

ISSN: 2378-8925

Research Triangle Park, North Carolina, USA 


\section{Foreword}

The National Toxicology Program (NTP), established in 1978, is an interagency program within the Public Health Service of the U.S. Department of Health and Human Services. Its activities are executed through a partnership of the National Institute for Occupational Safety and Health (part of the Centers for Disease Control and Prevention), the Food and Drug Administration (primarily at the National Center for Toxicological Research), and the National Institute of Environmental Health Sciences (part of the National Institutes of Health), where the program is administratively located. NTP offers a unique venue for the testing, research, and analysis of agents of concern to identify toxic and biological effects, provide information that strengthens the science base, and inform decisions by health regulatory and research agencies to safeguard public health. NTP also works to develop and apply new and improved methods and approaches that advance toxicology and better assess health effects from environmental exposures.

The Technical Report series began in 1976 with carcinogenesis studies conducted by the National Cancer Institute. In 1981, this bioassay program was transferred to NTP. The studies described in the NTP Technical Report series are designed and conducted to characterize and evaluate the toxicological potential, including carcinogenic activity, of selected substances in laboratory animals (usually two species, rats and mice). Substances (e.g., chemicals, physical agents, and mixtures) selected for NTP toxicity and carcinogenicity studies are chosen primarily on the basis of human exposure, level of commercial production, and chemical structure. The interpretive conclusions presented in NTP Technical Reports are derived solely from the results of these NTP studies, and extrapolation of the results to other species, including characterization of hazards and risks to humans, requires analyses beyond the intent of these reports. Selection for study per se is not an indicator of a substance's carcinogenic potential.

NTP conducts its studies in compliance with its laboratory health and safety guidelines and Food and Drug Administration Good Laboratory Practice Regulations and meets or exceeds all applicable federal, state, and local health and safety regulations. Animal care and use are in accordance with the Public Health Service Policy on Humane Care and Use of Laboratory Animals. Studies are subjected to retrospective quality assurance audits before they are presented for public review. Draft reports undergo external peer review before they are finalized and published.

The NTP Technical Reports are available free of charge on the NTP website and cataloged in PubMed, a free resource developed and maintained by the National Library of Medicine (part of the National Institutes of Health). Data for these studies are included in NTP's Chemical Effects in Biological Systems database.

For questions about the reports and studies, please email NTP or call 984-287-3211. 


\section{Table of Contents}

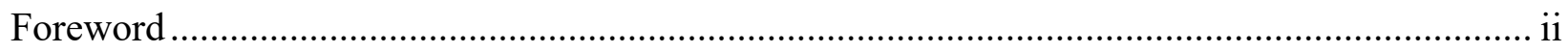

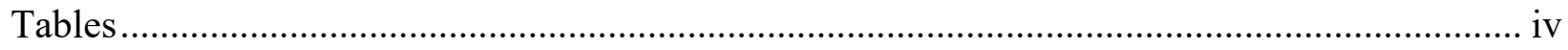

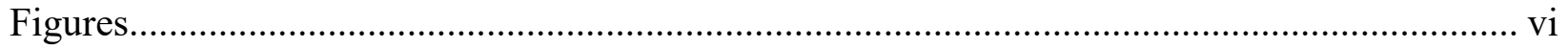

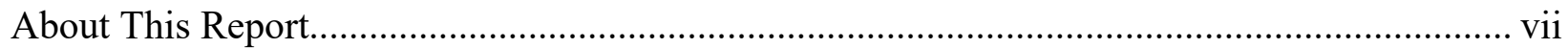

Explanation of Levels of Evidence of Carcinogenic Activity .................................................... xii

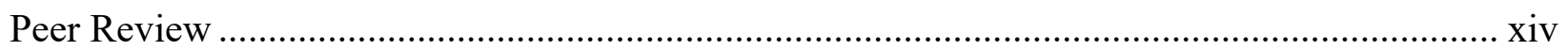

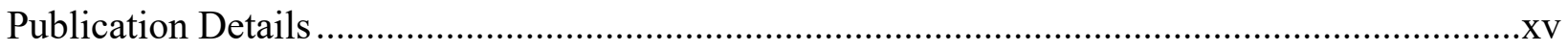

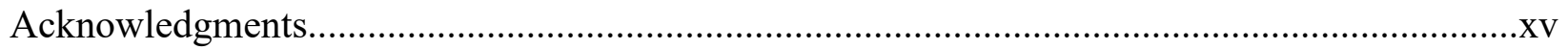

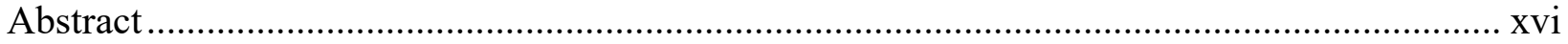

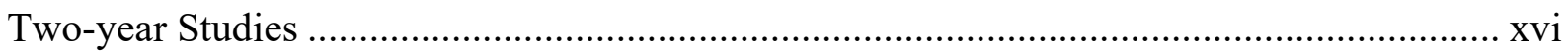

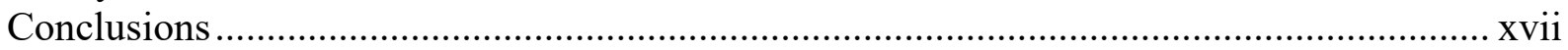

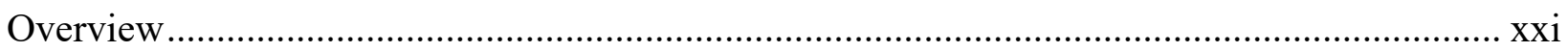

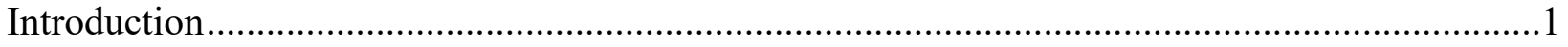

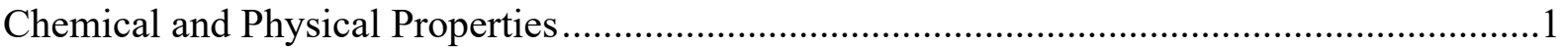

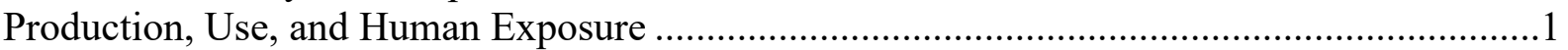

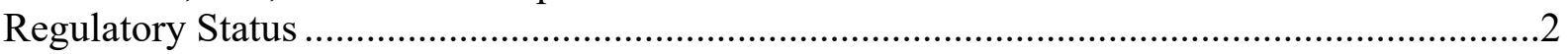

Absorption, Distribution, Metabolism, and Excretion ...............................................................

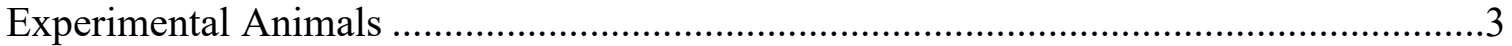

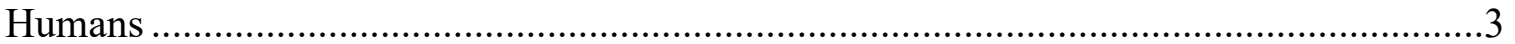

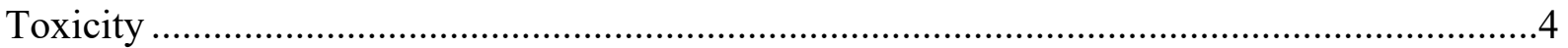

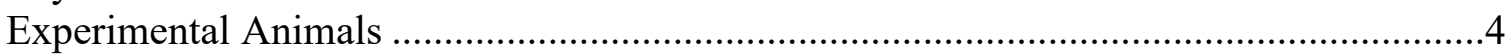

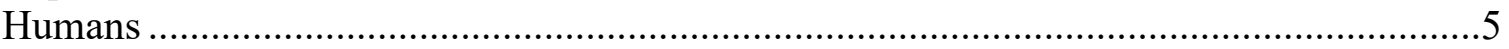

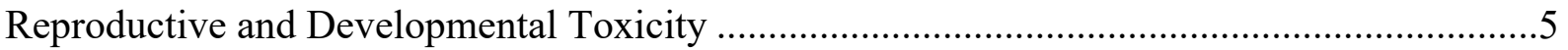

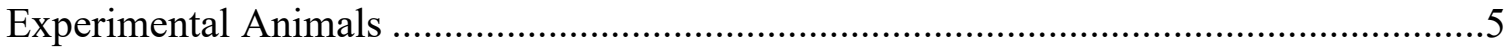

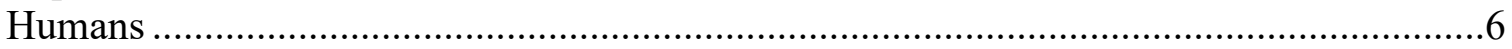

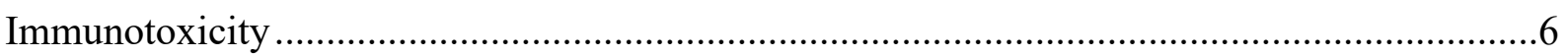

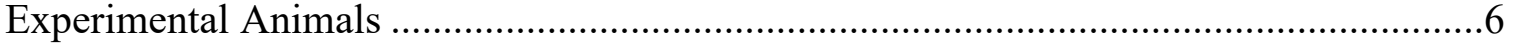

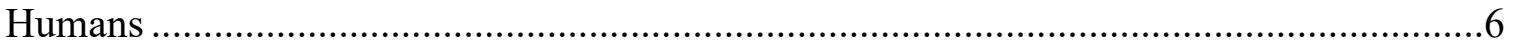

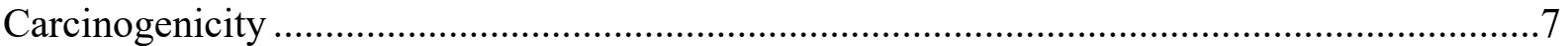

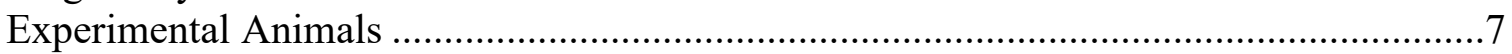

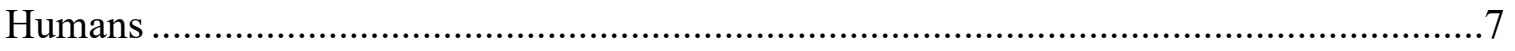

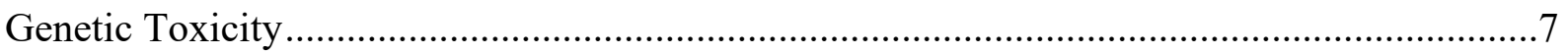

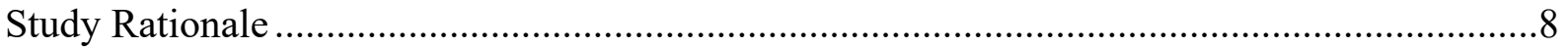

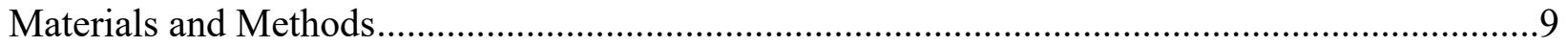

Procurement and Characterization of Di- $n$-butyl Phthalate ....................................................

Preparation and Analysis of Dose Formulations.............................................................

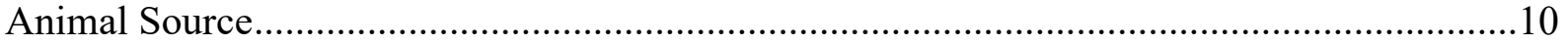

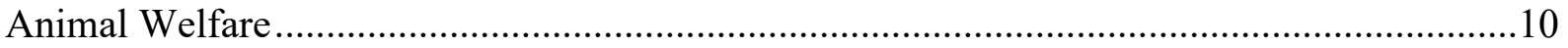

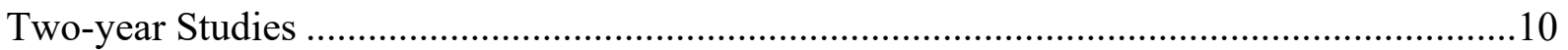


Exposure Concentration Selection Rationale ................................................................10

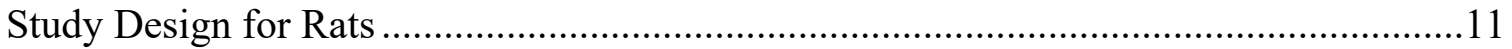

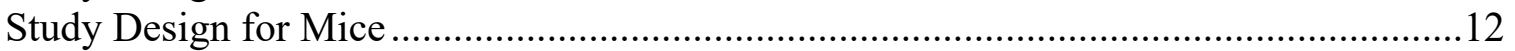

Clinical Examinations and Pathology ...........................................................................

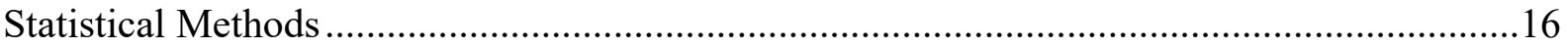

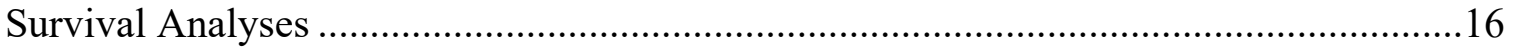

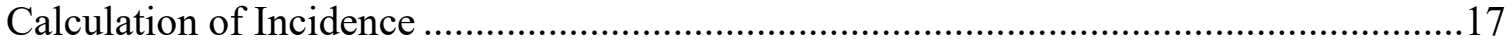

Analysis of Neoplasm and Nonneoplastic Lesion Incidence.............................................17

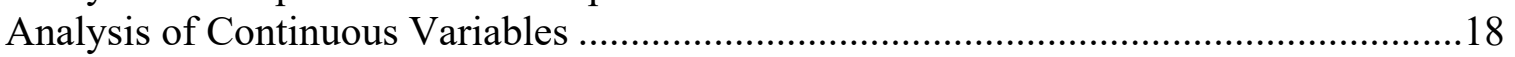

Analysis of Gestational and Fertility Indices..............................................................19

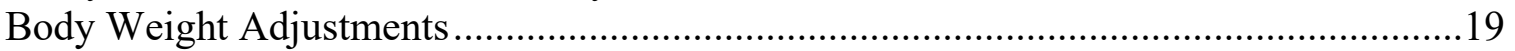

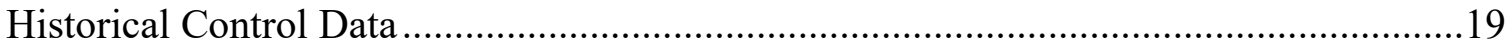

Quality Assurance Methods …………………………..................................................19

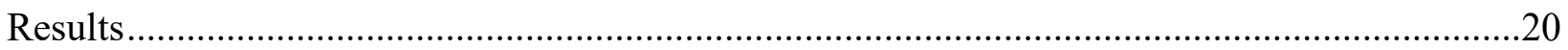

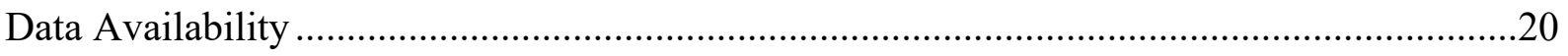

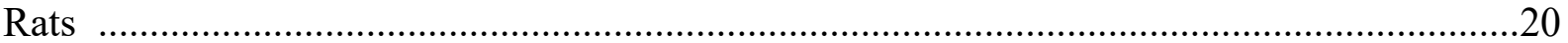

Two-year Study (Perinatal Phase) .................................................................................

Two-year Study (Postweaning Phase) ......................................................................28

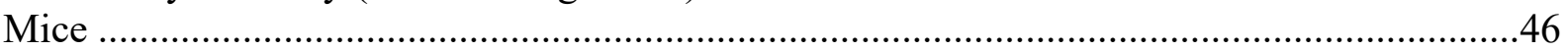

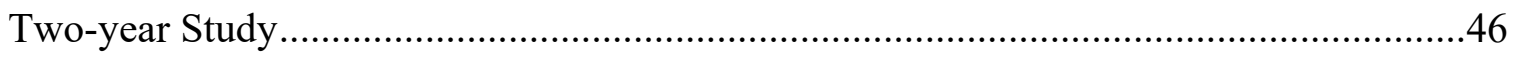

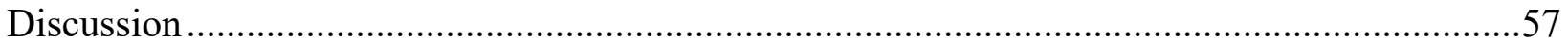

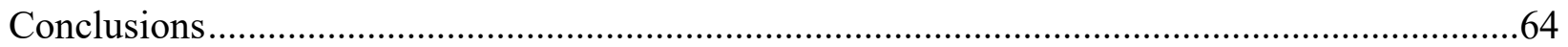

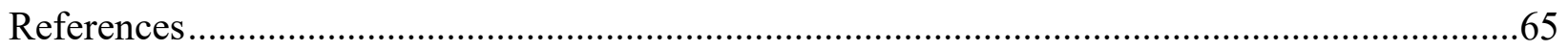

Appendix A. Chemical Characterization and Dose Formulation Studies................................. A-1

Appendix B. Ingredients, Nutrient Composition, and Contaminant Levels in NIH-07 and NTP-2000 Rat and Mouse Ration ....................................................................

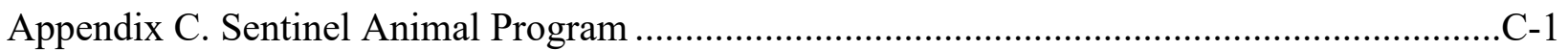

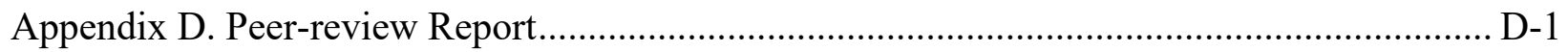

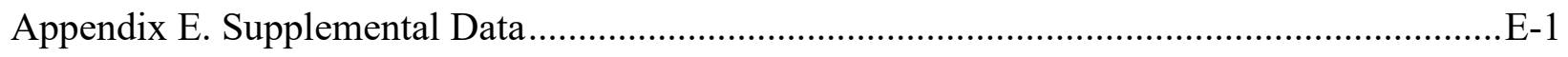

\section{Tables}

Summary of the Perinatal and Two-year Carcinogenesis Studies of Di- $n$-butyl Phthalate....... xviii

Table 1. Experimental Design and Materials and Methods in the Perinatal and Two-year Feed Studies of Di- $n$-butyl Phthalate...........................................................................

Table 2. Summary of the Disposition of $F_{0}$ Female Rats during Perinatal Exposure in the Perinatal and Two-year Feed Study of Di- $n$-butyl Phthalate..........................................20

Table 3. Summary of Mean Body Weights and Body Weight Gains of $F_{0}$ Female Rats during Gestation and Lactation in the Perinatal and Two-year Feed Study of Di$n$-butyl Phthalate.....

Table 4. Summary of Feed and Di- $n$-butyl Phthalate Consumption by Fo Female Rats during Gestation and Lactation in the Perinatal and Two-year Feed Study. 
Table 5. Summary of Mean Litter Size and Survival Ratio of $F_{1}$ Male and Female Rats during Lactation in the Perinatal and Two-year Feed Study of Di- $n$-butyl Phthalate

Table 6. Summary of Preweaning $F_{1}$ Male and Female Rat Pup Mean Body Weights Following Perinatal Exposure to Di- $n$-butyl Phthalate.

Table 7. Summary of Internal Dose Data for Rats in the Perinatal and Two-year Feed Study of Di-n-butyl Phthalate

Table 8. Summary of Survival of Male and Female Rats in the Perinatal and Two-year Feed Study of Di- $n$-butyl Phthalate.

Table 9. Summary of Survival and Mean Body Weights of Male Rats in the Perinatal and Two-year Feed Study of Di- $n$-butyl Phthalate.

Table 10. Summary of Survival and Mean Body Weights of Female Rats in the Perinatal and Two-year Feed Study of Di- $n$-butyl Phthalate

Table 11. Summary of Feed and Di- $n$-butyl Phthalate Consumption of Male Rats in the Perinatal and Two-year Feed Study....

Table 12. Summary of Feed and Di- $n$-butyl Phthalate Consumption of Female Rats in the Perinatal and Two-year Feed Study...

Table 13. Incidences of Neoplastic and Nonneoplastic Lesions of the Pancreas in Male Rats in the Perinatal and Two-year Feed Study of Di- $n$-butyl Phthalate.

Table 14. Summary of Gross Lesions in the Reproductive Tract of Male Rats in the Perinatal and Two-year Feed study of Di- $n$-butyl Phthalate

Table 15. Incidences of Nonneoplastic Lesions of the Testis, Epididymis, Prostate Gland, and Seminal Vesicle in Male Rats in the Perinatal and Two-year Feed Study of Di- $n$-butyl Phthalate

Table 16. Incidences of Nonneoplastic Lesions of the Pituitary Gland and Liver in Male and Female Rats in the Perinatal and Two-year Feed Study of Di- $n$-butyl Phthalate.

Table 17. Summary of Survival of Male and Female Mice in the Two-year Feed Study of Di- $n$-butyl Phthalate

Table 18. Summary of Survival and Mean Body Weights of Male Mice in the Two-year Feed Study of Di- $n$-butyl Phthalate

Table 19. Summary of Survival and Mean Body Weights of Female Mice in the Twoyear Feed Study of Di-n-butyl Phthalate

Table 20. Summary of Feed and Di- $n$-butyl Phthalate Consumption of Male Mice in the Two-year Feed Study

Table 21. Summary of Feed and Di- $n$-butyl Phthalate Consumption of Female Mice in the Two-year Feed Study.

Table 22. Incidences of Nonneoplastic Lesions of the Testis, Epididymis, Coagulating Gland, and Seminal Vesicle in Male Mice in the Two-year Feed Study of Di- $n$ butyl Phthalate

Table 23. Incidences of Nonneoplastic Lesions of the Liver and Kidney in Male and Female Mice in the Two-year Feed Study of Di- $n$-butyl Phthalate. 


\section{Figures}

Figure 1. Di-n-butyl Phthalate (CASRN 84-74-2; Chemical Formula C16H22O4;

Molecular Weight: 278.34)

Figure 2. Kaplan-Meier Survival Curves for Rats Exposed to Di- $n$-butyl Phthalate in Feed for Two Years.

Figure 3. Growth Curves for Rats Exposed to Di- $n$-butyl Phthalate in Feed for Two Years .........33

Figure 4. Representative Images Depicting Seminiferous Tubule Dysgenesis in a Male Rat in the Perinatal and Two-year Feed Study of Di-n-butyl Phthalate.

Figure 5. Representative Images of the Testis from Male Rats in the Perinatal and Twoyear Feed Study of Di- $n$-butyl Phthalate.

Figure 6. Representative Images Depicting Sperm Granuloma in the Rete Testis of a Male Rat in the Perinatal and Two-year Feed Study of Di- $n$-butyl Phthalate

Figure 7. Representative Images Depicting Fibrosis in the Rete Testis of a Male Rat in the Perinatal and Two-year Feed Study of Di- $n$-butyl Phthalate

Figure 8. Representative Images of the Pituitary Gland from Male Rats in the Perinatal and Two-year Feed Study of Di- $n$-butyl Phthalate

Figure 9. Representative Images of the Liver from Female Rats in the Perinatal and Twoyear Feed Study of Di- $n$-butyl Phthalate.

Figure 10. Kaplan-Meier Survival Curves for Mice Exposed to Di-n-butyl Phthalate in Feed for Two Years.

Figure 11. Growth Curves for Mice Exposed to Di- $n$-butyl Phthalate in Feed for Two Years.

Figure 12. Representative Images Depicting Degeneration of the Germinal Epithelium of the Testis in a Male Mouse in the Two-year Feed Study of Di-n-butyl

Phthalate

Figure 13. Representative Image Depicting Multinucleated Hepatocytes in the Liver of a Male Mouse in the Two-year Feed Study of Di- $n$-butyl Phthalate

Figure 14. Representative Image Depicting Renal Tubule Hyperplasia in the Kidney in a Female Mouse in the Two-year Feed Study of Di- $n$-butyl Phthalate. 


\section{About This Report}

National Toxicology Program ${ }^{1}$

${ }^{1}$ Division of the National Toxicology Program, National Institute of Environmental Health

Sciences, Research Triangle Park, North Carolina, USA

\section{Collaborators}

M.C. Huang, M.F. Cesta, C.J. Willson, J.C. Blake, C.R. Blystone, P. Brown, B.L. Burback, K.Y. Cimon, B.J. Collins, D.A. Contos, S.D. Cooper, M.C. Cora, H.C. Cunny, R.A. Fernando, J.M. Fostel, D.K. Gerken, J. Gilliam, H. Gong, M. Gruebbel, M.R. Hejtmancik, M.J. Hooth, A.P. King-Herbert, K.A.B. Knostman, D.E. Malarkey, C. Martini, B.S. McIntyre, R.A. Miller, C. Myers, G.K. Roberts, N. Sayers, C.C. Shackelford, M. Shaw, K.A. Shipkowski,

K.R. Shockley, M. Silinski, A.J. Skowronek, S.L. Smith-Roe, N.L. South, M.D. Stout, G.S. Travlos, S. Waidyanatha, N.J. Walker, R. Whittlesey, G.A. Willson, K.L. Witt

Division of the National Toxicology Program, National Institute of Environmental Health Sciences, Research Triangle Park, North Carolina, USA

Designed studies, evaluated and interpreted results, and reported findings

M.C. Huang, Ph.D., Study Scientist

M.F. Cesta, D.V.M., Ph.D., Co-Study Pathologist

C.R. Blystone, Ph.D.

B.J. Collins, M.S.P.H.

M.C. Cora, Ph.D.

H.C. Cunny, Ph.D.

M.J. Hooth, Ph.D.

A.P. King-Herbert, D.V.M.

D.E. Malarkey, D.V.M., Ph.D. (Retired)

B.S. McIntyre, Ph.D.

G.K. Roberts, Ph.D.

K.A. Shipkowski, Ph.D.

K.R. Shockley, Ph.D.

S.L. Smith-Roe, Ph.D.

M.D. Stout, Ph.D.

G.S. Travlos, D.V.M.

S. Waidyanatha, Ph.D.

N.J. Walker, Ph.D.

K.L. Witt, M.S.

Provided oversight for data management

J.M. Fostel, Ph.D.

Integrated Laboratory Systems, LLC, Research Triangle Park, North Carolina, USA

Evaluated and interpreted results and reported findings

C.J. Willson, D.V.M., Ph.D., Co-Study Pathologist 


\section{Battelle, Columbus, Ohio, USA}

Conducted studies and evaluated pathology findings

M.R. Hejtmancik, Ph.D., Principal Investigator

D.K. Gerken, D.V.M., Ph.D.

K.A.B. Knostman, D.V.M., Ph.D.

A.J. Skowronek, D.V.M., Ph.D.

Conducted prestart chemistry activities and dose formulations

B.L. Burback, Ph.D.

D.A. Contos, M.S.

N.L. South, B.S.

\section{RTI International, Research Triangle Park, North Carolina, USA}

Conducted preliminary chemistry activities and biological sample analyses

R.A. Fernando, Ph.D., Principal Investigator

J.C. Blake, B.A., Deputy Principal Investigator

S.D. Cooper, M.S.

J. Gilliam, B.S.

M. Silinski, Ph.D.

Experimental Pathology Laboratories, Inc., Research Triangle Park, North Carolina, USA Provided pathology review

K.Y. Cimon, D.V.M.

R.A. Miller, D.V.M., Ph.D.

C.C. Shackelford, D.V.M., Ph.D.

G.A. Willson, B.V.M.S.

Coordinated NTP Pathology Working Groups on perinatal and 2-year rats (May 10, 2018) and on 2-year mice (September 29, 2016)

R.A. Miller, D.V.M., Ph.D. (Mice)

C.C. Shackelford, D.V.M., Ph.D. (Rats)

Coordinated NTP Pathology Peer Review on brain glial cell proliferative lesions in rats (April 18, 2016)

M. Gruebbel, D.V.M., Ph.D.

Coordinated NTP Pathology Peer Review on brain granular cell proliferative lesions and head/neck schwannomas/sarcomas in rats (April 18, 2016)

M. Gruebbel, D.V.M., Ph.D.

\section{ASRC Federal, Research Triangle Park, North Carolina, USA}

Prepared data for report

P. Brown, B.S.

H. Gong, M.S.

C. Martini, B.S.

C. Myers, M.S.

N. Sayers, B.S. 
M. Shaw, B.S.

R. Whittlesey, M.S.

\section{Contributors}

Division of the National Toxicology Program, National Institute of Environmental Health Sciences, Research Triangle Park, North Carolina, USA

Provided oversight of external peer review

S.L. Scruggs, Ph.D.

M.S. Wolfe, Ph.D.

Kelly Government Services, Research Triangle Park, North Carolina, USA

Supported external peer review

E.A. Maull, Ph.D. (retired from NIEHS, Research Triangle Park, North Carolina, USA)

Experimental Pathology Laboratories, Inc., Research Triangle Park, North Carolina, USA Supervised pathology review

G.A. Willson, B.V.M.S., Principal Investigator

NTP Pathology Working Group, National Institute of Environmental Health Sciences, Research Triangle Park, North Carolina, USA

Participated in NTP Pathology Working Group on perinatal and 2-year rats (May 10, 2018)

N. Barlow, D.V.M., Ph.D., Seattle Genetics, Inc.

M.F. Cesta, D.V.M., Ph.D., National Institute of Environmental Health Sciences

D. Dixon, D.V.M., Ph.D., National Institute of Environmental Health Sciences

S.A. Elmore, D.V.M., M.S., National Institute of Environmental Health Sciences

D.E. Malarkey, D.V.M., Ph.D., National Institute of Environmental Health Sciences

A.K.R. Pandiri, B.V.Sc., Ph.D., National Institute of Environmental Health Sciences

C. Picut, V.M.D., J.D., Charles River Laboratories, Inc.

C.C. Shackelford, D.V.M., Ph.D., Experimental Pathology Laboratories, Inc.

C.J. Willson, D.V.M., Ph.D., Integrated Laboratory Systems, LLC

Participated in NTP Pathology Working Group on 2-year mice (September 29, 2016)

A.E. Brix, D.V.M., Ph.D., Experimental Pathology Laboratories, Inc.

M.F. Cesta, D.V.M., Ph.D., National Institute of Environmental Health Sciences

R.A. Miller, D.V.M., Ph.D., Experimental Pathology Laboratories, Inc.

A.K.R. Pandiri, B.V.Sc., Ph.D., National Institute of Environmental Health Sciences

J.C. Seely, D.V.M., Experimental Pathology Laboratories, Inc.

C.J. Willson, D.V.M., Ph.D., Integrated Laboratory Systems, LLC

NTP Pathology Peer Review, National Institute of Environmental Health Sciences, Research Triangle Park, North Carolina, USA

Participated in NTP Pathology Peer Review on liver lesions in rats (June 1, 2018)

M.F. Cesta, D.V.M., Ph.D., National Institute of Environmental Health Sciences

R. Herbert, D.V.M., Ph.D., National Institute of Environmental Health Sciences

K. Janardhan, Ph.D., Integrated Laboratory Systems, LLC

A.K.R. Pandiri, B.V.Sc., Ph.D., National Institute of Environmental Health Sciences 
C.C. Shackelford, D.V.M., Ph.D., Experimental Pathology Laboratories, Inc.

C.J. Willson, D.V.M., Ph.D., Integrated Laboratory Systems, LLC

Participated in NTP Pathology Peer Review on brain glial cell proliferative lesions in rats (April 18, 2016)

M.F. Cesta, D.V.M., Ph.D., National Institute of Environmental Health Sciences

P. Little, D.V.M., Ph.D., Experimental Pathology Laboratories, Inc.

D. Malarkey, D.V.M., Ph.D., National Institute of Environmental Health Sciences

Participated in NTP Pathology Peer Review on brain granular cell proliferative lesions and head/neck schwannomas/sarcomas in rats (April 18, 2016)

M.F. Cesta, D.V.M., Ph.D., National Institute of Environmental Health Sciences

P. Little, D.V.M., Ph.D., Experimental Pathology Laboratories, Inc.

D.E. Malarkey, D.V.M., Ph.D., National Institute of Environmental Health Sciences

CSS Corporation, Research Triangle Park, North Carolina, USA

Prepared quality assessment audits

S. Brecher, Ph.D., Principal Investigator

S. Iyer, B.S.

V.S. Tharakan, D.V.M.

Social \& Scientific Systems, a DLH Company, Research Triangle Park, North Carolina, USA

Provided statistical analyses

S.J. McBride, Ph.D., Principal Investigator

L.J. Betz, M.S.

S.F. Harris, M.S.

J.D. Krause, Ph.D.

G. Xie, Ph.D.

\section{ICF, Fairfax, Virginia, USA}

Provided contract oversight

D. Burch, M.E.M., Principal Investigator

J. Cleland, M.E.M.

J.A. Wignall, M.S.P.H.

Prepared and edited report

K.S. Duke, Ph.D.

S.R. Gunnels, M.A.

T. Hamilton, M.S.

B. Ingle, Ph.D.

P.E. Kellar, M.S.

K. McKinley, M.E.M.

M.E. McVey, Ph.D.

K. O'Donovan, B.A.

K.E. Setty, Ph.D.

K.A. Shipkowski, Ph.D. 
S.J. Snow, Ph.D.

Supported external peer review

C.N. Byrd, B.S.

L.M. Green, M.P.H.

M.C. Rooney, B.A.

A.J. Schumacher, B.A. 


\section{Explanation of Levels of Evidence of Carcinogenic Activity}

The National Toxicology Program (NTP) describes the results of individual experiments on a chemical agent and notes the strength of the evidence for conclusions regarding each study. Negative results, in which the study animals do not have a greater incidence of neoplasia than control animals, do not necessarily mean that a chemical is not a carcinogen, in as much as the experiments are conducted under a limited set of conditions. Positive results demonstrate that a chemical is carcinogenic for laboratory animals under the conditions of the study and indicate that exposure to the chemical has the potential for hazard to humans. Other organizations, such as the International Agency for Research on Cancer, assign a strength of evidence for conclusions based on an examination of all available evidence, including animal studies such as those conducted by NTP, epidemiologic studies, and estimates of exposure. Thus, the actual determination of risk to humans from chemicals found to be carcinogenic in laboratory animals requires a wider analysis that extends beyond the purview of these studies.

Five categories of evidence of carcinogenic activity are used in the Technical Report series to summarize the strength of evidence observed in each experiment: two categories for positive results (clear evidence and some evidence); one category for uncertain findings (equivocal evidence); one category for no observable effects (no evidence); and one category for experiments that cannot be evaluated because of major flaws (inadequate study). These categories of interpretative conclusions were first adopted in June 1983 and then revised on March 1986 for use in the Technical Report series to incorporate more specifically the concept of actual weight of evidence of carcinogenic activity. For each separate experiment (male rats, female rats, male mice, female mice), one of the following five categories is selected to describe the findings. These categories refer to the strength of the experimental evidence and not to potency or mechanism.

- Clear evidence of carcinogenic activity is demonstrated by studies that are interpreted as showing a dose-related (i) increase of malignant neoplasms, (ii) increase of a combination of malignant and benign neoplasms, or (iii) marked increase of benign neoplasms if there is an indication from this or other studies of the ability of such tumors to progress to malignancy.

- Some evidence of carcinogenic activity is demonstrated by studies that are interpreted as showing a chemical-related increased incidence of neoplasms (malignant, benign, or combined) in which the strength of the response is less than that required for clear evidence.

- Equivocal evidence of carcinogenic activity is demonstrated by studies that are interpreted as showing a marginal increase of neoplasms that may be chemical related.

- No evidence of carcinogenic activity is demonstrated by studies that are interpreted as showing no chemical-related increases in malignant or benign neoplasms.

- Inadequate study of carcinogenic activity is demonstrated by studies that, because of major qualitative or quantitative limitations, cannot be interpreted as valid for showing either the presence or absence of carcinogenic activity. 
For studies showing multiple chemical-related neoplastic effects that if considered individually would be assigned to different levels of evidence categories, the following convention has been adopted to convey completely the study results. In a study with clear evidence of carcinogenic activity at some tissue sites, other responses that alone might be deemed some evidence are indicated as "were also related" to chemical exposure. In studies with clear or some evidence of carcinogenic activity, other responses that alone might be termed equivocal evidence are indicated as "may have been" related to chemical exposure.

When a conclusion statement for a particular experiment is selected, consideration must be given to key factors that would extend the actual boundary of an individual category of evidence. Such consideration should allow for incorporation of scientific experience and current understanding of long-term carcinogenesis studies in laboratory animals, especially for those evaluations that may be on the borderline between two adjacent levels. These considerations should include:

- adequacy of the experimental design and conduct;

- occurrence of common versus uncommon neoplasia;

- progression (or lack thereof) from benign to malignant neoplasia as well as from preneoplastic to neoplastic lesions;

- some benign neoplasms have the capacity to regress but others (of the same morphologic type) progress. At present, it is impossible to identify the difference. Therefore, where progression is known to be a possibility, the most prudent course is to assume that benign neoplasms of those types have the potential to become malignant;

- combining benign and malignant tumor incidence known or thought to represent stages of progression in the same organ or tissue;

- latency in tumor induction;

- multiplicity in site-specific neoplasia;

- metastases;

- supporting information from proliferative lesions (hyperplasia) in the same site of neoplasia or other experiments (same lesion in another sex or species);

- presence or absence of dose relationships;

- statistical significance of the observed tumor increase;

- concurrent control tumor incidence as well as the historical control rate and variability for a specific neoplasm;

- survival-adjusted analyses and false positive or false negative concerns;

- structure-activity correlations; and

- in some cases, genetic toxicology. 


\section{Peer Review}

The National Toxicology Program (NTP) convened a virtual external ad hoc panel to peer review the draft NTP Technical Report on the Toxicology and Carcinogenesis Studies of Di-n-butyl Phthalate (CASRN 84-74-2) Administered in Feed to Sprague Dawley (Hsd:Sprague Dawley ${ }^{\circledR}$ $\left.S D^{\circledR}\right)$ Rats and B6C3F1/N Mice on April 2, 2021. NTP announced the peer-review meeting in the Federal Register (86 FR. 9947. February 17, 2021). The public could view the proceedings online, and opportunities were provided for submission of written and oral public comments. The selection of panel members and conduct of the peer review were in accordance with federal policies and regulations. The panel was charged to:

(1) Review and evaluate the scientific and technical elements of each study and its presentation.

(2) Determine whether each study's experimental design, conduct, and findings support the NTP's conclusions regarding the conditions of each study.

NTP carefully considered the panel's recommendations in finalizing the report. The peer-review report is provided in Appendix D. Other meeting materials are available on the NTP website (https://ntp.niehs.nih.gov/go/meeting).

\section{Peer Reviewers}

\section{Gabriele Ludewig, Ph.D., Chairperson}

Professor, Department of Occupational and Environmental Health, College of Public Health University of Iowa

Iowa City, Iowa, USA

Tracie Bunton, D.V.M., Ph.D.

Founder

Eicarte LLC: Pharmaceutical Preclinical Toxicology and Pathology Consultancy

Gettysburg, Pennsylvania, USA

Michael Elwell, D.V.M., Ph.D.

Consultant, Toxicologic Pathology

APEX TOXPATH, LLC

Apex, North Carolina, USA

Charles Mahrt, D.V.M., Ph.D.

Flagship Biosciences (Retired)

Broomfield, Colorado, USA

\section{Daniel Spade, Ph.D.}

Assistant Professor, Department of Pathology and Laboratory Medicine

Brown University

Providence, Rhode Island, USA

John Pierce Wise, Sr., Ph.D.

Professor, Department of Pharmacology and Toxicology

University of Louisville

Louisville, Kentucky, USA 


\section{Publication Details}

Publisher: National Toxicology Program

Publishing Location: Research Triangle Park, NC

ISSN: $2378-8925$

DOI: https://doi.org/10.22427/NTP-TR-600

Report Series: NTP Technical Report Series

Report Series Number: 600

Official citation: National Toxicology Program (NTP). 2021. NTP technical report on the toxicology and carcinogenesis studies of di- $n$-butyl phthalate (CASRN 84-74-2) administered in feed to Sprague Dawley (Hsd:Sprague Dawley ${ }^{\circledR} \mathrm{SD}^{\circledR}$ ) rats and B6C3F1/N mice. Research Triangle Park, NC: National Toxicology Program. Technical Report 600.

\section{Acknowledgments}

This work was supported by the Intramural Research Program (ES103316, ES103318, and ES103319) at the National Institute of Environmental Health Sciences, National Institutes of Health and performed for the National Toxicology Program, Public Health Service, U.S. Department of Health and Human Services under contracts HHSN273201800006C, HHSN271201800012I, HHSN273201600020C, HHSN273201600011C, GS00Q14OADU417 (Order No. HHSN273201600015U), HHSN273201500013C, HHSN273201500014C, HHSN273201500006C, HHSN273201400015C, HHSN273201400022C, HHSN316201200054W, HHSN273201100003C, HHSN273200800005C, N01-ES-65554, and N01-ES-55541. 


\section{Abstract}

Di- $n$-butyl phthalate (DBP) is a phthalate used in the manufacture of consumer products such as plastics and personal care products. Widespread exposure in the population occurs throughout life, including during pregnancy and lactation. Because limited data are available in both animals and humans to evaluate DBP as a human carcinogen, the National Toxicology Program conducted 2-year studies of DBP in rats and mice. Time-mated female Sprague Dawley (Hsd:Sprague Dawley ${ }^{\circledR} \mathrm{SD}^{\circledR}$ ) rats were exposed to 0, 300, 1,000, 3,000, or 10,000 ppm DBP in feed during gestation and lactation. Postweaning, $\mathrm{F}_{1}$ offspring consumed diets with the same exposure concentrations as the dam for 2 years $(n=50 /$ sex/exposure group). Male and female adult B6C3F1/N mice were exposed to $0,1,000,3,000$, or 10,000 ppm DBP in feed for 2 years $(\mathrm{n}=50 /$ sex/exposure group). Estimated average chronic chemical consumption was 16-17, 54$57,152-169$, and 510-600 $\mathrm{mg} \mathrm{DBP} / \mathrm{kg}$ body weight/day $(\mathrm{mg} / \mathrm{kg} / \mathrm{day})$ in rats in the $300,1,000$, 3,000 , and 10,000 ppm groups, respectively, and 105-112, 329-347, and 1,306-1,393 mg/kg/day in mice in the 1,000,3,000, and 10,000 ppm groups, respectively.

\section{Two-year Studies}

In rats, no exposure-related effect in mortality between exposed and control groups was observed. DBP did not affect rat reproductive or littering parameters. Marginal $\mathrm{F}_{0}$ weight effects ( $\leq 6 \%$ difference from the control group) were observed during gestation and by the end of lactation; $F_{1}$ male and female pup weights in the 10,000 ppm group were significantly decreased by $12 \%$ and $13 \%$, respectively, compared to the control groups upon weaning. Throughout the postweaning period, $\mathrm{F}_{1}$ body weights were approximately within $20 \%$ of the control animals. At 2 years, the incidence of pancreatic acinus adenomas was slightly higher in the $10,000 \mathrm{ppm}$ group compared to the control group in male rats only. Because pancreatic acinus adenomas and carcinomas are associated with peroxisome proliferator-activated receptor alpha activation — and have been observed with exposure to other phthalates - the marginal increase observed could have been related to chemical exposure. The male reproductive tract was a primary target system of DBP in rats. A high incidence of small or absent organs of the male reproductive tract and undescended testes occurred only in the 10,000 ppm group. Some gross lesions correlated with microscopic lesions in the testes (germinal epithelium atrophy), epididymis (hypospermia), and prostate and seminal vesicles (decreased secretory fluid) in the $10,000 \mathrm{ppm}$ groups. Additional microscopic lesions in the reproductive tract in rats included seminiferous tubule dysgenesis, testicular interstitial cell hyperplasia, testicular edema, and fibrosis and granuloma of the rete testis.

In mice, there were no exposure-related effects on survival, and mean body weights were lower only in the 10,000 ppm groups compared to the control groups. There was no exposure-related increase in neoplasms. No gross lesions were observed in the male reproductive tract, but significantly increased incidences of germinal epithelium degeneration in the testes and exfoliated germ cells in the epididymal duct were observed microscopically. The lesions generally occurred only in the $10,000 \mathrm{ppm}$ group and were fewer and less severe in the mouse study, which did not include perinatal exposure, compared to the rat study.

Other nonneoplastic lesions observed were generally limited to the $10,000 \mathrm{ppm}$ group. These lesions were found in the liver (hepatocyte cytoplasmic alteration in male and female rats and mice and multinucleated hepatocytes in male mice), in the pituitary gland (pars distalis hypertrophy in male rats), and in the kidney (renal tubule hyperplasia in female mice). 


\section{Conclusions}

Under the conditions of these 2-year feed studies, there was equivocal evidence of carcinogenic activity of di- $n$-butyl phthalate (DBP) in male Hsd:Sprague Dawley ${ }^{\circledR} \mathrm{SD}^{\circledR}$ rats based on marginal increases in the incidence of pancreatic acinus adenomas. There was no evidence of carcinogenic activity of DBP in female Hsd:Sprague Dawley ${ }^{\circledR} \mathrm{SD}^{\circledR}$ rats at exposure concentrations of 300 , $1,000,3,000$, or $10,000 \mathrm{ppm}$.

There was no evidence of carcinogenic activity of DBP in male or female B6C3F1/N mice at exposure concentrations of $1,000,3,000$, or $10,000 \mathrm{ppm}$.

Exposure to DBP increased incidences of gross lesions in the male reproductive system in rats and of nonneoplastic microscopic lesions in the male reproductive system (rats and mice), liver (male and female rats and mice), pituitary gland pars distalis (male rats), and kidney (female mice).

Synonyms: dibutyl benzene-1,2-dicarboxylate; 1,2-benzenedicarboxylic acid, dibutyl ester; di-n-butylorthophthalate 
Summary of the Perinatal and Two-year Carcinogenesis Studies of Di- $n$-butyl Phthalate

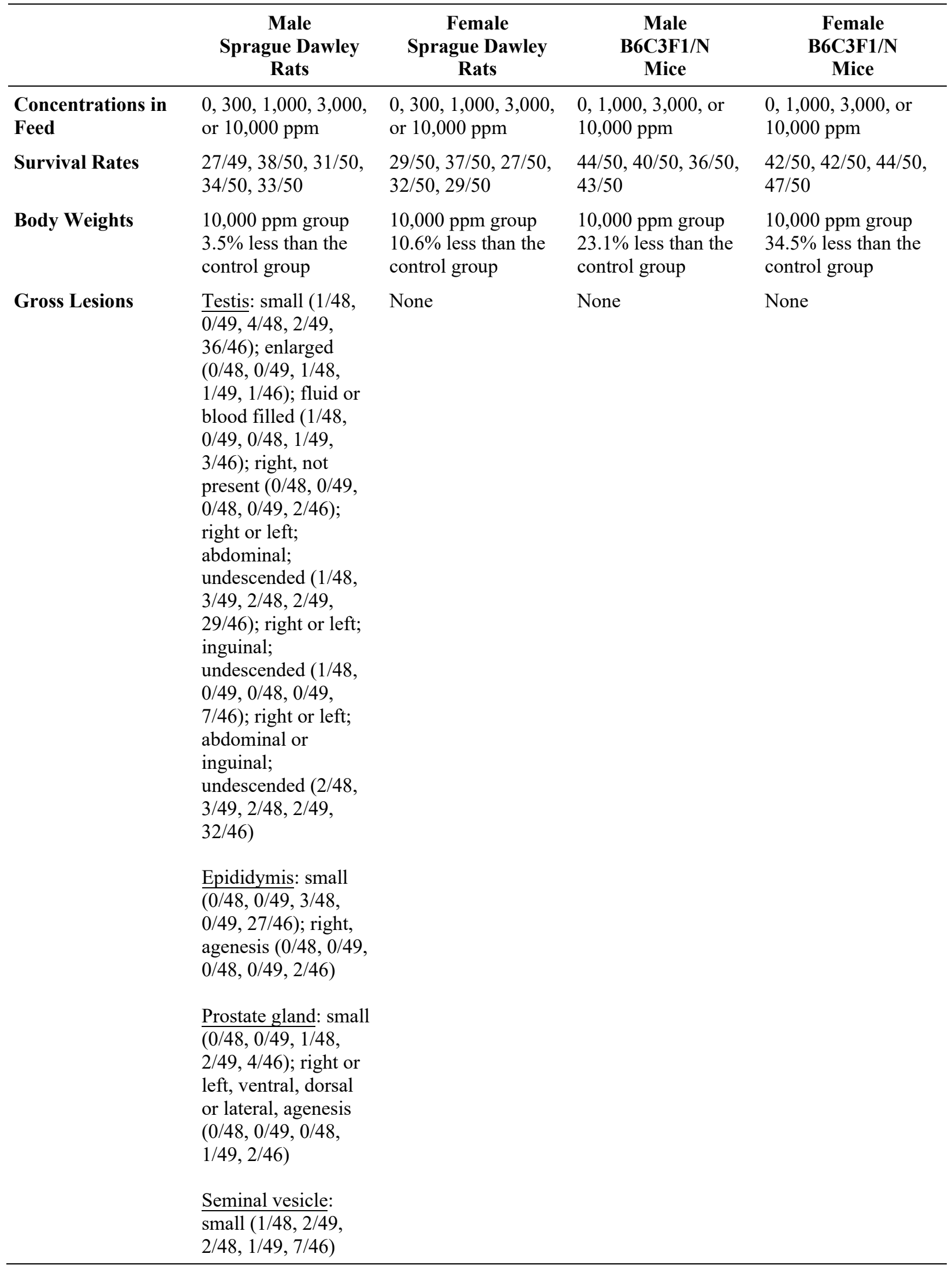




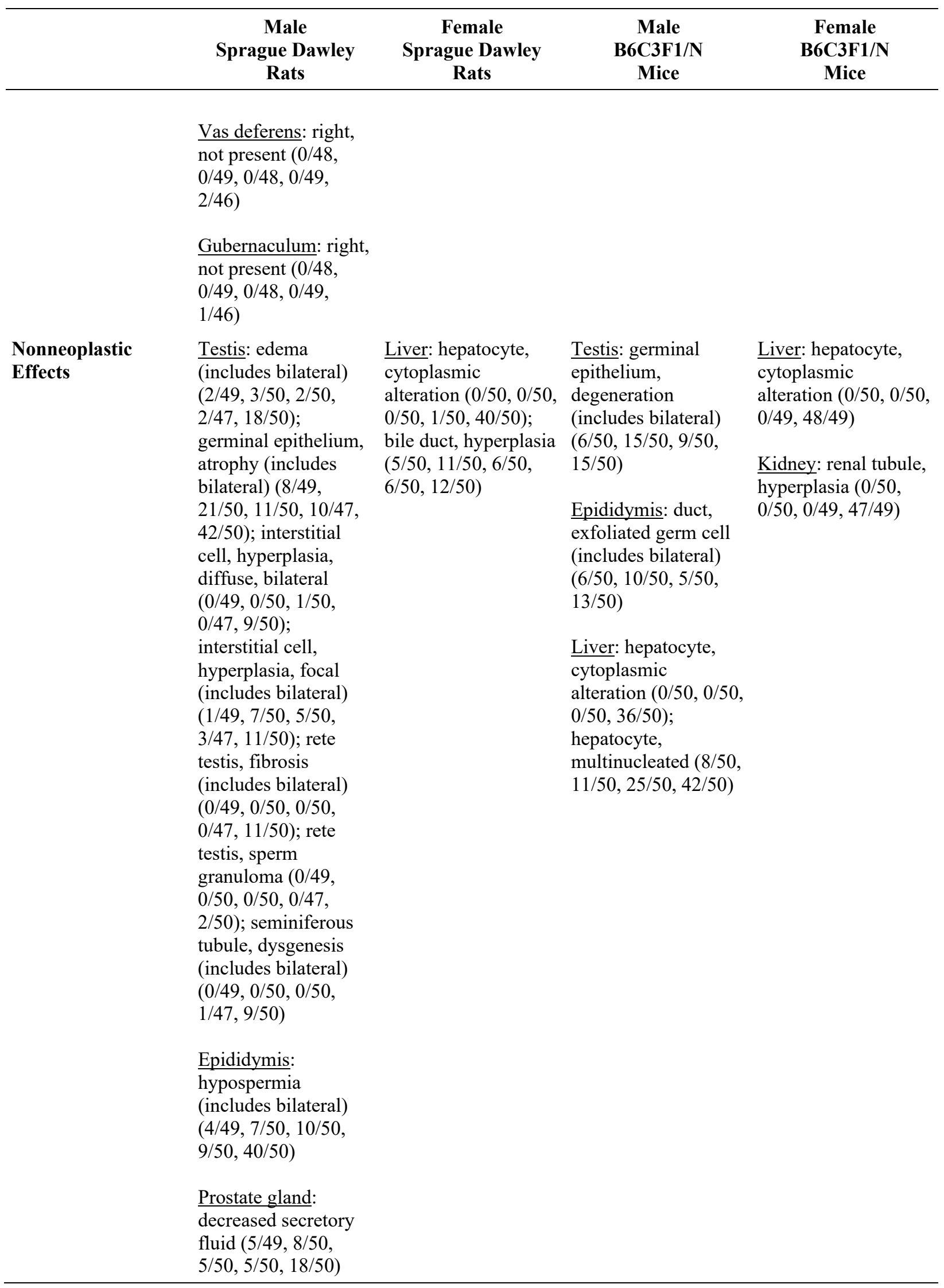


Di- $n$-butyl Phthalate, NTP TR 600

\begin{tabular}{|c|c|c|c|c|}
\hline & $\begin{array}{c}\text { Male } \\
\text { Sprague Dawley } \\
\text { Rats }\end{array}$ & $\begin{array}{c}\text { Female } \\
\text { Sprague Dawley } \\
\text { Rats }\end{array}$ & $\begin{array}{c}\text { Male } \\
\text { B6C3F1/N } \\
\text { Mice }\end{array}$ & $\begin{array}{c}\text { Female } \\
\text { B6C3F1/N } \\
\text { Mice }\end{array}$ \\
\hline & $\begin{array}{l}\text { Seminal vesicle: } \\
\text { decreased secretory } \\
\text { fluid }(6 / 49,7 / 50, \\
9 / 50,6 / 50,15 / 49)\end{array}$ & & & \\
\hline & $\begin{array}{l}\text { Pituitary gland: pars } \\
\text { distalis, hypertrophy } \\
(0 / 48,0 / 50,0 / 50 \\
0 / 50,29 / 50)\end{array}$ & & & \\
\hline & $\begin{array}{l}\text { Liver: hepatocyte, } \\
\text { cytoplasmic } \\
\text { alteration }(0 / 49,0 / 50, \\
0 / 50,0 / 50,39 / 50)\end{array}$ & & & \\
\hline Neoplastic Effects & None & None & None & None \\
\hline Equivocal Findings & $\begin{array}{l}\text { Pancreas: acinus } \\
\text { adenoma }(4 / 49,4 / 50 \\
3 / 50,1 / 50,10 / 49)\end{array}$ & None & None & None \\
\hline $\begin{array}{l}\text { Level of Evidence of } \\
\text { Carcinogenic } \\
\text { Activity }\end{array}$ & Equivocal evidence & No evidence & No evidence & No evidence \\
\hline
\end{tabular}




\section{Overview}

Phthalates are plasticizers typically used to provide flexibility to products composed of polyvinyl chloride plastic or vinyl chloride resins. Significant concerns have been raised about in utero and early-life phthalate exposure and resultant adverse reproductive, developmental, and carcinogenic effects.

Previous hazard assessments of phthalates typically did not assess the effects of exposure throughout the perinatal period (gestation and lactation), and no carcinogenicity assessments of phthalates have used a lifetime exposure paradigm that includes the perinatal period. Thus, whether developmental exposure would alter lifetime phthalate-associated carcinogenic risk is unknown. Exposure during these critical periods of development and growth might be relevant for the evaluation of lifetime toxicological and carcinogenic risk.

In response to these data gaps, the National Toxicology Program initiated a broad program of work to provide toxicity data and a cancer hazard assessment for lifetime exposure to environmental phthalates. The program would also provide critical data to inform cumulative and aggregate risk characterization efforts for multiple phthalates including di(2-ethylhexyl) phthalate, di-isobutyl phthalate, and di- $n$-butyl phthalate. 


\section{Introduction}

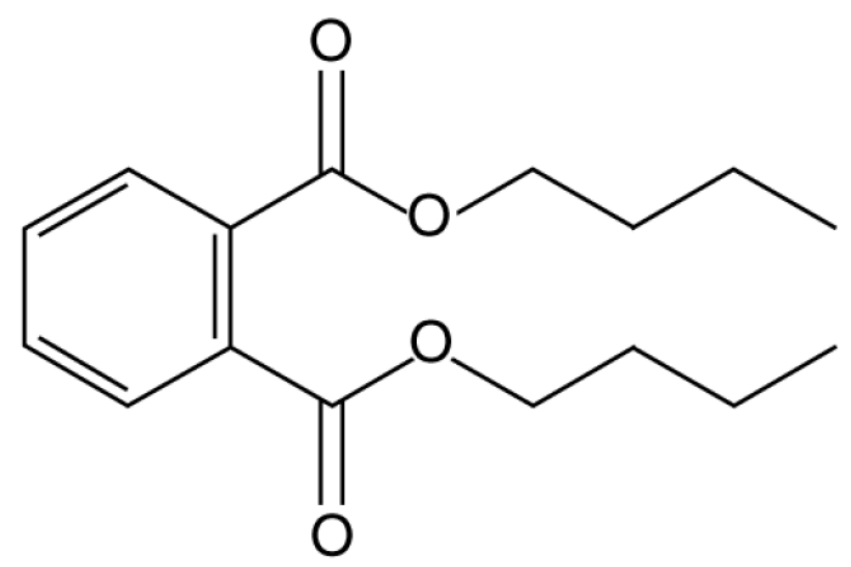

Figure 1. Di-n-butyl Phthalate (CASRN 84-74-2; Chemical Formula C16H22O4; Molecular Weight: 278.34)

Synonyms: dibutyl benzene-1,2-dicarboxylate; 1,2-benzenedicarboxylic acid, dibutyl ester; di- $n$-butylorthophthalate.

\section{Chemical and Physical Properties}

Di- $n$-butyl phthalate (DBP) is a colorless, oily liquid at room temperature. It is soluble in most solvents but minimally so in water, having a $\mathrm{K}_{\text {ow }}$ of 3.70 to 4.72 . DBP has a melting point of $-35^{\circ} \mathrm{C}$ and a boiling point of $340^{\circ} \mathrm{C} .{ }^{1}$ At $25^{\circ} \mathrm{C}$, its vapor pressure is approximately $2.67 \mathrm{mPa} .^{2}$

\section{Production, Use, and Human Exposure}

DBP is a phthalate ester and is produced primarily in Europe, the United States, Asia, and Pacific Rim countries. ${ }^{3}$ Between 1980 and 1994, U.S. production of DBP, including di-iso-butyl phthalate, ranged from 6.5 to 11.5 million $\mathrm{kg}$, according to the U.S. International Trade Commission. ${ }^{1}$ The national imported volume of DBP reported in the U.S. Environmental Protection Agency's (EPA's) Chemical Data Reporting database was approximately 7 million pounds in $2011 .^{4}$

DBP is primarily used as a plasticizer, which increases the malleability of plastics, particularly in nitrocellulose plastics that can be used as food packaging materials. Lower molecular weight phthalates, like DBP, also are used in solvents, inks, and latex adhesives ${ }^{5-7}$ DBP is the primary plasticizer in nail polish and has been detected in cosmetics and personal care products such as perfume and hair spray. ${ }^{7-10}$ DBP also is used as an enteric coating for some pharmaceutical products to modulate drug absorption. ${ }^{11 ; 12}$

Due to the widespread use of phthalates, metabolites of phthalates are detectable in humans (reviewed in Wang et al. ${ }^{13}$ ). The primary metabolite of DBP, mono- $n$-butyl phthalate (MBP), has been detected in human urine with median concentrations ranging from 0 to $2,540 \mu \mathrm{g} / \mathrm{L}$. ${ }^{13} \mathrm{In}$ biomonitoring data from the National Health and Nutrition Evaluation Survey (NHANES) for 2013-2014, urinary MBP in the U.S. population ranged from 0.3 to $489.6 \mu \mathrm{g} / \mathrm{L} .{ }^{14} \mathrm{In}$ workers at plastic manufacturing plants in Slovakia, urinary MBP concentrations ranged from 11.9 to $1,221.8 \mu \mathrm{g} / \mathrm{L} .{ }^{15}$ 
Concentrations of MBP in serum tend to be lower than those in urine. ${ }^{13}$ In a study of Danish men, serum MBP concentration was two orders of magnitude lower than urinary MBP $(0.4$ versus $42.5 \mu \mathrm{g} / \mathrm{L}) .{ }^{16}$ Additionally, MBP has been detected in cord blood, amniotic fluid, and breast milk, suggesting gestational and lactational transfer. Concentrations of MBP in these matrices are lower than urinary MBP concentrations. Median maternal plasma concentration of MBP was $4.37 \mu \mathrm{g} / \mathrm{L}$, whereas median cord plasma concentration was $5.15 \mu \mathrm{g} / \mathrm{L} .{ }^{17} \mathrm{MBP}$ was detected in approximately $93 \%$ of amniotic fluid samples collected in the United States, and concentrations ranged from below the limit of detection to $0.264 \mu \mathrm{g} / \mathrm{L} .{ }^{18}$ Median breast milk concentrations of MBP from various cohorts ranged from 0.5 to $12 \mu \mathrm{g} / \mathrm{L}$. $^{19-21}$

Human exposure to DBP occurs primarily through consumption of DBP-contaminated food, typically dairy, fish, or seafood products. ${ }^{1}$ Because phthalates do not bind to plastic, they are prone to leaching into foods from the packaging products to which they have been added. Estimated exposure through food, based on surveys of phthalates in various food products, is 0 $7 \mu \mathrm{g} \mathrm{DBP} / \mathrm{kg}$ body weight/ day ( $\mu \mathrm{g} / \mathrm{kg} /$ day $){ }^{22}$ although some estimates suggest a maximum likely food intake of DBP of approximately $31 \mu \mathrm{g} / \mathrm{kg} /$ day. ${ }^{7}$ Actual exposure depends highly on food consumption patterns and usage of food packaging, as some food products tend to have higher DBP concentrations than others. ${ }^{23}$ Exposure to DBP through oral pharmaceuticals in a Danish population was estimated at $0.5-32.8 \mathrm{mg}$ DBP per defined daily dose. ${ }^{11}$ Many pharmaceutical products, assuming an intake of one defined dose per day, exceeded the maximum daily exposure limit of $0.01 \mathrm{mg} / \mathrm{kg} /$ day for DBP. ${ }^{11}$

DBP exposure via inhalation and dermal routes is also pertinent, both for the general population and for certain occupations. Estimated inhalation of DBP in indoor air by the general adult population - due to off-gassing of household products and/or inhalation of dust containing DBP_ranged from 0.01 to $6.18 \mu \mathrm{g} / \mathrm{m}^{3}$. 7; 23;24 Inhalation exposures for children tended to be higher. ${ }^{23}$ For workers in various manufacturing industries, phthalate exposure levels were found to exceed that of the general population, and one exposure estimate via inhalation was $143 \mu \mathrm{g} / \mathrm{kg} /$ day $^{22 ; 25 ; 26}$ Manicurists at nail salons are also exposed via inhalation and dermal absorption; use of exhaust systems and gloves decreased urinary MBP concentrations measured after work. ${ }^{27}$ Dermal exposure to DBP in the general population occurs through use of personal care products containing phthalates. An estimate of the maximal daily DBP dermal dose in Canadian women, based on detected concentrations in 252 products, was $0.36 \mu \mathrm{g} / \mathrm{kg} / \mathrm{day} .{ }^{28}$

\section{Regulatory Status}

Six phthalate chemicals, including DBP, were banned from use in the United States in children's toys at concentrations $>0.1 \%$ by the Consumer Product Safety Commission, starting in 2008. ${ }^{29}$ The final rule was published in $2017 .^{30}$

The U.S. Food and Drug Administration (FDA) has not published a safety assessment of DBP but did release industry guidance in 2012 that recommended not using it as an excipient. ${ }^{31}$ Additionally, in 2018, FDA proposed an amendment to the Code of Federal Regulations to remove 26 phthalates, including DBP, from food-additive and food-contact use. ${ }^{32}$

DBP is listed as a hazardous air pollutant under the Clean Air Act, it is listed in the Toxic Substances Control Act Chemical Substance Inventory, and it is reportable to the Toxic Release Inventory. As such, EPA has established an oral reference dose (RfD) for DBP: $0.1 \mathrm{mg} / \mathrm{kg} / \mathrm{day}$ 
based on increased mortality with a no-observed-adverse-effect level of $125 \mathrm{mg} / \mathrm{kg} / \mathrm{day} .{ }^{33 ; 34}$ Confidence in this RfD is low, however, due to limitations of the Smith et al. study; animals of only one sex were used, and mortality was observed early in the study with no indication of the cause of death. ${ }^{34}$ The ATSDR minimal risk level (MRL), an estimate of exposure that is likely without appreciable risk of adverse, noncancer health effects, for acute oral exposure is $0.5 \mathrm{mg} / \mathrm{kg} / \mathrm{day} .{ }^{35}$ This value was based on a no-observed-adverse-effect level of $50 \mathrm{mg} / \mathrm{kg} / \mathrm{day}$ for developmental effects. In addition, EPA has classified DBP as a group D carcinogen, not classifiable as to human carcinogenicity, due to the lack of adequate studies. ${ }^{34}$ DBP has not been evaluated for human carcinogenicity by the International Agency for Research on Cancer.

\section{Absorption, Distribution, Metabolism, and Excretion}

\section{Experimental Animals}

Following oral administration, DBP is hydrolyzed to MBP by lipases and esterases in the gastrointestinal tract; hence, the available data primarily concerns MBP. ${ }^{36-39} \mathrm{MBP}$ is rapidly absorbed and distributed in the body after oral exposure to DBP. In Wistar and Sprague Dawley rats, most of an oral dose (ranging from 0 to $250 \mathrm{mg} / \mathrm{kg}$ ) is accounted for in urine within

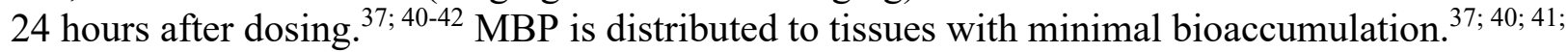
${ }^{43}$ In male Sprague Dawley rats given $30 \mathrm{mg} / \mathrm{kg}$ intravenously, the half-life of DBP was approximately 3.6 hours. ${ }^{42}$

MBP and its glucuronide are the primary metabolites of DBP, eliminated mostly in urine. ${ }^{37}$ Some fecal elimination does occur, ${ }^{40-43}$ and enterohepatic recirculation has been reported. ${ }^{40 ; 41}$ In plasma, tissues, and urine, most MBP exists as unconjugated MBP. ${ }^{41 ; 43 ; 44} \mathrm{MBP}$ can be metabolized further through oxidation to produce 3-hydroxybutyl phthalate (3OH-MBP), 4-hydroxybutyl phthalate (4OH-MBP), 3-ketobutyl phthalate, or 4-carboxypropyl phthalate. ${ }^{1}$

Gestational transfer of DBP has been evaluated in two studies. ${ }^{41 ; 43}$ Pregnant Sprague Dawley rats given a single dose of DBP $(50,100$, or $250 \mathrm{mg} / \mathrm{kg})$ on gestational day 20 via oral gavage had a maternal plasma $T_{\max }$ of MBP and MBP-glucuronide of 0.5 and 2 hours, respectively. ${ }^{41}$ MBP was detected in fetal plasma; $\mathrm{C}_{\max }$ was 2.4- to 4-fold higher in maternal plasma, but the area under the curve was only 1.4- to 1.7-fold higher. The ratio of MBP:MBP-glucuronide in maternal plasma was higher than that in the fetal plasma. ${ }^{41}$ At higher doses of DBP (500 and $1,500 \mathrm{mg} / \mathrm{kg}$ ), the plasma $\mathrm{T}_{\max }$ of MBP was similar to that observed with lower doses, ranging from 1.4 to 2.6 hours. ${ }^{43}$ Concentrations of MBP in embryos and the placenta were $<33 \%$ of maternal plasma concentrations; MBP-glucuronide was lower than MBP. ${ }^{43} \mathrm{MBP}$ and MBPglucuronide were detected in the amniotic fluid at concentrations similar to those in embryos. Overall, these studies indicate fetal exposure to MBP and MBP-glucuronide occurs, although the concentrations are lower than those observed in the dam. This exposure could occur through transfer of metabolites across the placenta and/or by fetal metabolism.

\section{Humans}

As in animals, DBP in humans is converted to MBP in the gastrointestinal tract before it is absorbed. Human and rodent lipases show similar rates of conversion of DBP to MBP. ${ }^{45}$ Three studies have evaluated human absorption, distribution, metabolism, and excretion of DBP after oral consumption. In one study, one male volunteer ingested $60 \mu \mathrm{g} / \mathrm{kg}$ body weight of DBP. ${ }^{46} \mathrm{In}$ 
the second study, 17 volunteers consumed one capsule of an herbal drug containing 3,600 $\mu \mathrm{g}$ of DBP. ${ }^{47}$ In the third study, 24 volunteers consumed phthalates, including DBP (255 and $\left.510 \mu \mathrm{g}\right)$, spiked into margarine and administered on toast. ${ }^{48}$

As shown for animals, most of the dose administered to humans was excreted as MBP in the urine within the first 24 hours. ${ }^{46-48}$ Hydroxylated monoester DBP metabolites were detected in urine after DBP consumption in Koch et al. ${ }^{46}$ In urine, MBP was the dominant metabolite, comprising $84 \%$ of the metabolites, followed by $3 \mathrm{OH}-\mathrm{MBP}(7 \%)$; other excreted metabolites included 2-hydroxybutyl phthalate (2OH-MBP), 4OH-MBP, and mono-carboxy-propyl phthalate (MCPP), which contributed $<1 \%$ each. ${ }^{46}$ In plasma, MBP, 3OH-MBP, and MCPP were detected at $196,13.5$, and $2.8 \mu \mathrm{g} / \mathrm{L}$, respectively. ${ }^{46}$ Unlike rodent studies, in which most MBP is unconjugated, most MBP in human urine and plasma is conjugated with glucuronide. This pattern has been observed in urine and plasma samples from NHANES studies, ${ }^{49}$ in urine after oral ingestion of DBP,${ }^{47}$ and in urine after topical exposure to DBP. ${ }^{50}$

The urinary half-life of MBP reported for an individual who ingested DBP was 2.6 hours; $3 \mathrm{OH}-\mathrm{MBP}$ and $4 \mathrm{OH}-\mathrm{MBP}$ had half-lives similar to that of MBP, but the other detected metabolites had longer (approximately 6 hours) half-lives. ${ }^{46}$

\section{Toxicity}

\section{Experimental Animals}

Several studies have been conducted to evaluate the toxicity of DBP following oral exposure. NTP has conducted both subchronic and reproductive and developmental studies on DBP; these findings are reported in NTP Toxicity Report $30 .{ }^{51}$ Generally, oral DBP exposure is well tolerated in animal models, as indicated by some studies reporting an acute oral $\mathrm{LD}_{50}$ (median lethal dose) in rodents $>20,000 \mathrm{mg} / \mathrm{kg} .{ }^{52 ; 53} \mathrm{NTP}$ Toxicity Report 30 studies in rats and mice show minimal differences in survival after 3 months of exposure of up to approximately $4,278 \mathrm{mg} / \mathrm{kg} /$ day. $^{51}$ Toxicity to the male reproductive tract is the primary endpoint studied with DBP exposure; these effects are summarized in the reproductive and developmental toxicity section below. Neurotoxicity, particularly following in utero DBP exposure, has been reported in some rodent studies ${ }^{54-56}$ but not others. ${ }^{57}$ Other target organs include the liver and the hematopoietic system.

Increased liver weight has been observed in rats following exposure to DBP for 7 or more days, ${ }^{51 ; 58 ; 59}$ which might be related to proliferation of peroxisomes. Some phthalates are known peroxisome proliferator-activated receptor (PPAR) agonists ${ }^{60}$; DBP and its metabolites weakly activate the three PPAR receptor subtypes in vitro. ${ }^{61 ; 62}$ In the NTP 13 -week study of rats administered DBP in feed, peroxisomal enzyme activity was induced at exposure concentrations of $\geq 356 \mathrm{mg} / \mathrm{kg} / \mathrm{day} .{ }^{51}$ Hepatic cytoplasmic alteration was noted in male and female rats exposed to $\geq 720 \mathrm{mg} / \mathrm{kg} / \mathrm{day}$ and in male and female mice exposed to $\geq 1,601 \mathrm{mg} / \mathrm{kg} / \mathrm{day}$ and $\geq 4,278 \mathrm{mg} / \mathrm{kg} /$ day, respectively. Decreases in serum triglyceride and/or cholesterol were observed in the NTP 3-month studies and in other studies ${ }^{51 ; 58 ; 63}$ and could be due to hepatic toxicity because the liver is the site of cholesterol synthesis. These changes also could be due to PPAR activation, which could lead to impaired lipid and glucose homeostasis. 
Decreases in erythrocyte, hemoglobin, and hematocrit levels were observed in male rats given DBP at $752 \mathrm{mg} / \mathrm{kg} /$ day. ${ }^{57}$ In the NTP 13 -week rodent studies, dietary exposure to DBP resulted in minimally severe anemia characterized by decreases in erythrocyte, hemoglobin, and hematocrit levels in male rats only at exposure concentrations $>359 \mathrm{mg} / \mathrm{kg} / \mathrm{day} .{ }^{51}$ Decreased hematocrit was observed in female mice following exposure to $4,278 \mathrm{mg} / \mathrm{kg} / \mathrm{day} .{ }^{51}$

\section{Humans}

Studies that followed humans after ingestion of up to $5.4 \mathrm{mg}$ DBP reported no adverse effects after acute exposure. ${ }^{46-48}$ Epidemiological studies have focused on associations of phthalate exposure with asthma, reproductive health, metabolic disease, neurodevelopmental disorders, and cancer (particularly breast cancer due to potential estrogen binding of phthalates) (reviewed in Benjamin et al. ${ }^{64}$ ). Specifically, MBP exposure was significantly associated with metabolic disease and with spermatotoxicity in some studies. ${ }^{64}$

\section{Reproductive and Developmental Toxicity}

\section{Experimental Animals}

Reproductive and developmental toxicity is the main toxicity associated with phthalate exposure in rodents (reviewed in Kavlock et al. ${ }^{22}$ ). Developmental abnormalities in the male rodent reproductive tract following in utero DBP exposure include malformations of the male reproductive tract, undescended testes, and decreased anogenital distance. ${ }^{22 ; 65 ; 66} \mathrm{In}$ addition to small and atrophic testes, hypoplastic epididymides, and decreased size or absence of prostate, seminal vesicles, and vas deferens, male rats exposed to $100 \mathrm{or} 500 \mathrm{mg} / \mathrm{kg} /$ day via gavage in utero (gestation day [GD] 12 to 21) were diagnosed with testicular dysgenesis. ${ }^{65}$ These lesions were characterized by areas of malformed seminiferous tubules surrounded by Leydig cell aggregates ${ }^{65}$ The testicular dysgenesis lesions did not increase over time, suggesting these lesions were of developmental origin. Low testosterone and decreased insulin-like peptide 3 (Insl3) levels have been observed after in utero exposure in some studies, ${ }^{51 ; 67}$ which are proposed mechanisms of phthalate toxicity ${ }^{68-72}$ Delayed puberty was observed in male rats, ${ }^{73}$ but not in females, following exposure to DBP. ${ }^{74}$

Other developmental effects observed with in utero DBP exposure (generally $>600 \mathrm{mg} / \mathrm{kg} /$ day) include increased resorptions, decreased pup body weight, delayed ossification, and fetal malformations. ${ }^{1}$ External (e.g., cleft palate) and skeletal (e.g., fused sternebrae, deformed vertebral column) malformations have been reported at doses $>500 \mathrm{mg} / \mathrm{kg} /$ day and depend on the window of exposure during gestation. ${ }^{43 ; 75-78}$ Administration of MBP has elicited similar developmental impairments, suggesting that the metabolite might be responsible for these effects. ${ }^{43 ; 79 ; 80}$

Exposure to DBP impaired fertility and decreased the number of live pups per litter in multiple rodent studies. ${ }^{51 ; 73 ; 81}$ Acute and subchronic oral exposure (feed and gavage) to DBP causes reproductive toxicity in male rodents, guinea pigs, and rabbits, characterized by malformations of the reproductive tract, reduced sperm count, and testicular damage and atrophy. ${ }^{51 ; 67 ; 73 ; 81-83}$ The effects of DBP on female reproduction are less clear and have been reviewed by Kay et al. ${ }^{74}$ Minimal effects on the ovary or estrous cycling were observed in Sprague Dawley and Long Evans rats ${ }^{51 ; 81 ; 84}$ ) and in CD-1 mice. ${ }^{51} \mathrm{~A}$ crossover breeding study in CD-1 mice, however, 
suggests some effect of DBP on female fertility, as decreases in fertility and in the number of pups per litter occurred in exposed females mated with control males. ${ }^{51}$ Furthermore, treatment of Long Evans rats with $500 \mathrm{mg} / \mathrm{kg} /$ day DBP increased midterm abortions, and $\mathrm{F}_{1}$ female offspring in the study displayed reduced fecundity. ${ }^{84 ; 85}$ The embryonic loss after DBP exposure could be mediated in part by reduced uterine decidualization and/or by disruptions in hormones during gestation. ${ }^{84 ; 86}$

\section{Humans}

The epidemiological data on phthalate exposure and male and female reproductive health have been reviewed by Radke et al. ${ }^{87 ; 88}$ Some evidence supports the relationship between increasing DBP exposure and adverse male reproductive effects, including decreased semen quality, decreased anogenital distance, and decreased fecundability ${ }^{87}$ Ten studies evaluated testosterone concentrations and DBP exposure. Of those, five reported decreased testosterone with increasing DBP exposure ${ }^{87}$; the association was statistically significant in only one study. ${ }^{89}$ Concerning female reproductive health, no significant associations of DBP exposure with time to pregnancy, spontaneous abortion, or pubertal development were found. ${ }^{88}$ Six studies evaluated DBP exposure and preterm birth; three showed a positive association (significant in two), and three showed no or a negative association. ${ }^{88}$

\section{Immunotoxicity}

\section{Experimental Animals}

Hansen et al. ${ }^{90}$ have reviewed the immunotoxicity of phthalates. Generally, experimental studies indicate that phthalates can affect immune cells and modify cytokine expression; however, the effect is inconsistent across studies and phthalates. Only a few studies have evaluated DBP specifically. Exposure of murine peritoneal exudate macrophages to DBP $(1-100 \mu \mathrm{M})$ resulted in a dose-dependent decrease in expression of some cell surface markers, decreased phagocytosis, decreased cytokine production, and impaired antigen-presenting capacity. ${ }^{91}$ Testicular macrophages isolated from Sprague Dawley rats after a 90 -day exposure to $250 \mathrm{mg} / \mathrm{kg} / \mathrm{day}$ DBP had higher interleukin (IL)-1 $\beta$ protein expression. ${ }^{92}$ Another study in female Wistar rats found that DBP exposure exacerbated chronic lymphocytic thyroiditis, increased thyroid autoantibodies, disrupted Thelper Type 1 (Th1) and Th2 balances, and activated proinflammatory cytokines. ${ }^{93}$ DBP did not elicit these effects in animals without chronic lymphocytic thyroiditis. ${ }^{93}$

\section{Humans}

To date, epidemiological studies evaluating phthalate exposure and immune function have focused on asthma. Overall, these studies suggest a possible correlation between phthalate exposure and childhood asthma but are limited by the cross-sectional study design and the use of polyvinyl chloride materials or di(2-ethylhexyl)phthalate dust as surrogates of exposure (summarized in Bornehag and Nanberg ${ }^{94}$ ). One in vitro study stimulated human whole blood with DBP and found that DBP might exert immunosuppressive effects. ${ }^{95}$ 


\section{Carcinogenicity}

\section{Experimental Animals}

Two rodent studies have examined the carcinogenic effects of chronic DBP exposure. The first exposed 10 male rats per group to $0 \%, 0.01 \%, 0.05 \%, 0.25 \%$, and $1.25 \%$ DBP in feed for 1 year. ${ }^{33}$ High mortality occurred at the highest exposure concentration (approximately $625 \mathrm{mg} / \mathrm{kg}$ /day) within the first week of the study; the cause of death or whether the deaths were exposure-related was not reported. No hematological or gross pathological changes were observed. ${ }^{33}$ The second study evaluated male Sprague Dawley rats at 6, 12, and 18 months of age after in utero-only exposure to DBP. ${ }^{65}$ Pregnant Sprague Dawley rats were administered 0, 100, or $500 \mathrm{mg} / \mathrm{kg} /$ day DBP via oral gavage from GD 12 to 21 . Leydig cell adenomas, categorized according to the morphological criteria of the Society of Toxicologic Pathology, were observed only in the $100 \mathrm{mg} / \mathrm{kg}$ /day dose group at 18 months of age. ${ }^{65}$ Areas composed of Leydig cell aggregates surrounding malformed, contorted seminiferous tubules, defined as testicular dysgenesis, however, were observed consistently in the high dose group. Low incidences of other neoplasms (e.g., pituitary adenoma, basal cell adenoma, sarcoma) also were reported. Female animals were not evaluated.

\section{Humans}

Carcinogenicity of DBP in humans has not been evaluated by the International Agency for Research on Cancer, and EPA has been unable to classify it due to a lack of adequate studies, both in animal and in epidemiological or human studies. Phthalates have been implicated in breast cancer due to their reactivity with the estrogen receptor in vitro. However, DBP binds weakly to the estrogen receptor in mammalian in vitro screens. ${ }^{96}$ In six epidemiological studies, MBP was not found to be associated with breast cancer (reviewed in Zuccarello et al. ${ }^{97}$ ). Other epidemiological studies have examined associations of DBP with uterine tumors and gastrointestinal cancers. Urinary MBP was associated with uterine leiomyomas, ${ }^{98}$ but DBP exposure was not associated with increased gastric cancers, ${ }^{99}$ although sample sizes for both studies were small. Cumulative phthalate exposure from drug excipients had an overall protective effect against colorectal cancer; exclusion of nonsteroidal anti-inflammatory drug users from the analysis reversed the relationship. ${ }^{100}$

\section{Genetic Toxicity}

The genetic toxicity of DBP has been evaluated in a variety of in vitro and in vivo assays, and results are mixed. In bacterial mutation assays that examined reversion to histidine prototrophy, DBP was reported to be negative or weakly positive in a variety of Salmonella typhimurium tester strains, both with and without exogenous metabolic activation (S9). ${ }^{101-104}$ In a bacterial forward mutation assay, DBP $(0.18-0.45 \mathrm{mM})$ induced a weak but dose-related increase in 8 -azaguanine resistance in S. typhimurium strain TA100 in the absence of, but not the presence of, S9. ${ }^{105} \mathrm{DBP}$ at concentrations of 10 or $20 \mu \mathrm{L} / \mathrm{mL}$ did not increase gene reversion frequencies in the yeast Saccharomyces cerevesiae strain XV185-14c after 48 hours of exposure, with or without S9. ${ }^{106 ;} 107$

In contrast to the mostly negative results in bacteria and yeast, positive results were obtained in most genotoxicity assays in cultured mammalian cells. DBP $(46-54 \mu \mathrm{g} / \mathrm{mL})$ induced mutations 
in mouse lymphoma L $5178 \mathrm{Y}^{\mathrm{tk}+/-}$ cells treated in the absence of $\mathrm{S} 9$ at concentrations that induced high levels of cytotoxicity; it was not tested with S9. ${ }^{51}$ In a second mouse lymphoma cell gene mutation assay that used concentrations of DBP ranging up to $0.15 \mu \mathrm{L} / \mathrm{mL}$, a significant increase in mutations was reported in the presence of S9 and at concentrations that induced marked cytotoxicity (relative total growth $<20 \%) .{ }^{108} \mathrm{DBP}(354 \mathrm{mM}$ for 60 minutes) induced DNA damage in cultured human oropharyngeal mucosal cells, human nasal mucosal cells, human mucosal cells of the upper aerodigestive tract, and human lymphocytes, as measured by the alkaline comet assay. ${ }^{109 ; 110}$ Negative results were reported for DBP $(1 \mu \mathrm{M}-1 \mathrm{mM})$ in tests for induction of chromosomal aberrations and sister chromatid exchanges in Chinese hamster DON cells. ${ }^{111}$

Conflicting results were obtained in vivo in genotoxicity tests conducted in mice. No increases in the frequencies of micronucleated normochromatic erythrocytes were observed in peripheral blood samples obtained from male and female $\mathrm{B} 6 \mathrm{C} 3 \mathrm{~F} 1 / \mathrm{N}$ mice after 3 months of exposure to DBP $(1,250-20,000 \mathrm{ppm}$ or $163-4,278 \mathrm{mg} / \mathrm{kg} / \mathrm{day})$ in dosed feed. ${ }^{51}$ In contrast, significant increases in the percentages of chromosomally aberrant splenic lymphocytes and micronucleated peripheral blood erythrocytes were observed in male and female B6C3F1 mice following 16 to 52 weeks of exposure to 5,000 ppm DBP in dosed feed. ${ }^{112}$ In addition, increases in $h p r t$ transversion mutations in splenic T-cells of these male and female mice exposed to DBP $(5,000 \mathrm{ppm})$ for 32 or 52 weeks were reported. ${ }^{113}$ Recently, DBP was reported to disrupt meiotic prophase, disrupt homologous recombination, and increase the number of $\gamma \mathrm{H} 2 \mathrm{AX}$ foci (indicative of DNA double-strand breaks) in oocytes of fetal mice following exposure of the dam via oral administration of 10 or $100 \mathrm{mg} / \mathrm{kg} /$ day for 3 days. ${ }^{114}$

\section{Study Rationale}

Available studies to evaluate DBP carcinogenicity are limited to two rodent studies that evaluated a small number of male animals with adult-only exposure. Given widespread exposure to DBP in the general population and that previous literature indicates developmental toxicities, a perinatal exposure was included in the rat study to provide a hazard assessment of lifetime exposure to environmental phthalates. To emulate the primary route of human exposure, the animals in this study were exposed via feed. In addition, this study is part of a larger body of work that aims to inform cumulative and aggregate risk characterization efforts for a range of environmental phthalates. 


\section{Materials and Methods}

\section{Procurement and Characterization of Di- $\boldsymbol{n}$-butyl Phthalate}

Di- $n$-butyl phthalate (DBP) was obtained from Sigma-Aldrich (St. Louis, MO) in a single lot (lot MKBB8432) and was used in the perinatal and 2-year studies. Identity, purity, and stability analyses were conducted by the analytical chemistry laboratory at RTI International (Research Triangle Park, NC) (Appendix A). Reports on analyses performed in support of the DBP studies are on file at the National Institute of Environmental Health Sciences (NIEHS).

Lot MKBB8432 of the chemical, a clear liquid, was identified as DBP by infrared (IR), ${ }^{1} \mathrm{H}$ and

${ }^{13} \mathrm{C}$ nuclear magnetic resonance (NMR) spectroscopy, and gas chromatography (GC) with mass spectrometry (MS) detection. The IR spectrum was in good agreement with a reference spectrum, and the structure was consistent with DBP. Both ${ }^{1} \mathrm{H}$ and ${ }^{13} \mathrm{C}$ NMR spectra were consistent with reference and predicted spectra. The GC/MS spectrum correlated well with the structure of DBP. The boiling point, elemental analysis, and precise mass determination of lot MKBB8432 matched those of DBP.

Karl Fischer titration was used to determine the water content of lot MKBB8432, which was $0.204 \%$. Ultra-performance liquid chromatography (UPLC) with photodiode array detection (PDA) and GC with flame ionization detection (FID) were used to determine a purity of 99.9\%. The UPLC/PDA analysis identified one minor impurity peak with $<0.1 \%$ of the total response. The overall purity of lot MKBB8432 was determined to be $>99 \%$.

Accelerated stability studies, performed on an additional lot of DBP (lot 91997PJ) obtained from Sigma-Aldrich (St. Louis, MO), confirmed that it was stable for at least 2 weeks when stored in sealed glass vials at temperatures from $5^{\circ} \mathrm{C}$ to $60^{\circ} \mathrm{C}$. The bulk chemical of lot MKBB8432 was homogenized by mixing for 15 minutes and transferred to 1-gallon amber storage bottles, which were stored at room temperature (approximately $25^{\circ} \mathrm{C}$ ). Periodic reanalysis of the bulk chemical was performed during the perinatal and 2-year studies by the study laboratory using high-performance liquid chromatography (HPLC) with ultraviolet (UV) detection, and no degradation was detected.

\section{Preparation and Analysis of Dose Formulations}

Dose formulations were prepared approximately monthly by mixing DBP with NIH-07 or NTP-2000 feed (Table A-2). The rat perinatal and 2-year study used dose formulations of 300, $1,000,3,000$, and 10,000 ppm, whereas the mouse 2-year study used dose formulations of 1,000, 3,000 , and 10,000 ppm. Formulations were stored in sealed, plastic bag-lined containers at room temperature (approximately $25^{\circ} \mathrm{C}$ ) for up to 42 days. The plastic bags used by the study laboratory in the preparation and storage of blank and dosed feed were determined to have no DBP above the limit of detection of the assay (1.47 ppm).

Homogeneity studies of the dose formulations in a $72 \mathrm{~kg} \mathrm{NIH-07} \mathrm{feed} \mathrm{batch} \mathrm{(300} \mathrm{and}$ 1,000 ppm), a $92 \mathrm{~kg} \mathrm{NTP-2000} \mathrm{feed} \mathrm{batch} \mathrm{(300} \mathrm{ppm),} \mathrm{and} \mathrm{a} 60 \mathrm{~kg}$ NTP-2000 feed batch (1,000 and $10,000 \mathrm{ppm}$ ) were performed prior to animal studies by the study laboratory with HPLC/UV (Table A-1). Additional homogeneity studies of the $300 \mathrm{ppm}$ dose formulation in a $60 \mathrm{~kg}$ NTP-2000 batch size and of the 10,000 ppm dose formulation in a $72 \mathrm{~kg}$ NTP-2000 batch size 
were performed during the 2-year studies by the study laboratory. Formulations were determined to be homogenous and stable for 42 days at room temperature.

Periodic analyses of the dose formulations of DBP were conducted by the study laboratory using HPLC/UV to determine purity (Table A-3, Table A-4). All preadministration dose formulations were within $10 \%$ of the target concentrations. In the perinatal and 2-year rat studies, two samples collected from the residual food in the feeders and one sample from the storage barrel were below $90 \%$ of the target concentrations ( $\%$ relative error, RE: $-10.0 \%$ to $-13.2 \%$ ). In the 2 -year mouse study, three samples collected from the residual food in the feeders and one sample from the storage barrel were below $90 \%$ of the target concentrations (\%RE: $-11.1 \%$ to $-13.4 \%$ ). All other postadministration values were within $10 \%$ of the target concentrations.

\section{Animal Source}

Time-mated $\left(\mathrm{F}_{0}\right)$ female Sprague Dawley $\left(\mathrm{Hsd}\right.$ :Sprague Dawley $\left.{ }^{\circledR} \mathrm{SD}^{\circledR}\right)$ rats were obtained from Envigo (formerly Harlan Laboratories, Inc., Indianapolis, IN). Male and female B6C3F1/N mice were obtained from Taconic Biosciences, Inc. (Germantown, NY).

\section{Animal Welfare}

Animal care and use are in accordance with the Public Health Service Policy on Humane Care and Use of Animals. All animal studies were conducted in an animal facility accredited by AAALAC International. Studies were approved by the Battelle (Columbus, OH) Animal Care and Use Committee and conducted in accordance with all relevant National Institutes of Health and National Toxicology Program (NTP) animal care and use policies and applicable federal, state, and local regulations and guidelines.

\section{Two-year Studies}

\section{Exposure Concentration Selection Rationale}

Studies summarized in NTP Toxicity Report $30^{51}$ established 10,000 ppm as the highest safe exposure concentration of DBP that could be used in rat and mouse reproductive studies; at 20,000 ppm, pups died and the body weight of postweaning and adult rodents was reduced by more than $10 \%$ relative to the control groups. At $10,000 \mathrm{ppm}$, a significant increase in the incidence of nonneoplastic lesions of the liver and testis and alterations in organ weights were observed.

Additionally, these exposures are consistent with another prenatal exposure study showing adverse effects and limited dose-related mortality of rats 18 months of age in the $500 \mathrm{mg} \mathrm{DBP} / \mathrm{kg}$ body weight/day (mg/kg/day) dose group but not in rats in the $100 \mathrm{mg} / \mathrm{kg} /$ day dose group. ${ }^{65}$ Estimated compound intake documented in NTP Toxicity Report 30 suggests that 100 and $500 \mathrm{mg} / \mathrm{kg}$ /day are about equivalent to $<2,500 \mathrm{ppm}$ and 5,000-10,000 ppm in feed consumption, respectively, for Fischer 344 rats. ${ }^{51}$ For these reasons, 10,000 ppm was chosen as the highest exposure concentration for both rats and mice for the 2-year bioassay. 


\section{Study Design for Rats}

$\mathrm{F}_{0}$ female rats were 11 to 14 weeks old upon receipt. Evidence of mating is defined as gestation day (GD) 1; $F_{0}$ females were received on GD 2 and held for 4 days. Fo females were randomly assigned to one of five exposure groups on GD 5. Randomization was stratified by body weight that produced similar group mean weights using PATH/TOX SYSTEM software (Xybion Medical Systems Corporation, Cedar Knolls, NJ).

$\mathrm{F}_{0}$ females were quarantined for 11 days after receipt. Ten nonmated females received with the time-mated females were designated for disease monitoring 11 days after arrival; samples were collected for serological analyses, and the rats were euthanized, necropsied, and examined for the presence of disease or parasites. The health of the $\mathrm{F}_{1}$ rats was monitored during the study according to the protocols of the NTP Sentinel Animal Program (Appendix C). Pinworms (Syphacia spp.) were diagnosed in sentinel animals during routine health monitoring evaluations. Infected animals did not display clinical signs, and no pathological lesions were noted in relation to the presence of the pinworms. As a follow-up to this finding, NTP, in coordination with the testing laboratory, developed and implemented a successful plan of pinworm containment and eradication. NTP required the testing laboratories to monitor animals actively to ensure the continued exclusion of pinworms from all subsequent studies. All other test results were negative.

Beginning on GD 6, groups of $45(0,300,1,000$, and 3,000 ppm) or 47 (10,000 ppm; includes two extra rats received in the animal order) $\mathrm{F}_{0}$ time-mated female rats were fed diets containing $0,300,1,000,3,000$, or 10,000 ppm DBP, respectively, throughout gestation and lactation. Groups of $50 \mathrm{~F}_{1}$ rats per sex per exposure concentration continued in the study after weaning and were fed diets containing the same respective DBP concentrations for 2 years.

$\mathrm{F}_{0}$ female rats were housed individually during gestation and with their respective litters during lactation. Dosed feed and water were available ad libitum. $\mathrm{F}_{0}$ female body weights were recorded on GDs 5, 6, 9, 12, 15, 18, and 21 and on lactation days (LDs) 1, 4, 7, 10, 14, and 21. During gestation, feed consumption was continuously measured over 3-day intervals from GD 6 through GD 21 (GDs 6-9, 9-12, 12-15, 15-18, and 18-21). The day of parturition was considered LD 0 or postnatal day (PND) 0. On apparent GD 27, all time-mated female rats that failed to deliver were euthanized, and the uteri were examined and stained for evidence of implantation. Total litter weight and litter weights by sex were collected on PND 1. Individual F1 pup weights were recorded on PNDs 4, 7, 14, and 21. Clinical observations and survival were evaluated throughout lactation. During lactation, feed consumption was measured over 3-day intervals from PND 1 through PND 21 (PNDs 1-4, 4-7, 7-10, 10-14, 14-17, and 17-21).

Select dams and their litters were removed on GD 18 and PND 4 to quantify mono- $n$-butyl phthalate (MBP) concentrations. On GD 18, blood was collected from the retroorbital sinus of randomly selected dams ( $\mathrm{n}=5$ per exposure group). Blood samples were collected into tubes containing tripotassium ethylene diamine tetraacetic acid ( $\mathrm{K}_{3}$ EDTA) and centrifuged, and the plasma was harvested. Amniotic fluid was collected and pooled by dam. Each dam's fetuses were collected, pooled by litter, and flash frozen in liquid nitrogen. On PND 4, randomly selected dams ( $\mathrm{n}=5$ per exposure group) and their pups not selected to continue in the study were used for biological sampling. Plasma was collected from dams in the same manner as on GD 18. Up to four pups were collected from each dam (two per sex when possible) and flash 
frozen in liquid nitrogen. All samples were stored frozen at approximately $-20^{\circ} \mathrm{C}$ before shipment to RTI International (Research Triangle Park, NC) for analysis. All samples were analyzed using a previously validated method. ${ }^{115}$

$F_{1}$ litters were standardized on PND 4 to eight pups per litter, with at least two pups of each sex and a preference for four males and four females each. Litters that did not meet the minimum of eight pups (or had fewer than two pups of either sex) were removed from the study. For continuation of exposure after weaning, two males and two females per litter were randomly selected from 28 (0 ppm), 25 (300 ppm), $27(1,000$ and 10,000 ppm), and 30 (3,000 ppm) litters. Before weaning, on the day the last litter reached PND 19, 25 litters per exposure group were randomly selected, and pups (generally two/sex/litter) were randomly assigned to the 2-year study. On the day the last litter reached PND 21, dams were removed from the cages, and the pups were weaned. Weaning marked the beginning of the 2-year study.

After weaning, $F_{1}$ rats were housed up to two (males) or four (females) per cage. Water and dosed feed were available ad libitum. Feed consumption was measured weekly for the first 3 months, then for one 7-day period every 4 weeks thereafter, and at study termination. Cages were changed at least once weekly through PND 4, then changed at least twice weekly. Racks were changed and rotated at least every 2 weeks. Further details of animal maintenance are given in Table 1.

Two diets were used in the rat studies: (1) NIH-07 during the perinatal phase and (2) NTP-2000 during the postnatal phase. $\mathrm{NIH}-07$ is a higher protein diet that supports reproduction and lactation in rodents, whereas NTP-2000 is a lower protein diet that decreases the incidence of chronic nephropathy in adult rats. Information on feed composition and contaminants for both diets is provided in Appendix B.

\section{Study Design for Mice}

Male and female $\mathrm{B} 6 \mathrm{C} 3 \mathrm{~F} 1 / \mathrm{N}$ mice were approximately 3 to 4 weeks old upon receipt and were quarantined for 11 (females) or 12 (males) days before study start. Mice were randomly assigned to one of four exposure groups ( $\mathrm{n}=50 \mathrm{mice} / \mathrm{sex} /$ group $)$. Randomization was stratified by body weight that produced similar group mean weights using PATH/TOX SYSTEM software (Xybion Medical Systems Corporation, Cedar Knolls, NJ). Mice were fed diets containing 0, 1,000, 3,000 , or $10,000 \mathrm{ppm}$ DBP for 2 years.

Five male and five female mice were randomly selected for parasite evaluation and gross observation of disease. The health of the mice was monitored during the study according to the protocols of the NTP Sentinel Animal Program (Appendix C). All test results were negative.

Mice were housed individually (males) or up to four (females) per cage. Water and dosed feed were available ad libitum. Feed consumption was measured weekly for the first 3 months, then for one 7-day period every 4 weeks thereafter. Cages were changed at least once weekly (males) or twice weekly (females) and rotated every 2 weeks. Racks were changed and rotated every 2 weeks. Further details of animal maintenance are given in Table 1. Information on feed composition and contaminants is given in Appendix B. 


\section{Clinical Examinations and Pathology}

In the 2-year studies of rats and mice, animals were observed twice daily for signs of morbidity and moribundity and were weighed before dosed feed exposure on day 1, weekly for the next 3 months, every 4 weeks thereafter, and at study termination. Clinical observations were recorded every 4 weeks beginning on day 29 (rats) or day 1 (mice) and at study termination.

For determination of internal dose in rats, plasma, amniotic fluid, and fetal tissue samples were analyzed using a previously validated method. ${ }^{115}$

Complete necropsies and microscopic examinations were performed on all $\mathrm{F}_{1}$ rats and all mice at the end of the 2-year study. At necropsy, all organs and tissues were examined for grossly visible lesions, and all major tissues were fixed and preserved in 10\% neutral buffered formalin except for eyes, which were first fixed in Davidson's solution, and testes, vaginal tunics, and epididymides, which were first fixed in modified Davidson's solution. Tissues were processed and trimmed, embedded in paraffin, sectioned to a thickness of 4 to $6 \mu \mathrm{m}$, and stained with hematoxylin and eosin (H\&E) for microscopic examination. For all paired organs (e.g., adrenal gland, kidney, ovary), samples from each organ were examined. Three transverse sections of each testis were taken: approximately one-third of the way down from the cranial pole containing the rete testis, at the midpoint, and approximately one-third of the way up from the caudal pole. Two transverse sections of the uterus, one from approximately the midpoint of each horn, were collected. Tissues examined microscopically are listed in Table 1.

Microscopic evaluations were completed by the study laboratory pathologist, and the pathology data were entered into the Toxicology Data Management System. The report, slides, paraffin blocks, residual wet tissues, and pathology data were sent to the NTP Archives for inventory, slide/block match, wet tissue audit, and storage. The slides, individual animal data records, and pathology tables were evaluated by a quality assessment (QA) pathologist at a pathology laboratory independent of the study laboratory. The individual animal records and tables were compared for accuracy, the slide and tissue counts were verified, and the histotechnique was evaluated. For the 2-year studies, a QA pathologist evaluated slides from all tumors and all potential target organs, which included the liver of rats and mice; the testis, epididymis, prostate gland, seminal vesicles, and pituitary gland of male rats and male mice; the kidney of male and female mice; the exocrine pancreas of rats; and the Harderian gland of female rats.

The QA report and the reviewed slides were submitted to the NTP Pathology Working Group (PWG) coordinator, who reviewed the selected tissues and addressed any inconsistencies in the diagnoses made by the laboratory and QA pathologists. Representative histopathology slides containing examples of lesions related to chemical administration, examples of disagreements in diagnoses between the laboratory and QA pathologists, or lesions of general interest were presented by the coordinator to the PWG for review. The PWG consisted of the QA pathologist and other pathologists experienced in rodent toxicological pathology. This group examined the tissues without any knowledge of exposure groups. When the PWG consensus differed from that of the laboratory pathologist, the diagnosis was changed. Final diagnoses for reviewed lesions represent a consensus between the laboratory pathologist, reviewing pathologist(s), and the PWG. Details of these review procedures have been described, in part, by Maronpot and Boorman $^{116}$ and Boorman et al. ${ }^{117}$ For subsequent analyses of the pathology data, the decision to 
evaluate the diagnosed lesions for each tissue type separately or combined was generally based on the guidelines of McConnell et al. ${ }^{118}$

Table 1. Experimental Design and Materials and Methods in the Perinatal and Two-year Feed Studies of Di- $n$-butyl Phthalate

\begin{tabular}{|c|c|}
\hline Rats & Mice \\
\hline \multicolumn{2}{|l|}{ Study Laboratory } \\
\hline Battelle (Columbus, $\mathrm{OH}$ ) & Same as rat study \\
\hline \multicolumn{2}{|l|}{ Strain and Species } \\
\hline Sprague Dawley (Hsd:Sprague Dawley ${ }^{\circledR}$ SD $^{\circledR}$ ) & $\mathrm{B} 6 \mathrm{C} 3 \mathrm{~F} 1 / \mathrm{N}$ \\
\hline \multicolumn{2}{|l|}{ Animal Source } \\
\hline $\begin{array}{l}\text { Envigo (formerly Harlan Laboratories, Inc., } \\
\text { Indianapolis, IN) }\end{array}$ & Taconic Biosciences, Inc. (Germantown, NY) \\
\hline \multicolumn{2}{|l|}{ Time Held Before Studies } \\
\hline $\mathrm{F}_{0}$ females: 11 days & 11 (females) or 12 (males) days \\
\hline \multicolumn{2}{|l|}{ Average Age When Studies Began } \\
\hline$F_{0}$ females: $12-15$ weeks & $5-6$ weeks \\
\hline \multicolumn{2}{|l|}{ Date of First Exposure } \\
\hline$F_{0}$ females: July 23, 2010 & August 16 (females) or 17 (males), 2010 \\
\hline \multicolumn{2}{|l|}{$F_{1}$ : August 30, 2010 (males and females) } \\
\hline \multicolumn{2}{|l|}{ Duration of Exposure } \\
\hline$F_{0}$ females: GD 6 to LD 21 & 2 years \\
\hline \multicolumn{2}{|l|}{$\mathrm{F}_{1}$ : Perinatal plus 2 years } \\
\hline \multicolumn{2}{|l|}{ Date of Last Exposure } \\
\hline $\mathrm{F}_{0}$ females: August 30, 2010 & August 15 (females) or 17 (males), 2012 \\
\hline \multicolumn{2}{|l|}{$\mathrm{F}_{1}$ : August 29 (males) or 31 (females), 2012} \\
\hline \multicolumn{2}{|l|}{ Necropsy Dates } \\
\hline $\mathrm{F}_{1}$ : August 27-29 (males) or 29-31 (females), 2012 & August 13-15 (females) or 15-17 (males), 2012 \\
\hline \multicolumn{2}{|l|}{ Average Age at Necropsy } \\
\hline $\mathrm{F}_{1}: 2$ years & 2 years \\
\hline \multicolumn{2}{|l|}{ Size of Study Groups } \\
\hline $\begin{array}{l}\mathrm{F}_{0} \text { females: } 45(0,300,1,000,3,000 \mathrm{ppm}) \text { or } 47 \\
(10,000 \mathrm{ppm})\end{array}$ & $50 /$ sex \\
\hline \multicolumn{2}{|l|}{$F_{1}(2$-year study): $50 /$ sex } \\
\hline \multicolumn{2}{|l|}{ Method of Distribution } \\
\hline $\begin{array}{l}\text { Animals were distributed randomly into groups of } \\
\text { approximately equal initial mean body weights }\end{array}$ & Same as rat study \\
\hline \multicolumn{2}{|l|}{ Animals per Cage } \\
\hline$F_{0}$ females: 1 (with litter) & Males: 1 \\
\hline
\end{tabular}




\begin{tabular}{l}
\hline \multicolumn{1}{c}{ Rats } \\
$\mathrm{F}_{1}: 2$ (males) or 4 (females) \\
Method of Animal Identification \\
$\mathrm{F}_{0}$ female: Cage card and tail marking with permanent \\
pen \\
$\mathrm{F}_{1}$ (pups): Limb tattoo \\
$\mathrm{F}_{1}$ (2-year study): Cage card and tail tattoo
\end{tabular}

Females: Up to 4

Mice

\section{Diet}

Irradiated NIH-07 meal feed (perinatal phase) or irradiated NTP-2000 meal feed (2-year study) (Zeigler Brothers, Inc., Gardners, PA), available ad libitum, changed twice weekly

Cage card and tail tattoo

\section{Water}

Tap water (Columbus, $\mathrm{OH}$ municipal supply) via automatic watering system (Edstrom Industries, Inc., Waterford, WI), available ad libitum

\section{Cages}

Solid polycarbonate (Lab Products, Inc., Seaford, DE), changed weekly through PND 4, then twice weekly, rotated every 2 weeks

Irradiated NTP-2000 meal feed (Zeigler Brothers, Inc., Gardners, PA), available ad libitum, changed twice weekly

\section{Bedding}

Irradiated Sani-Chips ${ }^{\circledR}$ (P.J. Murphy Forest Products Corporation, Montville, NJ), changed with cage changes

Solid polycarbonate (Lab Products, Inc., Seaford, DE), changed weekly (males) or twice weekly (females), rotated every 2 weeks

\section{Rack Filters}

Spun-bonded polyester (Snow Filtration Company, Cincinnati, OH or National Filter Media Corporation, Olive Branch, MS), changed every 2 weeks

\section{Racks}

Stainless steel (Lab Products, Inc., Seaford, DE), changed and rotated every 2 weeks

\section{Same as rat study}

Same as rat study

\section{Animal Room Environment}

Temperature: $72^{\circ} \mathrm{F} \pm 3^{\circ} \mathrm{F}$

Relative humidity: $50 \% \pm 15 \%$

Room fluorescent light: 12 hours/day

Room air changes: at least 10/hour

\section{Exposure Concentrations}

$0,300,1,000,3,000$, or $10,000 \mathrm{ppm}$ in feed

\section{Type and Frequency of Observation}

$F_{0}$ females: Observed twice daily. Weighed on GDs 5, 6, Observed twice daily. Weighed initially, weekly for the $9,12,15,18$, and 21 and on LDs $1,4,7,10,14$, and 21 . Feed consumption was measured continuously over 3-day intervals from GD 6 to LD 21.

$0,1,000,3,000$, or $10,000 \mathrm{ppm}$ in feed

Spun-bonded polyester (Snow Filtration Company, Cincinnati, $\mathrm{OH})$, changed every 2 weeks

Same as rat study

Same as rat study

first 13 weeks, every 4 weeks thereafter, and at study termination. Clinical observations were recorded every 4 weeks beginning at week 6 and at study termination. Feed consumption was measured weekly for the first 3 months and then at 4-week intervals thereafter. 


\begin{tabular}{cc}
\hline Rats & Mice \\
\hline
\end{tabular}

$\mathrm{F}_{1}$ : Observed twice daily. Litter data (litter count by sex, litter weights by sex, and litter observations) were recorded on PND 1. Pups per litter were recorded on PNDs 2 and 3. Pups were weighed on PNDs 4, 7, 14, and 21, weekly for the first 13 weeks, every 4 weeks thereafter, and at study termination. Clinical observations were recorded every 4 weeks beginning on day 29 and at study termination. Feed consumption was recorded weekly for 3 months, and then at 4-week intervals thereafter.

\section{Method of Euthanasia}

Carbon dioxide

\section{Necropsy}

Necropsies were performed on all $\mathrm{F}_{1}$ rats.

\section{Histopathology}

Complete histopathology was performed on all $\mathrm{F}_{1}$ rats. In addition to gross lesions and tissue masses, the following tissues were examined: adrenal gland, brain, clitoral gland, esophagus, eyes, femur, Harderian gland, heart and aorta, large intestine (cecum, colon, and rectum), small intestine (duodenum, jejunum, and ileum), kidneys, liver, lung, lymph nodes (mandibular and mesenteric), mammary gland, nose, ovary, pancreas, parathyroid gland, pituitary gland, preputial gland, prostate gland, salivary gland, seminal vesicle, spleen, stomach (forestomach and glandular), testis with epididymis, thymus, thyroid gland, trachea, urinary bladder, and uterus.

\section{Internal Dose Assessment}

Maternal plasma, amniotic fluid (pooled by litter), and fetuses (pooled by litter) $(n=5)$ were collected at GD 18, and maternal plasma $(\mathrm{n}=5)$ and whole pup $(\mathrm{n}=2 / \mathrm{sex})$ were collected at PND 4 to determine mono$n$-butyl phthalate concentration to estimate gestational and lactational transfer, respectively.
Same as rat study

Necropsies were performed on all mice.

Complete histopathology was performed on all mice. In addition to gross lesions and tissue masses, the following tissues were examined: adrenal gland, brain, clitoral gland, esophagus, eyes, femur, gallbladder, Harderian gland, heart and aorta, large intestine (cecum, colon, and rectum), small intestine (duodenum, jejunum, and ileum), kidneys, liver, lung, lymph nodes (mandibular and mesenteric), mammary gland, nose, ovary, pancreas, parathyroid gland, pituitary gland, preputial gland, prostate gland, salivary gland, seminal vesicle, spinal cord, spleen, stomach (forestomach and glandular), testis with epididymis, thymus, thyroid gland, trachea, urinary bladder, uterus.

$\mathrm{PND}=$ postnatal day; $\mathrm{GD}=$ gestation day $\mathrm{LD}=$ lactation day.

\section{Statistical Methods}

\section{Survival Analyses}

The probability of survival was estimated by the product-limit procedure of Kaplan and Meier ${ }^{119}$ and is presented graphically. Animals surviving to the end of the observation period are treated as censored observations, as are animals dying from unnatural causes within the observation period. Animals dying from natural causes are included in analyses and are treated as uncensored observations. For the 2-year mouse study, exposure concentration-related trends are identified with Tarone's life table test, ${ }^{120}$ and pairwise exposure concentration-related effects are assessed using Cox's method. ${ }^{121}$ For the rat perinatal study, exposure concentration-related trends and 
pairwise exposure concentration-related effects on survival are assessed using a Cox proportional hazards model ${ }^{121}$ with a random litter effect. All reported $\mathrm{p}$ values for the survival analyses are two-sided.

\section{Calculation of Incidence}

The incidence of neoplasms or nonneoplastic lesions is presented as the numbers of animals bearing such lesions at a specific anatomic site. For calculation of incidence rates, the denominator for most neoplasms and all nonneoplastic lesions is the number of animals where the site was examined microscopically. When macroscopic examination was required to detect neoplasms in certain tissues (e.g., mesentery, pleura, peripheral nerve, skeletal muscle, tongue, tooth, Zymbal's gland) before microscopic evaluation, however, the denominator consists of the number of animals that had a gross abnormality. When neoplasms had multiple potential sites of occurrence (e.g., leukemia or lymphoma), the denominator consists of the number of animals on which a necropsy was performed. Additional study data also give the survival-adjusted neoplasm rate for each group and each site-specific neoplasm. This survival-adjusted rate (based on the Poly-3 method described below) accounts for differential mortality by assigning a reduced risk of neoplasm, proportional to the third power of the fraction of time on study, only to site-specific, lesion-free animals that do not reach terminal euthanasia.

\section{Analysis of Neoplasm and Nonneoplastic Lesion Incidence}

Statistical analyses of neoplasm and nonneoplastic lesion incidence considered two features of the data. Some animals did not survive the entire 2 years of the study, so survival differences between groups had to be considered. In addition, up to two animals per sex were randomly selected from each litter to participate in the study. The statistical analysis of lesion incidence used the Poly-3 test to account for survival differences, with a Rao-Scott adjustment for litter effects, as described below.

The Poly-k test ${ }^{122-124}$ was used to assess neoplasm and nonneoplastic lesion prevalence. This test is a survival-adjusted quantal-response procedure that modifies the Cochran-Armitage linear trend test to account for survival differences. More specifically, this method modifies the denominator in the quantal estimate of lesion incidence to approximate more closely the total number of animal years at risk. For analysis of a given site, each animal is assigned a risk weight. This value is 1 if the animal had a lesion at that site or if it survived until terminal euthanasia; if the animal died before terminal euthanasia and did not have a lesion at that site, its risk weight is the fraction of the entire study time that it survived, raised to the kth power.

This method yields a lesion prevalence rate that depends only on the choice of a shape parameter for a Weibull hazard function describing cumulative lesion incidence over time. ${ }^{122}$ Unless otherwise specified, a value of $\mathrm{k}=3$ was used in the analysis of site-specific lesions. This value was recommended by Bailer and Portier ${ }^{122}$ after an evaluation of neoplasm onset time distributions for a variety of site-specific neoplasms in control Fischer 344 rats and B6C3F1 mice. ${ }^{125}$ Bailer and Portier ${ }^{122}$ showed that the Poly-3 test gave valid results if the true value of $\mathrm{k}$ was within the range of 1 to 5 . A further advantage of the Poly-3 method is that it does not require lesion lethality assumptions. Variation introduced by the use of risk weights, which reflect differential mortality, was accommodated by adjusting the variance of the Poly-3 statistic 
as recommended by Bieler and Williams. ${ }^{126}$ Poly-3 tests used the continuity correction described by Nam. ${ }^{127}$

Littermates tend to be more like each other than like fetuses or pups in other litters. Failure to account for correlation within litters leads to underestimates of variance in statistical tests, resulting in higher probabilities of Type I errors ("false positives"). Because up to two pups per sex per litter were present in the core rat study, the Poly-3 test was modified to accommodate litter effects using the Rao-Scott approach. ${ }^{128}$ The Rao-Scott approach accounts for litter effects by estimating the ratio of the variance in the presence of litter effects to the variance in the absence of litter effects. This ratio is then used to adjust the sample size downward to yield the estimated variance in the presence of litter effects. The Rao-Scott approach was implemented in the Poly-3 test as recommended by the Fung et al. ${ }^{129}$ formula $\overline{\bar{T}}_{R S 2}$.

Tests of significance included pairwise comparisons of each exposed group with control groups and a test for an overall exposure concentration-related trend. Continuity-corrected Rao-Scottadjusted Poly-3 tests were used in the analysis of lesion incidence and reported $p$ values are onesided. The significance of a lower incidence or negative trend in lesions is approximated as $1-p$ with the letter $\mathrm{N}$ added (e.g., $\mathrm{p}=0.99$ is presented as $\mathrm{p}=0.01 \mathrm{~N}$ ). For neoplasms and nonneoplastic lesions observed without litter structure (e.g., at the interim evaluation), Poly-3 tests that included the continuity correction, but without adjustment for potential litter effects, were used for trend and pairwise comparisons to the control group.

To evaluate incidence rates by litter, the proportions of litters affected by each lesion type were tested among groups. Cochran-Armitage trend tests and Fisher's exact tests ${ }^{130}$ were used to test for trends and pairwise differences from the control group, respectively.

\section{Analysis of Continuous Variables}

Before statistical analysis, extreme values identified by the outlier test of Dixon and Massey ${ }^{131}$ for small samples $(n<20)$ and Tukey's outer fences method ${ }^{132}$ for large samples $(n \geq 20)$ were examined by NTP personnel, and implausible values were eliminated from the analysis. Body weight measurements, which historically have approximately normal distributions, were analyzed with the parametric multiple comparison procedures of Dunnett ${ }^{133}$ and Williams. ${ }^{134 ; 135}$ Dam gestational and lactational feed consumption, litter sizes, pup survival, implantations, number of resorptions, and proportions of male pups per litter for all studies were analyzed using the nonparametric multiple comparison methods of Shirley, ${ }^{136}$ as modified by Williams, ${ }^{137}$ and Dunn, ${ }^{138}$ given that these endpoints typically have skewed distributions. For all quantitative endpoints unaffected by litter structure, the Jonckheere test ${ }^{139}$ was used to assess the significance of the exposure concentration-related trends and to determine at the 0.01 level of significance whether a trend-sensitive test (the Williams or Shirley test) was more appropriate for pairwise comparisons than a test that does not assume a monotonic exposure concentration-related trend (the Dunnett or Dunn test).

Postweaning body weights were measured on two pups per sex per litter in the 2-year study; more than two pups per sex per litter were possible in preweaning body weight measurements. The analyses of pup mean body weights and mean body weights adjusted for litter size (described below) of these animals took litter effects into account using a mixed model with litter as a random effect. To adjust for multiple comparisons, a Dunnett-Hsu adjustment was used. ${ }^{140}$ 
Dam mean body weights during gestation and lactation were analyzed with the parametric multiple comparison procedures of Dunnett ${ }^{133}$ and Williams, ${ }^{134 ; 135}$ depending on whether the Jonckheere test indicated the use of a trend-sensitive test. P values for these analyses are twosided.

\section{Analysis of Gestational and Fertility Indices}

Cochran-Armitage trend tests were used to test the significance of trends in gestational and fertility indices across exposure groups. Fisher's exact test was used to conduct pairwise comparisons of each exposed group with the control group. $\mathrm{P}$ values for these analyses are two-sided.

\section{Body Weight Adjustments}

Preweaning pup body weights were adjusted for live litter size as follows: A linear model was fit to body weights as a function of exposure concentration and litter size. The estimated coefficient of litter size was then used to adjust each pup body weight based on the difference between its litter size and the mean litter size. Prestandardization PND 4 body weights were adjusted for PND 1 litter size, and body weights measured between PND 4 poststandardization and PND 21 were adjusted for PND 4 poststandardization litter size. After adjustment, mean body weights were analyzed with a linear mixed model with a random litter effect.

\section{Historical Control Data}

The concurrent control group is the most valid comparison to the exposed groups and is the only control group analyzed statistically in NTP bioassays. Historical control data are often helpful in interpreting potential exposure-related effects, however, particularly for uncommon or rare neoplasm types. For meaningful comparisons, the conditions for studies in the historical control data must be generally similar. Significant factors affecting the background incidence of neoplasms at a variety of sites are diet, sex, strain/stock, and route of exposure. The NTP historical control database contains all 2-year studies for each species, sex, and strain/stock with histopathological findings in control animals completed within the most recent 5-year period, ${ }^{141-}$ 143 including the concurrent control for comparison across multiple technical reports. In general, the historical control data for a given study includes studies using the same route of administration, and the overall incidence of neoplasms in control groups for all routes of administration are included for comparison, including the current study.

\section{Quality Assurance Methods}

The 2-year studies were conducted in compliance with U.S. Food and Drug Administration Good Laboratory Practice Regulations. ${ }^{144}$ In addition, the 2-year study reports were audited retrospectively by an independent QA contractor against study records submitted to the NTP Archives. Separate audits covered completeness and accuracy of the pathology data, pathology specimens, final pathology tables, and a draft of this NTP Technical Report. Audit procedures and findings are presented in the reports and are on file at NIEHS. The audit findings were reviewed and assessed by NTP staff, and all comments were resolved or otherwise addressed during the preparation of this Technical Report. 


\section{Results}

\section{Data Availability}

The National Toxicology Program (NTP) evaluated all study data. Data relevant for evaluating toxicological findings are presented here. All study data are available in the NTP Chemical Effects in Biological Systems (CEBS) database: https://doi.org/10.22427/NTP-DATA-TR$600 . .^{145}$

\section{Rats}

\section{Two-year Study (Perinatal Phase)}

No effects related to di- $n$-butyl phthalate (DBP) exposure were observed on the pregnancy status, maternal survival, gestation length, or number of dams that littered (Table 2).

Table 2. Summary of the Disposition of $F_{0}$ Female Rats during Perinatal Exposure in the Perinatal and Two-year Feed Study of Di-n-butyl Phthalate

\begin{tabular}{lccccc}
\hline \multicolumn{1}{c}{ Reproductive Performance } & $\mathbf{0 ~ p p m}$ & $\mathbf{3 0 0} \mathbf{~ p p m}$ & $\mathbf{1 , 0 0 0} \mathbf{~ p p m}$ & $\mathbf{3 , 0 0 0} \mathbf{~ p p m}$ & $\mathbf{1 0 , 0 0 0} \mathbf{~ p p m}$ \\
\hline Time-mated Females (GD 6) & 45 & 45 & 45 & 45 & $47^{\mathrm{a}}$ \\
Females Pregnant (\%) & $40(88.9)$ & $34(75.6)$ & $39(86.7)$ & $38(84.4)$ & $37(78.7)$ \\
Females Not Pregnant (\%) & $5(11.1)$ & $11(24.4)$ & $6(13.3)$ & $7(15.6)$ & $10(21.3)$ \\
Dams Not Delivering with Evidence & $5(12.5)$ & $7(20.6)$ & $6(15.4)$ & $3(7.9)$ & $5(13.5)$ \\
of Pregnancy (\%) & & & & & \\
Dams with Litters on LD 0 (\%) & $35(87.5)$ & $27(79.4)$ & $33(84.6)$ & $35(92.1)$ & $32(86.5)$ \\
Gestation Length (Days) ${ }^{\mathrm{c}, \mathrm{d}}$ & $22.2 \pm 0.1$ & $22.1 \pm 0.1$ & $22.0 \pm 0.0$ & $22.2 \pm 0.1$ & $22.1 \pm 0.1$ \\
Litters Poststandardization (LD 4) $^{\mathrm{e}}$ & 28 & 25 & 27 & 30 & 27 \\
Weaned Males/Females $^{\mathrm{b}}$ & $112 / 112$ & $97 / 102$ & $104 / 111$ & $120 / 120$ & $104 / 111$ \\
\hline
\end{tabular}

$\mathrm{GD}=$ gestation day; $\mathrm{LD}=$ lactation day.

${ }^{\text {aT }}$ Two additional time-mated animals were received for the study and were placed in the 10,000 ppm group.

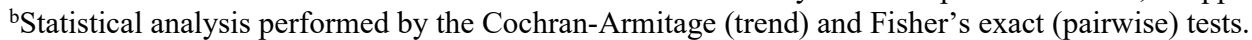

'Statistical analysis performed by the Jonckheere (trend) and Shirley or Dunn (pairwise) tests.

${ }^{\mathrm{d}}$ Gestation length calculated for sperm-positive females that delivered a litter. Data are presented as mean \pm standard error.

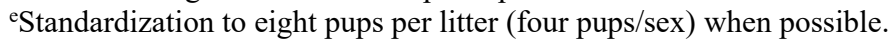

Maternal mean body weights and body weight gains of exposed dams during gestation were comparable to those of the control group (Table 3 ). During lactation, minimal differences in mean body weights were noted $(<6 \%)$ between the highest exposure group $(10,000 \mathrm{ppm})$ and control group, with sporadic differences observed in body weight gains across all exposure groups. 
Table 3. Summary of Mean Body Weights and Body Weight Gains of $F_{0}$ Female Rats during Gestation and Lactation in the Perinatal and Two-year Feed Study of Di-n-butyl Phthalate

\begin{tabular}{cccccc}
\hline Parameter $^{\mathbf{a}, \mathbf{b}}$ & $\mathbf{0 ~ p p m}$ & $\mathbf{3 0 0} \mathbf{~ p p m}$ & $\mathbf{1 , 0 0 0} \mathbf{~ p p m}$ & $\mathbf{3 , 0 0 0} \mathbf{~ p p m}$ & $\mathbf{1 0 , 0 0 0} \mathbf{~ p p m}$ \\
\hline Gestation Day & & & & & \\
6 & $230.1 \pm 2.6(40)$ & $231.7 \pm 2.0(34)$ & $231.4 \pm 1.8(39)$ & $232.5 \pm 1.7(38)$ & $226.8 \pm 3.1(37)$ \\
9 & $240.1 \pm 3.2^{*}(40)$ & $245.0 \pm 2.2(34)$ & $244.6 \pm 1.6(39)$ & $242.8 \pm 1.7(38)$ & $236.2 \pm 2.4(37)$ \\
12 & $259.2 \pm 2.3^{*}(40)$ & $262.1 \pm 2.3(34)$ & $261.5 \pm 1.7(39)$ & $261.0 \pm 1.4(38)$ & $254.1 \pm 2.2(37)$ \\
15 & $278.0 \pm 2.4(40)$ & $279.6 \pm 3.4(34)$ & $281.9 \pm 1.9(39)$ & $279.8 \pm 2.0(38)$ & $275.1 \pm 2.5(37)$ \\
18 & $314.7 \pm 2.7(40)$ & $318.6 \pm 3.5(34)$ & $317.2 \pm 2.7(39)$ & $320.3 \pm 1.9(38)$ & $315.7 \pm 3.4(37)$ \\
$21^{\text {c }}$ & $355.5 \pm 5.0(35)$ & $366.6 \pm 6.1(28)$ & $361.8 \pm 4.7(34)$ & $366.2 \pm 2.5(34)$ & $353.6 \pm 4.9(30)$
\end{tabular}

\section{Gestation Weight Change}

Gestation Day Interval

$\begin{array}{cccccc}6-9 & 10.0 \pm 0.9^{* *}(40) & 13.3 \pm 1.0(34) & 13.2 \pm 0.8(39) & 10.3 \pm 0.8(38) & 9.4 \pm 1.3(37) \\ 9-12 & 19.1 \pm 1.4(40) & 17.1 \pm 1.3(34) & 16.9 \pm 0.6(39) & 18.2 \pm 1.0(38) & 17.9 \pm 1.0(37) \\ 12-15 & 18.7 \pm 0.6^{*}(40) & 17.5 \pm 2.0(34) & 20.4 \pm 0.6(39) & 18.8 \pm 1.4(38) & 21.0 \pm 0.7(37) \\ 15-18 & 36.8 \pm 1.1^{*}(40) & 39.0 \pm 2.3(34) & 35.2 \pm 1.4(39) & 40.5 \pm 1.6(38) & 40.6 \pm 1.3(37) \\ 18-21 & 42.2 \pm 3.4^{* *(35)} & 49.1 \pm 2.7(28) & 45.3 \pm 2.0(34) & 46.9 \pm 1.2(34) & 39.7 \pm 1.3(30) \\ 6-21 & 126.4 \pm 4.6(35) & 136.3 \pm 5.8(28) & 129.6 \pm 4.4(34) & 133.7 \pm 2.4(34) & 127.3 \pm 3.7(30) \\ \text { tation Day } & & & & & \\ 1 & 271.5 \pm 2.6(35) & 277.5 \pm 3.3(27) & 274.4 \pm 1.9(33) & 274.4 \pm 1.6(35) & 270.7 \pm 3.1(32) \\ 4 & 286.6 \pm 2.5(35) & 291.6 \pm 2.8(27) & 294.5 \pm 2.2(33) & 293.7 \pm 1.9(35) & 282.9 \pm 2.9(32) \\ 7^{d} & 297.0 \pm 2.6^{* *}(28) & 299.6 \pm 2.9(25) & 298.7 \pm 2.1(27) & 294.9 \pm 1.9(30) & 286.4 \pm 2.9^{* *}(27) \\ 10 & 304.4 \pm 3.1^{* *}(28) & 311.6 \pm 2.7(25) & 307.4 \pm 2.3(27) & 305.6 \pm 2.0(30) & 291.8 \pm 3.3 * *(27) \\ 14 & 318.4 \pm 3.0^{* *}(28) & 322.1 \pm 3.1(25) & 317.4 \pm 2.3(27) & 313.0 \pm 2.2(30) & 299.5 \pm 2.5 * *(27) \\ 21 & 299.0 \pm 2.9^{*}(28) & 301.9 \pm 2.9(25) & 301.5 \pm 2.6(27) & 290.7 \pm 4.3(30) & 290.8 \pm 3.1(27)\end{array}$

\section{Lactation Weight Change}

Lactation Day Interval

\begin{tabular}{cccccc}
$1-4$ & $15.1 \pm 1.3(35)$ & $14.1 \pm 1.4(27)$ & $20.1 \pm 1.4^{*}(33)$ & $19.3 \pm 1.1(35)$ & $12.2 \pm 1.2(32)$ \\
$4-7$ & $11.0 \pm 1.3^{* *}(28)$ & $7.4 \pm 1.1 *(25)$ & $3.4 \pm 1.3^{* *}(27)$ & $2.2 \pm 1.1 * *(30)$ & $3.0 \pm 1.2^{* *(27)}$ \\
$7-10$ & $7.4 \pm 1.3(28)$ & $12.0 \pm 1.0(25)$ & $8.7 \pm 1.3(27)$ & $10.7 \pm 1.4(30)$ & $5.4 \pm 1.4(27)$ \\
$10-14$ & $14.0 \pm 1.9^{* *}(28)$ & $10.5 \pm 1.4(25)$ & $10.0 \pm 1.5(27)$ & $7.4 \pm 1.3 * *(30)$ & $7.7 \pm 1.7 * *(27)$ \\
$14-21$ & $-19.4 \pm 1.9^{* *}(28)$ & $-20.2 \pm 1.9(25)$ & $-15.9 \pm 2.0(27)$ & $-22.3 \pm 3.8(30)$ & $-8.7 \pm 1.5^{* *}(27)$ \\
$1-21$ & $26.8 \pm 2.2(28)$ & $23.2 \pm 1.8(25)$ & $26.7 \pm 2.1(27)$ & $17.0 \pm 4.5(30)$ & $19.6 \pm 2.4(27)$ \\
\hline
\end{tabular}

Statistical significance for an exposure group indicates a significant pairwise test compared to the vehicle control group.

Statistical significance for the vehicle control group indicates a significant trend test.

$*$ Statistically significant at $\mathrm{p} \leq 0.05 ; * * \mathrm{p} \leq 0.01$.

${ }^{a}$ Data are presented as mean \pm standard error (number of dams). Body weight data are presented in grams.

${ }^{b}$ Each exposure group was compared to the vehicle control group with the Williams test when a trend was present $(\mathrm{p} \leq 0.01$ from the Jonckheere trend test) or with the Dunnett test when no trend was present.

${ }^{\mathrm{c}}$ Decreased number of dams at gestation day 21 reflects animals removed at gestation day 18 for internal dose assessment. ${ }^{\mathrm{d} D e c r e a s e d ~ n u m b e r ~ o f ~ d a m s ~ a t ~ l a c t a t i o n ~ d a y ~} 7$ reflects animal removal at postnatal day 4 for sample collection to determine gestational and lactational transfer. 
Feed consumption during gestation was significantly higher $(5 \%-6 \%)$ only in the $10,000 \mathrm{ppm}$ group compared to the control group during gestation day (GD) 12-15 and GD 15-18 intervals (Table 4). Feed consumption in all exposed groups, except the 10,000 ppm group, was significantly increased (1\%-9\%) compared to the control group from lactation day (LD) 1 to 4 (Table 4). Feed consumption for LD 10-14 and LD 17-21 intervals, and overall during lactation in the $10,000 \mathrm{ppm}$ group, was $4 \%-9 \%$ less than in control animals. Chemical intake throughout gestation and lactation was generally proportional to the exposure concentration and was higher during lactation than gestation. Chemical intake from LD 14 to 21 was not calculated because the entire litter ate feed; therefore, an accurate assessment could not be made for $\mathrm{F}_{0}$ or F1 consumption.

Table 4. Summary of Feed and Di-n-butyl Phthalate Consumption by $F_{0}$ Female Rats during Gestation and Lactation in the Perinatal and Two-year Feed Study

\begin{tabular}{|c|c|c|c|c|c|}
\hline Parameter $^{\mathrm{a}}$ & 0 ppm & 300 ppm & 1,000 ppm & 3,000 ppm & 10,000 ppm \\
\hline \multicolumn{6}{|c|}{ Gestation Day Interval $^{b, c}$} \\
\hline $6-9$ & $16.1 \pm 0.6(40)$ & $17.6 \pm 0.3(34)$ & $17.6 \pm 0.3(39)$ & $17.2 \pm 0.3(38)$ & $18.0 \pm 0.7(36)$ \\
\hline $9-12$ & $18.9 \pm 0.3(40)$ & $19.7 \pm 0.3(34)$ & $19.7 \pm 0.3(39)$ & $19.5 \pm 0.3(37)$ & $19.1 \pm 0.3(34)$ \\
\hline $12-15$ & $18.6 \pm 0.2 * *(40)$ & $18.5 \pm 0.4(34)$ & $19.1 \pm 0.2(39)$ & $18.7 \pm 0.3(38)$ & $19.6 \pm 0.3 * *(37)$ \\
\hline $15-18$ & $20.8 \pm 0.2 *(40)$ & $21.7 \pm 0.3(34)$ & $21.0 \pm 0.3(39)$ & $21.4 \pm 0.3(38)$ & $22.1 \pm 0.4^{*}(37)$ \\
\hline $18-21$ & $22.1 \pm 0.5(35)$ & $22.9 \pm 0.4(29)$ & $22.6 \pm 0.3(34)$ & $22.5 \pm 0.3(34)$ & $23.0 \pm 0.5(30)$ \\
\hline $6-21$ & $19.3 \pm 0.2(35)$ & $20.1 \pm 0.3(29)$ & $20.0 \pm 0.2(34)$ & $19.9 \pm 0.2(33)$ & $20.0 \pm 0.3(28)$ \\
\hline \multicolumn{6}{|c|}{ Lactation Day Interval $^{\text {b,c }}$} \\
\hline $1-4$ & $33.24 \pm 0.56(35)$ & $36.30 \pm 0.96^{*}(27)$ & $36.20 \pm 0.76^{* *}(33)$ & $36.39 \pm 0.59 * *(35)$ & $33.50 \pm 0.66(32)$ \\
\hline $4-7$ & $39.89 \pm 0.50 *(28)$ & $40.36 \pm 0.69(25)$ & $40.41 \pm 0.44(27)$ & $40.12 \pm 0.52(30)$ & $38.06 \pm 0.45(27)$ \\
\hline $7-10$ & $47.45 \pm 0.92(28)$ & $49.54 \pm 0.78(25)$ & $49.55 \pm 0.55(27)$ & $49.89 \pm 0.56(30)$ & $46.44 \pm 0.59(27)$ \\
\hline $10-14$ & $56.81 \pm 0.77 * *(27)$ & $58.55 \pm 0.87(25)$ & $57.12 \pm 0.61(27)$ & $56.10 \pm 0.71(30)$ & $53.12 \pm 0.58 * *(27)$ \\
\hline $14-17$ & $58.00 \pm 0.88(28)$ & $58.14 \pm 0.83(25)$ & $57.53 \pm 0.79(27)$ & $58.64 \pm 0.91(30)$ & $57.83 \pm 0.73(27)$ \\
\hline $17-21$ & $72.03 \pm 1.29 * *(28)$ & $72.80 \pm 1.14(25)$ & $72.31 \pm 1.27(27)$ & $66.38 \pm 1.74 *(30)$ & $65.58 \pm 1.08 * *(27)$ \\
\hline $1-14$ & $45.45 \pm 0.64 * *(27)$ & $47.21 \pm 0.61(25)$ & $46.87 \pm 0.49(27)$ & $46.38 \pm 0.51(30)$ & $43.63 \pm 0.43 *(27)$ \\
\hline \multicolumn{6}{|c|}{ Chemical Intake $(\mathrm{mg} / \mathrm{kg} / \mathrm{day})^{\mathrm{d}, \mathrm{e}}$} \\
\hline GD 6-21 & $0.00 \pm 0.00(35)$ & $21.62 \pm 0.18(29)$ & $71.60 \pm 0.64(34)$ & $213.5 \pm 2.14(33)$ & $739.9 \pm 12.57(28)$ \\
\hline LD $1-14$ & $0.00 \pm 0.00(27)$ & $46.61 \pm 0.45(25)$ & $155.4 \pm 1.36(27)$ & $465.6 \pm 4.84(30)$ & $1,514 \pm 15.81(27)$ \\
\hline
\end{tabular}

Statistical significance for an exposure group indicates a significant pairwise test compared to the vehicle control group.

Statistical significance for the vehicle control group indicates a significant trend test.

*Statistically significant at $\mathrm{p} \leq 0.05 ; * \mathrm{p} \leq 0.01$.

$\mathrm{GD}=$ gestation day; $\mathrm{LD}=$ lactation day.

${ }^{\text {aData }}$ are presented as mean \pm standard error (number of dams).

${ }^{b}$ Feed consumption data are presented as grams/animal/day.

${ }^{c}$ Each exposure group was compared to the vehicle control group with the Shirley test when a trend was present $(p \leq 0.01$ from the Jonckheere trend test) or with the Dunn test when no trend was present.

${ }^{\mathrm{d}}$ Chemical intake calculated as: ([exposure concentration $\times$ feed consumption]/[average body weight of day range]).

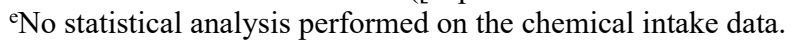

In the lowest exposure group (300 ppm), total and live litter size were significantly increased $(12 \%)$ relative to the control group on postnatal day (PND) 1 and PND 4 prestandardization 
(Table 5). On PND 21, all groups had similar live litter sizes. No significant effects on live litter size occurred in other exposed groups at any time point. No differences in sex ratio or survival during lactation were found.

Table 5. Summary of Mean Litter Size and Survival Ratio of $F_{1}$ Male and Female Rats during Lactation in the Perinatal and Two-year Feed Study of Di- $n$-butyl Phthalate

\begin{tabular}{|c|c|c|c|c|c|}
\hline Parameter $^{\mathrm{a}}$ & 0 ppm & 300 ppm & 1,000 ppm & 3,000 ppm & 10,000 ppm \\
\hline \multicolumn{6}{|l|}{ PND $1^{b, c}$} \\
\hline Total & $\begin{array}{c}11.49 \pm 0.35 \\
(35)\end{array}$ & $\begin{array}{c}12.85 \pm 0.39 * \\
(26)\end{array}$ & $\begin{array}{c}12.21 \pm 0.34 \\
\quad(33)\end{array}$ & $\begin{array}{c}12.30 \pm 0.25 \\
(33)\end{array}$ & $\begin{array}{c}12.09 \pm 0.44 \\
(32)\end{array}$ \\
\hline Live & $\begin{array}{c}11.37 \pm 0.34 \\
(35)\end{array}$ & $\begin{array}{c}12.77 \pm 0.39 * \\
(26)\end{array}$ & $\begin{array}{c}12.18 \pm 0.34 \\
\quad(33)\end{array}$ & $\begin{array}{c}12.12 \pm 0.26 \\
\quad(33)\end{array}$ & $\begin{array}{c}11.91 \pm 0.46 \\
(32)\end{array}$ \\
\hline$\%$ Male per Litter & $50.4 \pm 3.1(31)$ & $47.7 \pm 3.2(23)$ & $46.0 \pm 3.1(32)$ & $48.1 \pm 1.7(32)$ & $46.1 \pm 2.5(20)$ \\
\hline$\%$ Male $^{\mathrm{d}, \mathrm{e}}$ & $50.7(355)$ & $47.4(293)$ & 46.5 (389) & $48.2(388)$ & $46.1(243)$ \\
\hline \multicolumn{6}{|l|}{ Male ${ }^{\mathbf{b}, \mathbf{c}}$} \\
\hline PND 1 & $\begin{array}{l}5.81 \pm 0.40 \\
\quad(31)\end{array}$ & $\begin{array}{l}6.04 \pm 0.46 \\
\quad(23)\end{array}$ & $\begin{array}{c}5.66 \pm 0.42 \\
(32)\end{array}$ & $\begin{array}{c}5.84 \pm 0.26 \\
\quad(32)\end{array}$ & $\begin{array}{l}5.60 \pm 0.48 \\
\quad(20)\end{array}$ \\
\hline PND 4 Prestandardization & $\begin{array}{l}5.77 \pm 0.40 \\
\quad(31)\end{array}$ & $\begin{array}{l}6.04 \pm 0.46 \\
\quad(23)\end{array}$ & $\begin{array}{c}5.66 \pm 0.42 \\
\quad(32)\end{array}$ & $\begin{array}{c}5.84 \pm 0.26 \\
(32)\end{array}$ & $\begin{array}{l}5.60 \pm 0.48 \\
\quad(20)\end{array}$ \\
\hline PND 4 Poststandardization & $\begin{array}{c}4.00 \pm 0.10 \\
\quad(28)\end{array}$ & $\begin{array}{c}3.88 \pm 0.09 \\
\quad(25)\end{array}$ & $\begin{array}{c}3.89 \pm 0.15 \\
\quad(27)\end{array}$ & $\begin{array}{c}4.00 \pm 0.00 \\
(30)\end{array}$ & $\begin{array}{l}3.85 \pm 0.12 \\
\quad(27)\end{array}$ \\
\hline PND 21 & $\begin{array}{c}4.00 \pm 0.10 \\
(28)\end{array}$ & $\begin{array}{c}3.88 \pm 0.09 \\
(25)\end{array}$ & $\begin{array}{c}3.85 \pm 0.16 \\
(27)\end{array}$ & $\begin{array}{c}4.00 \pm 0.00 \\
(30)\end{array}$ & $\begin{array}{l}3.85 \pm 0.12 \\
(27)\end{array}$ \\
\hline \multicolumn{6}{|l|}{ Female $^{\mathrm{b}, \mathrm{c}}$} \\
\hline PND 1 & $\begin{array}{l}5.65 \pm 0.37 \\
\quad(31)\end{array}$ & $\begin{array}{l}6.70 \pm 0.46 \\
\quad(23)\end{array}$ & $\begin{array}{c}6.50 \pm 0.38 \\
\quad(32)\end{array}$ & $\begin{array}{c}6.28 \pm 0.25 \\
\quad(32)\end{array}$ & $\begin{array}{l}6.55 \pm 0.51 \\
\quad(20)\end{array}$ \\
\hline PND 4 Prestandardization & $\begin{array}{c}5.65 \pm 0.37 \\
(31)\end{array}$ & $\begin{array}{c}6.70 \pm 0.46 \\
\quad(23)\end{array}$ & $\begin{array}{c}6.47 \pm 0.38 \\
\quad(32)\end{array}$ & $\begin{array}{c}6.28 \pm 0.25 \\
\quad(32)\end{array}$ & $\begin{array}{l}6.55 \pm 0.51 \\
\quad(20)\end{array}$ \\
\hline PND 4 Poststandardization & $\begin{array}{c}4.00 \pm 0.10 \\
\quad(28)\end{array}$ & $\begin{array}{c}4.12 \pm 0.09 \\
\quad(25)\end{array}$ & $\begin{array}{c}4.11 \pm 0.15 \\
\quad(27)\end{array}$ & $\begin{array}{c}4.00 \pm 0.00 \\
\quad(30)\end{array}$ & $\begin{array}{c}4.15 \pm 0.12 \\
\quad(27)\end{array}$ \\
\hline PND 21 & $\begin{array}{c}4.00 \pm 0.10 \\
\quad(28)\end{array}$ & $\begin{array}{l}4.08 \pm 0.10 \\
\quad(25)\end{array}$ & $\begin{array}{c}4.11 \pm 0.15 \\
(27)\end{array}$ & $\begin{array}{l}4.00 \pm 0.00 \\
\quad(30)\end{array}$ & $\begin{array}{c}4.11 \pm 0.10 \\
\quad(27)\end{array}$ \\
\hline \multicolumn{6}{|l|}{ Male and Female $e^{b, c}$} \\
\hline PND 4 Prestandardization & $\begin{array}{c}11.34 \pm 0.34 \\
(35)\end{array}$ & $\begin{array}{c}12.77 \pm 0.39^{*} \\
\quad(26)\end{array}$ & $\begin{array}{c}12.15 \pm 0.35 \\
(33)\end{array}$ & $\begin{array}{c}12.12 \pm 0.26 \\
(33)\end{array}$ & $\begin{array}{c}11.88 \pm 0.46 \\
(32)\end{array}$ \\
\hline PND 4 Poststandardization & $\begin{array}{l}8.00 \pm 0.00 \\
\quad(28)\end{array}$ & $\begin{array}{l}8.00 \pm 0.00 \\
\quad(25)\end{array}$ & $\begin{array}{l}8.00 \pm 0.00 \\
\quad(27)\end{array}$ & $\begin{array}{c}8.00 \pm 0.00 \\
\quad(30)\end{array}$ & $\begin{array}{l}8.00 \pm 0.00 \\
\quad(27)\end{array}$ \\
\hline PND 21 & $\begin{array}{c}8.00 \pm 0.00 \\
(28)\end{array}$ & $\begin{array}{c}7.96 \pm 0.04 \\
(25)\end{array}$ & $\begin{array}{c}7.96 \pm 0.04 \\
(27)\end{array}$ & $\begin{array}{c}8.00 \pm 0.00 \\
(30)\end{array}$ & $\begin{array}{l}7.96 \pm 0.04 \\
\text { (27) }\end{array}$ \\
\hline
\end{tabular}




\begin{tabular}{|c|c|c|c|c|c|}
\hline Parameter $^{\mathrm{a}}$ & 0 ppm & 300 ppm & 1,000 ppm & 3,000 ppm & 10,000 ppm \\
\hline \multicolumn{6}{|l|}{ Survival per Litter } \\
\hline Total Dead: PND $1-4^{\mathrm{e}, \mathrm{f}}$ & $5(35)$ & $2(26)$ & $2(33)$ & $6(33)$ & $7(32)$ \\
\hline Total Dead: PND 4-21e,f & $0(28)$ & $1(25)$ & $1(27)$ & $0(30)$ & $1(27)$ \\
\hline Dead: PND $1-4^{\mathrm{b}, \mathrm{c}, \mathrm{g}}$ & $\begin{array}{c}0.14 \pm 0.07 \\
(35)\end{array}$ & $\begin{array}{c}0.08 \pm 0.05 \\
(26)\end{array}$ & $\begin{array}{c}0.06 \pm 0.04 \\
(33)\end{array}$ & $\begin{array}{c}0.18 \pm 0.11 \\
(33)\end{array}$ & $\begin{array}{c}0.22 \pm 0.10 \\
(32)\end{array}$ \\
\hline Dead: PND 4-21 $1^{b, c, g}$ & $\begin{array}{c}0.00 \pm 0.00 \\
(28)\end{array}$ & $\begin{array}{c}0.04 \pm 0.04 \\
(25)\end{array}$ & $\begin{array}{c}0.04 \pm 0.04 \\
(27)\end{array}$ & $\begin{array}{c}0.00 \pm 0.00 \\
(30)\end{array}$ & $\begin{array}{c}0.04 \pm 0.04 \\
(27)\end{array}$ \\
\hline Survival Ratio: PND 1-4 & $\begin{array}{c}0.998 \pm 0.002 \\
(35)\end{array}$ & $\begin{array}{c}1.000 \pm 0.000 \\
\text { (26) }\end{array}$ & $\begin{array}{c}0.997 \pm 0.003 \\
\text { (33) }\end{array}$ & $\begin{array}{c}1.000 \pm 0.000 \\
\text { (33) }\end{array}$ & $\begin{array}{c}0.997 \pm 0.003 \\
\text { (32) }\end{array}$ \\
\hline Survival Ratio: PND 4-21 & $\begin{array}{c}1.000 \pm 0.000 \\
\text { (28) }\end{array}$ & $\begin{array}{c}0.995 \pm 0.005 \\
(25)\end{array}$ & $\begin{array}{c}0.995 \pm 0.005 \\
(27)\end{array}$ & $\begin{array}{c}1.000 \pm 0.000 \\
(30)\end{array}$ & $\begin{array}{c}0.995 \pm 0.005 \\
(27)\end{array}$ \\
\hline
\end{tabular}

Statistical significance for an exposure group indicates a significant pairwise test compared to the vehicle control group.

*Statistically significant at $\mathrm{p} \leq 0.05$.

$\mathrm{PND}=$ postnatal day.

${ }^{a}$ Litters in which the male/female pup counts were inconsistent between PND 1 and PND 4 were excluded from the male- or female-specific endpoints.

${ }^{b}$ Each exposure group was compared to the vehicle control group with the Shirley test when a trend was present $(p \leq 0.01$ from the Jonckheere trend test) or with the Dunn test when no trend was present.

${ }^{\mathrm{c}}$ Data are presented as mean \pm standard error (number of litters).

$\mathrm{d}[100 \times($ number of live males in dietary exposure group)/(number of live males and females in dietary exposure group) $]$ (number of pups).

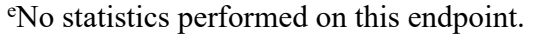

${ }^{\mathrm{f}}$ Total number of dead pups in exposure group (number of litters).

gNumber dead per litter.

${ }^{\text {h}}$ Survival per litter: Number of pups prestandardization on PND 4/number of live pups on PND 1.

iSurvival per litter: Number of live pups on PND 21/number of live pups poststandardization on PND 4.

Male and female pup mean body weight on PND 1 was $\leq 4 \%$ less in the 10,000 ppm group compared to the control group (Table 6). By the end of the lactation period (PND 21), significant decreases in male and female pup weight occurred only in the 10,000 ppm groups, approximately $12 \%$ and $13 \%$ less than their respective control groups (Table 6 ). 
Di- $n$-butyl Phthalate, NTP TR 600

Table 6. Summary of Preweaning $F_{1}$ Male and Female Rat Pup Mean Body Weights Following Perinatal Exposure to Di- $n$-butyl Phthalate

\begin{tabular}{|c|c|c|c|c|c|}
\hline Parameter $^{\mathrm{a}}$ & 0 ppm & 300 ppm & 1,000 ppm & 3,000 ppm & 10,000 ppm \\
\hline \multicolumn{6}{|l|}{ Male (g) } \\
\hline PND $1^{\mathrm{b}, \mathrm{c}, \mathrm{d}}$ & $7.28 \pm 0.12(31)$ & $7.38 \pm 0.11(23)$ & $7.33 \pm 0.09(32)$ & $7.48 \pm 0.08(32)$ & $7.00 \pm 0.13(20)$ \\
\hline PND $4^{\mathrm{e}, \mathrm{f}, \mathrm{g}, \mathrm{h}}$ & $\begin{array}{c}10.57 \pm 0.17^{* *} \\
(202 / 35)\end{array}$ & $\begin{array}{l}10.90 \pm 0.14 \\
(159 / 26)\end{array}$ & $\begin{array}{c}10.86 \pm 0.14 \\
(185 / 33)\end{array}$ & $\begin{array}{c}10.89 \pm 0.12 \\
(193 / 33)\end{array}$ & $\begin{array}{c}10.16 \pm 0.13 \\
(178 / 32)\end{array}$ \\
\hline PND $7^{\mathrm{e}, \mathrm{i}}$ & $\begin{array}{c}16.32 \pm 0.29 \\
(112 / 28)\end{array}$ & $\begin{array}{c}16.29 \pm 0.27 \\
(97 / 25)\end{array}$ & $\begin{array}{c}16.61 \pm 0.29 \\
(105 / 27)\end{array}$ & $\begin{array}{l}17.04 \pm 0.22 \\
\quad(120 / 30)\end{array}$ & $\begin{array}{c}16.76 \pm 1.07 \\
(104 / 27)\end{array}$ \\
\hline PND $14^{e, i}$ & $\begin{array}{c}33.35 \pm 0.50 * * \\
(112 / 28)\end{array}$ & $\begin{array}{c}34.50 \pm 0.36 \\
(97 / 25)\end{array}$ & $\begin{array}{c}34.28 \pm 0.48 \\
(105 / 27)\end{array}$ & $\begin{array}{c}34.39 \pm 0.38 \\
\quad(119 / 30)\end{array}$ & $\begin{array}{l}31.56 \pm 0.39 * \\
\quad(104 / 27)\end{array}$ \\
\hline PND $21^{\mathrm{e}, \mathrm{i}}$ & $\begin{array}{c}54.15 \pm 0.86^{* *} \\
(112 / 28)\end{array}$ & $\begin{array}{c}55.77 \pm 0.67 \\
(97 / 25)\end{array}$ & $\begin{array}{c}55.34 \pm 0.87 \\
\quad(104 / 27)\end{array}$ & $\begin{array}{l}53.27 \pm 0.72 \\
\quad(120 / 30)\end{array}$ & $\begin{array}{c}47.85 \pm 0.61 * * \\
(104 / 27)\end{array}$ \\
\hline \multicolumn{6}{|l|}{ Female (g) } \\
\hline PND $1^{b, c, d}$ & $6.96 \pm 0.13(31)$ & $7.09 \pm 0.15(23)$ & $6.96 \pm 0.10(32)$ & $7.17 \pm 0.08$ & $6.77 \pm 0.14(20)$ \\
\hline PND $4^{\mathrm{e}, \mathrm{f}, \mathrm{g}, \mathrm{h}}$ & $\begin{array}{c}10.19 \pm 0.16^{* *} \\
(195 / 35)\end{array}$ & $\begin{array}{c}10.39 \pm 0.14 \\
(173 / 26)\end{array}$ & $\begin{array}{c}10.39 \pm 0.15 \\
(216 / 33)\end{array}$ & $\begin{array}{c}10.40 \pm 0.12 \\
(207 / 33)\end{array}$ & $9.76 \pm 0.11(202 / 32)$ \\
\hline PND $7^{\mathrm{e}, \mathrm{i}}$ & $\begin{array}{l}15.93 \pm 0.28 * \\
\quad(112 / 28)\end{array}$ & $\begin{array}{c}15.56 \pm 0.27 \\
(103 / 25)\end{array}$ & $\begin{array}{l}15.82 \pm 0.32 \\
(111 / 27)\end{array}$ & $\begin{array}{c}16.30 \pm 0.24 \\
(120 / 30)\end{array}$ & $\begin{array}{l}15.05 \pm 0.25 \\
(111 / 27)\end{array}$ \\
\hline PND $14^{e, i}$ & $\begin{array}{c}32.79 \pm 0.54 * * \\
(112 / 28)\end{array}$ & $\begin{array}{c}33.39 \pm 0.33 \\
(102 / 25)\end{array}$ & $\begin{array}{c}33.02 \pm 0.49 \\
(111 / 27)\end{array}$ & $\begin{array}{c}33.10 \pm 0.37 \\
(120 / 30)\end{array}$ & $\begin{array}{l}30.54 \pm 0.35^{* *} \\
\quad(110 / 27)\end{array}$ \\
\hline PND $21^{e, i}$ & $\begin{array}{c}52.65 \pm 0.90^{* *} \\
(112 / 28)\end{array}$ & $\begin{array}{l}52.72 \pm 0.54 \\
(102 / 25)\end{array}$ & $\begin{array}{c}52.16 \pm 0.88 \\
\quad(111 / 27)\end{array}$ & $\begin{array}{c}50.25 \pm 0.79 \\
(120 / 30)\end{array}$ & $\begin{array}{l}45.88 \pm 0.58^{* *} \\
\quad(111 / 27)\end{array}$ \\
\hline \multicolumn{6}{|c|}{ Male and Female (g) } \\
\hline PND $1^{\mathrm{b}, \mathrm{c}, \mathrm{d}}$ & $7.12 \pm 0.10(35)$ & $7.15 \pm 0.10(26)$ & $7.16 \pm 0.08$ & $7.34 \pm 0.08$ & $6.77 \pm 0.09 *(32)$ \\
\hline PND $4^{\mathrm{e}, \mathrm{f}, \mathrm{g}, \mathrm{h}}$ & $\begin{array}{c}10.40 \pm 0.16^{* *} \\
(397 / 35)\end{array}$ & $\begin{array}{c}10.60 \pm 0.12 \\
(332 / 26)\end{array}$ & $\begin{array}{c}10.64 \pm 0.13 \\
(401 / 33)\end{array}$ & $\begin{array}{c}10.64 \pm 0.11 \\
(400 / 33)\end{array}$ & $9.96 \pm 0.11(380 / 32)$ \\
\hline PND $7^{e, i}$ & $\begin{array}{l}16.12 \pm 0.28 \\
(224 / 28)\end{array}$ & $\begin{array}{l}15.91 \pm 0.25 \\
(200 / 25)\end{array}$ & $\begin{array}{l}16.23 \pm 0.28 \\
(216 / 27)\end{array}$ & $\begin{array}{c}16.67 \pm 0.22 \\
(240 / 30)\end{array}$ & $\begin{array}{l}15.89 \pm 0.55 \\
(215 / 27)\end{array}$ \\
\hline PND $14^{e, i}$ & $\begin{array}{c}33.05 \pm 0.50 * * \\
(224 / 28)\end{array}$ & $\begin{array}{c}33.94 \pm 0.32 \\
(199 / 25)\end{array}$ & $\begin{array}{c}33.68 \pm 0.41 \\
(216 / 27)\end{array}$ & $\begin{array}{c}33.74 \pm 0.35 \\
(239 / 30)\end{array}$ & $\begin{array}{l}31.03 \pm 0.33 * * \\
\quad(214 / 27)\end{array}$ \\
\hline PND $21^{e, i}$ & $\begin{array}{c}53.34 \pm 0.82 * * \\
(224 / 28)\end{array}$ & $\begin{array}{l}54.22 \pm 0.54 \\
(199 / 25)\end{array}$ & $\begin{array}{c}53.78 \pm 0.72 \\
(215 / 27)\end{array}$ & $\begin{array}{l}51.76 \pm 0.72 \\
(240 / 30)\end{array}$ & $\begin{array}{c}46.86 \pm 0.55^{* *} \\
(215 / 27)\end{array}$ \\
\hline
\end{tabular}

Statistical significance for an exposure group indicates a significant pairwise test compared to the vehicle control group.

Statistical significance for the vehicle control group indicates a significant trend test.

*Statistically significant at $\mathrm{p} \leq 0.05 ; * \mathrm{p} \leq 0.01$.

PND = postnatal day.

aStatistical analysis performed using mixed models with random litter effect for both trend and pairwise tests, using the

Dunnett-Hsu adjustment for multiple comparisons.

${ }^{b}$ Data are presented as mean \pm standard error (number of litters).

${ }^{c}$ Each exposure group was compared to the vehicle control group with the Williams test when a trend was present $(p \leq 0.01$ from the Jonckheere trend test) or with the Dunnett test when no trend was present.

${ }^{\mathrm{d}}$ Total pup weight at PND 1 divided by number of live pups at PND 1.

eData are presented as mean of litter means \pm standard error (number of pups/number of litters).

fPND 4 prestandardization.

gIndividual pup weights first adjusted for live litter size on PND 1.

hLitters in which the male/female pup counts were inconsistent between PND 1 and PND 4 were excluded from the male- or female-specific endpoints.

individual pup weights first adjusted for live litter size on PND 4 poststandardization. 
Mono- $n$-butyl phthalate (MBP) concentrations were measured using validated analytical methods in samples taken on GD 18 and PND 4 (Table 7). ${ }^{115}$ Low concentrations were detected in some matrices in control groups, likely due to a combination of background levels from sample collection and from the analytical assay. At GD 18, MBP concentrations increased more than proportionally to the exposure concentration, despite a linear increase in chemical consumption. There was an approximately 137 -fold and 83 -fold increase in dam plasma and fetus MBP concentrations, respectively, in the $10,000 \mathrm{ppm}$ group compared to the $300 \mathrm{ppm}$ group, but exposure concentration increased only approximately 33 -fold. Concentrations in fetuses were approximately $17 \%-29 \%$ that of dam plasma, demonstrating moderate gestational transfer of MBP (Table 7). MBP was also measured in amniotic fluid at concentrations lower than those found in fetuses (Table 7).

MBP concentrations in exposed dams on PND 4 were slightly higher than concentrations detected at GD 18 in respective exposure groups likely due to higher feed and, subsequently, chemical consumption (Table 7). Similar to what was found in dams on GD 18, MBP concentrations in dam plasma on PND 4 increased more than proportionally to the exposure concentration, despite a linear increase in chemical consumption, with an approximately 99 -fold increase in concentration when exposure concentration increased approximately 33 -fold. MBP concentrations in whole pups increased proportionally to the exposure concentration. Concentrations in whole pups were approximately $3 \%-11 \%$ that of dams, demonstrating low lactational transfer of MBP in rats. 
Di-n-butyl Phthalate, NTP TR 600

Table 7. Summary of Internal Dose Data for Rats in the Perinatal and Two-year Feed Study of Di-n-butyl Phthalate

\begin{tabular}{|c|c|c|c|c|c|}
\hline & 0 ppm & 300 ppm & 1,000 ppm & 3,000 ppm & 10,000 ppm \\
\hline \multicolumn{6}{|c|}{ Mono-n-butyl Phthalate Concentration ${ }^{\mathrm{a}, \mathrm{b}}$} \\
\hline $\mathbf{n}$ & 5 & 5 & 5 & $3^{c}$ & 5 \\
\hline \multicolumn{6}{|l|}{ Gestation Day 18} \\
\hline Dam plasma $(\mathrm{ng} / \mathrm{mL})^{\mathrm{d}}$ & $9.2 \pm 4.0 * *$ & $1,148.0 \pm 48.3 * *$ & $4,372.0 \pm 567.1 * *$ & $19,633.3 \pm 3,077.5^{* *}$ & $156,800.0 \pm 3,878.1^{* *}$ \\
\hline Amniotic fluid $(\mathrm{ng} / \mathrm{mL})$ & $\mathrm{BD}^{\mathrm{e}}$ & $84.5 \pm 13.7$ & $403.8 \pm 34.5$ & $1,693.3 \pm 153.4$ & $22,760.0 \pm 2,183.3$ \\
\hline Fetuses $(\mathrm{ng} / \mathrm{g})^{\mathrm{f}}$ & $\mathrm{BD}$ & $323.6 \pm 17.8$ & $1,270.6 \pm 127.7$ & $3,930.0 \pm 705.0$ & $26,840.0 \pm 2,763.6$ \\
\hline $\mathbf{n}$ & 5 & $2^{\mathrm{g}}$ & 5 & 5 & 5 \\
\hline \multicolumn{6}{|l|}{ Postnatal Day 4} \\
\hline Dam plasma (ng/mL) & $\mathrm{BD}$ & $1,625.0 \pm 75.0$ & $6,234.0 \pm 897.2$ & $25,580.0 \pm 2,272.1$ & $161,200.0 \pm 17,690.1$ \\
\hline Pups (ng/g) $)^{\mathrm{h}, \mathrm{i}}$ & $8.6 \pm 1.3 * *$ & $146.6 \pm 103.7$ & $350.8 \pm 70.8 * *$ & $2,743.2 \pm 725.5^{* *}$ & $4,721.5 \pm 1,044.6^{* *}$ \\
\hline
\end{tabular}

Statistical significance for an exposure group indicates a significant pairwise test compared to the vehicle control group.

Statistical significance for the vehicle control group indicates a significant trend test.

**Statistically significant at $\mathrm{p} \leq 0.01$.

$\mathrm{BD}=$ below detection; group did not have more than $20 \%$ of its values above the limit of detection (LOD).

${ }^{a}$ Data are presented as mean \pm standard error except for pup concentrations, which are displayed as mean \pm standard error of the litter means.

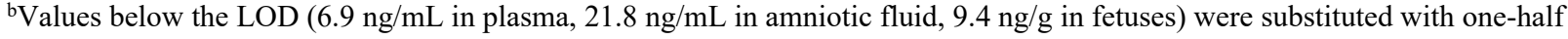
the LOD value.

${ }^{\mathrm{c}}$ Three of the five dams designated for biological sampling were determined not to be pregnant. Although the replacement dams for this group were pregnant, only three complete sample sets (dam plasma, amniotic fluid, fetuses) were able to be collected. ${ }^{\mathrm{d} S t a t i s t i c a l ~ a n a l y s i s ~ p e r f o r m e d ~ b y ~ t h e ~ J o n c k h e e r e ~(t r e n d) ~ a n d ~ t h e ~ S h i r l e y ~ o r ~ D u n n ~(p a i r w i s e) ~ t e s t s . ~}$

If $80 \%$ or more of the values in the vehicle control group were below the LOD, no mean or standard error were calculated and no statistical analysis was performed.

${ }^{\mathrm{f}}$ All fetuses from the dam were used and weights recorded.

gOnly one extra litter (beyond the 25 minimum used for the 2-year study) met the collection criteria for this exposure group. An additional litter consisting of two male pups and one female pup (that would have been standardized due to unacceptable sex split) was used for biological sample collection.

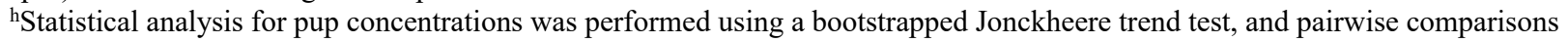
used the Datta-Satten modified Wilcoxon test with a Hommel adjustment for multiple comparisons.

${ }^{i}$ The number of pups evaluated was 20 in all groups ( 2 male pups and 2 female pups per dam) except for the 300 ppm group in which only 7 pups were able to be evaluated. Data reported are for male and female pup data combined. 


\section{Two-year Study (Postweaning Phase)}

Survival of all male and female exposure groups was similar to that of the control groups (Table 8; Figure 2). There were no exposure-related clinical observations (Appendix E).

Table 8. Summary of Survival of Male and Female Rats in the Perinatal and Two-year Feed Study of Di-n-butyl Phthalate

\begin{tabular}{|c|c|c|c|c|c|}
\hline & O ppm & 300 ppm & $1,000 \mathrm{ppm}$ & 3,000 ppm & $10,000 \mathrm{ppm}$ \\
\hline \multicolumn{6}{|l|}{ Male } \\
\hline Animals Initially in Study & $49^{\mathrm{a}}$ & 50 & 50 & 50 & 50 \\
\hline Moribund & 9 & 4 & 10 & 9 & 10 \\
\hline Natural Deaths & 13 & 8 & 9 & 7 & 7 \\
\hline $\begin{array}{l}\text { Animals Surviving to Study } \\
\text { Termination }\end{array}$ & $27^{\mathrm{b}}$ & 38 & 31 & 34 & $33^{\mathrm{b}}$ \\
\hline $\begin{array}{l}\text { Percent Probability of } \\
\text { Survival at End of Study }\end{array}$ & 55.1 & 76.0 & 62.0 & 68.0 & 66.0 \\
\hline Mean Survival (Days) ${ }^{\mathrm{d}}$ & 674 & 691 & 694 & 685 & 655 \\
\hline Survival Analysis ${ }^{\mathrm{e}}$ & $\mathrm{p}=0.948$ & $\mathrm{p}=0.029 \mathrm{~N}$ & $\mathrm{p}=0.354 \mathrm{~N}$ & $\mathrm{p}=0.168 \mathrm{~N}$ & $\mathrm{p}=0.359 \mathrm{~N}$ \\
\hline \multicolumn{6}{|l|}{ Female } \\
\hline Animals Initially in Study & 50 & 50 & 50 & 50 & 50 \\
\hline Moribund & 9 & 8 & 14 & 11 & 13 \\
\hline Natural Deaths & 12 & 5 & 9 & 7 & 8 \\
\hline $\begin{array}{l}\text { Animals Surviving to Study } \\
\text { Termination }\end{array}$ & $29^{f}$ & 37 & $27^{\mathrm{b}}$ & 32 & 29 \\
\hline $\begin{array}{l}\text { Percent Probability of } \\
\text { Survival at End of Study }\end{array}$ & 58.0 & 74.0 & 54.0 & 64.0 & 58.0 \\
\hline Mean Survival (Days) & 669 & 679 & 645 & 671 & 648 \\
\hline Survival Analysis & $\mathrm{p}=0.490$ & $\mathrm{p}=0.137 \mathrm{~N}$ & $\mathrm{p}=0.540$ & $\mathrm{p}=0.590 \mathrm{~N}$ & $\mathrm{p}=0.803$ \\
\hline
\end{tabular}

${ }^{\mathrm{a}}$ One pup was missexed at the beginning of the study and was removed.

bIncludes one animal that died naturally during the last week of the study.

${ }^{\mathrm{c}}$ Kaplan-Meier determinations.

${ }^{\mathrm{d}}$ Mean of litter means of all deaths (uncensored, censored, and study termination).

${ }^{\mathrm{e}}$ The result of the Cox proportional hazards trend test is in the vehicle control group column, and the results of the Cox proportional hazards pairwise comparisons with the vehicle control group are in the exposed group columns. A negative trend or lower mortality in an exposure group is indicated by $\mathrm{N}$.

f Includes one animal that was euthanized moribund during the last week of the study. 

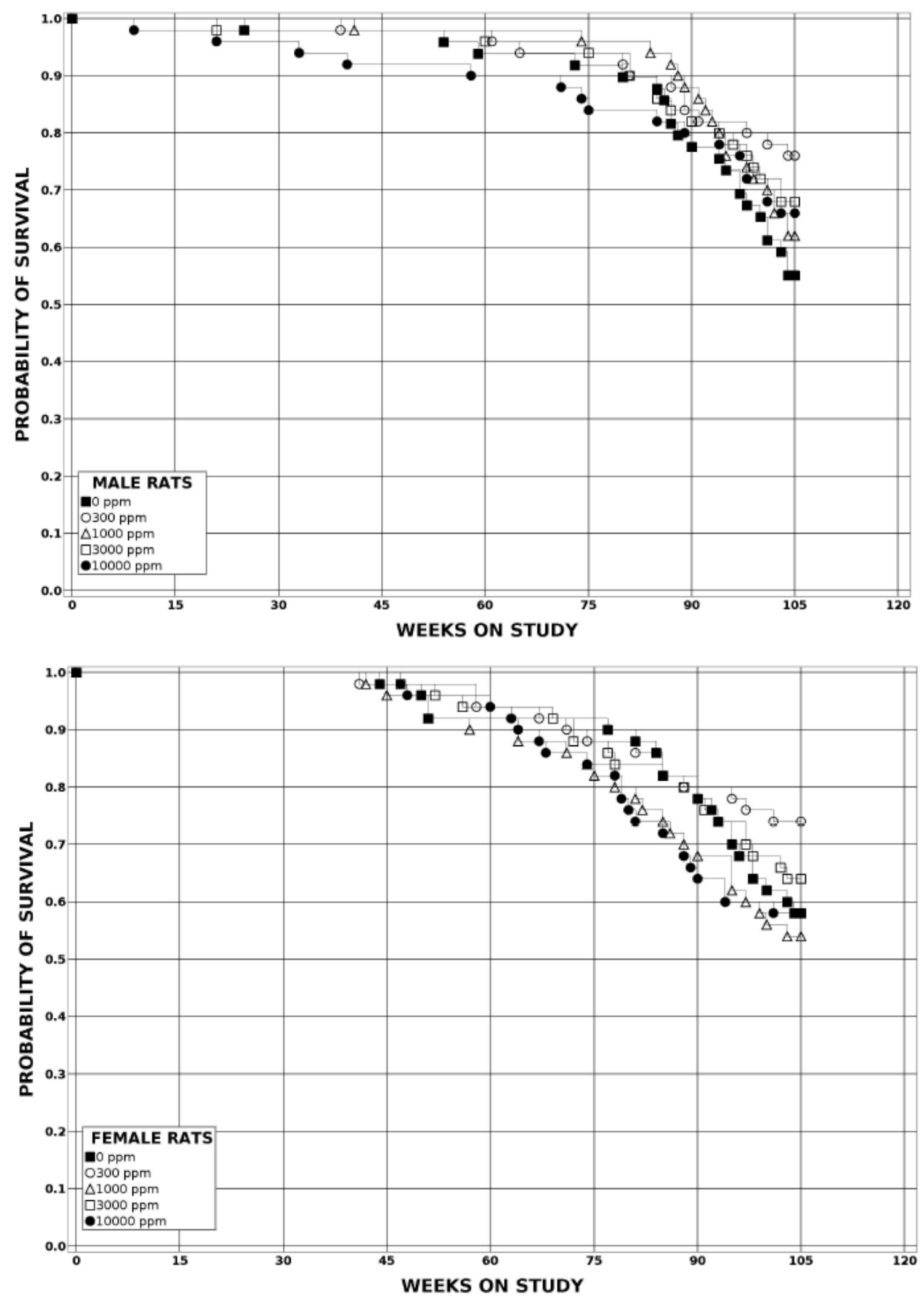

Figure 2. Kaplan-Meier Survival Curves for Rats Exposed to Di-n-butyl Phthalate in Feed for Two Years 
Exposure-related significant decreases in group mean body weight were observed throughout the study in both males and females in the 10,000 ppm groups (Table 9, Table 10; Figure 3). At study termination, group mean body weights of the $10,000 \mathrm{ppm}$ group were lower than those of the control groups by $3.5 \%$ in males and by $10.6 \%$ in females. Group mean feed consumption over the course of the study was similar across exposed and control groups, except that males in the 10,000 ppm group tended to consume less than control males ( $1 \%-25 \%$ less) (Table 11, Table 12; Appendix E). Group mean chemical consumption increased proportionally to exposure concentration and was similar across male and female animals. Average daily chemical consumption $(\mathrm{mg} / \mathrm{kg} / \mathrm{day})$ by the $300,1,000,3,000$, and $10,000 \mathrm{ppm}$ groups was $16.4,53.6$, 152.3 , and $510.4 \mathrm{mg} / \mathrm{kg} /$ day, respectively, for males and $17.2,57.4,168.8$, and $599.9 \mathrm{mg} / \mathrm{kg} / \mathrm{day}$, respectively, for females. 
Table 9. Summary of Survival and Mean Body Weights of Male Rats in the Perinatal and Two-year Feed Study of Di-n-butyl Phthalate

\begin{tabular}{|c|c|c|c|c|c|c|c|c|c|c|c|c|c|c|}
\hline \multirow[b]{2}{*}{$\begin{array}{l}\text { Study } \\
\text { Day }^{\mathrm{a}}\end{array}$} & \multicolumn{2}{|c|}{0 ppm } & \multicolumn{3}{|c|}{300 ppm } & \multicolumn{3}{|c|}{1,000 ppm } & \multicolumn{3}{|c|}{$3,000 \mathrm{ppm}$} & \multicolumn{3}{|c|}{10,000 ppm } \\
\hline & $\begin{array}{l}\text { Av. } \\
\text { Wt. } \\
(\mathrm{g})^{\mathbf{b}}\end{array}$ & $\begin{array}{l}\text { No. of } \\
\text { Litters }\end{array}$ & $\begin{array}{l}\text { Av. } \\
\text { Wt. } \\
\text { (g) }\end{array}$ & $\begin{array}{c}\text { Wt. } \\
\text { (\% of } \\
\text { Controls) }\end{array}$ & $\begin{array}{l}\text { No. of } \\
\text { Litters }\end{array}$ & $\begin{array}{l}\text { Av. } \\
\text { Wt. } \\
\text { (g) }\end{array}$ & $\begin{array}{c}\text { Wt. } \\
(\% \text { of } \\
\text { Controls) }\end{array}$ & $\begin{array}{l}\text { No. of } \\
\text { Litters }\end{array}$ & $\begin{array}{l}\text { Av. } \\
\text { Wt. } \\
\text { (g) }\end{array}$ & $\begin{array}{c}\text { Wt. (\% } \\
\text { of } \\
\text { Controls) }\end{array}$ & $\begin{array}{c}\text { No. of } \\
\text { Litters }\end{array}$ & $\begin{array}{l}\text { Av. } \\
\text { Wt. } \\
\text { (g) }\end{array}$ & $\begin{array}{c}\text { Wt. } \\
\text { (\% of } \\
\text { Controls) }\end{array}$ & $\begin{array}{l}\text { No. of } \\
\text { Litters }\end{array}$ \\
\hline 1 & 55.1 & 25 & 57.3 & 104.0 & 25 & 56.7 & 103.0 & 25 & 53.7 & 97.4 & 25 & 50.0 & 90.7 & 25 \\
\hline 8 & 87.0 & 25 & 89.5 & 102.9 & 25 & 90.1 & 103.6 & 25 & 86.6 & 99.6 & 25 & 80.0 & 91.9 & 25 \\
\hline 15 & 130.4 & 25 & 135.5 & 103.9 & 25 & 135.5 & 103.9 & 25 & 131.2 & 100.6 & 25 & 120.9 & 92.7 & 25 \\
\hline 22 & 179.0 & 25 & 184.1 & 102.6 & 25 & 184.3 & 102.8 & 25 & 179.9 & 100.3 & 25 & 166.9 & 93.1 & 25 \\
\hline 29 & 226.3 & 25 & 231.3 & 102.2 & 25 & 233.5 & 103.2 & 25 & 225.5 & 99.6 & 25 & 212.0 & 93.7 & 25 \\
\hline 36 & 269.4 & 25 & 276.2 & 102.5 & 25 & 276.8 & 102.7 & 25 & 271.7 & 100.8 & 25 & 252.0 & 93.6 & 25 \\
\hline 43 & 304.5 & 25 & 310.3 & 101.9 & 25 & 309.0 & 101.5 & 25 & 302.5 & 99.3 & 25 & 285.8 & 93.9 & 25 \\
\hline 50 & 328.9 & 25 & 335.6 & 102.0 & 25 & 331.3 & 100.7 & 25 & 331.5 & 100.8 & 25 & 308.0 & 93.7 & 25 \\
\hline 57 & 352.6 & 25 & 354.7 & 100.6 & 25 & 353.2 & 100.2 & 25 & 352.5 & 100.0 & 25 & 320.3 & 90.8 & 25 \\
\hline 64 & 370.4 & 25 & 373.1 & 100.7 & 25 & 371.2 & 100.2 & 25 & 369.4 & 99.7 & 25 & 332.2 & 89.7 & 25 \\
\hline 71 & 385.0 & 25 & 382.5 & 99.3 & 25 & 381.4 & 99.1 & 25 & 378.0 & 98.2 & 25 & 342.1 & 88.9 & 25 \\
\hline 78 & 396.8 & 25 & 388.9 & 98.0 & 25 & 390.8 & 98.5 & 25 & 385.8 & 97.2 & 25 & 348.5 & 87.8 & 25 \\
\hline 85 & 404.0 & 25 & 394.1 & 97.5 & 25 & 397.3 & 98.3 & 25 & 389.8 & 96.5 & 25 & 353.0 & 87.4 & 25 \\
\hline 92 & 411.1 & 25 & 402.1 & 97.8 & 25 & 407.0 & 99.0 & 25 & 396.2 & 96.4 & 25 & 358.7 & 87.3 & 25 \\
\hline 120 & 438.9 & 25 & 435.8 & 99.3 & 25 & 442.5 & 100.8 & 25 & 428.5 & 97.6 & 25 & 389.2 & 88.7 & 25 \\
\hline 148 & 454.8 & 25 & 462.8 & 101.8 & 25 & 461.7 & 101.5 & 25 & 458.1 & 100.7 & 25 & 411.1 & 90.4 & 25 \\
\hline 176 & 482.5 & 25 & 474.2 & 98.3 & 25 & 485.2 & 100.6 & 25 & 479.4 & 99.4 & 25 & 428.6 & 88.8 & 25 \\
\hline 204 & 504.4 & 25 & 490.0 & 97.1 & 25 & 505.2 & 100.2 & 25 & 492.4 & 97.6 & 25 & 442.4 & 87.7 & 25 \\
\hline 232 & 509.7 & 25 & 507.2 & 99.5 & 25 & 521.0 & 102.2 & 25 & 505.0 & 99.1 & 25 & 456.2 & 89.5 & 25 \\
\hline 260 & 515.6 & 25 & 520.5 & 100.9 & 25 & 531.5 & 103.1 & 25 & 521.6 & 101.2 & 25 & 471.2 & 91.4 & 25 \\
\hline 288 & 541.9 & 25 & 534.0 & 98.5 & 25 & 546.1 & 100.8 & 25 & 536.3 & 99.0 & 25 & 477.9 & 88.2 & 25 \\
\hline 316 & 552.7 & 25 & 537.6 & 97.3 & 25 & 559.0 & 101.1 & 25 & 539.5 & 97.6 & 25 & 485.0 & 87.7 & 25 \\
\hline 344 & 561.4 & 25 & 545.8 & 97.2 & 25 & 571.0 & 101.7 & 25 & 548.8 & 97.8 & 25 & 493.1 & 87.8 & 25 \\
\hline 372 & 574.7 & 25 & 556.6 & 96.9 & 25 & 583.8 & 101.6 & 25 & 565.5 & 98.4 & 25 & 505.1 & 87.9 & 25 \\
\hline 400 & 580.8 & 25 & 565.4 & 97.4 & 25 & 587.4 & 101.1 & 25 & 572.6 & 98.6 & 25 & 512.3 & 88.2 & 25 \\
\hline 428 & 601.1 & 25 & 576.2 & 95.9 & 25 & 606.0 & 100.8 & 25 & 583.2 & 97.0 & 25 & 529.4 & 88.1 & 25 \\
\hline 456 & 604.9 & 25 & 585.4 & 96.8 & 25 & 614.5 & 101.6 & 25 & 587.3 & 97.1 & 25 & 536.2 & 88.7 & 25 \\
\hline 484 & 609.6 & 25 & 600.7 & 98.5 & 25 & 621.1 & 101.9 & 25 & 598.5 & 98.2 & 25 & 546.9 & 89.7 & 25 \\
\hline 512 & 619.7 & 25 & 606.9 & 97.9 & 25 & 625.3 & 100.9 & 25 & 607.9 & 98.1 & 25 & 552.9 & 89.2 & 25 \\
\hline 540 & 624.8 & 25 & 605.9 & 97.0 & 25 & 625.6 & 100.1 & 25 & 608.7 & 97.4 & 25 & 554.7 & 88.8 & 25 \\
\hline 568 & 623.1 & 25 & 614.3 & 98.6 & 24 & 631.1 & 101.3 & 25 & 623.0 & 100.0 & 25 & 560.2 & 89.9 & 25 \\
\hline 596 & 626.2 & 25 & 607.2 & 97.0 & 24 & 624.5 & 99.7 & 25 & 630.1 & 100.6 & 25 & 556.1 & 88.8 & 25 \\
\hline 624 & 624.6 & 25 & 624.2 & 99.9 & 24 & 624.4 & 100.0 & 25 & 632.3 & 101.2 & 25 & 571.3 & 91.5 & 24 \\
\hline 652 & 617.4 & 25 & 612.8 & 99.3 & 24 & 624.8 & 101.2 & 25 & 631.4 & 102.3 & 25 & 565.1 & 91.5 & 24 \\
\hline 680 & 605.4 & 24 & 595.3 & 98.3 & 24 & 624.5 & 103.2 & 25 & 626.5 & 103.5 & 25 & 558.5 & 92.3 & 24 \\
\hline 708 & 583.3 & 22 & 591.9 & 101.5 & 23 & 606.5 & 104.0 & 25 & 610.0 & 104.6 & 24 & 565.0 & 96.9 & 23 \\
\hline EOS & 589.1 & 20 & 592.0 & 100.5 & 23 & 611.6 & 103.8 & 23 & 608.9 & 103.4 & 23 & 568.5 & 96.5 & 23 \\
\hline
\end{tabular}

$\mathrm{EOS}=$ end of study; No. of litters = number of litters represented in weight average.

${ }^{a}$ Study day 1 is the day animals were placed on study after pups were weaned.

${ }^{\mathrm{b}}$ Average weights shown are means of litter means. 
Di- $n$-butyl Phthalate, NTP TR 600

Table 10. Summary of Survival and Mean Body Weights of Female Rats in the Perinatal and Two-year Feed Study of Di-n-butyl Phthalate

\begin{tabular}{|c|c|c|c|c|c|c|c|c|c|c|c|c|c|c|}
\hline \multirow[b]{2}{*}{$\begin{array}{l}\text { Study } \\
\text { Day }^{\text {a }}\end{array}$} & \multicolumn{2}{|c|}{ O ppm } & \multicolumn{3}{|c|}{300 ppm } & \multicolumn{3}{|c|}{$1,000 \mathrm{ppm}$} & \multicolumn{3}{|c|}{ 3,000 ppm } & \multicolumn{3}{|c|}{10,000 ppm } \\
\hline & $\begin{array}{l}\text { Av. } \\
\text { Wt. } \\
(\mathbf{g})^{\mathbf{b}}\end{array}$ & $\begin{array}{l}\text { No. of } \\
\text { Litters }\end{array}$ & $\begin{array}{l}\text { Av. } \\
\text { Wt. } \\
\text { (g) }\end{array}$ & $\begin{array}{c}\text { Wt. } \\
\text { (\% of } \\
\text { Controls) }\end{array}$ & $\begin{array}{l}\text { No. of } \\
\text { Litters }\end{array}$ & $\begin{array}{l}\text { Av. } \\
\text { Wt. } \\
\text { (g) }\end{array}$ & $\begin{array}{c}\text { Wt. } \\
\text { (\% of } \\
\text { Controls) } \\
\end{array}$ & $\begin{array}{l}\text { No. of } \\
\text { Litters }\end{array}$ & $\begin{array}{l}\text { Av. } \\
\text { Wt. } \\
\text { (g) }\end{array}$ & $\begin{array}{c}\text { Wt. } \\
\text { (\% of } \\
\text { Controls })\end{array}$ & $\begin{array}{l}\text { No. of } \\
\text { Litters }\end{array}$ & $\begin{array}{l}\text { Av. } \\
\text { Wt. } \\
\text { (g) }\end{array}$ & $\begin{array}{c}\text { Wt. } \\
\text { (\% of } \\
\text { Controls) }\end{array}$ & $\begin{array}{l}\text { No. of } \\
\text { Litters }\end{array}$ \\
\hline 1 & 56.5 & 25 & 56.8 & 100.5 & 25 & 54.8 & 96.9 & 25 & 54.2 & 95.9 & 25 & 48.7 & 86.2 & 25 \\
\hline 8 & 86.0 & 25 & 85.5 & 99.4 & 25 & 84.2 & 97.9 & 25 & 83.6 & 97.2 & 25 & 77.3 & 89.9 & 25 \\
\hline 15 & 120.4 & 25 & 120.7 & 100.3 & 25 & 119.6 & 99.4 & 25 & 118.3 & 98.2 & 25 & 111.0 & 92.1 & 25 \\
\hline 22 & 151.2 & 25 & 149.7 & 99.0 & 25 & 148.6 & 98.3 & 25 & 149.0 & 98.5 & 25 & 141.1 & 93.3 & 25 \\
\hline 29 & 170.2 & 25 & 165.6 & 97.3 & 25 & 168.5 & 99.0 & 25 & 169.7 & 99.7 & 25 & 162.5 & 95.5 & 25 \\
\hline 36 & 190.3 & 25 & 190.7 & 100.2 & 25 & 187.9 & 98.7 & 25 & 188.3 & 98.9 & 25 & 179.6 & 94.4 & 25 \\
\hline 43 & 203.9 & 25 & 204.5 & 100.3 & 25 & 197.3 & 96.8 & 25 & 203.3 & 99.7 & 25 & 194.8 & 95.5 & 25 \\
\hline 50 & 217.0 & 25 & 218.1 & 100.5 & 25 & 212.8 & 98.1 & 25 & 215.1 & 99.1 & 25 & 204.2 & 94.1 & 25 \\
\hline 57 & 224.4 & 25 & 227.3 & 101.3 & 25 & 221.7 & 98.8 & 25 & 223.6 & 99.6 & 25 & 215.3 & 96.0 & 25 \\
\hline 64 & 233.3 & 25 & 235.8 & 101.1 & 25 & 231.1 & 99.0 & 25 & 233.6 & 100.1 & 25 & 223.9 & 96.0 & 25 \\
\hline 71 & 238.8 & 25 & 239.7 & 100.4 & 25 & 237.2 & 99.3 & 25 & 240.2 & 100.6 & 25 & 228.4 & 95.6 & 25 \\
\hline 78 & 243.8 & 25 & 244.0 & 100.1 & 25 & 241.4 & 99.0 & 25 & 241.5 & 99.1 & 25 & 233.3 & 95.7 & 25 \\
\hline 85 & 249.6 & 25 & 249.0 & 99.8 & 25 & 247.0 & 99.0 & 25 & 248.3 & 99.5 & 25 & 237.9 & 95.3 & 25 \\
\hline 92 & 255.0 & 25 & 253.6 & 99.4 & 25 & 249.6 & 97.9 & 25 & 251.9 & 98.8 & 25 & 242.9 & 95.3 & 25 \\
\hline 120 & 268.6 & 25 & 267.4 & 99.6 & 25 & 264.6 & 98.5 & 25 & 266.2 & 99.1 & 25 & 256.4 & 95.5 & 25 \\
\hline 148 & 276.7 & 25 & 275.5 & 99.6 & 25 & 273.7 & 98.9 & 25 & 272.9 & 98.6 & 25 & 262.9 & 95.0 & 25 \\
\hline 176 & 288.4 & 25 & 287.1 & 99.6 & 25 & 284.8 & 98.8 & 25 & 286.7 & 99.4 & 25 & 269.6 & 93.5 & 25 \\
\hline 204 & 297.3 & 25 & 292.7 & 98.4 & 25 & 290.1 & 97.6 & 25 & 292.2 & 98.3 & 25 & 276.7 & 93.1 & 25 \\
\hline 232 & 303.8 & 25 & 301.5 & 99.2 & 25 & 296.6 & 97.6 & 25 & 298.8 & 98.4 & 25 & 278.9 & 91.8 & 25 \\
\hline 260 & 311.0 & 25 & 307.4 & 98.9 & 25 & 306.7 & 98.6 & 25 & 306.3 & 98.5 & 25 & 284.3 & 91.4 & 25 \\
\hline 288 & 313.8 & 25 & 311.5 & 99.3 & 25 & 311.9 & 99.4 & 25 & 312.6 & 99.6 & 25 & 292.0 & 93.1 & 25 \\
\hline 316 & 322.9 & 25 & 316.7 & 98.1 & 25 & 320.9 & 99.4 & 25 & 319.6 & 99.0 & 25 & 294.8 & 91.3 & 25 \\
\hline 344 & 329.5 & 25 & 322.6 & 97.9 & 25 & 325.5 & 98.8 & 25 & 324.3 & 98.4 & 25 & 295.9 & 89.8 & 25 \\
\hline 372 & 327.4 & 25 & 328.0 & 100.2 & 25 & 335.0 & 102.3 & 25 & 329.8 & 100.7 & 25 & 298.9 & 91.3 & 25 \\
\hline 400 & 329.5 & 25 & 336.1 & 102.0 & 25 & 338.0 & 102.6 & 25 & 328.6 & 99.7 & 25 & 299.0 & 90.7 & 25 \\
\hline 428 & 341.4 & 25 & 338.0 & 99.0 & 25 & 347.7 & 101.9 & 25 & 339.4 & 99.4 & 25 & 307.2 & 90.0 & 25 \\
\hline 456 & 343.8 & 25 & 342.5 & 99.6 & 25 & 345.9 & 100.6 & 25 & 347.1 & 101.0 & 25 & 304.2 & 88.5 & 25 \\
\hline 484 & 354.5 & 25 & 350.3 & 98.8 & 25 & 352.7 & 99.5 & 25 & 353.0 & 99.6 & 25 & 309.0 & 87.2 & 25 \\
\hline 512 & 360.5 & 25 & 350.8 & 97.3 & 25 & 360.8 & 100.1 & 25 & 356.6 & 98.9 & 25 & 312.1 & 86.6 & 25 \\
\hline 540 & 363.9 & 25 & 356.8 & 98.1 & 25 & 370.0 & 101.7 & 25 & 366.1 & 100.6 & 24 & 320.0 & 88.0 & 25 \\
\hline 568 & 372.7 & 25 & 359.0 & 96.3 & 25 & 369.0 & 99.0 & 24 & 367.5 & 98.6 & 24 & 326.5 & 87.6 & 24 \\
\hline 596 & 378.9 & 25 & 366.0 & 96.6 & 24 & 371.0 & 97.9 & 24 & 374.4 & 98.8 & 24 & 321.3 & 84.8 & 23 \\
\hline 624 & 393.7 & 24 & 368.9 & 93.7 & 24 & 376.5 & 95.6 & 23 & 381.0 & 96.8 & 23 & 328.5 & 83.4 & 22 \\
\hline 652 & 397.4 & 24 & 371.9 & 93.6 & 24 & 380.1 & 95.6 & 22 & 375.6 & 94.5 & 22 & 330.3 & 83.1 & 21 \\
\hline 680 & 390.4 & 23 & 363.5 & 93.1 & 24 & 379.2 & 97.1 & 21 & 388.4 & 99.5 & 21 & 331.5 & 84.9 & 20 \\
\hline 708 & 391.3 & 23 & 366.0 & 93.5 & 23 & 375.0 & 95.8 & 19 & 386.8 & 98.9 & 21 & 339.0 & 86.6 & 19 \\
\hline EOS & 390.3 & 22 & 374.7 & 96.0 & 23 & 375.5 & 96.2 & 18 & 393.4 & 100.8 & 20 & 348.8 & 89.4 & 19 \\
\hline
\end{tabular}

$\mathrm{EOS}=$ end of study; No. of litters = number of litters represented in weight average.

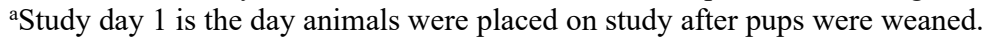

${ }^{\mathrm{b}}$ Average weights shown are means of litter means. 

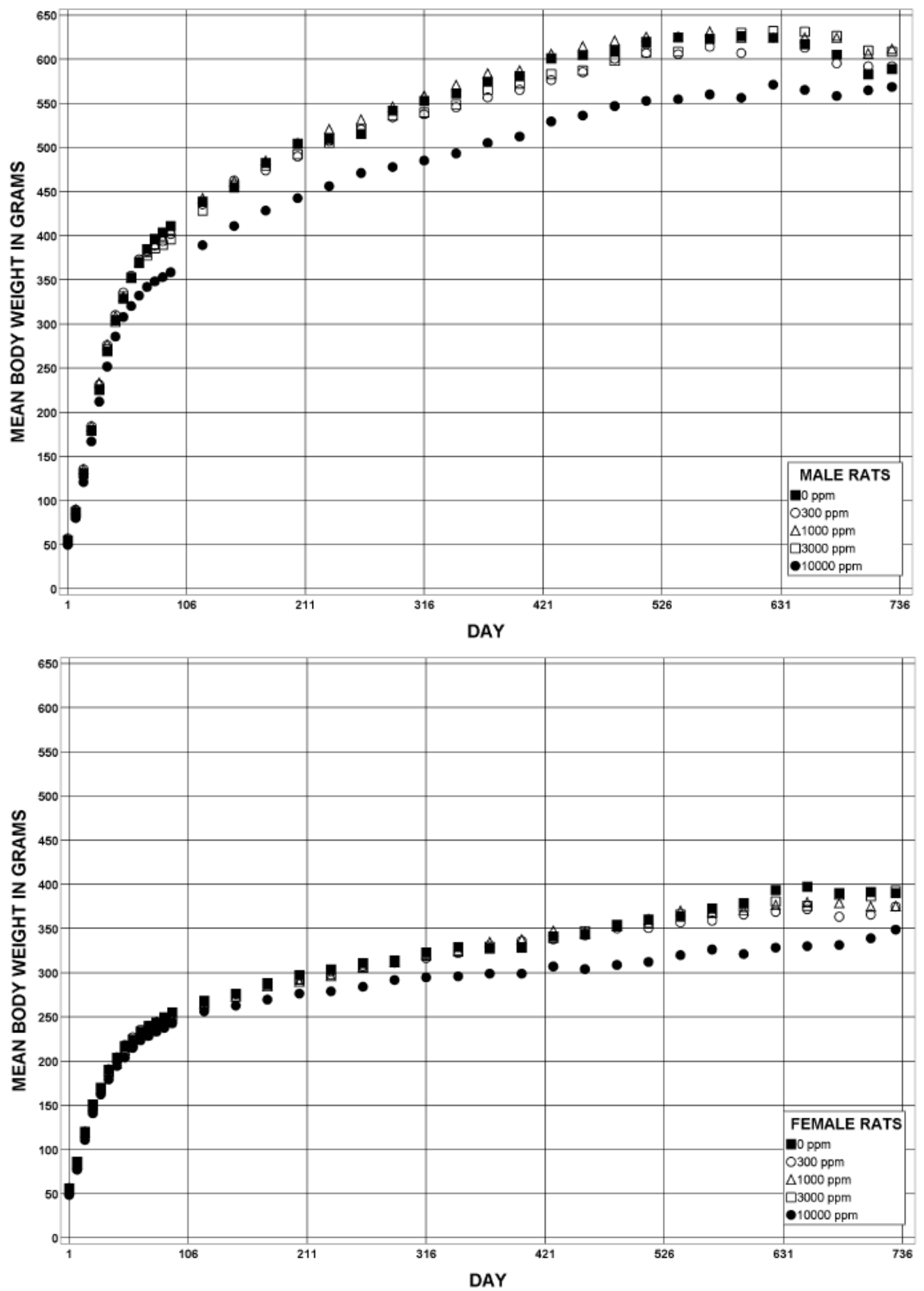

Figure 3. Growth Curves for Rats Exposed to Di-n-butyl Phthalate in Feed for Two Years 
Table 11. Summary of Feed and Di-n-butyl Phthalate Consumption of Male Rats in the Perinatal and Two-year Feed Study

\begin{tabular}{cccccccccc}
\hline \multirow{2}{*}{ Week } & $\mathbf{0 ~} \mathbf{~ p p m}$ & \multicolumn{2}{c}{$\mathbf{3 0 0} \mathbf{~ p p m}$} & \multicolumn{2}{c}{$\mathbf{1 , 0 0 0} \mathbf{~ p p m}$} & \multicolumn{2}{c}{$\mathbf{3 , 0 0 0} \mathbf{~ p p m}$} & \multicolumn{2}{c}{$\mathbf{1 0 , 0 0 0} \mathbf{~ p p m}$} \\
\cline { 2 - 9 } & $\begin{array}{c}\text { Feed } \\
(\mathbf{g} / \mathbf{d a y})^{\mathbf{a}}\end{array}$ & $\begin{array}{c}\text { Feed } \\
(\mathbf{g} / \mathbf{d a y})\end{array}$ & $\begin{array}{c}\text { Dose } \\
(\mathbf{m g} / \mathbf{k g} / \mathbf{d a y})^{\mathbf{b}}\end{array}$ & $\begin{array}{c}\text { Feed } \\
(\mathbf{g} / \mathbf{d a y})\end{array}$ & $\begin{array}{c}\text { Dose } \\
(\mathbf{m g} / \mathbf{k g} / \mathbf{d a y})\end{array}$ & $\begin{array}{c}\text { Feed } \\
(\mathbf{g} / \mathbf{d a y})\end{array}$ & $\begin{array}{c}\text { Dose } \\
(\mathbf{m g} / \mathbf{k g} / \mathbf{d a y})\end{array}$ & $\begin{array}{c}\text { Feed } \\
(\mathbf{g} / \mathbf{d a y})\end{array}$ & $\begin{array}{c}\text { Dose } \\
(\mathbf{m g} / \mathbf{k g} / \mathbf{d a y})\end{array}$ \\
\hline 1 & 9.0 & 9.1 & 47.7 & 9.2 & 162.2 & 8.8 & 492.0 & 7.8 & $1,560.5$ \\
13 & 24.3 & 23.9 & 18.2 & 24.0 & 60.4 & 21.5 & 165.5 & 19.9 & 562.7 \\
54 & 27.2 & 27.6 & 14.8 & 27.6 & 47.3 & 26.4 & 140.0 & 22.7 & 450.4 \\
102 & 21.4 & 24.6 & 12.4 & 22.7 & 37.3 & 23.0 & 112.9 & 22.1 & 391.4 \\
\hline
\end{tabular}

${ }^{\mathrm{a}}$ Grams of feed consumed per animal per day.

${ }^{b}$ Milligrams of di- $n$-butyl phthalate consumed per kilogram body weight per day.

Table 12. Summary of Feed and Di-n-butyl Phthalate Consumption of Female Rats in the Perinatal and Two-year Feed Study

\begin{tabular}{cccccccccc}
\hline \multirow{2}{*}{ Week } & $\mathbf{0 ~ p p m}$ & \multicolumn{2}{c}{$\mathbf{3 0 0} \mathbf{~ p p m}$} & \multicolumn{2}{c}{$\mathbf{1 , 0 0 0} \mathbf{~ p p m}$} & \multicolumn{2}{c}{$\mathbf{3 , 0 0 0} \mathbf{~ p p m}$} & \multicolumn{2}{c}{$\mathbf{1 0 , 0 0 0} \mathbf{~ p p m}$} \\
\cline { 2 - 9 } & $\begin{array}{c}\text { Feed } \\
(\mathbf{g} / \mathbf{d a y})^{\mathbf{a}}\end{array}$ & $\begin{array}{c}\text { Feed } \\
(\mathbf{g} / \mathbf{d a y})\end{array}$ & $\begin{array}{c}\text { Dose } \\
(\mathbf{m g} / \mathbf{k g} / \mathbf{d a y})^{\mathbf{b}}\end{array}$ & $\begin{array}{c}\text { Feed } \\
(\mathbf{g} / \mathbf{d a y})\end{array}$ & $\begin{array}{c}\text { Dose } \\
(\mathbf{m g} / \mathbf{k g} / \mathbf{d a y})\end{array}$ & $\begin{array}{c}\text { Feed } \\
(\mathbf{g} / \mathbf{d a y})\end{array}$ & $\begin{array}{c}\text { Dose } \\
(\mathbf{m g} / \mathbf{k g} / \mathbf{d a y})\end{array}$ & $\begin{array}{c}\text { Feed } \\
(\mathbf{g} / \mathbf{d a y})\end{array}$ & $\begin{array}{c}\text { Dose } \\
(\mathbf{m g} / \mathbf{k g} / \mathbf{d a y})\end{array}$ \\
\hline 1 & 9.6 & 9.2 & 48.6 & 9.7 & 177.0 & 9.6 & 531.2 & 8.6 & $1,764.6$ \\
13 & 15.6 & 15.3 & 18.4 & 15.2 & 61.5 & 15.5 & 187.3 & 15.0 & 630.5 \\
54 & 16.8 & 16.4 & 15.0 & 17.1 & 51.7 & 16.7 & 152.1 & 16.3 & 544.7 \\
102 & 19.9 & 19.4 & 15.8 & 19.2 & 51.6 & 19.4 & 149.8 & 20.2 & 600.3 \\
\hline
\end{tabular}

${ }^{\mathrm{a}}$ Grams of feed consumed per animal per day.

${ }^{b}$ Milligrams of di- $n$-butyl phthalate consumed per kilogram body weight per day.

\section{Pathology}

This section describes statistically significant or biologically noteworthy changes in the incidences of neoplasms and/or nonneoplastic lesions of the pancreas, testis, epididymis, prostate gland, seminal vesicle, preputial gland, pituitary gland, liver, and uterus. Summaries of the incidences of neoplasms and nonneoplastic lesions, individual animal tumor diagnoses, statistical analysis of primary neoplasms that occurred with an incidence of at least $5 \%$ in at least one animal group, and historical incidences for the biologically significant neoplasms mentioned in this section are presented as supplemental data in Appendix E.

Exocrine Pancreas: The incidence of exocrine pancreatic acinus adenomas in the male rats was slightly higher in the 10,000 ppm group compared to the control group, but only the positive trend was statistically significant (Table 13). Two pancreatic acinus carcinomas occurred in the control group and none in the exposed groups (Table 13). The incidence of pancreatic acinus adenomas in the 10,000 ppm group was within the historical control range $(0 \%$ to $28 \%)$ for studies in Sprague Dawley (Hsd:Sprague Dawley ${ }^{\circledR}$ SD $^{\circledR}$ ) rats on the NTP-2000 diet, all exposure routes, and all vehicles. The incidence of pancreatic acinus carcinomas in the control group exceeded the previous historical control range ( $0 \%$ to $4 \%)$. The incidence of pancreatic acinus hyperplasia was not significantly increased in any of the exposure groups (Table 13).

The adenomas of the exocrine pancreas were discrete masses of neoplastic acinar cells that often compressed the adjacent tissue. The masses were $>3 \mathrm{~mm}$ in diameter and largely devoid of islets 
of Langerhans, with the exception of the occasional entrapped islet at the edge of the mass. As opposed to the carcinomas, the adenomas lacked a fibrous capsule, were not invasive, and the neoplastic cells did not exhibit atypia. Mitotic figures were rare. Acinus hyperplasia was similar to adenoma but was smaller ( $<3 \mathrm{~mm}$ in diameter) and generally lacked compression of adjacent tissue.

Table 13. Incidences of Neoplastic and Nonneoplastic Lesions of the Pancreas in Male Rats in the Perinatal and Two-year Feed Study of Di-n-butyl Phthalate

\begin{tabular}{|c|c|c|c|c|c|}
\hline & $\mathbf{0}$ ppm & 300 ppm & 1,000 ppm & 3,000 ppm & $10,000 \mathrm{ppm}$ \\
\hline $\mathbf{n}^{\mathbf{a}}$ & 49 & 50 & 50 & 50 & 49 \\
\hline Acinus, Hyperplasia ${ }^{\mathrm{b}}$ & $19(2.3)^{\mathrm{c}}$ & $21(2.1)$ & $18(2.1)$ & $23(2.0)$ & $18(2.1)$ \\
\hline Acinus, Adenoma, Multiple & 2 & 1 & 0 & 0 & 2 \\
\hline \multicolumn{6}{|c|}{ Acinus, Adenoma (Includes Multiple) ${ }^{\mathrm{d}}$} \\
\hline Overall rate ${ }^{\mathrm{e}}$ & $4 / 49(8 \%)$ & $4 / 50(8 \%)$ & $3 / 50(6 \%)$ & $1 / 50(2 \%)$ & $10 / 49(20 \%)$ \\
\hline Rate per litters ${ }^{\mathrm{f}}$ & $4 / 25(16 \%)$ & $4 / 25(16 \%)$ & $3 / 25(12 \%)$ & $1 / 25(4 \%)$ & $9 / 25(36 \%)$ \\
\hline Adjusted rate ${ }^{g}$ & $9.7 \%$ & $8.9 \%$ & $6.8 \%$ & $2.3 \%$ & $24.1 \%$ \\
\hline Terminal rate ${ }^{\mathrm{h}}$ & $2 / 27(7 \%)$ & $3 / 38(8 \%)$ & $3 / 31(10 \%)$ & $1 / 34(3 \%)$ & $8 / 33(24 \%)$ \\
\hline First incidence (days) & 676 & 565 & $729(\mathrm{~T})$ & $729(\mathrm{~T})$ & 684 \\
\hline Rao-Scott-adjusted Poly- 3 test ${ }^{\mathrm{i}}$ & $\mathrm{p}=0.010$ & $\mathrm{p}=0.595 \mathrm{~N}$ & $\mathrm{p}=0.472 \mathrm{~N}$ & $\mathrm{p}=0.192 \mathrm{~N}$ & $\mathrm{p}=0.094$ \\
\hline Acinus, Carcinoma ${ }^{\mathrm{j}}$ & 2 & 0 & 0 & 0 & 0 \\
\hline \multicolumn{6}{|c|}{ Acinus, Adenoma or Carcinoma (Combined $)^{1}$} \\
\hline Overall rate & $6 / 49(12 \%)$ & $4 / 50(8 \%)$ & $3 / 50(6 \%)$ & $1 / 50(2 \%)$ & $10 / 49(20 \%)$ \\
\hline Rate per litters & $6 / 25(24 \%)$ & $4 / 25(16 \%)$ & $3 / 25(12 \%)$ & $1 / 25(4 \%)$ & $9 / 25(36 \%)$ \\
\hline Adjusted rate & $14.3 \%$ & $8.9 \%$ & $6.8 \%$ & $2.3 \%$ & $24.1 \%$ \\
\hline Terminal rate & $2 / 27(7 \%)$ & $3 / 38(8 \%)$ & $3 / 31(10 \%)$ & $1 / 34(3 \%)$ & $8 / 33(24 \%)$ \\
\hline First incidence (days) & 611 & 565 & $729(\mathrm{~T})$ & $729(\mathrm{~T})$ & 684 \\
\hline Rao-Scott-adjusted Poly-3 test & $\mathrm{p}=0.024$ & $\mathrm{p}=0.349 \mathrm{~N}$ & $\mathrm{p}=0.243 \mathrm{~N}$ & $\mathrm{p}=0.072 \mathrm{~N}$ & $\mathrm{p}=0.217$ \\
\hline
\end{tabular}

$(\mathrm{T})=$ terminal euthanasia.

aNumber of animals with tissue examined microscopically.

${ }^{b}$ Number of animals with lesion.

${ }^{\mathrm{c}}$ Average severity grade of lesions in affected animals: $1=$ minimal, $2=$ mild, 3 = moderate, $4=$ marked.

${ }^{\mathrm{d}}$ Historical control incidence for all routes of 2-year studies (mean \pm standard deviation): 60/488 (11.58\% \pm 9.25\%); range: $0 \%-28 \%$.

${ }^{\mathrm{e} N u m b e r}$ of animals with neoplasm per number of animals necropsied.

fNumber of litters with tumor-bearing animals per number of litters examined at anatomical site.

gPoly-3-estimated neoplasm incidence after adjustment for intercurrent mortality.

hObserved incidence at study termination.

${ }^{i}$ Beneath the control incidence is the $p$ value associated with the trend test. Beneath the exposed group incidences are the $p$ values corresponding to pairwise comparisons between the control group and that exposed group. The Rao-Scott test adjusts the Poly-3 test, which accounts for differential mortality in animals that do not reach study termination, for within-litter correlation. A negative trend or a lower incidence in an exposure group is indicated by $\mathrm{N}$.

${ }^{\mathrm{j} H i s t o r i c a l}$ control incidence: $4 / 488(0.8 \% \pm 1.42 \%)$; range: $0 \%-4 \%$.

kNot applicable; no neoplasms in animal group.

${ }^{l}$ Historical control incidence: $62 / 488(12.03 \% \pm 9.16 \%)$; range: $0 \%-28 \%$.

Male Reproductive Tract: Several exposure-related gross lesions occurred in the reproductive tract of male rats (Table 14). These lesions included undescended testes; fluid- or blood-filled testes; missing or small testes, epididymides, prostate glands, seminal vesicles, or vas deferens; and missing gubernaculum or gubernaculum with a length $>20 \mathrm{~mm}$. These lesions occurred with 
the greatest frequency in the $10,000 \mathrm{ppm}$ group. Of a total of 46 animals examined in this group, 36 had small testes, 27 had small epididymides, 4 had small prostate glands, 7 had small seminal vesicles, 19 (of the 40 measured) had an increased gubernacular length $(>20 \mathrm{~mm}$ ), and 36 had undescended testes.

In general, the diagnosis of small testis correlated microscopically to germinal epithelial atrophy, enlarged testis correlated to interstitial cell adenoma and/or interstitial edema, and fluid-filled testis correlated to interstitial edema. Small testes tended to also be undescended (either abdominal or inguinal locations). In the two male rats exposed to $10,000 \mathrm{ppm}$ DBP with right testis not present (synonymous with agenesis), both also had the right vas deferens not present, and agenesis of the right epididymis (caput, corpus, and cauda) and ventral prostate gland (right and left). In addition, the left testis in both animals was undescended (abdominal location) and small. A single animal was exposed to 3,000 ppm DBP with agenesis of the right side of the prostate (ventral, dorsal, or lateral lobes). There did not appear to be differences in laterality of other male reproductive tract lesions; therefore, combined incidences are shown.

In general, small epididymis correlated to hypospermia, and small seminal vesicle and small prostate gland both correlated to decreased secretory fluid. There were low occurrences of other gross lesions in the male and female reproductive tracts, but they were considered sporadic and unrelated to DBP exposure (Appendix E).

Table 14. Summary of Gross Lesions in the Reproductive Tract of Male Rats in the Perinatal and Two-year Feed study of Di-n-butyl Phthalate

\begin{tabular}{|c|c|c|c|c|c|}
\hline & 0 ppm & 300 ppm & 1,000 ppm & 3,000 ppm & $10,000 \mathrm{ppm}$ \\
\hline $\mathbf{n}^{\mathbf{a}}$ & 48 & 49 & 48 & 49 & 46 \\
\hline \multicolumn{6}{|l|}{ Testis $^{b}$} \\
\hline Size, small & $1 * * \mathrm{c}(1)^{\mathrm{d}}$ & 0 & $4(4)$ & $2(2)$ & $36^{* *}(23)$ \\
\hline Size, enlarged (or swelling) & 0 & 0 & $1(1)$ & $1(1)$ & $1(1)$ \\
\hline Fluid or blood filled & $1(1)$ & 0 & 0 & $1(1)$ & $3(3)$ \\
\hline Right, not present & 0 & 0 & 0 & 0 & $2(2)$ \\
\hline $\begin{array}{l}\text { Right or left; abdominal; } \\
\text { undescended }\end{array}$ & $1 * *(1)$ & $3(3)$ & $2(2)$ & $2(2)$ & $29 * *(21)$ \\
\hline $\begin{array}{l}\text { Right or left; inguinal; } \\
\text { undescended }\end{array}$ & $1 * *(1)$ & 0 & 0 & 0 & $7(7)$ \\
\hline $\begin{array}{l}\text { Right or left; abdominal or } \\
\text { inguinal; undescended }\end{array}$ & $2 * *(2)$ & $3(3)$ & $2(2)$ & $2(2)$ & $32 * *(23)$ \\
\hline \multicolumn{6}{|l|}{ Epididymis $^{\mathrm{b}}$} \\
\hline Size, small & $0 * *$ & 0 & $3(3)$ & 0 & $27 * *(19)$ \\
\hline Right, agenesis & 0 & 0 & 0 & 0 & $2(2)$ \\
\hline \multicolumn{6}{|l|}{ Prostate Glands ${ }^{\mathrm{b}}$} \\
\hline Size, small & $0 *$ & 0 & $1(1)$ & $2(2)$ & $4(4)$ \\
\hline $\begin{array}{l}\text { Right or left, ventral, dorsal, } \\
\text { or lateral, agenesis }\end{array}$ & 0 & 0 & 0 & $1(1)$ & $2(2)$ \\
\hline
\end{tabular}




\begin{tabular}{lccccc}
\hline & $\mathbf{0 ~} \mathbf{p p m}$ & $\mathbf{3 0 0} \mathbf{~ p p m}$ & $\mathbf{1 , 0 0 0} \mathbf{~ p p m}$ & $\mathbf{3 , 0 0 0} \mathbf{~ p p m}$ & $\mathbf{1 0 , 0 0 0} \mathbf{~ p p m}$ \\
\hline $\begin{array}{l}\text { Seminal Vesicles } \\
\quad \text { bize, small }\end{array}$ & $1^{*}(1)$ & $2(2)$ & $2(2)$ & $1(1)$ & $7(6)$ \\
$\begin{array}{l}\text { Vas Deferens } \\
\text { b }\end{array}$ & & & & & \\
Right, not present & 0 & 0 & 0 & 0 & $2(2)$ \\
Gubernaculum ${ }^{\mathrm{e} f \mathrm{f}}$ & & & & & \\
Right, not present & 0 & 0 & 0 & 0 & $1(1)$ \\
Left, length (mm) & $14.24 \pm 0.83$ & $14.73 \pm 0.71$ & $13.18 \pm 0.78$ & $14.78 \pm 0.89$ & $30.92 \pm 4.09$ \\
& $33(23)^{\mathrm{g}}$ & $41(24)$ & $39(25)$ & $38(23)$ & $35(24)$ \\
Right, length (mm) & $14.04 \pm 0.71$ & $14.52 \pm 0.70$ & $13.84 \pm 0.85$ & $14.80 \pm 0.75$ & $33.86 \pm 4.80$ \\
& $33(23)$ & $41(24)$ & $39(25)$ & $38(23)$ & $33(22)$ \\
\hline
\end{tabular}

Statistical significance for an exposure group indicates a significant pairwise test compared to the vehicle control group.

Statistical significance for the vehicle control group indicates a significant trend test.

*Statistically significant at $\mathrm{p} \leq 0.05 ; * * \mathrm{p} \leq 0.01$.

aNumber of animals examined for each tissue.

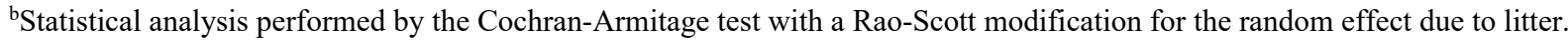
All trend and pairwise $\mathrm{p}$ values are reported as one-sided.

${ }^{\mathrm{c}}$ Number of animals affected given each observation.

${ }^{\mathrm{d} N u m b e r}$ of litters with observations for $\mathrm{F}_{1}$ animals. $\mathrm{F}_{1}$ litter incidence based on the number of $\mathrm{F}_{0}$ dams.

eStatistical analysis performed using a bootstrapped Jonckheere test for trend and a Datta-Satten modified Wilcoxon test with Hommel adjustment for pairwise comparisons.

fData are presented as mean \pm standard error.

gNumber of animals examined (number of litters represented).

Testis: Several lesions were observed in the testis involving the seminiferous tubules, the interstitium, or the rete testis (Table 15). There were significant increases in the incidences of the combination of unilateral and bilateral edema, bilateral germinal epithelial atrophy, the combination of unilateral and bilateral germinal epithelial atrophy, diffuse interstitial cell hyperplasia (always bilateral when it was diagnosed), the combination of unilateral and bilateral focal interstitial cell hyperplasia, the combination of unilateral and bilateral rete testis fibrosis, and the combination of unilateral and bilateral seminiferous tubule dysgenesis (Table 15, Appendix E). The incidences of these lesions were all significantly increased in the 10,000 ppm group compared to the control group, and the positive trends also were statistically significant. The incidences of germinal epithelial atrophy and focal interstitial cell hyperplasia also were significantly increased in the $300 \mathrm{ppm}$ group. The average severities of germinal epithelium atrophy were higher in the 1,000, 3,000, and 10,000 ppm groups than in the control group. The incidence of sperm granuloma in the rete testis also was higher in the 10,000 ppm group; although not statistically significant, it was considered related to DBP exposure as sperm granuloma is thought to be the precursor lesion to rete testis fibrosis. The incidences of the combination of unilateral and bilateral germinal epithelium degeneration were not higher compared to the control group (Table 15). The average severity of this lesion was higher in the exposed groups. This is a common background change in laboratory rodents, but the lower incidence of degeneration in the $10,000 \mathrm{ppm}$ group is likely due to exacerbation by DBP exposure, resulting in progression to atrophy, which was clearly exposure-related (degeneration is considered to be on a continuum with atrophy, with atrophy the end stage of ongoing degeneration). 
Table 15. Incidences of Nonneoplastic Lesions of the Testis, Epididymis, Prostate Gland, and Seminal Vesicle in Male Rats in the Perinatal and Two-year Feed Study of Di-n-butyl Phthalate

\begin{tabular}{|c|c|c|c|c|c|}
\hline & 0 ppm & 300 ppm & $1,000 \mathrm{ppm}$ & 3,000 ppm & $10,000 \mathrm{ppm}$ \\
\hline Testis $^{\mathrm{a}}$ & 49 & 50 & 50 & 47 & 50 \\
\hline Edema (includes bilateral) ${ }^{\mathrm{b}}$ & $2 * *(3.0)^{\mathrm{c}}$ & $3(2.0)$ & $2(2.5)$ & $2(3.0)$ & $18^{* *}(3.5)$ \\
\hline $\begin{array}{l}\text { Germinal epithelium, atrophy } \\
\text { (includes bilateral) }\end{array}$ & $8^{* *}(2.3)$ & $21 * *(1.8)$ & $11(2.5)$ & $10(2.9)$ & $42 * *(3.9)$ \\
\hline $\begin{array}{l}\text { Germinal epithelium, degeneration } \\
\text { (includes bilateral) }\end{array}$ & $8(1.1)$ & $7(2.6)$ & $12(2.2)$ & $7(2.0)$ & $3(2.0)$ \\
\hline $\begin{array}{l}\text { Interstitial cell, hyperplasia, } \\
\text { diffuse, bilateral }^{\mathrm{d}}\end{array}$ & $0 * *$ & 0 & $1(2.0)$ & 0 & $9 * *(2.2)$ \\
\hline $\begin{array}{l}\text { Interstitial cell, hyperplasia, } \\
\text { focal (includes bilateral) }\end{array}$ & $1 *(3.0)$ & $7 *(1.6)$ & $5(1.2)$ & $3(1.7)$ & $11 * *(1.5)$ \\
\hline $\begin{array}{l}\text { Rete testis, fibrosis (includes } \\
\text { bilateral) }\end{array}$ & $0 * *$ & 0 & 0 & 0 & $11 * *(2.5)$ \\
\hline $\begin{array}{l}\text { Rete testis, sperm granuloma } \\
\text { (includes bilateral) }\end{array}$ & 0 & 0 & 0 & 0 & 2 \\
\hline $\begin{array}{l}\text { Seminiferous tubule, dysgenesis } \\
\text { (includes bilateral) }\end{array}$ & $0 * *$ & 0 & 0 & $1(2.0)$ & $9 *(1.9)$ \\
\hline Epididymis & 49 & 50 & 50 & 50 & 50 \\
\hline Hypospermia (includes bilateral) & $4 * *(3.5)$ & $7(3.1)$ & $10(3.0)$ & $9(3.2)$ & $40 * *(3.9)$ \\
\hline Prostate Gland & 49 & 50 & 50 & 50 & 50 \\
\hline Decreased secretory fluid ${ }^{\mathrm{e}}$ & $5 * *$ & 8 & 5 & 5 & $18^{* *}$ \\
\hline Seminal Vesicle & 49 & 50 & 50 & 50 & 49 \\
\hline Decreased secretory fluide & $6^{* *}$ & 7 & 9 & 6 & $15^{*}$ \\
\hline
\end{tabular}

Statistical significance for an exposure group indicates a significant pairwise test compared to the vehicle control group. Statistical significance for the vehicle control group indicates a significant trend test.

*Statistically significant $(\mathrm{p} \leq 0.05)$ from the vehicle control group by the Rao-Scott adjusted Poly- 3 test; ** $\mathrm{p} \leq 0.01$.

${ }^{a}$ Number of animals with tissue examined microscopically.

${ }^{b}$ Incidence reported is the combination of unilateral and bilateral lesions. Severity grade for these types of lesions $=$ sum of unilateral and bilateral severity scores/number of unilateral and bilateral incidences.

${ }^{\mathrm{c}}$ Average severity grade of lesions in affected animals: $1=$ minimal, $2=$ mild, $3=$ moderate, $4=$ marked.

dThis lesion was observed only as a bilateral lesion.

${ }^{\mathrm{e}}$ This lesion was not graded.

Microscopically, germinal epithelium atrophy was seen as seminiferous tubules devoid of germ cells and lined only by Sertoli cells. Germinal epithelium degeneration was observed as several degenerative features, frequently co-occurring, including tubular vacuolation, focal to segmental germ cell dropout, general depletion of germ cells, degeneration of germ cells not restricted to stage or cell type, and disorganization of the germinal epithelium.

Seminiferous tubule dysgenesis (Figure 4) was observed microscopically as malformed, anastomosing seminiferous tubules. Generally, lesions of dysgenesis consisted of a single focus per testis, but, occasionally, up to three foci were observed. Tubules in dysgenetic lesions were not active in spermatogenesis and contained immature-appearing Sertoli cells with small, elongated nuclei and a less prominent nucleolus than observed in mature Sertoli cells. The 
basement membranes were thickened and convoluted and appeared discontinuous in some areas. Small "islands" of entrapped Leydig cells were occasionally present within the malformed tubules. Dysgenetic lesions often were surrounded by angular aggregates of Leydig cells, which were smaller, spindle-shaped, and contained less cytoplasm than typically observed in focal Leydig cell hyperplasia or adenomas. Dysgenesis was usually observed in only one of the three sections of a single testis and was generally located in a section of testis that also contained the rete testis.
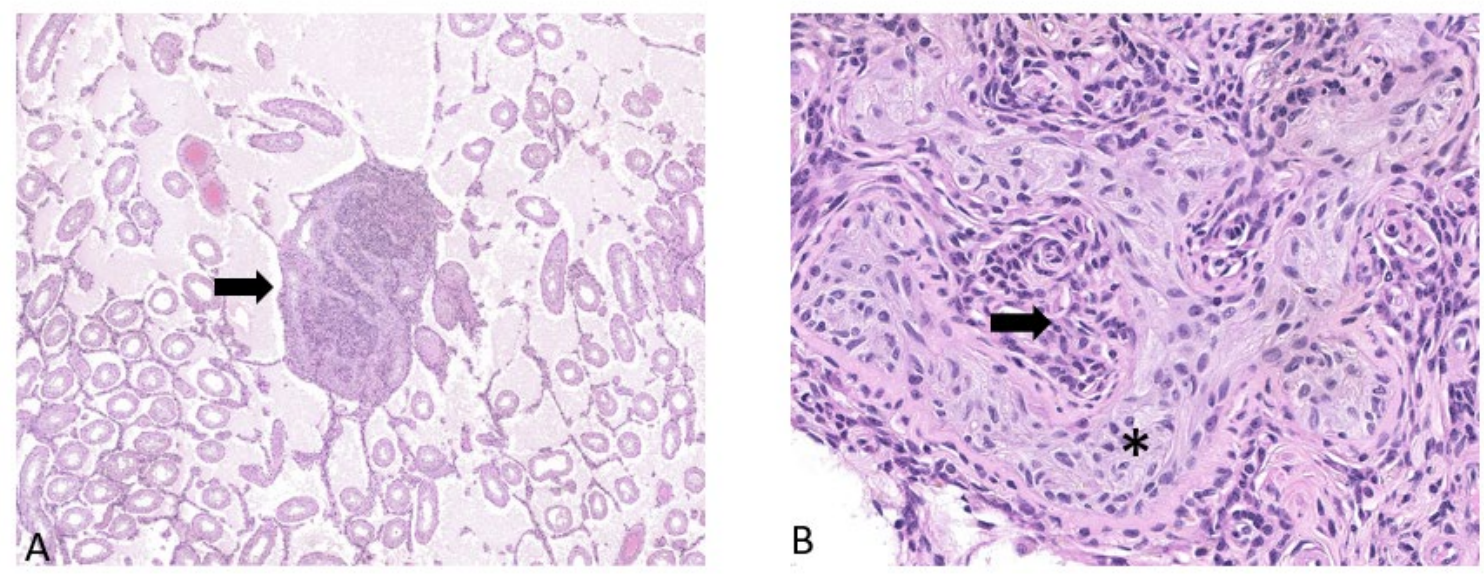

Figure 4. Representative Images Depicting Seminiferous Tubule Dysgenesis in a Male Rat in the Perinatal and Two-year Feed Study of Di-n-butyl Phthalate

A) Seminiferous tubule dysgenesis (arrow) in a 10,000 ppm male rat. There is also germinal epithelial atrophy in all seminiferous tubules, as well as interstitial edema. B) Higher magnifications of the dysgenesis lesion in panel A showing the convoluted, malformed seminiferous tubules (asterisk) with immature-appearing Sertoli cells and thickened basement membranes, surrounded by aggregated Leydig cells (arrow). Original magnification: $A=4 \times, B=20 \times$.

Edema and interstitial cell hyperplasia were lesions present in the testicular interstitium in DBP-exposed male rats. Microscopically, testicular edema (Figure 4) appeared as increased amounts of eosinophilic fluid within the interstitium. Another lesion of the interstitium was hyperplasia of Leydig cells, both diffuse and focal. Diffuse interstitial cell hyperplasia (Figure 5) was observed as increased numbers of Leydig cells with bridging strands several layers thick between seminiferous tubules, generally involving a large portion of the testis. Focal interstitial cell hyperplasia was seen as a single angular or rounded Leydig cell aggregate between seminiferous tubules with a diameter less than or equal to three seminiferous tubules. 

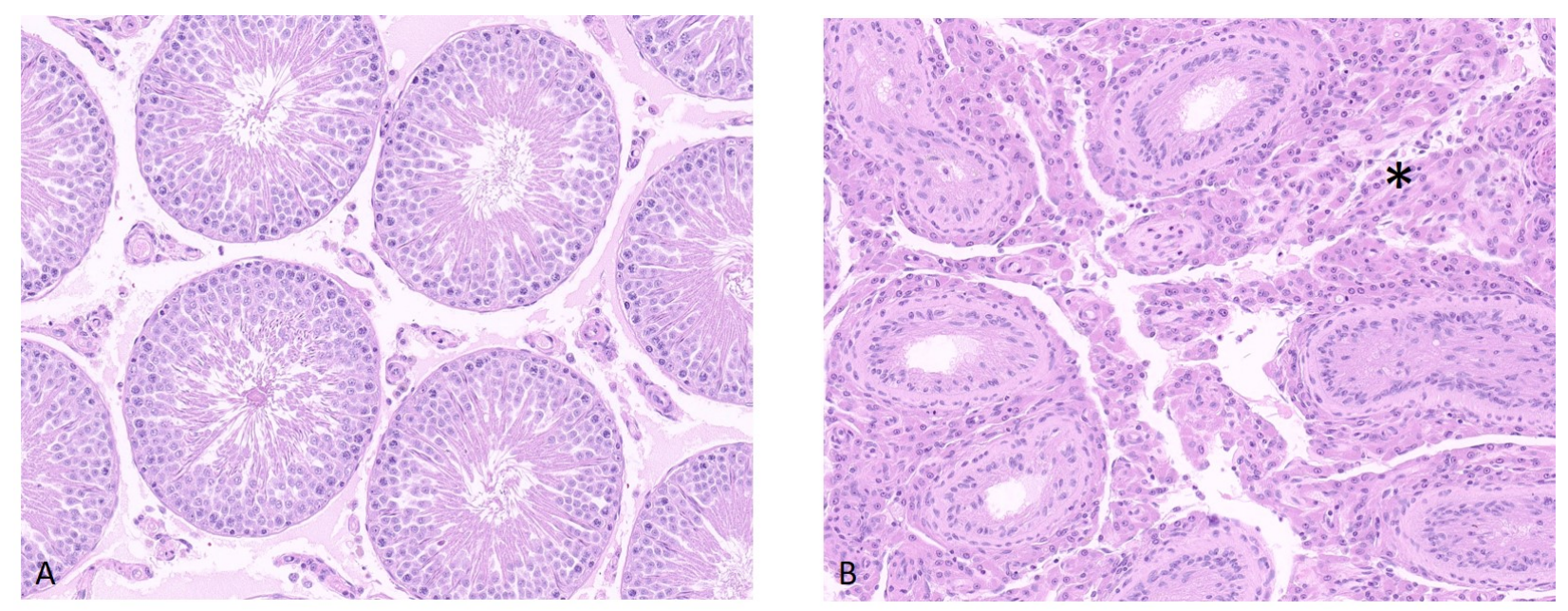

Figure 5. Representative Images of the Testis from Male Rats in the Perinatal and Two-year Feed Study of Di-n-butyl Phthalate

A) Normal testis and Leydig cell population from a control male rat. B) Diffuse interstitial (Leydig) cell hyperplasia (asterisk) from a 10,000 ppm male rat with seminiferous tubule atrophy. Original magnification: $A=20 \times, B=20 \times$.

In the rete testis region, two lesions were observed microscopically. Rete testis granuloma (Figure 6) was seen as expansion of a profile in the rete testis region, subjacent to the capsule at the cranial pole of the testis, by an accumulation of abundant spermatozoa and occasional cholesterol clefts. These spermatozoa and cholesterol clefts were surrounded by a granulomatous inflammatory response, including numerous multinucleated giant cells, which was in turn surrounded by fibrous connective tissue with interspersed macrophages and fibroblasts. Rete testis fibrosis (Figure 7) was observed as a lesion similar in magnitude and location as the rete testis granulomas but consisted of disorganized fibrous connective tissue containing occasional macrophages and fibroblasts and numerous, apparently anastomosing channels, which were lined by cuboidal epithelium. Three sections of a single testis were examined histologically; of the 11 males diagnosed with rete testis fibrosis, 2 also had a rete testis sperm granuloma present in a different section of testis. 

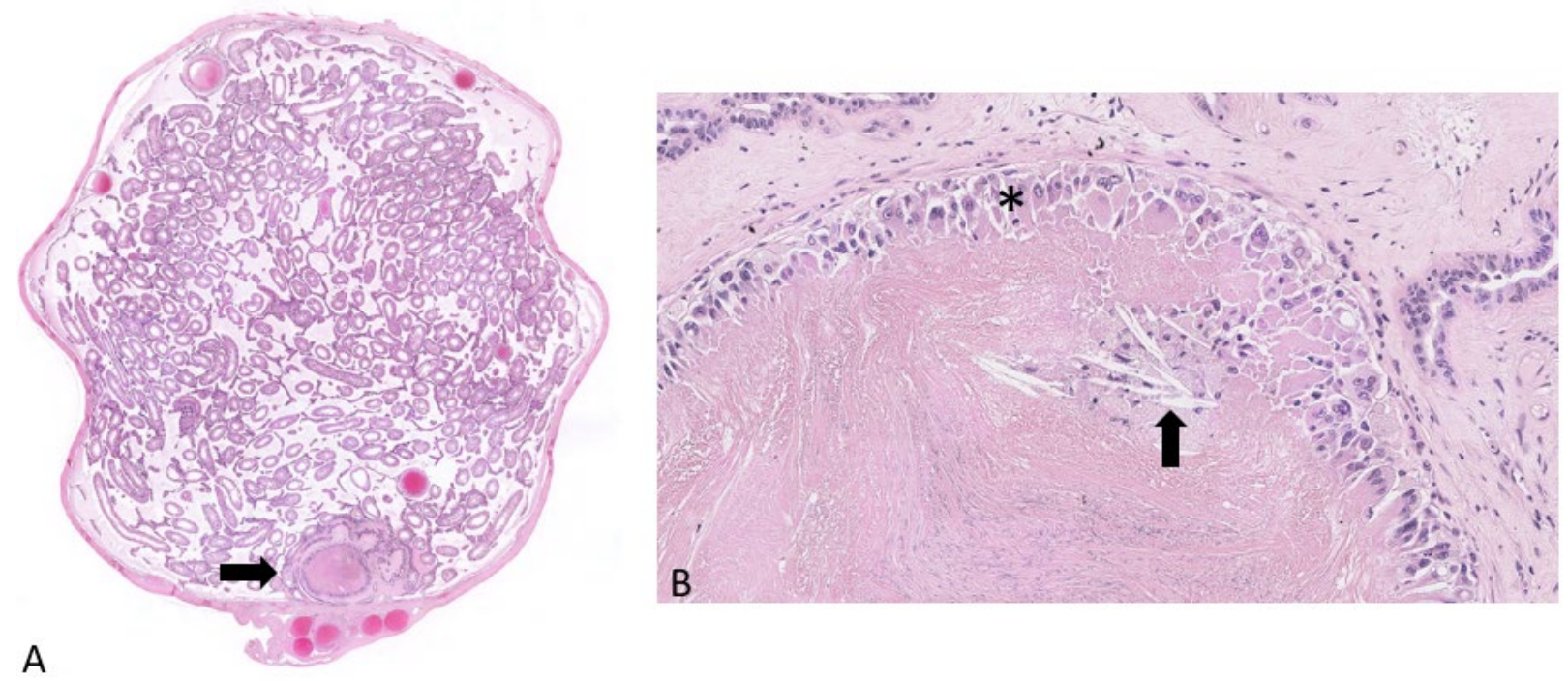

Figure 6. Representative Images Depicting Sperm Granuloma in the Rete Testis of a Male Rat in the Perinatal and Two-year Feed Study of Di-n-butyl Phthalate

A) Sperm granuloma in the rete testis (arrow) in a 10,000 ppm male rat. There is also germinal epithelial atrophy and interstitial edema. B) Higher magnification of the lesion in panel A showing the macrophages at the periphery of the lesion (asterisk) and surrounding the cholesterol clefts (arrow). There are degenerating spermatozoa in the center of the lesion and fibrosis surrounding the lesion. Original magnification: $\mathrm{A}=1.4 \times, \mathrm{B}=20 \times$.
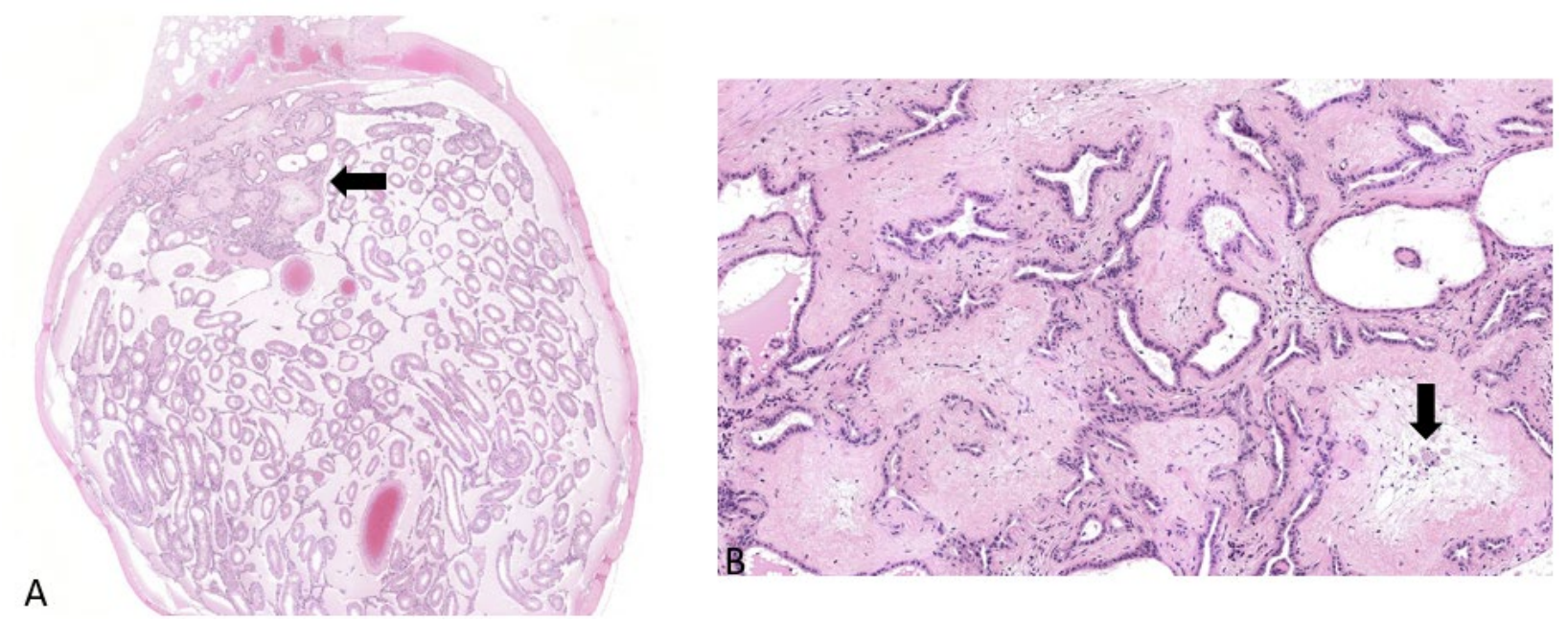

\section{Figure 7. Representative Images Depicting Fibrosis in the Rete Testis of a Male Rat in the Perinatal and Two-year Feed Study of Di-n-butyl Phthalate}

A) Fibrosis in the rete testis in a 10,000 ppm male rat (arrow). There is an increased number of tubular profiles within the lesion. There is also germinal epithelial atrophy and interstitial edema. B) Higher magnification of the lesion in panel A showing the fibrosis separating the tubular profiles. There are several macrophages within the lesion (arrow) suggesting progression of a sperm granuloma. Original magnification: $\mathrm{A}=2.5 \times, \mathrm{B}=10 \times$.

Epididymis: In the epididymis, the incidence of the combination of unilateral and bilateral hypospermia was significantly increased in the $10,000 \mathrm{ppm}$ group compared to the control group (Table 15). The incidence of bilateral hypospermia alone was also significantly increased in the 
high exposure group compared to the control group (Appendix E). The incidence of unilateral hypospermia alone also was significantly increased in the 10,000 $\mathrm{ppm}$ group compared to the control group (Appendix E).

Hypospermia was observed microscopically as reduced density or absence of sperm in the epididymal duct lumen throughout the epididymis. This reduction in sperm and fluid volume was typically accompanied by ductal atrophy, the generalized narrowing of the duct lumen with occasional intraductal epithelial folding, which was considered to be a component of the hypospermia.

Accessory Sex Organs: The incidences of decreased secretory fluid in the prostate gland and seminal vesicle were significantly increased in the 10,000 ppm group compared to the control group (Table 15). These lesions were not graded.

Microscopically, decreased secretory fluid in the prostate gland and seminal vesicle was seen as reduced acinar or vesicular luminal size with reduced luminal secretion. In the seminal vesicle, decreased secretory fluid also was seen as crowding of the intravesicle epithelial folds.

Preputial Gland: The incidences of chronic inflammation $(7 / 49,10 / 49,2 / 50,0 / 49,0 / 50)$, chronic active inflammation $(27 / 49,8 / 49,1 / 50,1 / 49,2 / 50)$, and duct dilation $(35 / 49,16 / 49,3 / 50,2 / 49$, $3 / 50$ ) in the preputial gland were decreased compared to the control group (Appendix E). Duct dilation is a common age-related change. The pathogenesis of the decreased incidences of these lesions in exposed male rats is unclear, but it could be related to hormonal disturbance as preputial gland secretion is influenced by testosterone and pituitary hormones. ${ }^{146}$

Pituitary Gland: In the males, the incidence of hypertrophy of endocrine cells in the pars distalis was significantly increased in only the 10,000 ppm group compared to the control group. The incidence of this lesion in the high exposure group was significant as was the positive trend (Table 16).

The hypertrophy (Figure 8) was characterized by increased amounts of pale-staining, eosinophilic cytoplasm and, in many of the cells, by the presence of multiple small vacuoles or a single large vacuole that displaced the nucleus peripherally. The lesion affected individual cells often clustered in the pars distalis.

There was a positive trend in the incidence of hyperplasia (generally focal increases in numbers) of cells of the pars distalis $(15 / 48,13 / 50,13 / 50,18 / 50,22 / 50)$ in males, but there were no statistically significant pairwise increases, nor was there evidence of progression to pars distalis adenomas in either males or females (Appendix E). The lesion of hyperplasia of the pars distalis was not considered related to DBP exposure. 
Table 16. Incidences of Nonneoplastic Lesions of the Pituitary Gland and Liver in Male and Female Rats in the Perinatal and Two-year Feed Study of Di-n-butyl Phthalate

\begin{tabular}{|c|c|c|c|c|c|}
\hline & $\mathbf{0}$ ppm & 300 ppm & 1,000 ppm & 3,000 ppm & $10,000 \mathrm{ppm}$ \\
\hline \multicolumn{6}{|l|}{ Male } \\
\hline Pituitary Gland ${ }^{\mathrm{a}}$ & 48 & 50 & 50 & 50 & 50 \\
\hline Pars distalis, hypertrophy ${ }^{\mathrm{b}}$ & $0 * *$ & 0 & 0 & 0 & $29 * *(1.0)^{\mathrm{c}}$ \\
\hline Liver & 49 & 50 & 50 & 50 & 50 \\
\hline Hepatocyte, cytoplasmic alteration & $0 * *$ & 0 & 0 & 0 & $39 * *(1.0)$ \\
\hline Bile duct, hyperplasia & $15(1.1)$ & $14(1.1)$ & $14(1.0)$ & $9(1.0)$ & $9(1.0)$ \\
\hline \multicolumn{6}{|l|}{ Female } \\
\hline Pituitary Gland & 50 & 50 & 50 & 50 & 50 \\
\hline Pars distalis, hypertrophy & $1(1.0)$ & 0 & 0 & $1(1.0)$ & $1(1.0)$ \\
\hline Liver & 50 & 50 & 50 & 50 & 50 \\
\hline Hepatocyte, cytoplasmic alteration & $0^{* *}$ & 0 & 0 & $1(1.0)$ & $40 * *(1.0)$ \\
\hline Bile duct, hyperplasia & $5(1.0)$ & $11(1.1)$ & $6(1.2)$ & $6(1.2)$ & $12 *(1.3)$ \\
\hline
\end{tabular}

Statistical significance for an exposure group indicates a significant pairwise test compared to the vehicle control group. Statistical significance for the vehicle control group indicates a significant trend test.

*Statistically significant $(\mathrm{p} \leq 0.05)$ from the vehicle control group by the Rao-Scott adjusted Poly-3 test; **p $\leq 0.01$.

${ }^{a}$ Number of animals examined microscopically.

${ }^{b}$ Number of animals with lesion.

${ }^{\mathrm{c} A v e r a g e ~ s e v e r i t y ~ g r a d e ~ o f ~ o b s e r v e d ~ l e s i o n ~ i n ~ a f f e c t e d ~ a n i m a l s: ~} 1=$ minimal; $2=$ mild; $3=$ moderate; $4=$ marked. 
A
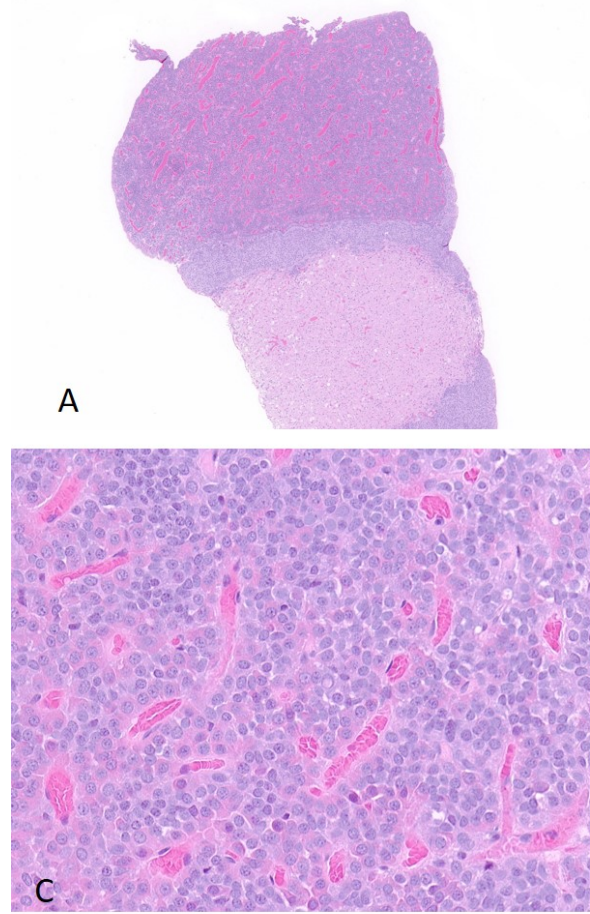
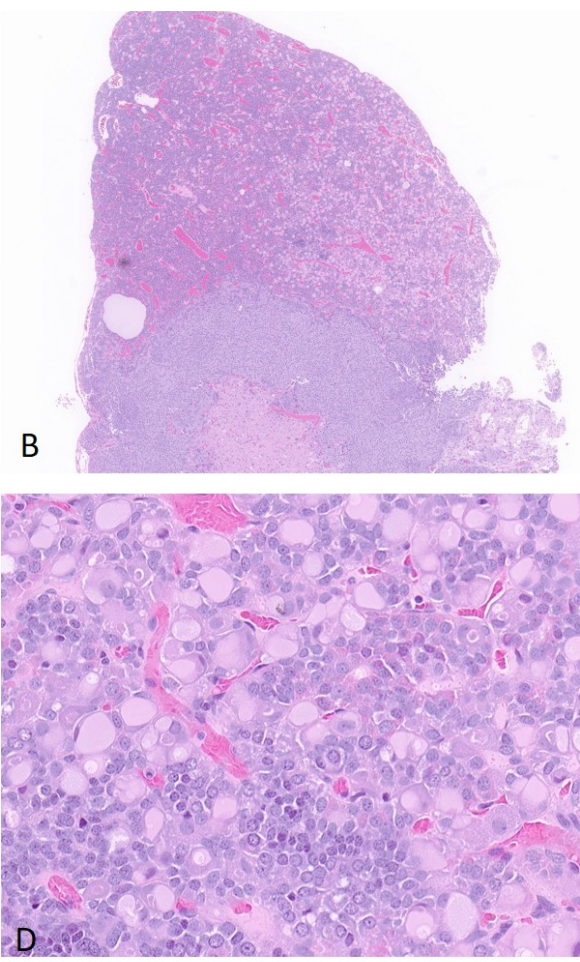

Figure 8. Representative Images of the Pituitary Gland from Male Rats in the Perinatal and Two-year Feed Study of Di-n-butyl Phthalate

A) Pituitary gland from a control male. B) Pituitary gland with hypertrophy of the pars distalis endocrine cells in a male exposed to $10,000 \mathrm{ppm}$ DBP. C) Higher magnification of the pars distalis in panel A. D) Higher magnification of the pars distalis in exposed male seen in panel B. Some of the endocrine cells of the pars distalis are enlarged and have a few to one large vacuole with pale eosinophilic cytoplasm. Original magnification: $A=4 \times, B=4 \times, C=40 \times, D=40 \times$.

Liver: Significantly increased incidences of cytoplasmic alteration of hepatocytes occurred in the 10,000 ppm groups of both males and females. This lesion was not observed in any other groups (except in one 3,000 ppm female), including the control groups (Table 16). In addition, a slight increase in the incidence of bile duct hyperplasia occurred in the 300 and 10,000 ppm groups of female rats but was significant only in the 10,000 ppm group.

The cytoplasmic alteration (Figure 9) was characterized by increased amounts of cytoplasm with fine eosinophilic granules, mainly in the centrilobular regions in the liver. The bile duct hyperplasia was characterized by increased numbers of bile duct profiles in some of the portal tracts accompanied by increased numbers of inflammatory cells (mainly lymphocytes). 

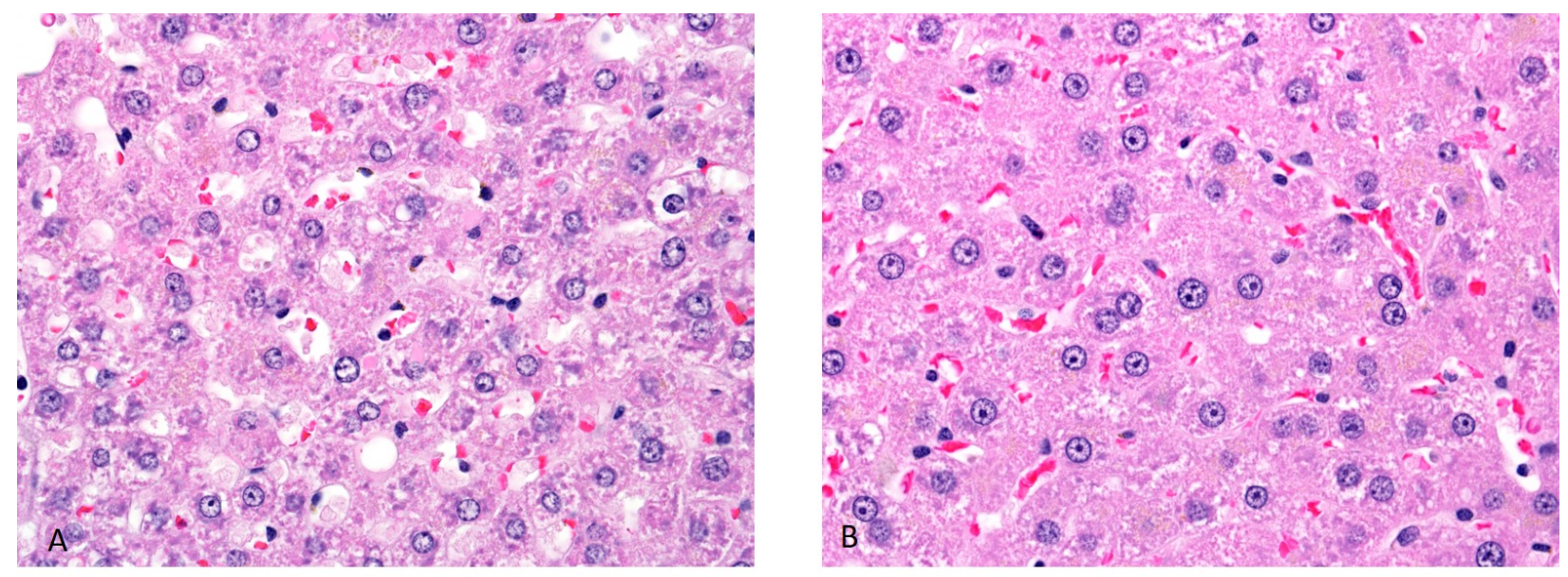

Figure 9. Representative Images of the Liver from Female Rats in the Perinatal and Two-year Feed Study of Di- $n$-butyl Phthalate

A) Normal liver from a control female rat. B) Cytoplasmic alteration in a 10,000 ppm female rat liver. The hepatocytes are enlarged by increased amounts of cytoplasm with fine eosinophilic granules, mainly in the centrilobular regions of the liver. Original magnification: $\mathrm{A}=40 \times, \mathrm{B}=40 \times$.

Uterus: The incidence of stromal polyps in the uterus was higher in the 10,000 ppm group compared to the control group $(5 / 50,6 / 50,5 / 50,5 / 50,10 / 50)$ (Appendix E). The positive trend was significant, but the incidences of these lesions were not significantly increased compared to the control group. Moreover, the incidence of uterine stromal polyps was similar to controls $(16 / 90 ; 18 \%)$ in a previous NTP study (cell-phone radiofrequency radiation) using the same rat stock and expanded microscopic evaluation for the uterus. ${ }^{147}$ Because there is no supportive evidence from the companion mouse study that this is an exposure-related response and because this lesion and exposure to DBP have no known association (as opposed to the pancreatic adenomas), the positive trend was not considered related to DBP exposure.

Other Lesions: Several lesions were observed in the male rats with lower incidences in exposed groups compared to the control group (Appendix E). These included keratoacanthomas of the skin, the combined incidences of epithelial neoplasms in the skin (basal or squamous cell carcinoma, carcinoma, basosquamous tumor [malignant or benign], basal cell adenoma, adenoma, papilloma, squamous papilloma, keratoacanthoma, and trichoepithelioma), adenomas of the pars distalis of the pituitary gland, focal hyperplasia of the adrenal cortex, and hyperplasia of the adrenal medulla. The toxicological relevance of the lower incidences of these nonneoplastic lesions is not clear. 


\section{Mice}

\section{Two-year Study}

Survival of all exposed groups was similar to that of the control group for both males and females (Table 17; Figure 10). There were no exposure-related clinical observations (Appendix E).

Table 17. Summary of Survival of Male and Female Mice in the Two-year Feed Study of Di-n-butyl Phthalate

\begin{tabular}{|c|c|c|c|c|}
\hline & O ppm & $1,000 \mathrm{ppm}$ & $3,000 \mathrm{ppm}$ & $10,000 \mathrm{ppm}$ \\
\hline \multicolumn{5}{|l|}{ Male } \\
\hline Animals Initially in Study & 50 & 50 & 50 & 50 \\
\hline Moribund & 2 & 2 & 3 & 2 \\
\hline Natural Deaths & 4 & 8 & 11 & 5 \\
\hline $\begin{array}{l}\text { Animals Surviving to } \\
\text { Study Termination }\end{array}$ & 44 & $40^{\mathrm{a}}$ & 36 & 43 \\
\hline $\begin{array}{l}\text { Percent Probability of } \\
\text { Survival at End of Study }\end{array}$ & 88.0 & 80.0 & 72.0 & 86.0 \\
\hline Mean Survival (Days) ${ }^{c}$ & 722 & 713 & 698 & 701 \\
\hline Survival Analysis ${ }^{\mathrm{d}}$ & $\mathrm{p}=0.927 \mathrm{~N}$ & $\mathrm{p}=0.386$ & $\mathrm{p}=0.070$ & $\mathrm{p}=0.921$ \\
\hline \multicolumn{5}{|l|}{ Female } \\
\hline Animals Initially in Study & 50 & 50 & 50 & 50 \\
\hline Moribund & 1 & 1 & 0 & 0 \\
\hline Natural Deaths & 7 & 7 & 6 & 3 \\
\hline $\begin{array}{l}\text { Animals Surviving to } \\
\text { Study Termination }\end{array}$ & 42 & 42 & 44 & 47 \\
\hline $\begin{array}{l}\text { Percent Probability of } \\
\text { Survival at End of Study }\end{array}$ & 84.0 & 84.0 & 88.0 & 94.0 \\
\hline Mean Survival (Days) & 713 & 709 & 714 & 722 \\
\hline Survival Analysis & $\mathrm{p}=0.126 \mathrm{~N}$ & $\mathrm{p}=1.000$ & $p=0.775 \mathrm{~N}$ & $\mathrm{p}=0.198 \mathrm{~N}$ \\
\hline
\end{tabular}

ancludes one animal that died naturally during the last week of the study.

${ }^{b}$ Kaplan-Meier determinations.

${ }^{\mathrm{c}}$ Mean of litter means of all deaths (uncensored, censored, and study termination).

${ }^{\mathrm{d}}$ The result of the Tarone trend test is in the vehicle control group column, and the results of the Cox proportional hazards pairwise comparisons with the vehicle control group are in the exposed group columns. A negative trend or lower mortality in an exposure group is indicated by $\mathrm{N}$. 

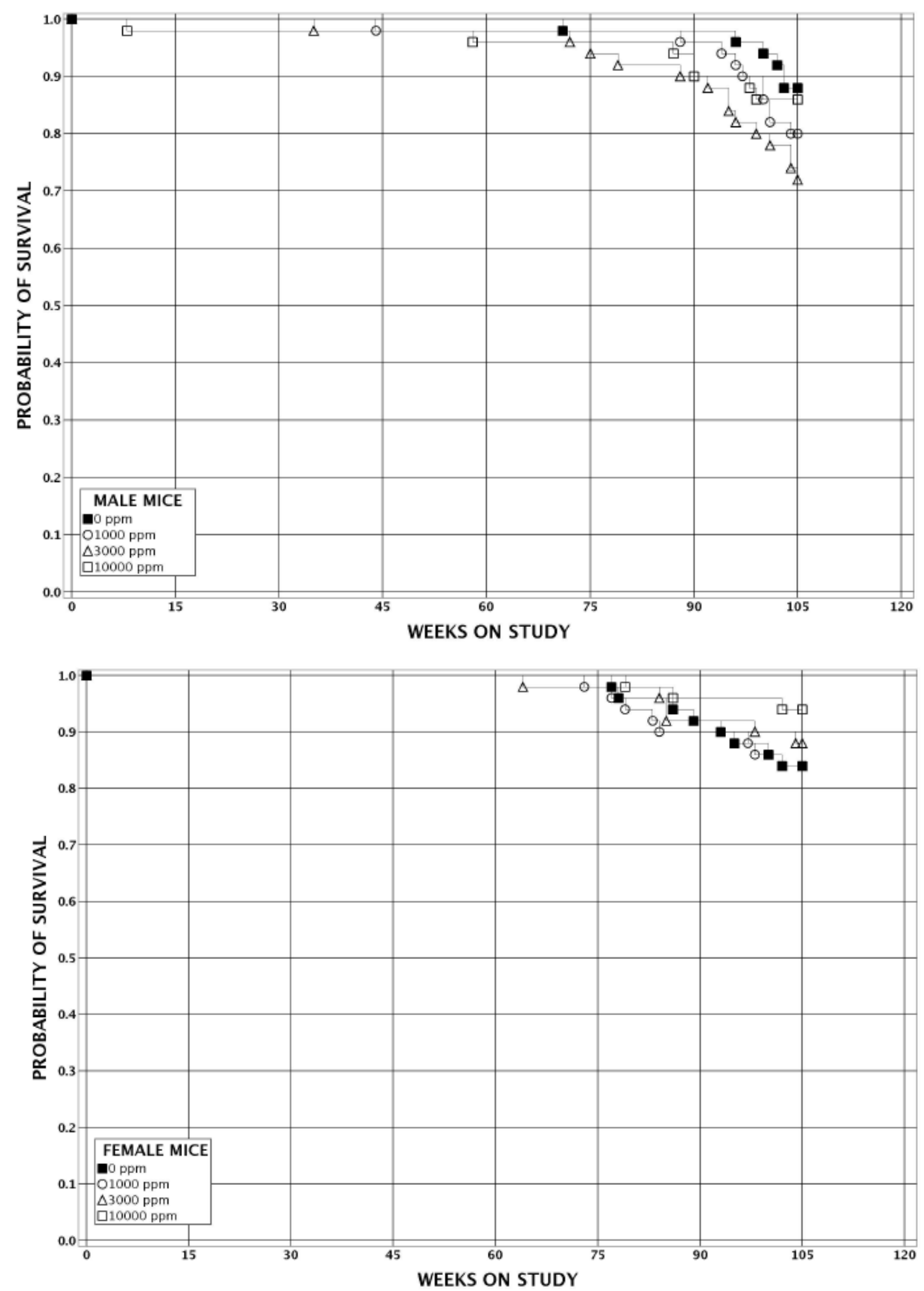

Figure 10. Kaplan-Meier Survival Curves for Mice Exposed to Di-n-butyl Phthalate in Feed for Two Years 
Exposure-related significant decreases of group mean body weights were observed in the highest exposure group $(10,000 \mathrm{ppm})$ throughout the study in both males and females (Table 18,

Table 19; Figure 11). At study termination, group mean body weights for the 10,000 ppm groups were lower than those of the control group by $23.1 \%$ for males and by $34.5 \%$ for females. Group mean feed consumption over the course of the study was similar across exposed and control groups (Table 20, Table 21). Group mean chemical consumption increased proportionally with exposure concentration and was similar among males and females. Daily chemical consumption by the $1,000,3,000$, and 10,000 ppm groups averaged $111.6,346.5$, and $1,306.0 \mathrm{mg} / \mathrm{kg} / \mathrm{day}$, respectively, for males and $105.2,329.4$, and $1,393.3 \mathrm{mg} / \mathrm{kg} / \mathrm{day}$, respectively, for females. 
Table 18. Summary of Survival and Mean Body Weights of Male Mice in the Two-year Feed Study of Di-n-butyl Phthalate

\begin{tabular}{|c|c|c|c|c|c|c|c|c|c|c|c|}
\hline \multirow[b]{2}{*}{$\begin{array}{l}\text { Study } \\
\text { Day }^{\mathrm{a}}\end{array}$} & \multicolumn{2}{|r|}{0 ppm } & \multicolumn{3}{|c|}{ 1,000 ppm } & \multicolumn{3}{|c|}{$3,000 \mathrm{ppm}$} & \multicolumn{2}{|c|}{10,000 ppm } & \multirow[b]{2}{*}{$\begin{array}{c}\text { No. of } \\
\text { Survivors }\end{array}$} \\
\hline & $\begin{array}{l}\text { Av. } \\
\text { Wt. } \\
\text { (g) }\end{array}$ & $\begin{array}{c}\text { No. of } \\
\text { Survivors }\end{array}$ & $\begin{array}{l}\text { Av. } \\
\text { Wt. } \\
\text { (g) }\end{array}$ & $\begin{array}{c}\text { Wt. (\% } \\
\text { of } \\
\text { Controls) }\end{array}$ & $\begin{array}{c}\text { No. of } \\
\text { Survivors }\end{array}$ & $\begin{array}{l}\text { Av. } \\
\text { Wt. } \\
\text { (g) }\end{array}$ & $\begin{array}{l}\text { Wt. (\% of } \\
\text { Controls) }\end{array}$ & No. of Survivors & $\begin{array}{l}\text { Av. } \\
\text { Wt. } \\
\text { (g) }\end{array}$ & $\begin{array}{c}\text { Wt. (\% } \\
\text { of } \\
\text { Controls) }\end{array}$ & \\
\hline 1 & 20.5 & 50 & 20.5 & 100.4 & 50 & 20.4 & 99.9 & 50 & 20.6 & 100.6 & 50 \\
\hline 8 & 21.7 & 50 & 21.8 & 100.4 & 50 & 21.4 & 98.6 & 50 & 20.9 & 96.2 & 50 \\
\hline 15 & 22.3 & 50 & 22.5 & 100.7 & 50 & 22.1 & 98.7 & 50 & 21.2 & 94.7 & 50 \\
\hline 22 & 22.9 & 50 & 23.2 & 101.3 & 50 & 23.0 & 100.2 & 50 & 22.0 & 95.7 & 50 \\
\hline 29 & 23.8 & 50 & 24.1 & 101.5 & 50 & 23.9 & 100.5 & 50 & 22.6 & 95.0 & 50 \\
\hline 36 & 24.8 & 50 & 24.9 & 100.4 & 50 & 24.5 & 98.6 & 50 & 23.0 & 92.7 & 50 \\
\hline 43 & 25.7 & 50 & 25.9 & 100.8 & 50 & 25.4 & 98.7 & 50 & 23.7 & 92.5 & 50 \\
\hline 50 & 26.3 & 50 & 26.6 & 101.2 & 50 & 26.0 & 98.9 & 50 & 24.0 & 91.2 & 50 \\
\hline 57 & 26.7 & 50 & 27.3 & 102.3 & 50 & 26.4 & 99.0 & 50 & 24.4 & 91.3 & 49 \\
\hline 64 & 27.0 & 50 & 28.0 & 103.7 & 50 & 27.0 & 100.0 & 50 & 25.0 & 92.7 & 49 \\
\hline 71 & 27.3 & 50 & 28.4 & 104.0 & 50 & 26.9 & 98.6 & 50 & 25.0 & 91.6 & 49 \\
\hline 78 & 28.5 & 50 & 29.0 & 101.7 & 50 & 28.3 & 99.2 & 50 & 25.7 & 90.3 & 49 \\
\hline 85 & 29.7 & 50 & 30.4 & 102.4 & 50 & 29.3 & 98.8 & 50 & 26.4 & 89.0 & 49 \\
\hline 92 & 30.4 & 50 & 30.9 & 101.7 & 50 & 29.9 & 98.2 & 50 & 26.0 & 85.5 & 49 \\
\hline 120 & 32.3 & 50 & 33.8 & 104.5 & 50 & 31.9 & 98.6 & 50 & 27.9 & 86.4 & 49 \\
\hline 148 & 35.2 & 50 & 37.1 & 105.5 & 50 & 34.7 & 98.6 & 50 & 29.1 & 82.8 & 49 \\
\hline 176 & 38.5 & 50 & 40.1 & 104.3 & 50 & 37.5 & 97.5 & 50 & 30.6 & 79.5 & 49 \\
\hline 204 & 39.4 & 50 & 41.7 & 105.8 & 50 & 38.9 & 98.6 & 50 & 31.9 & 80.8 & 49 \\
\hline 232 & 41.8 & 50 & 43.5 & 104.1 & 50 & 40.8 & 97.6 & 50 & 32.7 & 78.4 & 49 \\
\hline 260 & 43.3 & 50 & 44.6 & 102.9 & 50 & 42.6 & 98.3 & 49 & 33.5 & 77.4 & 49 \\
\hline 288 & 44.3 & 50 & 45.2 & 102.0 & 50 & 43.7 & 98.7 & 49 & 34.5 & 77.9 & 49 \\
\hline 316 & 45.2 & 50 & 46.4 & 102.6 & 49 & 44.1 & 97.5 & 49 & 34.8 & 76.9 & 49 \\
\hline 344 & 46.2 & 50 & 47.2 & 102.2 & 49 & 45.1 & 97.7 & 49 & 35.6 & 77.0 & 49 \\
\hline 372 & 46.3 & 50 & 47.3 & 102.1 & 49 & 45.5 & 98.1 & 49 & 36.2 & 78.0 & 49 \\
\hline 400 & 46.1 & 50 & 47.6 & 103.3 & 49 & 45.5 & 98.8 & 49 & 35.9 & 77.9 & 48 \\
\hline 428 & 46.7 & 50 & 47.7 & 102.1 & 49 & 46.4 & 99.4 & 49 & 36.8 & 78.8 & 48 \\
\hline 456 & 47.6 & 50 & 48.6 & 102.1 & 49 & 46.0 & 96.6 & 49 & 37.5 & 78.7 & 48 \\
\hline 484 & 47.9 & 50 & 49.3 & 103.1 & 49 & 47.2 & 98.7 & 49 & 37.8 & 79.0 & 48 \\
\hline 512 & 48.3 & 49 & 49.7 & 102.9 & 49 & 47.1 & 97.6 & 48 & 37.6 & 77.8 & 48 \\
\hline 540 & 48.8 & 49 & 50.5 & 103.5 & 49 & 47.3 & 96.9 & 47 & 38.2 & 78.4 & 48 \\
\hline 568 & 48.7 & 49 & 49.5 & 101.6 & 49 & 46.9 & 96.3 & 46 & 38.1 & 78.2 & 48 \\
\hline 596 & 48.2 & 49 & 48.9 & 101.5 & 49 & 46.3 & 96.1 & 46 & 37.7 & 78.2 & 48 \\
\hline 624 & 48.9 & 49 & 50.0 & 102.2 & 48 & 47.1 & 96.4 & 45 & 38.1 & 77.9 & 45 \\
\hline 652 & 48.7 & 49 & 48.8 & 100.2 & 47 & 45.6 & 93.6 & 44 & 37.4 & 76.9 & 45 \\
\hline 680 & 47.5 & 48 & 47.9 & 100.8 & 45 & 45.9 & 96.7 & 41 & 37.4 & 78.8 & 44 \\
\hline 708 & 47.3 & 47 & 47.9 & 101.1 & 41 & 45.9 & 97.0 & 39 & 37.0 & 78.1 & 43 \\
\hline EOS & 47.7 & 44 & 47.6 & 99.8 & 39 & 46.9 & 98.4 & 36 & 36.7 & 76.9 & 43 \\
\hline
\end{tabular}

EOS $=$ end of study.

aStudy day 1 is the day animals were placed on study. 
Di- $n$-butyl Phthalate, NTP TR 600

Table 19. Summary of Survival and Mean Body Weights of Female Mice in the Two-year Feed Study of Di-n-butyl Phthalate

\begin{tabular}{|c|c|c|c|c|c|c|c|c|c|c|c|}
\hline \multirow[b]{2}{*}{$\begin{array}{l}\text { Study } \\
\text { Day }^{\mathrm{a}}\end{array}$} & \multicolumn{2}{|c|}{ Control } & \multicolumn{3}{|c|}{1,000 ppm } & \multicolumn{3}{|c|}{$3,000 \mathrm{ppm}$} & \multicolumn{3}{|c|}{10,000 ppm } \\
\hline & $\begin{array}{l}\text { Av. } \\
\text { Wt. } \\
\text { (g) }\end{array}$ & $\begin{array}{c}\text { No. of } \\
\text { Survivors }\end{array}$ & $\begin{array}{l}\text { Av. } \\
\text { Wt. } \\
\text { (g) }\end{array}$ & $\begin{array}{l}\text { Wt. (\% of } \\
\text { Controls) }\end{array}$ & $\begin{array}{c}\text { No. of } \\
\text { Survivors }\end{array}$ & $\begin{array}{l}\text { Av. } \\
\text { Wt. } \\
\text { (g) }\end{array}$ & $\begin{array}{l}\text { Wt. (\% of } \\
\text { Controls) }\end{array}$ & $\begin{array}{c}\text { No. of } \\
\text { Survivors }\end{array}$ & $\begin{array}{l}\text { Av. } \\
\text { Wt. } \\
\text { (g) }\end{array}$ & $\begin{array}{l}\text { Wt. (\% of } \\
\text { Controls) }\end{array}$ & $\begin{array}{c}\text { No. of } \\
\text { Survivors }\end{array}$ \\
\hline 1 & 16.5 & 50 & 16.7 & 101.1 & 50 & 16.8 & 101.6 & 50 & 16.6 & 100.1 & 50 \\
\hline 8 & 17.5 & 50 & 17.5 & 100.4 & 50 & 17.4 & 99.4 & 50 & 16.7 & 95.8 & 50 \\
\hline 15 & 18.4 & 50 & 18.5 & 100.4 & 50 & 18.4 & 99.6 & 50 & 17.3 & 94.1 & 50 \\
\hline 22 & 19.4 & 50 & 19.3 & 99.4 & 50 & 19.4 & 99.8 & 50 & 17.6 & 90.6 & 50 \\
\hline 29 & 20.1 & 50 & 20.3 & 101.1 & 50 & 20.1 & 99.7 & 50 & 18.3 & 90.7 & 50 \\
\hline 36 & 21.1 & 50 & 21.1 & 100.1 & 50 & 20.8 & 98.7 & 50 & 18.8 & 89.2 & 50 \\
\hline 43 & 21.2 & 50 & 21.2 & 99.7 & 50 & 21.3 & 100.2 & 50 & 19.2 & 90.3 & 50 \\
\hline 50 & 22.0 & 50 & 21.8 & 99.5 & 50 & 21.7 & 99.0 & 50 & 19.3 & 87.8 & 50 \\
\hline 57 & 22.2 & 50 & 22.3 & 100.6 & 50 & 21.8 & 98.1 & 50 & 19.6 & 88.2 & 50 \\
\hline 64 & 23.5 & 50 & 23.1 & 98.5 & 50 & 22.9 & 97.4 & 50 & 20.3 & 86.6 & 50 \\
\hline 71 & 23.8 & 50 & 23.8 & 99.8 & 50 & 23.1 & 96.9 & 50 & 20.8 & 87.5 & 50 \\
\hline 78 & 24.5 & 50 & 24.4 & 99.4 & 50 & 23.7 & 96.7 & 50 & 21.4 & 87.4 & 50 \\
\hline 85 & 24.4 & 50 & 24.7 & 101.3 & 50 & 24.3 & 99.6 & 50 & 21.3 & 87.4 & 50 \\
\hline 92 & 25.2 & 50 & 25.0 & 99.5 & 50 & 24.7 & 98.1 & 50 & 21.9 & 86.9 & 50 \\
\hline 120 & 27.5 & 50 & 27.2 & 98.7 & 50 & 26.4 & 95.7 & 50 & 22.9 & 83.0 & 50 \\
\hline 148 & 29.5 & 50 & 30.0 & 101.4 & 50 & 28.7 & 97.1 & 50 & 23.5 & 79.5 & 50 \\
\hline 176 & 32.6 & 50 & 33.4 & 102.5 & 50 & 31.7 & 97.3 & 50 & 24.4 & 74.7 & 50 \\
\hline 204 & 34.0 & 50 & 34.7 & 102.0 & 50 & 33.3 & 97.9 & 50 & 25.1 & 73.8 & 50 \\
\hline 232 & 36.2 & 50 & 37.2 & 102.9 & 50 & 35.1 & 97.1 & 50 & 26.2 & 72.3 & 50 \\
\hline 260 & 38.6 & 50 & 38.7 & 100.5 & 50 & 35.7 & 92.6 & 50 & 26.9 & 69.7 & 50 \\
\hline 288 & 39.4 & 50 & 40.3 & 102.2 & 50 & 37.8 & 95.8 & 50 & 27.6 & 70.1 & 50 \\
\hline 316 & 41.7 & 50 & 42.2 & 101.1 & 50 & 39.8 & 95.4 & 50 & 28.3 & 67.8 & 50 \\
\hline 344 & 42.7 & 50 & 43.3 & 101.5 & 50 & 41.2 & 96.6 & 50 & 28.8 & 67.6 & 50 \\
\hline 372 & 44.6 & 50 & 45.6 & 102.4 & 50 & 43.2 & 96.9 & 50 & 30.5 & 68.4 & 50 \\
\hline 400 & 45.5 & 50 & 46.3 & 101.7 & 50 & 44.1 & 96.8 & 50 & 30.3 & 66.7 & 50 \\
\hline 428 & 46.5 & 50 & 47.5 & 102.3 & 50 & 44.8 & 96.5 & 50 & 31.1 & 67.0 & 50 \\
\hline 456 & 48.2 & 50 & 49.5 & 102.7 & 50 & 46.1 & 95.7 & 49 & 31.9 & 66.2 & 50 \\
\hline 484 & 48.1 & 50 & 51.0 & 105.9 & 50 & 46.7 & 97.0 & 49 & 32.7 & 67.9 & 50 \\
\hline 512 & 50.4 & 50 & 52.1 & 103.4 & 49 & 48.0 & 95.3 & 49 & 32.1 & 63.8 & 50 \\
\hline 540 & 50.9 & 49 & 51.6 & 101.4 & 48 & 48.1 & 94.5 & 49 & 31.9 & 62.6 & 50 \\
\hline 568 & 49.6 & 48 & 50.9 & 102.6 & 47 & 44.3 & 89.3 & 49 & 31.6 & 63.8 & 49 \\
\hline 596 & 49.3 & 48 & 52.0 & 105.5 & 45 & 45.3 & 91.8 & 46 & 32.4 & 65.7 & 49 \\
\hline 624 & 51.0 & 46 & 52.8 & 103.6 & 45 & 48.1 & 94.2 & 46 & 32.6 & 63.9 & 48 \\
\hline 652 & 51.5 & 45 & 53.4 & 103.6 & 45 & 48.7 & 94.6 & 46 & 33.8 & 65.7 & 48 \\
\hline 680 & 51.4 & 44 & 51.1 & 99.5 & 44 & 47.9 & 93.2 & 46 & 33.4 & 64.9 & 48 \\
\hline 708 & 51.4 & 43 & 50.9 & 98.9 & 43 & 48.2 & 93.7 & 45 & 33.7 & 65.5 & 47 \\
\hline EOS & 51.7 & 42 & $\mathbf{5 0 . 7}$ & 98.0 & 42 & 48.6 & 94.0 & 44 & 33.9 & 65.5 & 47 \\
\hline
\end{tabular}

EOS = end of study.

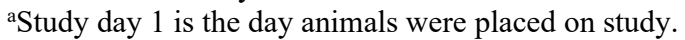



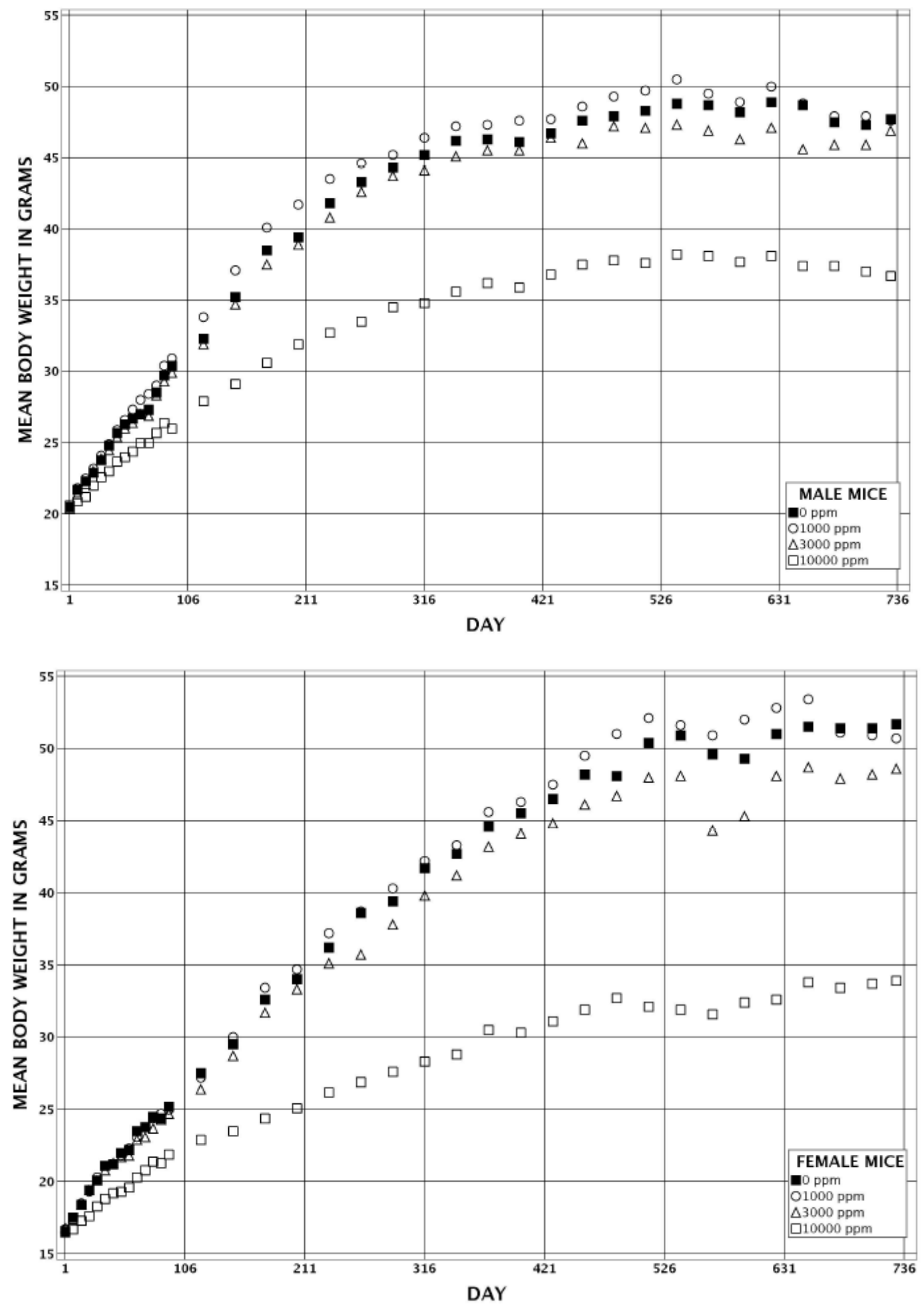

Figure 11. Growth Curves for Mice Exposed to Di-n-butyl Phthalate in Feed for Two Years 
Table 20. Summary of Feed and Di-n-butyl Phthalate Consumption of Male Mice in the Two-year Feed Study

\begin{tabular}{cccccccc}
\hline \multirow{2}{*}{ Week } & $\mathbf{0 ~ p p m}$ & \multicolumn{2}{c}{$\mathbf{1 , 0 0 0} \mathbf{~ p p m}$} & \multicolumn{2}{c}{$\mathbf{3 , 0 0 0} \mathbf{~ p p m}$} & \multicolumn{2}{c}{$\mathbf{1 0 , 0 0 0} \mathbf{~ p p m}$} \\
\cline { 2 - 8 } & $\begin{array}{c}\text { Feed } \\
(\mathbf{g} / \mathbf{d a y})^{\mathbf{a}}\end{array}$ & $\begin{array}{c}\text { Feed } \\
(\mathbf{g} / \mathbf{d a y})\end{array}$ & $\begin{array}{c}\text { Dose } \\
(\mathbf{m g} / \mathbf{k g} / \mathbf{d a y})^{\mathbf{b}}\end{array}$ & $\begin{array}{c}\text { Feed } \\
(\mathbf{g} / \mathbf{d a y})\end{array}$ & $\begin{array}{c}\text { Dose } \\
(\mathbf{m g} / \mathbf{k g} / \mathbf{d a y})\end{array}$ & $\begin{array}{c}\text { Feed } \\
(\mathbf{g} / \mathbf{d a y})\end{array}$ & $\begin{array}{c}\text { Dose } \\
(\mathbf{m g} / \mathbf{k g} / \mathbf{d a y})\end{array}$ \\
\hline 2 & 3.6 & 3.5 & 160.7 & 3.7 & 518.9 & 3.9 & $1,869.2$ \\
13 & 4.3 & 4.4 & 144.8 & 4.3 & 440.0 & 4.3 & $1,629.2$ \\
54 & 4.5 & 4.4 & 93.0 & 4.3 & 283.8 & 4.1 & $1,134.1$ \\
102 & 4.9 & 5.1 & 106.5 & 4.7 & 307.2 & 4.4 & $1,189.9$ \\
\hline
\end{tabular}

${ }^{\mathrm{a}}$ Grams of feed consumed per animal per day.

${ }^{b}$ Milligrams of di- $n$-butyl phthalate consumed per kilogram body weight per day.

Table 21. Summary of Feed and Di-n-butyl Phthalate Consumption of Female Mice in the Two-year Feed Study

\begin{tabular}{cccccccc}
\hline \multirow{2}{*}{ Week } & $\mathbf{0 ~ p p m}$ & \multicolumn{2}{c}{$\mathbf{1 , 0 0 0} \mathbf{~ p p m}$} & \multicolumn{2}{c}{$\mathbf{3 , 0 0 0} \mathbf{~ p p m}$} & \multicolumn{2}{c}{$\mathbf{1 0 , 0 0 0} \mathbf{~ p p m}$} \\
\cline { 2 - 8 } & $\begin{array}{c}\text { Feed } \\
(\mathbf{g} / \mathbf{d a y})^{\mathbf{a}}\end{array}$ & $\begin{array}{c}\text { Feed } \\
(\mathbf{g} / \mathbf{d a y})\end{array}$ & $\begin{array}{c}\text { Dose } \\
(\mathbf{m g} / \mathbf{k g} / \mathbf{d a y})^{\mathbf{b}}\end{array}$ & $\begin{array}{c}\text { Feed } \\
(\mathbf{g} / \mathbf{d a y})\end{array}$ & $\begin{array}{c}\text { Dose } \\
(\mathbf{m g} / \mathbf{k g} / \mathbf{d a y})\end{array}$ & $\begin{array}{c}\text { Feed } \\
(\mathbf{g} / \mathbf{d a y})\end{array}$ & $\begin{array}{c}\text { Dose } \\
(\mathbf{m g} / \mathbf{k g} / \mathbf{d a y})\end{array}$ \\
\hline 1 & 3.1 & 3.2 & 191.3 & 3.4 & 606.6 & 4.4 & $2,656.7$ \\
13 & 3.4 & 3.5 & 141.8 & 3.6 & 445.1 & 3.5 & $1,643.8$ \\
54 & 4.2 & 4.2 & 92.1 & 3.9 & 271.1 & 3.9 & $1,278.8$ \\
102 & 4.7 & 4.7 & 92.4 & 4.8 & 298.9 & 4.6 & $1,366.4$ \\
\hline
\end{tabular}

${ }^{\mathrm{a}}$ Grams of feed consumed per animal per day.

${ }^{b}$ Milligrams of di- $n$-butyl phthalate consumed per kilogram body weight per day.

\section{Pathology}

This section describes statistically significant or biologically noteworthy changes in the incidences of nonneoplastic lesions in the testis, epididymis, coagulating gland, seminal vesicle, liver, and kidney of mice. Summaries of the incidences of neoplasms and nonneoplastic lesions, individual animal tumor diagnoses, statistical analysis of primary neoplasms that occurred with an incidence of at least 5\% in at least one animal group, and historical incidences for the biologically significant neoplasms mentioned in this section are presented as supplemental data in Appendix E. No neoplasms or gross pathology lesions in male or female mice were considered to be related to DBP exposure.

Testis: In the testis, the incidences of the combination of unilateral and bilateral degeneration of the germinal epithelium were higher in all exposed groups compared to the control group, but the increases were significant only in the 1,000 and 10,000 ppm groups (Table 22). The incidence of bilateral (only) germinal epithelial degeneration was also higher in all exposed groups compared to the control group but was statistically significant only in the 10,000 ppm group (Appendix E).

Microscopically, degeneration of the germinal epithelium (Figure 12) consisted variably of scattered loss of germ cells (round and/or elongating spermatids), seminiferous tubules with vacuoles (variable in size and number), degenerating germ cells with eosinophilic cytoplasm, disorganization of germinal epithelium, occasional sloughing of germ cells, and occasional multinucleated germ cells. 
Table 22. Incidences of Nonneoplastic Lesions of the Testis, Epididymis, Coagulating Gland, and Seminal Vesicle in Male Mice in the Two-year Feed Study of Di-n-butyl Phthalate

\begin{tabular}{|c|c|c|c|c|}
\hline & 0 ppm & 1,000 ppm & 3,000 ppm & 10,000 ppm \\
\hline Testis $^{\mathrm{a}}$ & 50 & 50 & 50 & 50 \\
\hline $\begin{array}{l}\text { Germinal epithelium, degeneration } \\
\text { (includes bilateral) }^{\mathrm{b}}\end{array}$ & $6(2.2)^{\mathrm{c}}$ & $15^{*}(1.8)$ & $9(2.0)$ & $15 *(2.2)$ \\
\hline Epididymis & 50 & 50 & 50 & 50 \\
\hline $\begin{array}{l}\text { Duct, exfoliated germ cell (includes } \\
\text { bilateral) }\end{array}$ & $6^{*}(1.3)$ & $10(1.3)$ & $5(2.0)$ & $13 *(1.6)$ \\
\hline Hypospermia (includes bilateral) & $1(3.0)$ & $4(3.5)$ & $3(3.3)$ & $3(3.0)$ \\
\hline Duct, atrophy, bilateral $^{\mathrm{d}}$ & 0 & $1(3.0)$ & $3(3.0)$ & $1(3.0)$ \\
\hline Coagulating Gland $^{\mathrm{e}}$ & 0 & 1 & 4 & 1 \\
\hline Atrophy, bilateral ${ }^{\mathrm{d}}$ & 0 & $1(3.0)$ & $3(3.0)$ & $1(3.0)$ \\
\hline Seminal Vesicle & 50 & 50 & 50 & 50 \\
\hline Atrophy, bilateral ${ }^{\mathrm{d}}$ & $1(3.0)$ & $1(3.0)$ & $3(3.0)$ & $1(3.0)$ \\
\hline
\end{tabular}

Statistical significance for an exposure group indicates a significant pairwise test compared to the vehicle control group.

Statistical significance for the vehicle control group indicates a significant trend test.

* Statistically significant at $\mathrm{p} \leq 0.05$ by the Poly- 3 test.

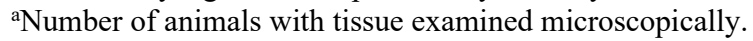

${ }^{b}$ Incidence reported is the combination of unilateral and bilateral lesions. Severity grade for these types of lesions $=$ sum of unilateral and bilateral severity scores/number of unilateral and bilateral incidences.

${ }^{\mathrm{c}}$ Average severity grade of observed lesion in affected animals: $1=$ minimal; $2=$ mild; $3=$ moderate; $4=$ marked.

${ }^{\mathrm{d}}$ This lesion was observed only as a bilateral lesion.

${ }^{e}$ Only tissues from animals with gross lesions of the indicated organ were collected at necropsy for histopathological evaluation.
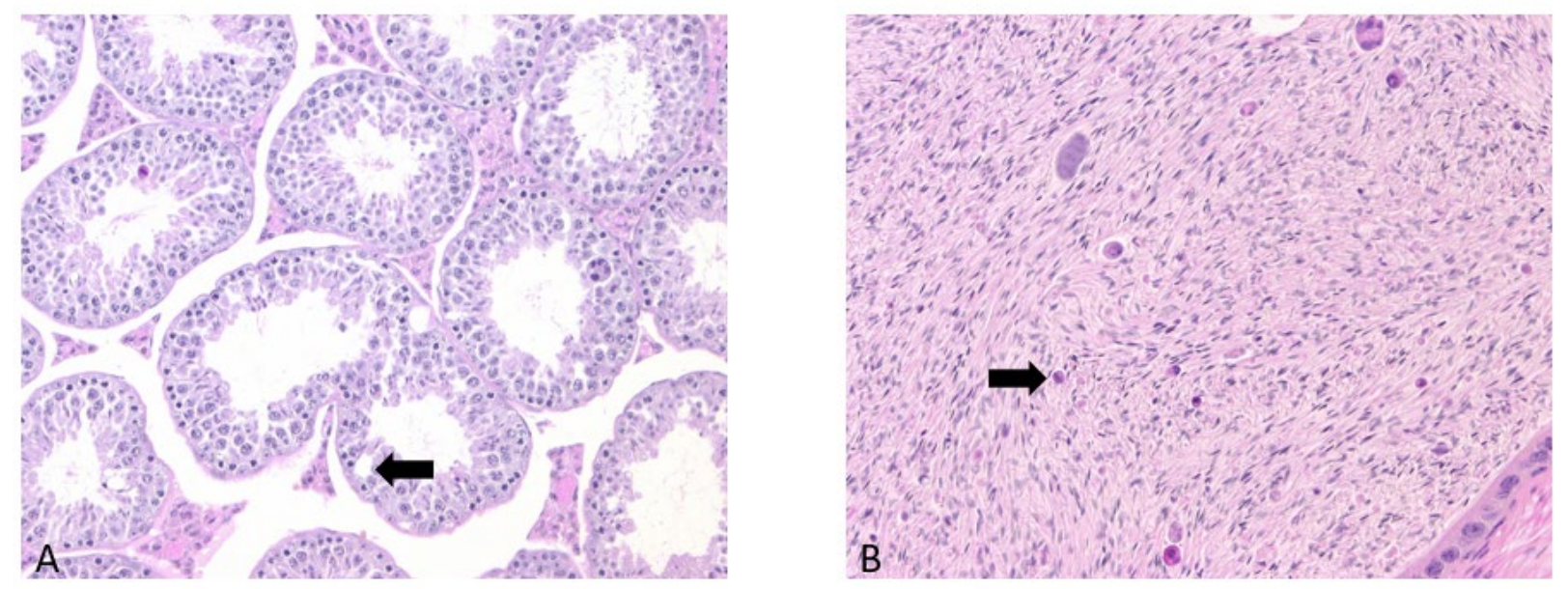

Figure 12. Representative Images Depicting Degeneration of the Germinal Epithelium of the Testis in a Male Mouse in the Two-year Feed Study of Di-n-butyl Phthalate

A) Degeneration of the germinal epithelium of the testis from a 10,000 ppm male mouse. The germinal epithelium is vacuolated (arrow). B) Exfoliated germ cells in the epididymal duct lumen from the same mouse in panel A. Exfoliated germ cells (arrow) and debris are present among the spermatozoa. Original magnification: $A=10 \times, B=20 \times$.

Epididymis: In the epididymal duct, the combined incidence of unilateral and bilateral exfoliated germ cells was higher in the 1,000 and $10,000 \mathrm{ppm}$ groups compared to the control group, but 
the incidence was statistically significant only in the 10,000 ppm group (Table 22). The incidence of bilateral (only) exfoliated germ cells was higher in all exposed groups compared to the control group, but none of the increases were statistically significant (Appendix E). The incidences of hypospermia and duct atrophy in the epididymis were also higher in all exposed groups compared to the control group (Table 22). Although these changes were small and not statistically significant and although severity did not increase with increasing exposure concentration, they were considered to be related to DBP exposure.

The microscopic lesion of exfoliated germ cells in the epididymis (Figure 12) was characterized by the presence of degenerating germ cells and cell debris in the epididymal lumen. Exfoliated germ cells were diagnosed when numbers were increased relative to the low concentration occurring in the control animals. When germinal epithelial damage to the testes occurs, it is often accompanied by the presence of exfoliated germ cells in the epididymides. In most mice diagnosed with testicular germinal epithelium degeneration, corroborating lesions of increased exfoliating germ cells and/or low incidences of hypospermia in the epididymis that reinforced a testicular effect were seen. Hypospermia was characterized microscopically by reduced sperm content throughout the epididymis and often was accompanied by reduced size of the duct lumen and exfoliated germ cells. Hypospermia coincided with diagnoses of germinal epithelium degeneration in the testis in all cases. In fewer cases, hypospermia also was diagnosed with seminal vesicle and/or coagulating gland atrophy or epididymal duct atrophy. Epididymis duct atrophy appeared as a diffuse collapse of the duct lumen, generally empty duct profiles, decreased epithelial height, and increased and prominent mesenchymal stroma. The animals with epididymal atrophy also had concomitant testicular degeneration and interstitial cell atrophy, hypospermia, and seminal vesicle and coagulating gland atrophy.

Accessory Sex Organs: The incidence of bilateral atrophy of the coagulating gland was slightly higher in the exposed groups compared to the control group, and the incidence of bilateral atrophy of the seminal vesicle was slightly higher in the 3,000 ppm group compared to the control group (Table 22). Although these changes were small and not statistically significant and although severity did not increase with increasing exposure concentration, they were considered to be related to DBP exposure.

Microscopically, atrophy of the seminal vesicle or coagulating gland was characterized by reduced lumina and crowding of intravesicular epithelial folds, reduced or absent luminal secretory material, and increased stroma. The atrophy was considered of moderate severity for both tissues and was always bilateral. These lesions are commonly seen with chronic androgen depletion. $^{148}$

Liver: Cytoplasmic alteration of hepatocytes was observed only in the $10,000 \mathrm{ppm}$ males and females, and the incidences of these lesions were significantly increased compared to the control groups (Table 23). In all cases, the severity of this lesion was considered minimal. The cytoplasmic alteration was characterized by increased amounts of cytoplasm with fine eosinophilic granules, mainly in the centrilobular regions of the liver. In the male mice, the incidences of multinucleated hepatocytes (Figure 13) were significantly increased in all exposed groups compared to the control group (Table 23). Only the incidences in the 3,000 and $10,000 \mathrm{ppm}$ groups were statistically significant. Multinucleated hepatocytes with up to three or, rarely, four nuclei can be seen as a background lesion in mice, but the multinucleated hepatocytes considered related to DBP exposure were much larger and contained up to 20 nuclei. 


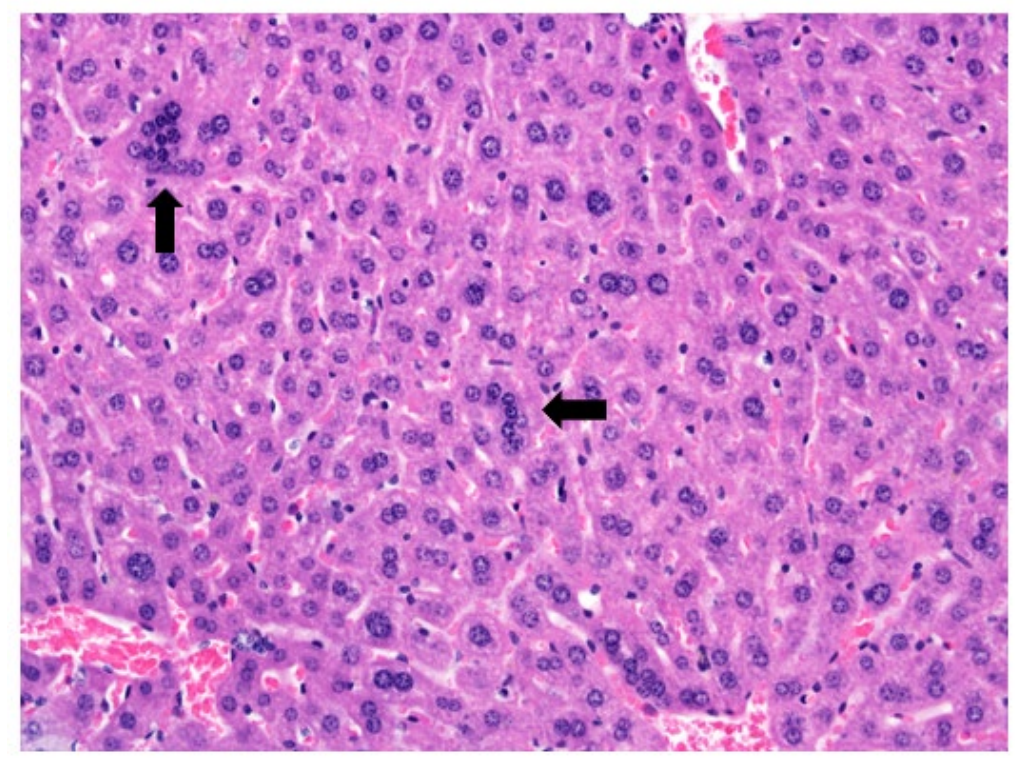

Figure 13. Representative Image Depicting Multinucleated Hepatocytes in the Liver of a Male Mouse in the Two-year Feed Study of Di-n-butyl Phthalate

Multinucleated hepatocytes in the liver from a 10,000 ppm male mouse (arrows). Original magnification: $20 \times$.

Table 23. Incidences of Nonneoplastic Lesions of the Liver and Kidney in Male and Female Mice in the Two-year Feed Study of Di-n-butyl Phthalate

\begin{tabular}{lcccc}
\hline & $\mathbf{0 ~ p p m}$ & $\mathbf{1 , 0 0 0} \mathbf{~ p p m}$ & $\mathbf{3 , 0 0 0} \mathbf{~ p m}$ & $\mathbf{1 0 , 0 0 0} \mathbf{~ p p m}$ \\
\hline Male & 50 & 50 & 50 & 50 \\
Liver $^{\mathrm{a}}$ & $0^{* *}$ & 0 & 0 & $36^{* *}(1.0)^{\mathrm{c}}$ \\
$\quad$ Hepatocyte, cytoplasmic alteration $^{\mathrm{b}}$ & $8^{* *}(1.0)$ & $11(1.0)$ & $25^{* *}(1.0)$ & $42^{* *}(1.0)$ \\
$\quad$ Hepatocyte, multinucleated & 50 & 50 & 49 & 49 \\
\hline Female & $0^{* *}$ & 0 & 0 & $48^{* *}(1.0)$ \\
Liver & 50 & 50 & 49 & 49 \\
$\quad$ Hepatocyte, cytoplasmic alteration & $0^{* *}$ & 0 & 0 & $47^{* *}(1.0)$ \\
Kidney & & & & \\
$\quad$ Renal tubule, hyperplasia &
\end{tabular}

Statistical significance for an exposure group indicates a significant pairwise test compared to the vehicle control group. Statistical significance for the vehicle control group indicates a significant trend test.

** Statistically significant at $\mathrm{p} \leq 0.01$ by the Poly-3 test.

${ }^{a}$ Number of animals with tissue examined microscopically.

${ }^{b}$ Number of animals with lesion.

${ }^{\mathrm{c}}$ Average severity grade of observed lesion in affected animals: $1=$ minimal; $2=$ mild; $3=$ moderate; $4=$ marked .

Kidney: In the female mice, hyperplasia of the renal tubule epithelium was observed, and the incidences were significantly increased in the $10,000 \mathrm{ppm}$ group; this lesion was not seen in any other group, including the control group (Table 23 ). In all cases, the severity was considered minimal. This lesion is unique and is distinct from the tubular epithelial hyperplasia found in association with chronic progressive nephropathy. It is characterized by segmental hyperplasia of the epithelium in tubules at the corticomedullary junction (Figure 14). Affected renal tubules 
often were dilated and lined by tightly crowded epithelial cells. The cells also were slightly enlarged with increased height and cytoplasmic volume. Some cells also had slightly enlarged nuclei, and some were multinucleated.

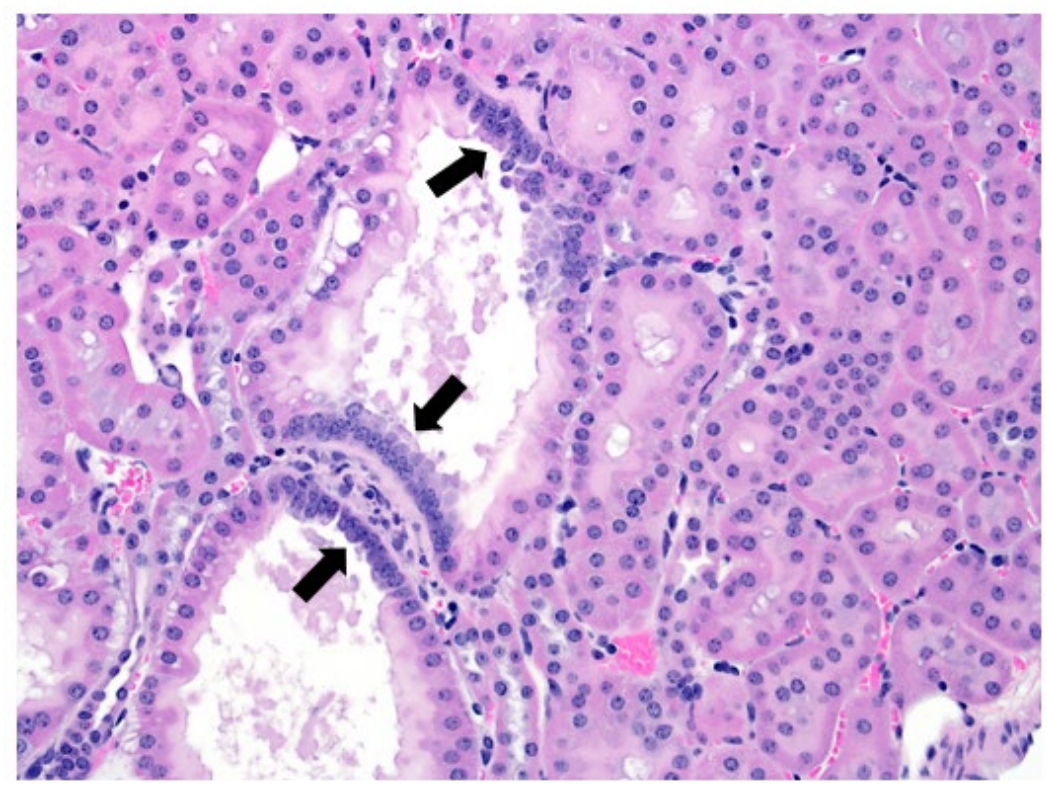

Figure 14. Representative Image Depicting Renal Tubule Hyperplasia in the Kidney in a Female Mouse in the Two-year Feed Study of Di-n-butyl Phthalate

Renal tubule hyperplasia in the kidney of a 10,000 ppm female mouse. There are crowded, basophilic epithelial cells lining portions of the dilated renal tubules (arrows). Original magnification: $20 \times$. 


\section{Discussion}

The use of di- $n$-butyl phthalate (DBP) in the manufacture of various consumer products has resulted in widespread exposure, as evidenced by its detection in human urine, plasma, and umbilical cord blood. DBP and other phthalates have well-documented effects on the male reproductive system, particularly with perinatal exposure. ${ }^{149}$ Data to evaluate DBP as a human carcinogen, however, are inadequate. To address this knowledge gap, the National Toxicology Program (NTP) conducted a 2-year bioassay in mice and rats. Given the widespread exposure and known effects of phthalates on male reproduction, perinatal exposure was included in the rat study. To emulate the primary route of exposure in humans, animals were exposed to DBP via feed.

Chemical consumption of DBP was calculated on the basis of feed consumption measurements. Few differences were found in feed consumption between control and exposed groups in rats and mice. Chemical consumption between sexes was similar in both species and increased with increasing exposure concentration in a generally proportional manner. Mice were exposed to twice as much DBP as rats fed the same concentration in feed due to differences in feed consumption.

Even though chemical consumption was linearly related to the exposure concentrations, mono- $n$-butyl phthalate (MBP) concentrations measured in biological matrices in rats did not increase linearly or in proportion to exposure concentration. For example, MBP concentrations in dam plasma on gestation day (GD) 18 in the 3,000 ppm group were 17-fold higher than concentrations in the $300 \mathrm{ppm}$ group; in the 10,000 ppm group, dam plasma MBP was 36 -fold higher than that in the 1,000 ppm group. Because DBP is primarily converted to MBP through first-pass metabolism, the nonproportional increase in MBP concentrations suggests a saturation of phase 2 metabolism and clearance processes at higher exposure concentrations (i.e., less MBP-glucuronide formed) and/or an induction of absorption process transporters. In this study, only unconjugated forms of MBP were assessed. Measuring both unconjugated and conjugated forms of MBP would help to inform the relationship between internal and external dose.

Although no DBP was administered via feed to control animals, MBP was detected in the plasma of some control rats. Because phthalates are ubiquitous in food packaging and many plastics, the presence of MBP in control animals could be due to exposure to background levels of DBP in the feed (although all measurements of DBP in the control diet were below the limit of quantitation). Another possibility is contamination during sample collection or analysis. The concentrations of MBP in control animals, however, were very low $(<1 \%$ of that in the lowest exposure group) compared to those in exposed animals and are likely not a confounder in the study.

The exposure concentration of DBP and the internal concentration of MBP in rats in this study were much higher than those observed in humans. Given that estimated human intake of DBP is $0-7 \mu \mathrm{g} / \mathrm{kg}$ body weight/day $(\mu \mathrm{g} / \mathrm{kg} / \mathrm{day})^{22}$ and that gestational and lactational DBP consumption in this study ranged from 19 to $66 \mathrm{mg} / \mathrm{kg} /$ day in the lowest exposure group (300 ppm), the exposure multiple comparing rats to humans is at least 3,000. Similarly, concentrations of MBP measured in the rat plasma were much higher than concentrations observed in human plasma. The GD 18 maternal plasma concentration in rats at the lowest exposure concentration was 
263-fold higher than plasma concentrations observed in pregnant Czech women. ${ }^{17}$ Gestational transfer of DBP and/or MBP was observed in this study, consistent with previous studies on gestational transfer in rodents. ${ }^{41 ; 43}$ Lactational transfer also was observed, although less was transferred during lactation than during gestation.

Transfer during gestation and lactation is suggested in humans, as MBP has been detected in human amniotic fluid and breast milk. ${ }^{18-21 ; 150} \mathrm{In}$ samples taken from 54 women during routine amniocentesis, the median MBP concentration in amniotic fluid was $5.8 \mathrm{ng} / \mathrm{mL}$ with a highest measured value of $263.9 \mathrm{ng} / \mathrm{mL} .{ }^{18}$ In another study, amniotic fluid samples from 100 women in Crete, Greece, contained, on average, $12 \mathrm{ng} / \mathrm{mL}$ MBP with a maximum of $24.5 \mathrm{ng} / \mathrm{mL} .{ }^{150}$ Exposure in this group of women was estimated to be $0.9 \mu \mathrm{g} \mathrm{DBP} / \mathrm{kg} / \mathrm{day}$ based on questionnaires and on measured urinary metabolite concentrations. Therefore, despite the much higher intake of DBP in rats, the exposure of the rodent fetus to MBP via amniotic fluid from dams in the lowest exposure group $(84.5 \mathrm{ng} / \mathrm{mL})$ is within an order of magnitude of the concentrations to which some human fetuses could be exposed.

In the rats, exposure to DBP during gestation had minimal effects on dam mean body weight, dam survival, and littering parameters. During lactation, there were minor decreases in dam mean body weight, mean body weight gain, and feed consumption in the 10,000 ppm group. The lower feed consumption in the later days of lactation could be due to less feed consumption by the pups. Chemical consumption by the pups might have contributed to the lower pup mean body weight at postnatal day (PND) 14 and PND 21 in the 10,000 ppm group, given the higher chemical-to-body-weight concentration in young animals. Findings here are similar to those from perinatal subchronic studies previously reported in NTP Toxicity Report 30 in which $\mathrm{F}_{0}$ fertility and gestation length of rats and mice were not affected by exposure at concentrations up to $10,000 \mathrm{ppm}$, but pup number, dam mean body weight, and pup mean body weight were significantly decreased in the 10,000 ppm group compared to the control group. ${ }^{51}$ These effects were observed in lower exposure groups $(1,000$ and 5,000 ppm) in the NTP reproductive and continuous breeding studies, particularly in later litters and in the $\mathrm{F}_{1}$ generation, suggesting a compounding effect of long-term DBP exposure on reproductive capacity. ${ }^{81}$

During the 2-year study phase, there were no decreases in survival related to DBP exposure. The only differences in mean body weight were observed in the highest dietary exposure groups $(10,000 \mathrm{ppm})$ in rats and mice. In both species, mean body weights of animals in the highest exposure groups were affected, with exposed females having marginally larger deficits in mean body weight than males compared to the respective control groups. Furthermore, female mice had the largest discrepancy in mean body weight compared to the control group. Two other studies have evaluated the chronic effects of DBP exposure ( $\geq 1$ year) in adult male rats ${ }^{33}$ and in male rats exposed only in utero. ${ }^{65}$ In both studies, no clear dose-dependent changes in mortality were found. In Smith et al. ${ }^{33}$ in which adult rats were administered DBP for 1 year, no differences in body weight due to DBP were reported. In Barlow et al., ${ }^{65}$ body weight was not reported. Studies in female animals are not available for comparison. Findings from this study suggest that female mice could be more susceptible to DBP effects on body weight than male mice.

DBP exposure might have resulted in an increase in the incidence of pancreatic acinus adenomas in male rats, as a statistically significant positive trend was found. Although the incidence in the $10,000 \mathrm{ppm}$ group was within the historical control range and there was no concurrent increase 
in the incidence of pancreatic acinus hyperplasia, this positive trend is consistent with reported effects of other phthalates. Pancreatic acinus adenomas and acinus carcinomas have been observed with exposure to other phthalates and peroxisome proliferator-activated receptor alpha (PPAR $\alpha$ ) agonists. Di-(2-ethylhexyl) phthalate (DEHP) and butyl benzyl phthalate (BBP) induced pancreatic acinus adenomas and acinus carcinomas in male Fischer 334/N rats. ${ }^{151 ; 152}$ These neoplasms and/or acinus hyperplasia were also reported following chronic exposure to other PPAR $\alpha$ agonists, such as perfluorooctanoic acid, ${ }^{153}$ Wyeth-14,643, ${ }^{153}$ and nafenopin. ${ }^{154}$ The marginal increase in the incidence of pancreatic acinus adenomas was considered equivocal evidence of carcinogenicity in male rats because of observations of similar pancreatic neoplasms with exposure to other phthalates and other agonists of the proposed mechanistic pathway.

The mode of action underlying the increase in the incidence of pancreatic acinus adenomas is not certain, but studies suggest that PPAR $\alpha$ agonists alter bile acid synthesis or decrease bile flow, leading to hepatic cholestasis. The altered bile acids or decreased bile acid flow lead to increased secretion of cholecystokinin, which acts as a growth factor on pancreatic acinar cells in rats. ${ }^{155-}$ ${ }^{158}$ Sustained release of cholecystokinin might lead to increased proliferation of acinar cells. Indeed, phthalates like DEHP, DBP, BBP, and their metabolites (mono(2-ethylhexyl) phthalate [MEHP], MBP, and monobenzyl phthalate [MBzP], respectively) bind to PPAR $\alpha$ nuclear receptors. ${ }^{61 ; 159} \mathrm{MEHP}$ is the most effective of the phthalate esters in activating mouse and human PPAR $\alpha$, followed by MBzP, and then MBP. ${ }^{159}$ Docking studies have also found DEHP and BBP to have stronger binding affinities to PPARs than DBP. ${ }^{160}$ Therefore, the small increase in the incidence of pancreatic acinus adenomas observed with DBP compared to stronger agonists could be due to the relatively lower binding affinity of DBP for PPAR $\alpha$.

In previous studies conducted by NTP, DBP exposure for 3 months appeared to activate hepatic PPAR $\alpha$ in rats. At 5,000 and 10,000 ppm DBP, male and female rats had elevated peroxisome enzyme activity, increased liver weight, and hepatocellular cytoplasmic alterations at the end of the study. ${ }^{51}$ Although peroxisome enzyme activity was not measured in the present study, the increased incidences of hepatocyte cytoplasmic alteration in male and female animals at the highest exposure concentration (10,000 ppm) suggests PPAR $\alpha$ activation by DBP. This activation, however, was apparently insufficient to stimulate hepatic neoplasm growth in this study. In support of this hypothesis, chronic exposure to BBP - a weaker PPAR $\alpha$ agonist relative to DEHP but stronger than DBP — did not produce hepatic neoplasms in rats. ${ }^{151}$ Hepatic neoplasms have been reported with exposure to DEHP. ${ }^{152}$

In rats and mice of both sexes, cytoplasmic alteration of hepatocytes was present in nearly all animals in the 10,000 ppm groups. This was visible as fine, eosinophilic granules in affected hepatocytes, was graded as minimal severity in all animals. Similar cytoplasmic alteration of hepatocytes was previously reported in the 3-month DBP dosed feed study, and ultrastructural examination suggested the presence of increased numbers of peroxisomes in the cytoplasm. ${ }^{51}$ An increase in the number and size of multinucleated hepatocytes was also observed in the livers of exposed male mice, but the biological relevance of this lesion is unclear.

In utero exposure to DBP and other phthalates has been shown to induce developmental malformations in male rats, collectively referred to as the "phthalate syndrome." 161 Phthalate syndrome is characterized by malformations in reproductive tissues and is considered to be androgen-dependent or Insl3-dependent. ${ }^{162}$ Insl3 is a peptide hormone synthesized by fetal Leydig cells. Phthalate syndrome includes malformations of the epididymis, penis (hypospadias), 
prostate, seminal vesicles, and vas deferens; reduced anogenital distance; retention of nipples/areolae (all considered androgen-dependent), gubernacular abnormalities (considered to be Insl3-dependent), and undescended testes (considered both androgen- and Insl3-dependent). ${ }^{65}$; $68 ; 162$

Characteristics of phthalate syndrome were observed in this study. Gross pathology findings at necropsy generally were limited to the male reproductive tract in rats (Table 14). These findings included decreased size of testis, epididymis, seminal vesicle, or prostate gland; gubernacular length exceeding $20 \mathrm{~mm}$; segmental or complete agenesis of the epididymis (caput, corpus, or cauda); agenesis of the prostate gland (ventral lobes); testis not present (at necropsy and synonymous with agenesis); vas deferens not present; and undescended (cryptorchid) testes. The most frequently occurring gross findings related to DBP exposure in the rat were undescended testes and small testes, both of which were present in most of the 10,000 ppm male rats. Undescended testes were more frequently seen in abdominal locations than in inguinal ones. Increased gubernacular length, observed in about half the $10,000 \mathrm{ppm}$ males, is associated with failure of testes to fully descend. The undescended testes observed in DBP-exposed male rats were consistent with previously reported decreased androgens and Insl3 in DBP-exposed males; both are involved in testis descent. ${ }^{65 ; 68 ; 162}$ The undescended testes were generally smaller and corresponded to decreased testis weights and, histologically, with germinal epithelial atrophy. In this 2-year study with perinatal exposure in the rats, ascertaining whether the decreased size of testes seen at necropsy is due to testicular atrophy, which is the decrease in size after having attained full size, or from hypoplasia, in which the tissue never developed properly, is difficult. The small epididymides observed grossly corresponded to reduced epididymis weights and hypospermia microscopically. As with the testis, however, the possibility of epididymis hypoplasia cannot be ruled out, especially given the male reproductive tract malformations observed in rats.

The male reproductive tract was a target of DBP exposure in both rats and mice. Lesions were generally more severe in rats (which included perinatal exposure) than in mice. For example, at $10,000 \mathrm{ppm}, 42$ of 50 male rats had testicular germinal epithelial atrophy (seminiferous tubules containing only Sertoli cells and few or no germ cells), which is the end stage of degeneration. In contrast, the main testicular lesion in male mice at 10,000 ppm was germinal epithelial degeneration (15/50), with far fewer incidences of atrophy and epididymal hypospermia in the mice compared to the rats. In rats, testicular germinal epithelial atrophy was generally concomitant with epididymal hypospermia (42/50 and 40/50, respectively, at 10,000 ppm). In mice, testicular germinal epithelial degeneration was generally concomitant with exfoliated germ cells in the epididymal duct (15/50 and 13/50, respectively, at 10,000 ppm), with few incidences of epididymal hypospermia in mice. In rats, 18 of 42 animals with germinal epithelial atrophy also had edema in the testis, which was observed at a significantly increased incidence in 10,000 ppm male rats than in control animals. Testicular edema was not observed in male mice. This species effect of increased sensitivity of rats compared to mice for testicular toxicity of phthalates has been demonstrated previously. ${ }^{83}$

In addition to testicular atrophy (rats) or degeneration (mice) and their corroborating epididymal lesions, additional microscopic lesions in the male reproductive tracts of rats and mice likely were due to DBP exposure. Incidences of decreased secretory fluid in the prostate gland or seminal vesicles were significantly increased in the $10,000 \mathrm{ppm}$ rats compared to the control rats. Similar incidences of atrophy in the coagulating gland or seminal vesicle were observed in a few 
exposed mice, but they were not significantly increased compared to the control group. Decreased incidences of secretory fluid or atrophy of the prostate gland or seminal vesicles are commonly found with chronic androgen depletion. ${ }^{148}$ Again, hypoplasia of the accessory glands cannot be ruled out in the perinatal rat study because the diagnostic features of hypoplasia and decreased secretory fluid are similar. In general, however, the overall structure of the prostate glands and seminal vesicles was considered normal rather than malformed; therefore, the diagnosis was decreased secretory fluid rather than hypoplasia.

Lesions suggestive of systemic hormonal disturbance, including disturbance of the hypothalamus-pituitary-gonad axis, included diffuse interstitial (Leydig) cell hyperplasia in the testis and hypertrophy in the pars distalis of the pituitary gland in male rats exposed to DBP. Diffuse testicular interstitial hyperplasia, which was always present in both testes when diagnosed, was seen in one male rat at $1,000 \mathrm{ppm}$ and nine male rats at 10,000 ppm. The pathogenesis of diffuse interstitial cell hyperplasia is generally related to a compensatory physiological response to hormonal imbalance. ${ }^{148}$ Specifically, decreased systemic testosterone can cause a decrease in the normal negative feedback of testosterone on the hypothalamuspituitary-gonad axis. This, in turn, leads to increased release of gonadotropin-releasing hormone by the hypothalamus and, subsequently, increased luteinizing hormone and follicle-stimulating hormone release by gonadotrophs in the pars distalis of the pituitary gland. This stimulation of gonadotrophs in the pars distalis might have led to the development of the lesion of hypertrophied and, often, vacuolated cells in the pituitary gland pars distalis ("gonadectomy" or "castration" cells) observed in 29 of 50 male rats exposed to 10,000 ppm DBP. Increased luteinizing hormone, owing to lack of the normal negative feedback of testosterone on the pars distalis, might have resulted in a stimulatory response of the Leydig cells, which produce testosterone, resulting microscopically in diffuse interstitial (Leydig) cell hyperplasia. Phthalates have been shown to decrease testosterone production by fetal Leydig cells. ${ }^{71}$ Reductions in fetal testicular testosterone production occurred at doses $\geq 100 \mathrm{mg} / \mathrm{kg} /$ day in another study ${ }^{163}$; these doses produce exposures similar to that experienced by the top two exposure groups in the current study. Reduced intratesticular testosterone production by fetal Leydig cells might result in compromised adult Leydig cell function. In utero exposure of rats to DBP has been demonstrated to reduce the number of adult Leydig stem cells by approximately $40 \%$ at birth to adulthood and affect their function by inducing compensated adult Leydig cell failure (low/normal serum testosterone and elevated luteinizing hormone). ${ }^{164}$

Certain microscopic lesions observed in the 2-year perinatal exposure study of DBP in rats are considered developmentally induced lesions resulting from in utero exposure. These lesions, which were not observed in mice, include dysgenesis of the seminiferous tubules and granuloma and fibrosis of the rete testis. These lesions have also been reported in a rat perinatal 2-year study of DEHP. ${ }^{152}$ In the current study of DBP, incidences of testicular seminiferous tubule dysgenesis were significantly increased at 10,000 ppm (9/50), with an additional occurrence at 3,000 ppm (Table 15). Testicular dysgenesis has been described in the literature as having occurred after in utero exposure to various phthalates during the masculinization programming window (embryonic day [E] 15.5-18.5 in rats). ${ }^{65 ; 165-168}$ Seminiferous tubule dysgenesis is characterized as a developmental malformation observed microscopically as aberrant or misshapen seminiferous tubules, either with no lumens or dilated lumens, which are often surrounded by focal Leydig cell aggregates. The Leydig cell aggregates within foci of dysgenesis differ morphologically from the Leydig cells in adenomas. The Leydig cells in the foci of dysgenesis 
appear to be poorly differentiated, are spindle-shaped, and resemble embryonic Leydig cells, and they do not have the abundant eosinophilic or vacuolated cytoplasm often apparent in hyperplasia or adenoma. ${ }^{65}$ Dysgenetic lesions can occur as one or more small foci per testis, which tend to be located near the center of the testis or may occupy the entire testis. ${ }^{65}$ The malformed tubules can appear to form anastomotic networks. The dysgenetic tubules contain poorly differentiated Sertoli cells, with small, elongated, and sometimes cleaved nuclei and less prominent nucleoli than the typically prominent tripartite nucleoli of mature Sertoli cells. Spermatogenesis is absent in these foci of dysgenesis but can be present elsewhere in the testis. Dysgenetic foci can be present in one or both testes and can be more severe in undescended testes than scrotal testes. ${ }^{165 ; 167}$ In human males, similar microscopic dysgenetic foci have been reported in undescended testes, ${ }^{169}$ in testes also containing testicular cancer (both scrotal and undescended testes ${ }^{170}$ ), and from testicular biopsies from the contralateral testis in men undergoing orchiectomy for testicular cancer. ${ }^{171}$

The microscopic lesion of dysgenesis appears to originate during gestation but is not evident in the embryonic testis; it becomes evident as malformed tubules only in early postnatal life. ${ }^{165}$ In rats exposed in utero to phthalates, immunohistochemical markers have been used to demonstrate Sertoli cells and gonocytes at ectopic locations within the interstitium and to identify Leydig cells at ectopic locations inside the malformed seminiferous tubules. ${ }^{165-167 ; 172}$ Rats exposed in utero to DBP showed normal formation of seminiferous cords between E 13.5 and $\mathrm{E}$ 14.5, followed by abnormal fetal Leydig cell aggregation at E 17.5. ${ }^{172}$ At E 18.5, based on triple staining for Sertoli cells, gonocytes, and peritubular myoid cells, the seminiferous cords in exposed rats appeared to rupture, releasing their contents (i.e., Sertoli cells and gonocytes) into the interstitium. The cords appeared normally formed at one end, with a normal smooth muscle, actin positive, and peritubular myoid layer, and appeared ruptured at the other end, with loss of smooth muscle actin staining. ${ }^{172}$ The ectopic Sertoli cells and gonocytes appear in late gestation and disappear early in postnatal life, but the ectopic intratubular Leydig cells can persist throughout postnatal life.

Additional lesions considered related to in utero DBP exposure include rete testis fibrosis and rete testis sperm granuloma. In this and other DBP studies, sperm stasis in the rete testis appears to lead to formation of sperm granulomas and, subsequently, fibrosis in the rete testis region. ${ }^{65}$;

${ }^{173}$ Fibrosis of the rete testis is a unique lesion that presumably begins as a sperm granuloma and resolves into a fibrotic lesion with increased fibrous connective tissue containing numerous embedded epithelial-lined profiles of the rete testis. ${ }^{65 ; 173}$ The mechanism is unknown but could occur as a result of toxicity and efferent duct occlusion. The efferent ducts, however, were not evaluated in the current study. The sperm granulomas or fibrosis of the rete testis, which did not always occur together, were co-incident with the lesion of seminiferous tubule dysgenesis in five of the nine animals with dysgenesis, so the rete testis and dysgenetic lesions might be linked to developmental exposure to DBP.

DBP exposure also resulted in a unique renal tubular hyperplastic lesion in female mice but not in male mice or in male or female rats. This lesion has been reported in a previous NTP study on peroxisome proliferators. ${ }^{174}$ Ozaki et al. ${ }^{174}$ reported this lesion in male rats and mice exposed to Wyeth-14,643 (a prototypical peroxisome proliferator) or 2,4-dichlorophenoxyacetic acid (2,4-D, a weak peroxisome proliferator). In contrast to the current study, in which the lesion was not observed in rats, Ozaki et al. ${ }^{174}$ reported that rats were more sensitive to the renal tubular effects 
of the two peroxisome proliferators tested. Similar to DBP, 2,4-D did not cause hepatic neoplasms typical of peroxisome proliferators. 


\section{Conclusions}

Under the conditions of these 2-year feed studies, there was equivocal evidence of carcinogenic activity of di- $n$-butyl phthalate (DBP) in male Hsd:Sprague Dawley ${ }^{\circledR} \mathrm{SD}^{\circledR}$ rats based on marginal increases in the incidence of pancreatic acinus adenomas. There was no evidence of carcinogenic activity of DBP in female Hsd:Sprague Dawley ${ }^{\circledR} \mathrm{SD}^{\circledR}$ rats at exposure concentrations of 300 , $1,000,3,000$, or $10,000 \mathrm{ppm}$.

There was no evidence of carcinogenic activity of DBP in male or female B6C3F1/N mice at exposure concentrations of 1,000,3,000, or 10,000 ppm.

Exposure to DBP increased incidences of gross lesions in the male reproductive system in rats and of nonneoplastic microscopic lesions in the male reproductive system (rats and mice), liver (male and female rats and mice), pituitary gland pars distalis (male rats), and kidney (female mice). 


\section{References}

1. Agency for Toxic Substance and Disease Registry (ATSDR). Toxicological profile for di- $n$ butyl phthalate. Atlanta, GA: U.S. Department of Health and Human Services, Public Health Service; 2001.

2. Hamilton DJ. Gas chromatographic measurement of volatility of herbicide esters. J Chromatogr A. 1980; 195(1):75-83. https://doi.org/10.1016/S0021-9673(00)81544-7

3. Cadogan D, Howick C. Plasticizers In: Kroschwitz J, Howe-Grant, editors. Kirk-Othmer Encyclopedia of Chemical Technology. New York, NY: John Wiley \& Sons Inc.; 1996. p. 258290.

4. U.S. Environmental Protection Agency (USEPA). Chemical Data Reporting Database. 2012.

5. National Toxicology Program (NTP). NTP-CERHR monograph on the potential human reproductive and developmental effects of di- $n$-butyl phthalate (DPB). Research Triangle Park, NC: U.S. Department of Health and Human Services, National Institute of Environmental Health Sciences, National Toxicology Program; 2003.

6. European Chemicals Bureau (ECB). European Union risk assessment report for dibutyl phthalate. 2003.

7. International Programme for Chemical Safety (IPCS). Environmental health criteria for di- $n$ butyl phthalate. 1997.

8. Koo HJ, Lee BM. Estimated exposure to phthalates in cosmetics and risk assessment. J Toxicol Environ Health A. 2004; 67(23-24):1901-1914. https://doi.org/10.1080/15287390490513300

9. Al-Saleh I, Elkhatib R. Screening of phthalate esters in 47 branded perfumes. Environ Sci Pollut Res Int. 2016; 23(1):455-468. https://doi.org/10.1007/s11356-015-5267-z

10. Guo Y, Kannan K. A survey of phthalates and parabens in personal care products from the United States and its implications for human exposure. Environ Sci Technol. 2013; 47(24):14442-14449. https://doi.org/10.1021/es4042034

11. Broe A, Ennis ZN, Pottegard A, Hallas J, Ahern T, Damkier P. Population exposure to phthalate-containing drugs. Basic Clin Pharmacol Toxicol. 2017; 121(3):153-158. https://doi.org/10.1111/bcpt.12781

12. Hauser R, Duty S, Godfrey-Bailey L, Calafat AM. Medications as a source of human exposure to phthalates. Environ Health Perspect. 2004; 112(6):751-753. https://doi.org/10.1289/ehp.6804

13. Wang Y, Zhu H, Kannan K. A review of biomonitoring of phthalate exposures. Toxics. 2019; 7(2). https://doi.org/10.3390/toxics7020021

14. Centers for Disease Control and Prevention (CDC). National Health and Nutrition Examination Survey data. Hyattsville, MD: U.S. Department of Health and Human Services, 
Centers for Disease Control and Prevention, National Center for Health Statistics; 2013-2014. https://wwwn.cdc.gov/nchs/nhanes/continuousnhanes/default.aspx?BeginYear=2013

15. Petrovicova I, Kolena B, Sidlovska M, Pilka T, Wimmerova S, Trnovec T. Occupational exposure to phthalates in relation to gender, consumer practices and body composition. Environ Sci Pollut Res Int. 2016; 23(23):24125-24134. https://doi.org/10.1007/s11356-016-7394-6

16. Frederiksen H, Jorgensen N, Andersson AM. Correlations between phthalate metabolites in urine, serum, and seminal plasma from young Danish men determined by isotope dilution liquid chromatography tandem mass spectrometry. J Anal Toxicol. 2010; 34(7):400-410. https://doi.org/10.1093/jat/34.7.400

17. Kolatorova L, Vitku J, Vavrous A, Hampl R, Adamcova K, Simkova M, Parizek A, Starka L, Duskova M. Phthalate metabolites in maternal and cord plasma and their relations to other selected endocrine disruptors and steroids. Physiol Res. 2018; 67(Suppl 3):S473-S487. https://doi.org/10.33549/physiolres.933962

18. Silva MJ, Reidy JA, Herbert AR, Preau JL, Jr., Needham LL, Calafat AM. Detection of phthalate metabolites in human amniotic fluid. Bull Environ Contam Toxicol. 2004; 72(6):12261231. https://doi.org/10.1007/s00128-004-0374-4

19. Main KM, Mortensen GK, Kaleva MM, Boisen KA, Damgaard IN, Chellakooty M, Schmidt IM, Suomi AM, Virtanen HE, Petersen JH et al. Human breast milk contamination with phthalates and alterations of endogenous reproductive hormones in infants three months of age. Environ Health Perspect. 2006; 114(2):270-276. https://doi.org/10.1289/ehp.8075

20. Hogberg J, Hanberg A, Berglund M, Skerfving S, Remberger M, Calafat AM, Filipsson AF, Jansson B, Johansson N, Appelgren M et al. Phthalate diesters and their metabolites in human breast milk, blood or serum, and urine as biomarkers of exposure in vulnerable populations. Environ Health Perspect. 2008; 116(3):334-339. https://doi.org/10.1289/ehp.10788

21. Fromme H, Gruber L, Seckin E, Raab U, Zimmermann S, Kiranoglu M, Schlummer M, Schwegler U, Smolic S, Volkel W. Phthalates and their metabolites in breast milk--results from the Bavarian Monitoring of Breast Milk (BAMBI). Environ Int. 2011; 37(4):715-722. https://doi.org/10.1016/j.envint.2011.02.008

22. Kavlock R, Boekelheide K, Chapin R, Cunningham M, Faustman E, Foster P, Golub M, Henderson R, Hinberg I, Little R et al. NTP Center for the Evaluation of Risks to Human Reproduction: Phthalates expert panel report on the reproductive and developmental toxicity of di-n-butyl phthalate. Reprod Toxicol. 2002; 16(5):489-527. https://doi.org/10.1016/s0890$\underline{6238(02) 00033-3}$

23. Chan PK, Meek ME. Di- $n$-butyl phthalate evaluation of risks to health from environmental exposure in Canada. J Environ Sci Health. 1994; 12:257-268. https://doi.org/10.1080/10590509409373444

24. Otake T, Yoshinaga J, Yanagisawa Y. Exposure to phthalate esters from indoor environment. J Expo Anal Environ Epidemiol. 2004; 14(7):524-528. https://doi.org/10.1038/sj.jea.7500352 
25. Hines CJ, Hopf NB, Deddens JA, Silva MJ, Calafat AM. Estimated daily intake of phthalates in occupationally exposed groups. J Expo Sci Environ Epidemiol. 2011; 21(2):133-141. https://doi.org/10.1038/jes.2009.62

26. Hines CJ, Nilsen Hopf NB, Deddens JA, Calafat AM, Silva MJ, Grote AA, Sammons DL. Urinary phthalate metabolite concentrations among workers in selected industries: A pilot biomonitoring study. Ann Occup Hyg. 2009; 53(1):1-17. https://doi.org/10.1093/annhyg/men066

27. Kwapniewski R, Kozaczka S, Hauser R, Silva MJ, Calafat AM, Duty SM. Occupational exposure to dibutyl phthalate among manicurists. J Occup Environ Med. 2008; 50(6):705-711. https://doi.org/10.1097/JOM.0b013e3181651571

28. Koniecki D, Wang R, Moody RP, Zhu J. Phthalates in cosmetic and personal care products: Concentrations and possible dermal exposure. Environ Res. 2011; 111(3):329-336. https://doi.org/10.1016/j.envres.2011.01.013

29. U.S. Consumer Product Safety Commission (CPSC). Consumer Product Safety Improvement Act of 2008. Public Law 110-314. 122 Stat. 3016.; 2008.

30. U.S. Consumer Product Safety Commission (CPSC). 16 CFR Part 1307. [Docket No. CPSC2014-0033] Prohibition of Children's Toys and Child Care Articles Containing Specified Phthalates. Final Rule. 2017.

31. Food and Drug Administration (FDA). Guidance for Industry Limiting the Use of Certain Phthalates as Excipients in CDER-Regulated Product. 2012. https://www.fda.gov/regulatoryinformation/search-fda-guidance-documents/limiting-use-certain-phthalates-excipients-cderregulated-products

32. Food and Drug Administration (FDA). 21 CFR Parts 175, 176, 177, and 178 [Docket No. FDA-2018-F-3757] Flexible Vinyl Alliance; Filing of Food Additive Petition. Proposed Rule.; 2018.

33. Smith CC. Toxicity of butyl stearate, dibutyl sebacate, dibutyl phthalate, and methoxyethyl oleate. AMA Arch Ind Hyg Occup Med. 1953; 7(4):310-318.

34. U.S. Environmental Protection Agency (USEPA). Integrated Risk Information System (IRIS), chemical assessment summary, dibutyl phthalate; CASRN 84-74-2. 1987. https://cfpub.epa.gov/ncea/iris/iris documents/documents/subst/0038 summary.pdf

35. Agency for Toxic Substance and Disease Registry (ATSDR). Minimal risk levels (MRLs). 2020. https://www.atsdr.cdc.gov/mrls/pdfs/ATSDR\%20MRLs\%20-\%20March\%202020\%20$\% 20$ H.pdf

36. Takahashi T, Tanaka A. Biochemical studies on phthalic esters V. Comparative studies on in vitro hydrolysis of di- $n$-butyl phthalate isomers in rats. Arch Toxicol. 1989; 63(1):72-74. https://doi.org/10.1007/bf00334638

37. Foster PM, Cook MW, Thomas LV, Walters DG, Gangolli SD. Differences in urinary metabolic profile from di- $n$-butyl phthalate-treated rats and hamsters. A possible explanation for species differences in susceptibility to testicular atrophy. Drug Metabolism Disposition. 1983; 11(1):59-61. 
38. White RD, Carter DE, Earnest D, Mueller J. Absorption and metabolism of three phthalate diesters by the rat small intestine. Food Cosmet Toxicol. 1980; 18(4):383-386.

https://doi.org/10.1016/0015-6264(80)90194-7

39. Rowland IR, Cottrell RC, Phillips JC. Hydrolysis of phthalate esters by the gastro-intestinal contents of the rat. Food Cosmet Toxicol. 1977; 15(1):17-21. https://doi.org/10.1016/s0015$\underline{6264(77) 80257-5}$

40. Tanaka A, Matsumoto A, Yamaha T. Biochemical studies on phthalic esters. III. Metabolism of dibutyl phthalate (DBP) in animals. Toxicology. 1978; 9(1-2):109-123.

https://doi.org/10.1016/0300-483x(78)90036-7

41. Fennell TR, Krol WL, Sumner SC, Snyder RW. Pharmacokinetics of dibutylphthalate in pregnant rats. Toxicol Sci. 2004; 82(2):407-418. https://doi.org/10.1093/toxsci/kfh294

42. Chang LW, Hou ML, Tsai TH. Pharmacokinetics of dibutyl phthalate (DBP) in the rat determined by UPLC-MS/MS. Int J Mol Sci. 2013; 14(1):836-849.

https://doi.org/10.3390/ijms14010836

43. Saillenfait AM, Payan JP, Fabry JP, Beydon D, Langonne I, Gallissot F, Sabate JP. Assessment of the developmental toxicity, metabolism, and placental transfer of di- $n$-butyl phthalate administered to pregnant rats. Toxicol Sci. 1998; 45(2):212-224.

https://doi.org/10.1006/toxs.1998.2518

44. Albro PW, Moore B. Identification of the metabolites of simple phthalate diesters in rat urine. J Chromatogr. 1974; 94:209-218. https://doi.org/10.1016/s0021-9673(01)92368-4

45. Lake BG, Phillips JC, Linnell JC, Gangolli SD. The in vitro hydrolysis of some phthalate diesters by hepatic and intestinal preparations from various species. Toxicol Appl Pharmacol. 1977; 39(2):239-248. https://doi.org/10.1016/0041-008x(77)90157-0

46. Koch HM, Christensen KL, Harth V, Lorber M, Bruning T. Di- $n$-butyl phthalate (DnBP) and diisobutyl phthalate (DiBP) metabolism in a human volunteer after single oral doses. Arch Toxicol. 2012; 86(12):1829-1839. https://doi.org/10.1007/s00204-012-0908-1

47. Seckin E, Fromme H, Volkel W. Determination of total and free mono-n-butyl phthalate in human urine samples after medication of a di- $n$-butyl phthalate containing capsule. Toxicol Lett. 2009; 188(1):33-37. https://doi.org/10.1016/j.toxlet.2009.03.002

48. Anderson WA, Castle L, Scotter MJ, Massey RC, Springall C. A biomarker approach to measuring human dietary exposure to certain phthalate diesters. Food Addit Contam. 2001; 18(12):1068-1074. https://doi.org/10.1080/02652030110050113

49. Silva MJ, Barr DB, Reidy JA, Kato K, Malek NA, Hodge CC, Hurtz D, 3rd, Calafat AM, Needham LL, Brock JW. Glucuronidation patterns of common urinary and serum monoester phthalate metabolites. Arch Toxicol. 2003; 77(10):561-567. https://doi.org/10.1007/s00204-003$\underline{0486-3}$

50. Janjua NR, Frederiksen H, Skakkebaek NE, Wulf HC, Andersson AM. Urinary excretion of phthalates and paraben after repeated whole-body topical application in humans. Int J Androl. 2008; 31(2):118-130. https://doi.org/10.1111/j.1365-2605.2007.00841.x 
51. National Toxicology Program (NTP). NTP technical report on the toxicity studies of dibutyl phthalate (CAS No. 84-74-2) administered in feed to F344/N rats and B6C3F1 mice. Research Triangle Park, NC: U.S. Department of Health and Human Services, National Institute of Environmental Health Sciences, National Toxicology Program; 1995. NTP Toxicity Report No 30.

https://ntp.niehs.nih.gov/publications/reports/tox/000s/tox030/index.html?utm_source=direct\&ut

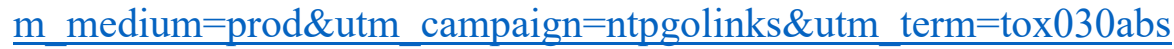

52. Hardin BD, Schuler RL, Burg JR, Booth GM, Hazelden KP, MacKenzie KM, Piccirillo VJ, Smith KN. Evaluation of 60 chemicals in a preliminary developmental toxicity test. Teratog Carcinog Mutagen. 1987; 7(1):29-48. https://doi.org/10.1002/tcm.1770070106

53. White RD, Earnest DL, Carter DE. The effect of intestinal esterase inhibition on the in vivo absorption and toxicity of di- $n$-butyl phthalate. Food Chem Toxicol. 1983; 21(1):99-101. https://doi.org/10.1016/0278-6915(83)90276-4

54. Li Y, Zhuang M, Li T, Shi N. Neurobehavioral toxicity study of dibutyl phthalate on rats following in utero and lactational exposure. J Appl Toxicol. 2009; 29(7):603-611.

https://doi.org/10.1002/jat.1447

55. Li XJ, Jiang L, Chen L, Chen HS, Li X. Neurotoxicity of dibutyl phthalate in brain development following perinatal exposure: A study in rats. Environ Toxicol Pharmacol. 2013; 36(2):392-402. https://doi.org/10.1016/j.etap.2013.05.001

56. Farzanehfar V, Naderi N, Kobarfard F, Faizi M. Determination of dibutyl phthalate neurobehavioral toxicity in mice. Food Chem Toxicol. 2016; 94:221-226. https://doi.org/10.1016/j.fct.2016.05.006

57. Schilling K, Kaufman W, Hildebrand B. Study on the oral toxicity of dibutyl phthalate in Wistar rats - administration via the diet over 3 months. Ludwigshafen, Germany: BASF Corporation; 1992. Microfiche No. OTS0535640; Document ID 86-920000903.

58. British Industrial Biological Research Association (BIBRA). A 21 day feeding study of di- $n$ butyl phthalate to rats: Effects on the liver and liver lipids. Report to the Chemical Manufacturers Association, Washington, DC. Carshalton, Surrey, UK: The British; 1986.

59. Murakami K, Nishiyama K, Higuti T. Toxicity of dibutyl phthalate and its metabolites in rats. Nippon Eiseigaku Zasshi (Jpn J Hyg). 1986; 41(4):775-781.

60. Feige JN, Gerber A, Casals-Casas C, Yang Q, Winkler C, Bedu E, Bueno M, Gelman L, Auwerx J, Gonzalez FJ et al. The pollutant diethylhexyl phthalate regulates hepatic energy metabolism via species-specific PPARalpha-dependent mechanisms. Environ Health Perspect. 2010; 118(2):234-241. https://doi.org/10.1289/ehp.0901217

61. Lapinskas PJ, Brown S, Leesnitzer LM, Blanchard S, Swanson C, Cattley RC, Corton JC. Role of PPARalpha in mediating the effects of phthalates and metabolites in the liver. Toxicology. 2005; 207(1):149-163. https://doi.org/10.1016/j.tox.2004.09.008

62. Kusu R, Oishi A, Kakizawa K, Kimura T, Toda C, Hashizume K, Ueda K, Kojima N. Effects of phthalate ester derivatives including oxidized metabolites on coactivator recruiting by 
PPARalpha and PPARgamma. Toxicol In Vitro. 2008; 22(6):1534-1538.

https://doi.org/10.1016/j.tiv.2008.05.010

63. Abdul Majeed K, Ur Rehman H, Yousaf MS, Zaneb H, Rabbani I, Tahir SK, Rashid MA. Sub-chronic exposure to low concentration of dibutyl phthalate affects anthropometric parameters and markers of obesity in rats. Environ Sci Pollut Res Int. 2017; 24(32):2546225467. https://doi.org/10.1007/s11356-017-9952-y

64. Benjamin S, Masai E, Kamimura N, Takahashi K, Anderson RC, Faisal PA. Phthalates impact human health: Epidemiological evidences and plausible mechanism of action. J Hazard Mater. 2017; 340:360-383. https://doi.org/10.1016/j.jhazmat.2017.06.036

65. Barlow NJ, McIntyre BS, Foster PM. Male reproductive tract lesions at 6, 12, and 18 months of age following in utero exposure to di(n-butyl) phthalate. Toxicol Pathol. 2004; 32(1):79-90. https://doi.org/10.1080/01926230490265894

66. Foster PM. Disruption of reproductive development in male rat offspring following in utero exposure to phthalate esters. Int J Androl. 2006; 29(1):140-147; discussion 181-145. https://doi.org/10.1111/j.1365-2605.2005.00563.x

67. Higuchi TT, Palmer JS, Gray LE, Jr., Veeramachaneni DN. Effects of dibutyl phthalate in male rabbits following in utero, adolescent, or postpubertal exposure. Toxicol Sci. 2003; 72(2):301-313. https://doi.org/10.1093/toxsci/kfg036

68. Wilson VS, Lambright C, Furr J, Ostby J, Wood C, Held G, Gray LE, Jr. Phthalate esterinduced gubernacular lesions are associated with reduced insl3 gene expression in the fetal rat testis. Toxicol Lett. 2004; 146(3):207-215. https://doi.org/10.1016/j.toxlet.2003.09.012

69. McKinnell C, Sharpe RM, Mahood K, Hallmark N, Scott H, Ivell R, Staub C, Jegou B, Haag $\mathrm{F}$, Koch-Nolte $\mathrm{F}$ et al. Expression of insulin-like factor 3 protein in the rat testis during fetal and postnatal development and in relation to cryptorchidism induced by in utero exposure to di (nButyl) phthalate. Endocrinology. 2005; 146(10):4536-4544. https://doi.org/10.1210/en.2005$\underline{0676}$

70. Li LH, Jester WF, Jr., Orth JM. Effects of relatively low levels of mono-(2-ethylhexyl) phthalate on cocultured Sertoli cells and gonocytes from neonatal rats. Toxicol Appl Pharmacol. 1998; 153(2):258-265. https://doi.org/10.1006/taap.1998.8550

71. Mylchreest E, Sar M, Wallace DG, Foster PM. Fetal testosterone insufficiency and abnormal proliferation of Leydig cells and gonocytes in rats exposed to di(n-butyl) phthalate. Reprod Toxicol. 2002; 16(1):19-28. https://doi.org/10.1016/s0890-6238(01)00201-5

72. Chou CK, Yang YT, Yang HC, Liang SS, Wang TN, Kuo PL, Wang HD, Tsai EM, Chiu CC. The impact of di(2-ethylhexyl)phthalate on cancer progression. Arch Immunol Ther Exp (Warsz). 2018; 66(3):183-197. https://doi.org/10.1007/s00005-017-0494-2

73. Gray LE, Jr, Wolf C, Lambright C, Mann P, Price M, Cooper RL, Ostby J. Administration of potentially antiandrogenic pesticides (procymidone, linuron, iprodione, chlozolinate, p,p'-DDE, and ketoconazole) and toxic substances (dibutyl- and diethylhexyl phthalate, PCB 169, and ethane dimethane sulphonate) during sexual differentiation produces diverse profiles of 
reproductive malformations in the male rat. Toxicol Ind Health. 1999; 15(1-2):94-118. https://doi.org/10.1177/074823379901500109

74. Kay VR, Chambers C, Foster WG. Reproductive and developmental effects of phthalate diesters in females. Crit Rev Toxicol. 2013; 43(3):200-219.

https://doi.org/10.3109/10408444.2013.766149

75. Ema M, Amano H, Itami T, Kawasaki H. Teratogenic evaluation of di- $n$-butyl phthalate in rats. Toxicol Lett. 1993; 69:197-203. https://doi.org/10.1016/0378-4274(93)90104-6

76. Ema M, Amano H, Ogawa Y. Characterization of the developmental toxicity of di- $n$-butyl phthalate in rats. Toxicology. 1994; 86(163-174). https://doi.org/10.1016/0300-483x(94)90002-7

77. Ema M, Miyawaki E, Kawasaki H. Further evaluation of developmental toxicity of di- $n$ butyl phthalate following administration during late pregnancy in rats. Toxicol Lett. 1998; 98(12):87-93. https://doi.org/10.1016/s0378-4274(98)00107-6

78. Dobrzynska MM, Tyrkiel EJ, Gajowik A. Three generation study of reproductive and developmental toxicity following exposure of pubescent F0 male mice to di- $n$-butyl phthalate. Mutagenesis. 2017; 32(4):445-454. https://doi.org/10.1093/mutage/gex011

79. Ema M, Kurosaka R, Amano H, Ogawa Y. Comparative developmental toxicity of n-butyl benzyl phthalate and di- $n$-butyl phthalate in rats. Arch Environ Contam Toxicol. 1995; 28:223228. https://doi.org/10.1007/BF00217620

80. Ema M, Kurosaka R, Harazono A, Amano H, Ogawa Y. Phase specificity of developmental toxicity after oral administration of mono-n-butyl phthalate in rats. Arch Environ Contam Toxicol. 1996; 31:170-176. https://doi.org/10.1007/BF00212362

81. Wine RN, Li LH, Barnes LH, Gulati DK, Chapin RE. Reproductive toxicity of di- $n$ butylphthalate in a continuous breeding protocol in Sprague-Dawley rats. Environ Health Perspect. 1997; 105(1):102-107. https://doi.org/10.1289/ehp.97105102

82. Fukuoka A, Zhou Y, Tanaka A, Ikemoto I, Machida T. Mechanism of testicular atrophy induced by di- $n$-butyl phthalate in rats. Part 2 . The effects on some testicular enzymes. J Appl Toxicol. 1990; 10(4):285-293. https://doi.org/10.1002/jat.2550100410

83. Gray TJ, Rowland IR, Foster PM, Gangolli SD. Species differences in the testicular toxicity of phthalate esters. Toxicol Lett. 1982; 11(1-2):141-147. https://doi.org/10.1016/0378$\underline{4274(82) 90119-9}$

84. Gray LE, Jr., Laskey J, Ostby J. Chronic di- $n$-butyl phthalate exposure in rats reduces fertility and alters ovarian function during pregnancy in female Long Evans hooded rats. Toxicol Sci. 2006; 93(1):189-195. https://doi.org/10.1093/toxsci/kfl035

85. Gray LE, Jr, Ostby J, Mylchreest E, Foster PM, Kelce WR. Dibutyl phthalate (DBP) induces antiandrogenic but not estrogenic in vivo effects in LE hooded rats Toxicologist. 1998; 42(1S):176. 
86. Ema M, Miyawaki E, Kawashima K. Effects of dibutyl phthalate on reproductive function in pregnant and pseudopregnant rats. Reprod Toxicol. 2000; 14(1):13-19.

https://doi.org/10.1016/s0890-6238(99)00066-0

87. Radke EG, Braun JM, Meeker JD, Cooper GS. Phthalate exposure and male reproductive outcomes: A systematic review of the human epidemiological evidence. Environ Int. 2018; 121(Pt 1):764-793. https://doi.org/10.1016/j.envint.2018.07.029

88. Radke EG, Glenn BS, Braun JM, Cooper GS. Phthalate exposure and female reproductive and developmental outcomes: A systematic review of the human epidemiological evidence. Environ Int. 2019; 130:104580. https://doi.org/10.1016/j.envint.2019.02.003

89. Pan Y, Jing J, Dong F, Yao Q, Zhang W, Zhang H, Yao B, Dai J. Association between phthalate metabolites and biomarkers of reproductive function in 1066 Chinese men of reproductive age. J Hazard Mater. 2015; 300:729-736.

https://doi.org/10.1016/j.jhazmat.2015.08.011

90. Hansen JF, Bendtzen K, Boas M, Frederiksen H, Nielsen CH, Rasmussen ÅK, FeldtRasmussen U. Influence of phthalates on cytokine production in monocytes and macrophages: A systematic review of experimental trials. PLoS One. 2015; 10(3):e0120083.

https://doi.org/10.1371/journal.pone.0120083

91. Li L, Li HS, Song NN, Chen HM. The immunotoxicity of dibutyl phthalate on the macrophages in mice. Immunopharmacol Immunotoxicol. 2013; 35(2):272-281. https://doi.org/10.3109/08923973.2013.768267

92. Zheng SJ, Tian HJ, Cao J, Gao YQ. Exposure to di(n-butyl)phthalate and benzo(a)pyrene alters IL-1beta secretion and subset expression of testicular macrophages, resulting in decreased testosterone production in rats. Toxicol Appl Pharmacol. 2010; 248(1):28-37.

https://doi.org/10.1016/j.taap.2010.07.008

93. Wu Y, Li J, Yan B, Zhu Y, Liu X, Chen M, Li D, Lee CC, Yang X, Ma P. Oral exposure to dibutyl phthalate exacerbates chronic lymphocytic thyroiditis through oxidative stress in female Wistar rats. Sci Rep. 2017; 7(1):15469. https://doi.org/10.1038/s41598-017-15533-Z

94. Bornehag CG, Nanberg E. Phthalate exposure and asthma in children. Int J Androl. 2010; 33(2):333-345. https://doi.org/10.1111/j.1365-2605.2009.01023.x

95. Maestre-Batlle D, Pena OM, Huff RD, Randhawa A, Carlsten C, Bolling AK. Dibutyl phthalate modulates phenotype of granulocytes in human blood in response to inflammatory stimuli. Toxicol Lett. 2018; 296:23-30. https://doi.org/10.1016/j.toxlet.2018.07.046

96. Jobling S, Reynolds T, White R, Parker MG, Sumpter JP. A variety of environmentally persistent chemicals, including some phthalate plasticizers, are weakly estrogenic. Environ Health Perspect. 1995; 103(6):582-587. https://doi.org/10.1289/ehp.95103582

97. Zuccarello P, Oliveri Conti G, Cavallaro F, Copat C, Cristaldi A, Fiore M, Ferrante M. Implication of dietary phthalates in breast cancer. A systematic review. Food Chem Toxicol. 2018; 118:667-674. https://doi.org/10.1016/j.fct.2018.06.011 
98. Sun J, Zhang MR, Zhang LQ, Zhao D, Li SG, Chen B. Phthalate monoesters in association with uterine leiomyomata in Shanghai. Int J Environ Health Res. 2016; 26(3):306-316. https://doi.org/10.1080/09603123.2015.1111310

99. Ennis ZN, Pedersen A, Hansen RM, Pottegard A, Ahern PT, Hallas J, Damkier P. Use of phthalate-containing prescription drugs and the risk of gastric cancer: A Danish nationwide casecontrol study. Acta Oncol. 2019; 58(6):852-858.

https://doi.org/10.1080/0284186x.2019.1585941

100. Ennis ZN, Pottegard A, Ahern TP, Hallas J, Damkier P. Exposure to phthalate-containing prescription drugs and the risk of colorectal adenocarcinoma: A Danish nationwide case-control study. Pharmacoepidemiol Drug Saf. 2019; 28(4):528-535. https://doi.org/10.1002/pds.4759

101. Agarwal DK, Lawrence WH, Nunez LJ, Autian J. Mutagenicity evaluation of phthalic acid esters and metabolites in Salmonella typhimurium cultures. J Toxicol Environ Health. 1985; 16(1):61-69. https://doi.org/10.1080/15287398509530719

102. Florin I, Rutberg L, Curvall M, Enzell CR. Screening of tobacco smoke constituents for mutagenicity using the Ames' test. Toxicology. 1980; 15(3):219-232.

https://doi.org/10.1016/0300-483x(80)90055-4

103. Kozumbo WJ, Kroll R, Rubin RJ. Assessment of the mutagenicity of phthalate esters. Environ Health Perspect. 1982; 45:103-109. https://doi.org/10.1289/ehp.8245103

104. Zeiger E, Haworth S, Mortelmans K, Speck W. Mutagenicity testing of di(2ethylhexyl)phthalate and related chemicals in Salmonella. Environ Mutagen. 1985; 7(2):213-232. https://doi.org/10.1002/em.2860070209

105. Seed JL. Mutagenic activity of phthalate esters in bacterial liquid suspension assays. Environ Health Perspect. 1982; 45:111-114. https://doi.org/10.1289/ehp.8245111

106. Shahin MM, Von Borstel RC. Mutagenic and lethal effects of alpha-benzene hexachloride, dibutyl phthalate and trichloroethylene in Saccharomyces cerevisiae. Mutat Res. 1977; 48(2):173-180. https://doi.org/10.1016/0027-5107(77)90157-9

107. Zimmermann FK, R.C. VB, Von Halle ES. Testing of chemicals for genetic activity with Saccharomyces cerevisiae: A report of the US Environmental Protection Agency Gene-Tox Program. Mutat Res. 1984; 133(3):199-244. https://doi.org/10.1016/0165-1110(84)90017-4

108. Barber ED, Cifone M, Rundell J, Przygoda R, Astill BD, Moran E, Mulholland A, Robinson E, Schneider B. Results of the L5178Y mouse lymphoma assay and the Balb/3t3 cell in vitro transformation assay for eight phthalate esters. J Appl Toxicol. 2000; 20(1):69-80. https://doi.org/10.1002/(sici)1099-1263(200001/02)20:1<69::aid-jat630>3.0.co;2-2

109. Kleinsasser NH, Kastenbauer ER, Weissacher H, Muenzenrieder RK, Harreus UA. Phthalates demonstrate genotoxicity on human mucosa of the upper aerodigestive tract. Environ Mol Mutagen. 2000; 35(1):9-12. https://doi.org/10.1002/(sici)1098-2280(2000)35:1<9::aidem2>3.0.co;2-1

110. Kleinsasser NH, Wallner BC, Kastenbauer ER, Muenzenrieder RK, Harreus UA. Comparing the genotoxic sensitivities of human peripheral blood lymphocytes and mucosa cells 
of the upper aerodigestive tract using the Comet assay. Mutat Res. 2000; 467(1):21-30. https://doi.org/10.1016/s1383-5718(00)00022-X

111. Abe S, Sasaki M. Chromosome aberrations and sister chromatid exchanges in Chinese hamster cells exposed to various chemicals. J Natl Cancer Inst. 1977; 58(6):1635-1641. https://doi.org/10.1093/jnci/58.6.1635

112. Kim MY, Kim YC, Cho MH. Combined treatment with 4-(N-methyl-N-nitrosamino)-1- (3pyridyl)-1-butanone and dibutyl phthalate enhances ozone-induced genotoxicity in B6C3F1 mice. Mutagenesis. 2002; 17(4):331-336. https://doi.org/10.1093/mutage/17.4.331

113. Kim MY, Kim HW, Park JH, Kim JS, Jin H, Moon SH, Eu KJ, Cho HS, Kang G, Kim YS et al. Molecular analysis of hprt mutation in $\mathrm{B} 6 \mathrm{C} 3 \mathrm{~F} 1$ mice exposed to ozone alone and combined treatment of 4-(N-methyl-N-nitrosamino)-1-(3-pyridyl)-1-butanone and/or dibutyl phthalate for 32 and 52 weeks. J Vet Sci. 2004; 5(4):379-385.

114. Tu Z, Mu X, Chen X, Geng Y, Zhang Y, Li Q, Gao R, Liu T, Wang Y, He J. Dibutyl phthalate exposure disrupts the progression of meiotic prophase I by interfering with homologous recombination in fetal mouse oocytes. Environ Pollut. 2019; 252(Pt A):388-398. https://doi.org/10.1016/j.envpol.2019.05.107

115. Silinski MA, Fernando RA, Robinson VG, Waidyanatha S. Development and validation of an analytical method for quantitation of monobutylphthalate, a metabolite of di- $n$-butylphthalate, in rat plasma, amniotic fluid, fetuses, and pups by UPLC-MS/MS. J Anal Toxicol. 2020. https://doi.org/10.1093/jat/bkz090

116. Maronpot RR, Boorman GA. Interpretation of rodent hepatocellular proliferative alterations and hepatocellular tumors in chemical safety assessment. Toxicol Pathol. 1982; 10(2):71-78. https://doi.org/10.1177/019262338201000210

117. Boorman GA, Haseman JK, Waters MD, Hardisty JF, Sills RC. Quality review procedures necessary for rodent pathology databases and toxicogenomic studies: The National Toxicology Program experience. Toxicol Pathol. 2002; 30(1):88-92.

https://doi.org/10.1080/01926230252824752

118. McConnell EE, Solleveld HA, Swenberg JA, Boorman GA. Guidelines for combining neoplasms for evaluation of rodent carcinogenesis studies. J Natl Cancer Inst. 1986; 76(2):283289.

119. Kaplan EL, Meier P. Nonparametric estimation from incomplete observations. J Am Stat Assoc. 1958; 53(282):457-481. https://doi.org/10.2307/2281868

120. Tarone RE. Tests for trend in life table analysis. Biometrika. 1975; 62(3):679-690.

121. Cox DR. Regression models and life-tables. J R Stat Soc Ser B. 1972; 34(2):187-202.

122. Bailer AJ, Portier CJ. Effects of treatment-induced mortality and tumor-induced mortality on tests for carcinogenicity in small samples. Biometrics. 1988; 44(2):417-431.

123. Piegorsch W, Bailer A. Statistics for environmental biology and toxicology: Section 6.3.2. . London, UK: Chapman and Hall; 1997. 
124. Portier CJ, Bailer AJ. Testing for increased carcinogenicity using a survival-adjusted quantal response test. Fundam Appl Toxicol. 1989; 12(4):731-737.

125. Portier CJ, Hedges JC, Hoel DG. Age-specific models of mortality and tumor onset for historical control animals in the National Toxicology Program's carcinogenicity experiments. Cancer Res. 1986; 46(9):4372-4378.

126. Bieler GS, Williams RL. Ratio estimates, the delta method, and quantal response tests for increased carcinogenicity. Biometrics. 1993; 49(3):793-801.

127. Nam JM. A simple approximation for calculating sample sizes for detecting linear trend in proportions. Biometrics. 1987; 43(3):701-705.

128. Rao JN, Scott AJ. A simple method for the analysis of clustered binary data. Biometrics. 1992; 48(2):577-585.

129. Fung KY, Krewski D, Rao JN, Scott AJ. Tests for trend in developmental toxicity experiments with correlated binary data. Risk Anal. 1994; 14(4):639-648.

130. Gart JJ, Chu KC, Tarone RE. Statistical issues in interpretation of chronic bioassay tests for carcinogenicity. J Natl Cancer Inst. 1979; 62(4):957-974.

131. Dixon W, Massey FJ. Introduction to Statistical Analysis. New York, NY: McGraw Hill Book Company, Inc.; 1957.

132. Tukey J. Easy summaries - numerical and graphical. Exploratory Data Analysis. Reading, MA: Addison-Wesley; 1977. p. 43-44.

133. Dunnett CW. A multiple comparison procedure for comparing several treatments with a control. J Am Stat Assoc. 1955; 50(272):1096-1121.

134. Williams DA. A test for differences between treatment means when several dose levels are compared with a zero dose control. Biometrics. 1971; 27(1):103-117.

135. Williams DA. The comparison of several dose levels with a zero dose control. Biometrics. 1972; 28(2):519-531.

136. Shirley E. A non-parametric equivalent of Williams' test for contrasting increasing dose levels of a treatment. Biometrics. 1977; 33(2):386-389.

137. Williams DA. A note on Shirley's nonparametric test for comparing several dose levels with a zero-dose control. Biometrics. 1986; 42(1):183-186.

138. Dunn OJ. Multiple comparisons using rank sums. Technometrics. 1964; 6(3):241-252.

139. Jonckheere AR. A distribution-free k-sample test against ordered alternatives. Biometrika. 1954; 41(1/2). https://doi.org/10.2307/2333011

140. Hsu JC. The factor analytic approach to simultaneous inference in the general linear model. J Comput Graph Stat. 1992; 1(2):151-168. https://doi.org/10.1080/10618600.1992.10477011 
141. Haseman JK. Value of historical controls in the interpretation of rodent tumor data. Drug Inf J. 1992; 26(2):191-200. https://doi.org/10.1177/009286159202600210

142. Haseman JK. Data analysis: Statistical analysis and use of historical control data. Regul Toxicol Pharmacol. 1995; 21(1):52-59; discussion 81-56. https://doi.org/10.1006/rtph.1995.1009

143. Haseman JK, Rao GN. Effects of corn oil, time-related changes, and inter-laboratory variability on tumor occurrence in control Fischer 344 (F344/N) rats. Toxicol Pathol. 1992; 20(1):52-60. https://doi.org/10.1177/019262339202000107

144. Code of Federal Regulations (CFR). 21(Part 58).

145. National Toxicology Program (NTP). TR-600: Pathology tables, survival and growth curves from NTP long-term studies. Research Triangle Park, NC: U.S. Department of Health and Human Services, National Institute of Environmental Health Sciences, National Toxicology Program; 2020. https://doi.org/10.22427/NTP-DATA-TR-600

146. Rudmann D, Cardiff R, Chouinard L, Goodman D, Küttler K, Marxfeld H, Molinolo A, Treumann S, Yoshizawa K. Proliferative and nonproliferative lesions of the rat and mouse mammary, Zymbal's, preputial, and clitoral glands. Toxicol Pathol. 2012; 40(6_suppl):7S-39S. https://doi.org/10.1177/0192623312454242

147. National Toxicology Program (NTP). NTP technical report on the toxicology and carcinogenesis studies in Hsd: Sprague Dawley SD rats exposed to whole-body radio frequency radiation at a frequency $(900 \mathrm{MHz})$ and modulations (GSM and CDMA) used by cell phones. Research Triangle Park, NC: U.S. Department of Health and Human Services, National Insitute of Environmental Health Sciences, National Toxicology Program; 2018. NTP Technical Report No 595 .

https://ntp.niehs.nih.gov/publications/reports/tr/500s/tr595/index.html?utm_source=direct\&utm medium=prod\&utm campaign=ntpgolinks\&utm term=tr595abs

148. Creasy D, Bube A, de Rijk E, Kandori H, Kuwahara M, Masson R, Nolte T, Reams R, Regan K, Rehm S et al. Proliferative and nonproliferative lesions of the rat and mouse male reproductive system. Toxicol Pathol. 2012; 40(6 Suppl):40s-121s.

https://doi.org/10.1177/0192623312454337

149. Kay VR, Bloom MS, Foster WG. Reproductive and developmental effects of phthalate diesters in males. Crit Rev Toxicol. 2014; 44(6):467-498.

https://doi.org/10.3109/10408444.2013.875983

150. Katsikantami I, Tzatzarakis MN, Alegakis AK, Karzi V, Hatzidaki E, Stavroulaki A, Vakonaki E, Xezonaki P, Sifakis S, Rizos AK et al. Phthalate metabolites concentrations in amniotic fluid and maternal urine: Cumulative exposure and risk assessment. Toxicol Rep. 2020; 7:529-538. https://doi.org/10.1016/j.toxrep.2020.04.008

151. National Toxicology Program (NTP). NTP technical report on the toxicology and carcinogenesis studies of butyl benzyl phthalate (CAS No. 85-68-7) in F334/N rats (feed studies). Research Triangle Park, NC: U.S. Department of Health and Human Services, National Institute of Environmental Health Sciences, National Toxicology Program; 1997. NTP Technical Report No 458. 
https://ntp.niehs.nih.gov/publications/reports/tr/400s/tr458/index.html?utm source=direct\&utm $\underline{\text { medium }=\text { prod\&utm campaign }=\text { ntpgolinks \&utm term }=\text { tr } 458 \mathrm{abs}}$

152. National Toxicology Program (NTP). NTP technical report on the toxicology and carcinogenesis studies of di(2-ethylhexyl) phthalate (CASRN 117-81-7) administered in feed to Sprague Dawley Hsd:Sprague Dawley ${ }^{\circledR}$ SD $\left.{ }^{\circledR}\right)$ rats. Research Triangle Park, NC: U.S. Department of Health and Human Services, National Institute of Environmental Health Sciences, National Toxicology Program; 2020. NTP Technical Report No. 601 [in progress].

153. Biegel LB, Hurtt ME, Frame SR, O'Connor JC, Cook JC. Mechanisms of extrahepatic tumor induction by peroxisome proliferators in male CD rats. Toxicol Sci. 2001; 60(1):44-55. https://doi.org/10.1093/toxsci/60.1.44

154. Reddy JK, Rao MS. Transplantable pancreatic carcinoma of the rat. Science. 1977; 198(4312):78-80. https://doi.org/10.1126/science.897688

155. Klaunig JE, Babich MA, Baetcke KP, Cook JC, Corton JC, David RM, DeLuca JG, Lai DY, McKee RH, Peters JM et al. PPARalpha agonist-induced rodent tumors: modes of action and human relevance. Crit Rev Toxicol. 2003; 33(6):655-780.

https://doi.org/10.1080/713608372

156. Klaunig JE, Hocevar BA, Kamendulis LM. Mode of action analysis of perfluorooctanoic acid (PFOA) tumorigenicity and human relevance. Reprod Toxicol. 2012; 33(4):410-418. https://doi.org/10.1016/j.reprotox.2011.10.014

157. Obourn JD, Frame SR, Bell RH, Jr., Longnecker DS, Elliott GS, Cook JC. Mechanisms for the pancreatic oncogenic effects of the peroxisome proliferator Wyeth-14,643. Toxicol Appl Pharmacol. 1997; 145(2):425-436. https://doi.org/10.1006/taap.1997.8210

158. Li T, Chiang JY. Regulation of bile acid and cholesterol metabolism by PPARs. PPAR Res. 2009; 2009:501739. https://doi.org/10.1155/2009/501739

159. Hurst $\mathrm{CH}$, Waxman DJ. Activation of PPARalpha and PPARgamma by environmental phthalate monoesters. Toxicol Sci. 2003; 74(2):297-308. https://doi.org/10.1093/toxsci/kfg145

160. Sarath Josh MK, Pradeep S, Amma VKS, Balachandran S, Abdul Jaleel UC, Doble M, Spener F, Benjamin S. Phthalates efficiently bind to human peroxisome proliferator activated receptor and retinoid X receptor alpha, beta, gamma subtypes: An in silico approach. J Appl Toxicol. 2014; 34(7):754-765. https://doi.org/10.1002/jat.2902

161. Gray LE, Foster PMD. Significance of experimental studies for assessing adverse effects of endocrine-disrupting chemicals. Pure Appl Chem. 2003; 75:2125-2141.

https://doi.org/10.1351/pac200375112125

162. Gray LE, Jr., Furr J, Tatum-Gibbs KR, Lambright C, Sampson H, Hannas BR, Wilson VS, Hotchkiss A, Foster PM. Establishing the "biological relevance" of dipentyl phthalate reductions in fetal rat testosterone production and plasma and testis testosterone levels. Toxicol Sci. 2016; 149(1):178-191. https://doi.org/10.1093/toxsci/kfv224

163. Furr JR, Lambright CS, Wilson VS, Foster PM, Gray LE, Jr. A short-term in vivo screen using fetal testosterone production, a key event in the phthalate adverse outcome pathway, to 
predict disruption of sexual differentiation. Toxicol Sci. 2014; 140(2):403-424. https://doi.org/10.1093/toxsci/kfu081

164. Kilcoyne KR, Smith LB, Atanassova N, Macpherson S, McKinnell C, van den Driesche S, Jobling MS, Chambers TJ, De Gendt K, Verhoeven G et al. Fetal programming of adult Leydig cell function by androgenic effects on stem/progenitor cells. Proc Natl Acad Sci U S A. 2014; 111(18):E1924-1932. https://doi.org/10.1073/pnas.1320735111

165. Fisher JS, Macpherson S, Marchetti N, Sharpe RM. Human 'testicular dysgenesis syndrome': A possible model using in-utero exposure of the rat to dibutyl phthalate. Hum Reprod. 2003; 18(7):1383-1394. https://doi.org/10.1093/humrep/deg273

166. Mahood IK, Hallmark N, McKinnell C, Walker M, Fisher JS, Sharpe RM. Abnormal leydig cell aggregation in the fetal testis of rats exposed to di (n-butyl) phthalate and its possible role in testicular dysgenesis. Endocrinology. 2005; 146(2):613-623. https://doi.org/10.1210/en.2004$\underline{0671}$

167. van den Driesche S, Kilcoyne KR, Wagner I, Rebourcet D, Boyle A, Mitchell R, McKinnell C, Macpherson S, Donat R, Shukla CJ et al. Experimentally induced testicular dysgenesis syndrome originates in the masculinization programming window. JCI Insight. 2017; 2(6):e91204. https://doi.org/10.1172/jci.insight.91204

168. Elmore SA, Carreira V, Labriola CS, Mahapatra D, McKeag SR, Rinke M, Shackelford C, Singh B, Talley A, Wallace SM et al. Proceedings of the 2018 National Toxicology Program Satellite Symposium. Toxicol Pathol. 2018; 46(8):865-897.

https://doi.org/10.1177/0192623318800734

169. Sohval AR. Testicular dysgenesis as an etiologic factor in cryptorchidism. J Urol. 1954; 72(4):693-702. https://doi.org/10.1016/s0022-5347(17)67649-3

170. Sohval AR. Testicular dysgenesis in relation to neoplasm of the testicle. J Urol. 1956; 75(2):285-291. https://doi.org/10.1016/s0022-5347(17)66809-5

171. Hoei-Hansen CE, Holm M, Rajpert-De Meyts E, Skakkebaek NE. Histological evidence of testicular dysgenesis in contralateral biopsies from 218 patients with testicular germ cell cancer. J Pathol. 2003; 200(3):370-374. https://doi.org/10.1002/path.1372

172. Lara NLM, van den Driesche S, Macpherson S, Franca LR, Sharpe RM. Dibutyl phthalate induced testicular dysgenesis originates after seminiferous cord formation in rats. Sci Rep. 2017; 7(1):2521. https://doi.org/10.1038/s41598-017-02684-2

173. Elmore SA, Cesta MF, Crabbs TA, Janardhan KS, Krane GA, Mahapatra D, Quist EM, Rinke M, Schaaf GW, Travlos GS et al. Proceedings of the 2019 National Toxicology Program Satellite Symposium. Toxicol Pathol. 2019; 47(8):913-953. https://doi.org/10.1177/0192623319876929

174. Ozaki K, Mahler JF, Haseman JK, Moomaw CR, Nicolette ML, Nyska A. Unique renal tubule changes induced in rats and mice by the peroxisome proliferators 2,4dichlorophenoxyacetic acid (2,4-D) and WY-14643. Toxicol Pathol. 2001; 29(4):440-450. https://doi.org/10.1080/01926230152499791 


\section{Appendix A. Chemical Characterization and Dose Formulation Studies}

\section{Table of Contents}

A.1. Procurement and Characterization of Di- $n$-butyl Phthalate A-2

A.2. Preparation and Analysis of Dose Formulations A-3

\section{Tables}

Table A-1. Chromatography Systems Used in the Perinatal and Two-year Feed Studies of Di- $n$-butyl Phthalate.

Table A-2. Preparation and Storage of Dose Formulations in the Perinatal and Two-year Feed Studies of Di- $n$-butyl Phthalate

Table A-3. Results of Analyses of Dose Formulations Administered to Rats in the Perinatal and Two-year Feed Study of Di- $n$-butyl Phthalate

Table A-4. Results of Analyses of Dose Formulations Administered to Mice in the Twoyear Feed Study of Di- $n$-butyl Phthalate.

\section{Figures}

Figure A-1. Reference Fourier Transformed Infrared Absorption Spectrum of Di- $n$-butyl Phthalate.

Figure A-2. ${ }^{1} \mathrm{H}$ NMR Spectrum of Sample of Di- $n$-butyl Phthalate (Lot MKBB8432) A-12

Figure A-3. ${ }^{13}$ C NMR Spectrum of Sample of Di- $n$-butyl Phthalate (Lot MKBB8432) A-13 


\section{A.1. Procurement and Characterization of Di-n-butyl Phthalate}

Di- $n$-butyl phthalate (DBP) was obtained from Sigma-Aldrich (St. Louis, MO) in a single lot (lot MKBB8432). Identity, purity, and stability analyses were conducted by the analytical chemistry laboratory at RTI International (Research Triangle Park, NC). Reports on analyses performed in support of the DBP studies are on file at the National Institute of Environmental Health Sciences.

The appearance, a clear liquid, and density of lot MKBB8432 $\left(1.05 \mathrm{~g} / \mathrm{mL}\right.$ at $\left.21.7^{\circ} \mathrm{C}\right)$ matched that of DBP $\left(1.043 \mathrm{~g} / \mathrm{mL}\right.$ at $\left.25^{\circ} \mathrm{C}\right)$. The boiling point of lot MKBB8 $432\left(335^{\circ} \mathrm{C}\right)$ matched that of DBP $\left(340^{\circ} \mathrm{C}\right)$, and elemental analysis confirmed the anticipated relative ratios; both analyses were performed by Galbraith Laboratories (Knoxville, TN). A precise molecular mass was measured using a research-grade high-resolution mass spectrometer (HRMS) at the University of South Carolina Mass Spectrometry Facility (Columbia, SC). The observed mass values (278.1514) were within acceptable limits $(\leq 5 \mathrm{ppm})$ of the calculated mass (278.1518).

The lot was identified using infrared (IR) spectroscopy. In addition, the lot was analyzed using ${ }^{1} \mathrm{H}$ and ${ }^{13} \mathrm{C}$ nuclear magnetic resonance (NMR) spectroscopy and gas chromatography (GC) with mass spectrometry (MS) detection. The IR spectrum was in good agreement with the structure of DBP and with the reference spectrum of DBP from Sigma-Aldrich (Product No. 524980, accessed December 22, 2009) (Figure A-1). ${ }^{1} \mathrm{H}$ and ${ }^{13} \mathrm{C}$ NMR spectra were consistent with the structure of DBP and the prediction from Advanced Chemistry Development's Spectral Prediction Program (Version 10.02, Toronto, Ontario, Canada) (Figure A-2, Figure A-3). GC/MS identified the major peak of lot MKBB8432 as DBP using fragmentation pattern and comparison with the National Institute of Standards and Technology (Gaithersburg, MD) reference spectrum (No. 312145) for DBP (Table A-1; System A).

The moisture content of lot MKBB8432 was determined by Karl Fischer titration. The purity of lot MKBB8432 was determined using ultra-performance liquid chromatography (UPLC) with photodiode array detection (PDA) and GC with flame ionization detection (FID) (Table A-1; Systems B and C, respectively). The Karl Fischer titration yielded a water content of $0.204 \%$. UPLC analysis demonstrated one major peak accounting for $99.9 \%$ and no minor peaks $>0.1 \%$ of the total integrated area, although one minor impurity $(<0.1 \%)$ was observed. GC/FID analysis also found one major peak accounting for $99.9 \%$ and no minor peaks $>0.1 \%$. The overall purity of lot MKBB 8432 was determined to be $>99 \%$.

Accelerated stability studies were conducted on samples of DBP by the analytical chemistry laboratory using lot 91997PJ from Sigma-Aldrich (St. Louis, MO) stored at ambient temperature (approximately $22^{\circ} \mathrm{C}$ ), refrigerated temperature (approximately $5^{\circ} \mathrm{C}$ ), and elevated temperature (approximately $60^{\circ} \mathrm{C}$ ) in amber vials. After 14 days, samples were analyzed by GC/FID (Table A-1; System C). Stability of DBP was confirmed for at least 2 weeks when stored in sealed glass vials at temperatures from $5^{\circ} \mathrm{C}$ to $60^{\circ} \mathrm{C}$. Upon receipt, the bulk chemical of lot MKBB8432 was homogenized by mixing for 15 minutes and transferred to 1-gallon amber storage bottles stored at room temperature. Periodic analyses of the bulk chemical lot MKBB8432 were performed prior to and during the animal studies by the laboratory using high-performance liquid chromatography (HPLC) with ultraviolet (UV) detection (Table A-1; System D), and no degradation of the test chemical was detected. 


\section{A.2. Preparation and Analysis of Dose Formulations}

The base diet was meal feed purchased from Zeigler Brothers, Inc. (Gardners, PA). The 2-year rat and mouse studies used NTP-2000 feed (24 lots milled June 2010 through June 2012), whereas NIH-07 feed (two lots milled May and June 2010) also was used during the perinatal phase of the rat study. No analysis was performed on the feed beyond determining suitability for feeding the animals.

Dose formulations were prepared monthly by mixing DBP with feed (Table A-2). For the perinatal and 2-year rat study, formulations were prepared in NIH-07 feed at concentrations of 0 , $300,1,000,3,000$, and 10,000 ppm (July 8 and July 29, 2010) and in NTP-2000 feed at concentrations of $0,300,1,000,3,000$, and 10,000 ppm (27 formulations; August 2010 to August 2012). For the 2-year mouse study, formulations were prepared in NTP-2000 feed at concentrations of $0,1,000,3,000$, and 10,000 ppm (27 formulations; August 2010 to August 2012).

Homogeneity studies of the 300 and 10,000 ppm dose formulations in $72 \mathrm{~kg} \mathrm{NIH}-07$ feed batch sizes, $300 \mathrm{ppm}$ dose formulation in a $92 \mathrm{~kg}$ NTP-2000 feed batch size, and 1,000 and $10,000 \mathrm{ppm}$ dose formulations in $60 \mathrm{~kg}$ NTP-2000 feed batch sizes were performed before the animal studies by the study laboratory using HPLC/UV (Table A-1; System D). Additional homogeneity studies for different batch sizes were performed during the 2-year studies by the study laboratory with the same HPLC/UV system: batch size of $60 \mathrm{~kg}$ for the $300 \mathrm{ppm}$ dose formulation in NTP-2000 feed (December 2010) and batch size of $72 \mathrm{~kg}$ for the 10,000 ppm dose formulation in NTP-2000 feed (July 2012). All formulations analyzed were determined homogeneous and of appropriate concentration. Stability was confirmed for 42 days at room temperature (approximately $25^{\circ} \mathrm{C}$ ).

The plastic bags used for preparation and storage of animal feed and dose formulations were analyzed for the presence of 11 different phthalates commonly found in plastics, including DBP, by the analytical chemistry laboratory at RTI International (Research Triangle Park, NC). Analysis of the extracts from plastic bags used by the study laboratory in the preparation and storage of control and dosed feed showed no DBP above the limit of detection (1.47 ppm) (Table A-1; System B). The developed method suggested no significant contribution of DBP from the plastic storage bags.

Control and treated formulations were stored in individual plastic bag-lined containers at room temperature (approximately $25^{\circ} \mathrm{C}$ ). The formulations were used within 42 days of preparation.

Periodic analyses of the preadministration dose formulations of DBP were conducted by the study laboratory every 1 to 3 months to determine purity, whereas postadministration (animal room) samples were analyzed every 1 to 8 months (Table A-3, Table A-4). All preadministration formulations for rats and mice were within $10 \%$ of the target concentrations. In the perinatal and 2 -year rat study, all postadministration barrel samples were within $10 \%$ of target concentration, except for the 10,000 ppm formulation prepared on August 9, 2010, which was 13.2\% below the target concentration. Postadministration samples collected from residual feed in the feeders prepared July 8, $2010(10,000 \mathrm{ppm})$ and August 9, $2010(300 \mathrm{ppm})$ were $11.8 \%$ and 10.0\% below the target concentrations, respectively. All other postadministration values were within $10 \%$ of the target concentration. In the 2-year mouse study, postadministration samples of the 
1,000 and 10,000 ppm formulations prepared on August 9, 2010, collected from residual feed in the feeders, were up to $13.4 \%$ below the target concentrations. Additionally, the $10,000 \mathrm{ppm}$ barrel sample was $13.2 \%$ below the target concentration. The postadministration barrel sample from the 10,000 ppm formulation prepared on February 21, 2011 was 12.1\% below the target concentration. All other postadministration values were within $10 \%$ of the target concentration.

Table A-1. Chromatography Systems Used in the Perinatal and Two-year Feed Studies of Di-n-butyl Phthalate

\begin{tabular}{llll}
\hline Chromatography & Detection System & Column & Mobile Phase \\
\hline
\end{tabular}

\section{System A}

Gas chromatography

Mass selective detector

J\&W DB-1 $(25 \mathrm{~m} \times 0.32 \mathrm{~mm}$ ID, $0.25 \mu \mathrm{m}$ film thickness)

Helium, $1.65 \mathrm{~mL} / \mathrm{min}$ flow rate

\section{System B}

Ultra-performance liquid chromatography

Photodiode array detector (205 to $400 \mathrm{~nm}$, extracted at $225 \mathrm{~nm}$ )
Waters Acquity UPLC BEH Phenyl $(2.1 \mathrm{~mm}$ ID $\times 50 \mathrm{~mm}, 1.7 \mu \mathrm{m}$ particle size), with Waters Acquity In-Line Filter $(0.2 \mu \mathrm{m})$
A: Methanol

B: Water Gradient program: A:B $25: 75$ to $75: 25$ in $3 \mathrm{~min}$, hold at 78:22 for $1 \mathrm{~min}$, ramp to 100:0 in $1 \mathrm{~min}$, hold at 100:0 for $1 \mathrm{~min}$, reverse to $25: 75$ in $0.5 \mathrm{~min}$, hold at 25:75 for $1.5 \mathrm{~min}$ $0.6 \mathrm{~mL} / \mathrm{min}$ flow rate

Helium, $1 \mathrm{~mL} / \mathrm{min}$ flow rate
Flame ionization detection $\left(325^{\circ} \mathrm{C}\right)$

\section{System D}

High-performance Ultraviolet $(225 \mathrm{~nm})$ liquid chromatography
J\&W HP-5 (30 m × $0.32 \mathrm{~mm}$ ID, film thickness $0.25 \mu \mathrm{m}$ )

Thermo Scientific Hypersil Phenyl $(250 \mathrm{~mm} \times 4.6 \mathrm{~mm}$ ID, $5 \mu \mathrm{m})$ with Hypersil Phenyl guard $(5 \mu \mathrm{m})$,
A: Methanol

B: ASTM Type I

Water

Gradient program:

A:B 70:30 to $85: 15$ in $5 \mathrm{~min}$, ramp to $100: 0$ in $4 \mathrm{~min}$, hold at 100:0 for $4 \mathrm{~min}$, reverse to $70: 30$ in $0.1 \mathrm{~min}$, hold at $70: 30$ for $10.9 \mathrm{~min}$ $1.0 \mathrm{~mL} / \mathrm{min}$ flow rate

$\mathrm{UPLC}=$ ultra-performance liquid chromatography; $\mathrm{BEH}=$ Ethylene Bridged Hybrid; ID = internal diameter; ATSM = American Society for Testing and Materials. 
Table A-2. Preparation and Storage of Dose Formulations in the Perinatal and Two-year Feed Studies of Di- $n$-butyl Phthalate

\section{Preparation}

Stock solutions of di- $n$-butyl phthalate were created by weighing an appropriate amount of lot MKBB8432 and adding it to a volumetric flask. Acetone was used to bring the solution to volume. Flasks of stock solutions were sealed and shaken until the chemical was dissolved (at least 10 inversions). An initial formulation premix was created by weighing an appropriate amount of feed (NIH-07 or NTP-2000) into a mixing bowl. The stock di- $n$ butyl phthalate solution was slowly poured onto the feed while the mixture was stirred using a Hobart mixer. The premix formulations were mixed for approximately 1 hour and acetone was used twice to rinse the sides of the bowl and incorporate any residuals. The entire procedure was conducted under a nitrogen stream to encourage cyclonic flow and ensure acetone fully evaporated. In a twin shell blender, half the remaining untreated feed was evenly covered with the premix. The sides were "rinsed" with the remaining untreated feed in two increments. The final formulation was mixed in the blender for 15 minutes. The dose formulations were prepared approximately every 4 weeks.

\section{Chemical Lot Number}

MKBB8432

\section{Maximum Storage Time}

42 days

\section{Storage Conditions}

Stored in sealed plastic bag-lined container at $\sim 25^{\circ} \mathrm{C}$

Study Laboratory

Battelle (Columbus, OH)

Table A-3. Results of Analyses of Dose Formulations Administered to Rats in the Perinatal and Two-year Feed Study of Di-n-butyl Phthalate

\begin{tabular}{lcccc}
\hline Date Prepared & Date Analyzed & $\begin{array}{c}\text { Target } \\
\text { Concentration } \\
(\mathbf{p p m})\end{array}$ & $\begin{array}{c}\text { Determined } \\
\text { Concentration } \\
(\mathbf{p p m})^{\mathbf{a}}\end{array}$ & $\begin{array}{c}\text { Difference from } \\
\text { Target (\%) }\end{array}$ \\
\hline July 8, 2010 & July 9, 2010 & 0 & BLOQ & NA \\
& & 300 & $288 \pm 10$ & -4.0 \\
& & 1,000 & $970 \pm 10$ & -3.0 \\
August 9, 2010 & 3,000 & $2,910 \pm 80$ & -3.0 \\
& August 10-12, 2010 & 10,000 & $9,920 \pm 500$ & -0.8 \\
& & 0 & BLOQ & NA \\
& & 300 & $304 \pm 2$ & 1.2 \\
& 1,000 & 997.0 & -0.3 \\
& & 3,000 & $2,775.0$ & -7.5 \\
\hline
\end{tabular}


Di- $n$-butyl Phthalate, NTP TR 600

\begin{tabular}{|c|c|c|c|c|}
\hline Date Prepared & Date Analyzed & $\begin{array}{c}\text { Target } \\
\text { Concentration } \\
(\mathbf{p p m})\end{array}$ & $\begin{array}{c}\text { Determined } \\
\text { Concentration } \\
(\mathrm{ppm})^{\mathrm{a}}\end{array}$ & $\begin{array}{l}\text { Difference from } \\
\text { Target }(\%)\end{array}$ \\
\hline \multirow[t]{5}{*}{ October 4, 2010} & October 5,2010 & 0 & BLOQ & NA \\
\hline & & 300 & $299 \pm 7$ & -0.5 \\
\hline & & 1,000 & 968.5 & -3.2 \\
\hline & & 3,000 & $2,875.0$ & -4.2 \\
\hline & & 10,000 & $9,645.0$ & -3.6 \\
\hline \multirow[t]{5}{*}{ December 20, 2010} & December 20, 2010 & 0 & BLOQ & NA \\
\hline & & 300 & 300.5 & 0.2 \\
\hline & & 1,000 & $1,025.0$ & 2.5 \\
\hline & & 3,000 & $3,040.0$ & 1.3 \\
\hline & & 10,000 & $10,650.0$ & 6.5 \\
\hline \multirow[t]{5}{*}{ February 21, 2011} & February 21, 2011 & 0 & BLOQ & NA \\
\hline & & 300 & 304 & 1.3 \\
\hline & & 1,000 & $1,050.0$ & 5.0 \\
\hline & & 3,000 & $3,045.0$ & 1.5 \\
\hline & & 10,000 & $9,970.0$ & -0.3 \\
\hline \multirow[t]{5}{*}{ May 16, 2011} & May 16, 2011 & 0 & BLOQ & NA \\
\hline & & 300 & 294.5 & -1.8 \\
\hline & & 1,000 & 976.5 & -2.4 \\
\hline & & 3,000 & $2,980.0$ & -0.7 \\
\hline & & 10,000 & $9,045.0$ & -9.6 \\
\hline \multirow[t]{5}{*}{ August 8, 2011} & August 9, 2011 & 0 & BLOQ & NA \\
\hline & & 300 & 293 & -2.3 \\
\hline & & 1,000 & 989.5 & -1.1 \\
\hline & & 3,000 & $3,015.0$ & 0.5 \\
\hline & & 10,000 & $9,210.0$ & -7.9 \\
\hline \multirow[t]{5}{*}{ October 3, 2011} & October 3, 2011 & 0 & BLOQ & NA \\
\hline & & 300 & 295.5 & -1.5 \\
\hline & & 1,000 & 990.5 & -1.0 \\
\hline & & 3,000 & $3,020.0$ & 0.7 \\
\hline & & 10,000 & $9,625.0$ & -3.8 \\
\hline \multirow[t]{5}{*}{ November 28, 2011} & November 30, 2011 & 0 & BLOQ & NA \\
\hline & & 300 & 291.5 & -2.8 \\
\hline & & 1,000 & 957.0 & -4.3 \\
\hline & & 3,000 & $2,975.0$ & -0.8 \\
\hline & & 10,000 & $9,410.0$ & -5.9 \\
\hline \multirow[t]{3}{*}{ February 20, 2012} & February 21, 2012 & 0 & BLOQ & NA \\
\hline & & 300 & 303.5 & 1.2 \\
\hline & & 1,000 & 964.5 & -3.6 \\
\hline
\end{tabular}




\begin{tabular}{|c|c|c|c|c|}
\hline Date Prepared & Date Analyzed & $\begin{array}{c}\text { Target } \\
\text { Concentration } \\
(\text { ppm) }\end{array}$ & $\begin{array}{c}\text { Determined } \\
\text { Concentration } \\
(\text { ppm })^{\mathrm{a}}\end{array}$ & $\begin{array}{l}\text { Difference from } \\
\text { Target }(\%)\end{array}$ \\
\hline \multirow{6}{*}{ May 14, 2012} & \multirow{6}{*}{ May 14, 2012} & 3,000 & $2,865.0$ & -4.5 \\
\hline & & 10,000 & $9,500.0$ & -5.0 \\
\hline & & 0 & BLOQ & NA \\
\hline & & 300 & 295.5 & -1.5 \\
\hline & & 1,000 & 991.5 & -0.9 \\
\hline & & 3,000 & $3,035.0$ & 1.2 \\
\hline \multirow{6}{*}{ July 9, 2012} & \multirow{6}{*}{ July 10, 2012} & 10,000 & $9,675.0$ & -3.3 \\
\hline & & 0 & BLOQ & NA \\
\hline & & 300 & 301.5 & 0.5 \\
\hline & & 1,000 & 1,005 & 0.5 \\
\hline & & 3,000 & $3,005.0$ & 0.2 \\
\hline & & 10,000 & $9,665.0$ & -3.4 \\
\hline \multicolumn{5}{|c|}{ Animal Room Samples } \\
\hline \multirow[t]{10}{*}{ July 8,2010} & \multirow{5}{*}{$\begin{array}{l}\text { August 17, } 2010 \\
\text { (feeder) }\end{array}$} & 0 & BLOQ & NA \\
\hline & & 300 & $284 \pm 4$ & -5.3 \\
\hline & & 1,000 & $923 \pm 15$ & -7.7 \\
\hline & & 3,000 & $2,710 \pm 40$ & -9.8 \\
\hline & & 10,000 & $8,820 \pm 190$ & -11.8 \\
\hline & \multirow{5}{*}{$\begin{array}{l}\text { August 17, } 2010 \\
\text { (barrel) }\end{array}$} & 0 & BLOQ & NA \\
\hline & & 300 & $282 \pm 3$ & -6.0 \\
\hline & & 1,000 & $918 \pm 14$ & -8.2 \\
\hline & & 3,000 & $2,710 \pm 30$ & -9.8 \\
\hline & & 10,000 & $9,050 \pm 110$ & -9.5 \\
\hline \multirow[t]{10}{*}{ August 9, 2010} & \multirow{5}{*}{$\begin{array}{l}\text { September 15, } 2010 \\
\text { (feeder) }\end{array}$} & 0 & BLOQ & NA \\
\hline & & 300 & $268 \pm 5$ & -10.7 \\
\hline & & 1,000 & $900 \pm 50$ & -10.0 \\
\hline & & 3,000 & $3,200 \pm N A^{b}$ & 6.7 \\
\hline & & 10,000 & $9,730 \pm 698$ & -2.7 \\
\hline & \multirow{5}{*}{$\begin{array}{l}\text { September 15, } 2010 \\
\text { (barrel) }\end{array}$} & 0 & BLOQ & NA \\
\hline & & 300 & $288 \pm 1$ & -4.1 \\
\hline & & 1,000 & $971 \pm 25$ & -2.9 \\
\hline & & 3,000 & $2,940 \pm 290$ & -2.0 \\
\hline & & 10,000 & $8,680 \pm 40$ & -13.2 \\
\hline \multirow[t]{5}{*}{ October 4, 2010} & \multirow{5}{*}{$\begin{array}{l}\text { November 9, } 2010 \\
\text { (feeder) }\end{array}$} & 0 & BLOQ & NA \\
\hline & & 300 & $285 \pm 6$ & -5.0 \\
\hline & & 1,000 & $957 \pm 16$ & -4.3 \\
\hline & & 3,000 & $2,790 \pm 50.3$ & -7.1 \\
\hline & & 10,000 & $9,740 \pm 66.6$ & -2.6 \\
\hline
\end{tabular}




\begin{tabular}{|c|c|c|c|c|}
\hline Date Prepared & Date Analyzed & $\begin{array}{c}\text { Target } \\
\text { Concentration } \\
(\mathrm{ppm})\end{array}$ & $\begin{array}{c}\text { Determined } \\
\text { Concentration } \\
(\mathrm{ppm})^{\mathrm{a}}\end{array}$ & $\begin{array}{l}\text { Difference from } \\
\text { Target (\%) }\end{array}$ \\
\hline \multirow{15}{*}{ February 21, 2011} & \multirow{5}{*}{$\begin{array}{l}\text { November 9, } 2010 \\
\text { (barrel) }\end{array}$} & 0 & BLOQ & NA \\
\hline & & 300 & $284 \pm 8$ & -5.3 \\
\hline & & 1,000 & $1,010 \pm 10$ & 0.6 \\
\hline & & 3,000 & $2,840 \pm 10$ & -5.2 \\
\hline & & 10,000 & $9,730 \pm 230$ & -2.7 \\
\hline & \multirow{5}{*}{$\begin{array}{l}\text { March 31, } 2011 \\
\text { (feeder) }\end{array}$} & 0 & BLOQ & NA \\
\hline & & 300 & $292 \pm 6$ & -2.7 \\
\hline & & 1,000 & $976 \pm 6$ & -2.4 \\
\hline & & 3,000 & $2,930 \pm 35.1$ & -2.4 \\
\hline & & 10,000 & $9,320 \pm 337$ & -6.8 \\
\hline & \multirow{5}{*}{$\begin{array}{l}\text { March 31, } 2011 \\
\text { (barrel) }\end{array}$} & 0 & BLOQ & NA \\
\hline & & 300 & $298 \pm 1$ & -0.8 \\
\hline & & 1,000 & $1,020 \pm 10$ & 1.7 \\
\hline & & 3,000 & $2,990 \pm 80$ & -0.4 \\
\hline & & 10,000 & $9,740 \pm 200$ & -2.6 \\
\hline \multirow[t]{10}{*}{ October 3, 2011} & \multirow{5}{*}{$\begin{array}{l}\text { November 9, } 2011 \\
\text { (feeder) }\end{array}$} & 0 & BLOQ & NA \\
\hline & & 300 & $289 \pm 4$ & -3.6 \\
\hline & & 1,000 & $962 \pm 4$ & -3.8 \\
\hline & & 3,000 & $2,880 \pm 51.3$ & -4.1 \\
\hline & & 10,000 & $9,210 \pm 191$ & -7.9 \\
\hline & \multirow{5}{*}{$\begin{array}{l}\text { November 9, } 2011 \\
\text { (barrel) }\end{array}$} & 0 & BLOQ & NA \\
\hline & & 300 & $294 \pm 3$ & -1.9 \\
\hline & & 1,000 & $989 \pm 7$ & -1.1 \\
\hline & & 3,000 & $3,010 \pm 20$ & 0.4 \\
\hline & & 10,000 & $9,470 \pm 420$ & -5.3 \\
\hline \multirow[t]{10}{*}{ May 14, 2012} & \multirow{5}{*}{$\begin{array}{l}\text { June 20, } 2012 \\
\text { (feeder) }\end{array}$} & 0 & BLOQ & NA \\
\hline & & 300 & $290 \pm 2$ & -3.2 \\
\hline & & 1,000 & $973 \pm 9$ & -2.7 \\
\hline & & 3,000 & $3,010 \pm 51.3$ & 0.2 \\
\hline & & 10,000 & $9,050 \pm 90.7$ & -9.5 \\
\hline & \multirow[t]{5}{*}{ June 20, 2012 (barrel) } & 0 & BLOQ & NA \\
\hline & & 300 & $298 \pm 1$ & -0.7 \\
\hline & & 1,000 & $999 \pm 11$ & -0.1 \\
\hline & & 3,000 & $3,020 \pm 50$ & 0.8 \\
\hline & & 10,000 & $9,210 \pm 70$ & -7.9 \\
\hline
\end{tabular}

$\mathrm{BLOQ}=$ below the limit of quantification; $\mathrm{NA}=$ not applicable.

aPreadministration samples are an average of triplicate analysis on two preparations from the same sample or an average and standard deviation of triplicate analysis of a single sample. Animal room samples are an average and standard deviation of triplicate analysis of a single sample.

${ }^{\mathrm{b}}$ Third replicate value Q-tested out, so standard deviation was not calculated. Precision of duplicates (POD) was 1.00. 
Table A-4. Results of Analyses of Dose Formulations Administered to Mice in the Two-year Feed Study of Di-n-butyl Phthalate

\begin{tabular}{|c|c|c|c|c|}
\hline Date Prepared & Date Analyzed & $\begin{array}{c}\begin{array}{c}\text { Target } \\
\text { Concentration } \\
(\mathrm{ppm})\end{array} \\
\end{array}$ & $\begin{array}{c}\text { Determined } \\
\text { Concentration } \\
(\mathrm{ppm})^{\mathrm{a}}\end{array}$ & $\begin{array}{c}\text { Difference from } \\
\text { Target (\%) }\end{array}$ \\
\hline \multirow[t]{4}{*}{ August 9, 2010} & August $10-12,2010$ & 0 & BLOQ & NA \\
\hline & & 1,000 & 997.0 & -0.3 \\
\hline & & 3,000 & $2,775.0$ & -7.5 \\
\hline & & 10,000 & $9,060.0$ & -9.4 \\
\hline \multirow[t]{4}{*}{ October 4, 2010} & October 5, 2010 & 0 & BLOQ & NA \\
\hline & & 1,000 & 968.5 & -3.2 \\
\hline & & 3,000 & $2,875.0$ & -4.2 \\
\hline & & 10,000 & $9,645.0$ & -3.6 \\
\hline \multirow[t]{4}{*}{ December 20, 2010} & December 20, 2010 & 0 & BLOQ & NA \\
\hline & & 1,000 & $1,025.0$ & 2.5 \\
\hline & & 3,000 & $3,040.0$ & 1.3 \\
\hline & & 10,000 & $10,650.0$ & 6.5 \\
\hline \multirow[t]{4}{*}{ February 21, 2011} & February 21, 2011 & 0 & BLOQ & NA \\
\hline & & 1,000 & $1,050.0$ & 5.0 \\
\hline & & 3,000 & $3,045.0$ & 1.5 \\
\hline & & 10,000 & $9,970.0$ & -0.3 \\
\hline \multirow[t]{4}{*}{ May 16, 2011} & May 16, 2011 & 0 & BLOQ & NA \\
\hline & & 1,000 & 976.5 & -2.4 \\
\hline & & 3,000 & $2,980.0$ & -0.7 \\
\hline & & 10,000 & $9,045.0$ & -9.6 \\
\hline \multirow[t]{4}{*}{ August 8, 2011} & August 9, 2011 & 0 & BLOQ & NA \\
\hline & & 1,000 & 989.5 & -1.1 \\
\hline & & 3,000 & $3,015.0$ & 0.5 \\
\hline & & 10,000 & $9,210.0$ & -7.9 \\
\hline \multirow[t]{4}{*}{ October 3, 2011} & October 3, 2011 & 0 & BLOQ & NA \\
\hline & & 1,000 & 990.5 & -1.0 \\
\hline & & 3,000 & $3,020.0$ & 0.7 \\
\hline & & 10,000 & $9,625.0$ & -3.8 \\
\hline \multirow[t]{4}{*}{ November 28, 2011} & November 30, 2011 & 0 & BLOQ & NA \\
\hline & & 1,000 & 957.0 & -4.3 \\
\hline & & 3,000 & $2,975.0$ & -0.8 \\
\hline & & 10,000 & $9,410.0$ & -5.9 \\
\hline
\end{tabular}




\begin{tabular}{|c|c|c|c|c|}
\hline Date Prepared & Date Analyzed & $\begin{array}{c}\text { Target } \\
\text { Concentration } \\
(\mathrm{ppm})\end{array}$ & $\begin{array}{c}\text { Determined } \\
\text { Concentration } \\
(\mathbf{p p m})^{\mathrm{a}}\end{array}$ & $\begin{array}{c}\text { Difference from } \\
\text { Target }(\%)\end{array}$ \\
\hline \multirow[t]{4}{*}{ February 20, 2012} & \multirow[t]{4}{*}{ February 21,2012} & 0 & BLOQ & NA \\
\hline & & 1,000 & 964.5 & -3.6 \\
\hline & & 3,000 & $2,865.0$ & -4.5 \\
\hline & & 10,000 & $9,500.0$ & -5.0 \\
\hline \multirow[t]{4}{*}{ May 14, 2012} & \multirow[t]{4}{*}{ May 14, 2012} & 0 & BLOQ & NA \\
\hline & & 1,000 & 991.5 & -0.9 \\
\hline & & 3,000 & $3,035.0$ & 1.2 \\
\hline & & 10,000 & $9,675.0$ & -3.3 \\
\hline \multirow[t]{4}{*}{ July 9, 2012} & \multirow[t]{4}{*}{ July 10,2012} & 0 & BLOQ & NA \\
\hline & & 1,000 & $1,005.0$ & 0.5 \\
\hline & & 3,000 & $3,005.0$ & 0.2 \\
\hline & & 10,000 & $9,665.0$ & -3.4 \\
\hline \multicolumn{5}{|c|}{ Animal Room Samples } \\
\hline \multirow[t]{8}{*}{ August 9, 2010} & \multirow{4}{*}{$\begin{array}{l}\text { September 15, } 2010 \\
\text { (feeder) }\end{array}$} & 0 & BLOQ & NA \\
\hline & & 1,000 & $866 \pm N^{b}$ & -13.4 \\
\hline & & 3,000 & $2,830 \pm 230$ & -5.7 \\
\hline & & 10,000 & $8,890 \pm 310$ & -11.1 \\
\hline & \multirow{4}{*}{$\begin{array}{l}\text { September 15, } 2010 \\
\text { (barrel) }\end{array}$} & 0 & BLOQ & NA \\
\hline & & 1,000 & $971 \pm 25$ & -2.9 \\
\hline & & 3,000 & $2,940 \pm 290$ & -2.0 \\
\hline & & 10,000 & $8,680 \pm 40$ & -13.2 \\
\hline \multirow[t]{8}{*}{ October 4, 2010} & \multirow{4}{*}{$\begin{array}{l}\text { November 9, } 2010 \\
\text { (feeder) }\end{array}$} & 0 & BLOQ & NA \\
\hline & & 1,000 & $953 \pm 6$ & -4.7 \\
\hline & & 3,000 & $2,730 \pm 60$ & -8.9 \\
\hline & & 10,000 & $9,100 \pm 120$ & -9.0 \\
\hline & \multirow{4}{*}{$\begin{array}{l}\text { November 9, } 2010 \\
\text { (barrel) }\end{array}$} & 0 & BLOQ & NA \\
\hline & & 1,000 & $1,010 \pm 10$ & 0.6 \\
\hline & & 3,000 & $2,840 \pm 10$ & -5.2 \\
\hline & & 10,000 & $9,730 \pm 230$ & -2.7 \\
\hline
\end{tabular}




\begin{tabular}{|c|c|c|c|c|}
\hline Date Prepared & Date Analyzed & $\begin{array}{c}\text { Target } \\
\text { Concentration } \\
(\mathbf{p p m})\end{array}$ & $\begin{array}{c}\text { Determined } \\
\text { Concentration } \\
(\mathrm{ppm})^{\mathrm{a}}\end{array}$ & $\begin{array}{l}\text { Difference from } \\
\text { Target }(\%)\end{array}$ \\
\hline \multirow[t]{8}{*}{ February 21, 2011} & \multirow{4}{*}{$\begin{array}{l}\text { March 31, } 2011 \\
\text { (feeder) }\end{array}$} & 0 & BLOQ & NA \\
\hline & & 1,000 & $973 \pm 5$ & -2.7 \\
\hline & & 3,000 & $2,960 \pm 30$ & -1.2 \\
\hline & & 10,000 & $8,790 \pm 50$ & -12.1 \\
\hline & \multirow{4}{*}{$\begin{array}{l}\text { March 31, } 2011 \\
\text { (barrel) }\end{array}$} & 0 & BLOQ & NA \\
\hline & & 1,000 & $1,020 \pm 10$ & 1.7 \\
\hline & & 3,000 & $2,990 \pm 80$ & -0.4 \\
\hline & & 10,000 & $9,740 \pm 200$ & -2.6 \\
\hline \multirow[t]{8}{*}{ October 3, 2011} & \multirow{4}{*}{$\begin{array}{l}\text { November 9, } 2011 \\
\text { (feeder) }\end{array}$} & 0 & BLOQ & NA \\
\hline & & 1,000 & $973 \pm 4$ & -2.7 \\
\hline & & 3,000 & $2,840 \pm 70$ & -5.4 \\
\hline & & 10,000 & $9,260 \pm 120$ & -7.4 \\
\hline & \multirow{4}{*}{$\begin{array}{l}\text { November 9, } 2011 \\
\text { (barrel) }\end{array}$} & 0 & BLOQ & NA \\
\hline & & 1,000 & $989 \pm 7$ & -1.1 \\
\hline & & 3,000 & $3,010 \pm 20$ & 0.4 \\
\hline & & 10,000 & $9,470 \pm 420$ & -5.3 \\
\hline \multirow[t]{8}{*}{ May 14, 2012} & \multirow{4}{*}{$\begin{array}{l}\text { June 20, } 2012 \\
\text { (feeder) }\end{array}$} & 0 & BLOQ & NA \\
\hline & & 1,000 & $993 \pm 8$ & -0.7 \\
\hline & & 3,000 & $2,990 \pm 20$ & -0.2 \\
\hline & & 10,000 & $9,240 \pm 100$ & -7.6 \\
\hline & \multirow{4}{*}{$\begin{array}{l}\text { June 20, } 2012 \\
\text { (barrel) }\end{array}$} & 0 & BLOQ & NA \\
\hline & & 1,000 & $999 \pm 11$ & -0.1 \\
\hline & & 3,000 & $3,020 \pm 50$ & 0.8 \\
\hline & & 10,000 & $9,210 \pm 70$ & -7.9 \\
\hline
\end{tabular}

$\mathrm{BLOQ}=$ below the limit of quantification; $\mathrm{NA}=$ not applicable.

aPreadministration samples are an average of triplicate analysis on two preparations from the same sample. Animal room samples are an average and standard deviation of triplicate analysis of a single sample.

${ }^{\mathrm{b}}$ Third replicate value Q-tested out, so standard deviation was not calculated. Precision of duplicates (POD) was 1.01. 


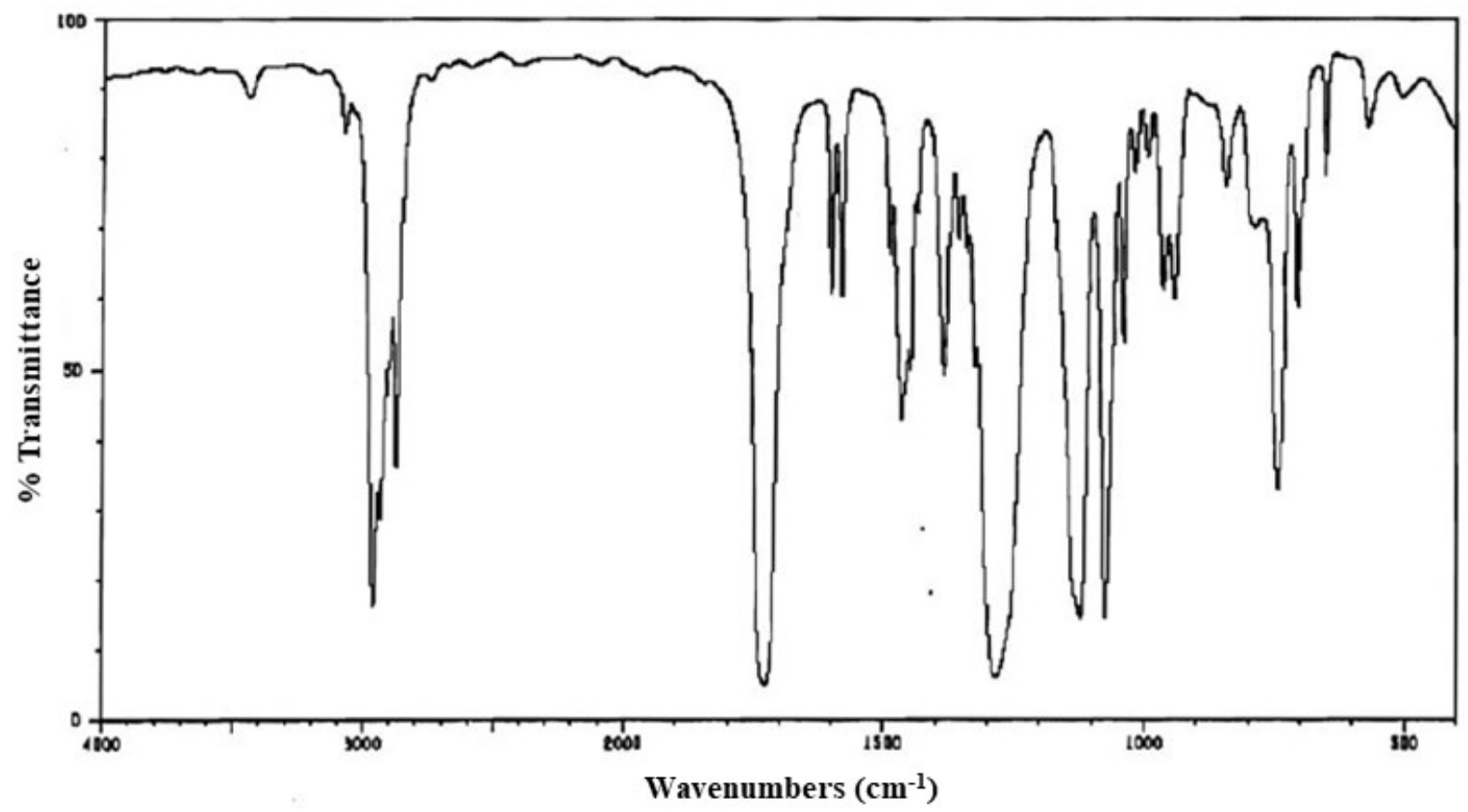

Figure A-1. Reference Fourier Transformed Infrared Absorption Spectrum of Di-n-butyl Phthalate

Reference spectra: Sigma-Aldrich Product No. 524980, http://www.sigmaaldrich.com/spectra/ftir/FTIR001338.PDF (accessed Dec 22, 2009).

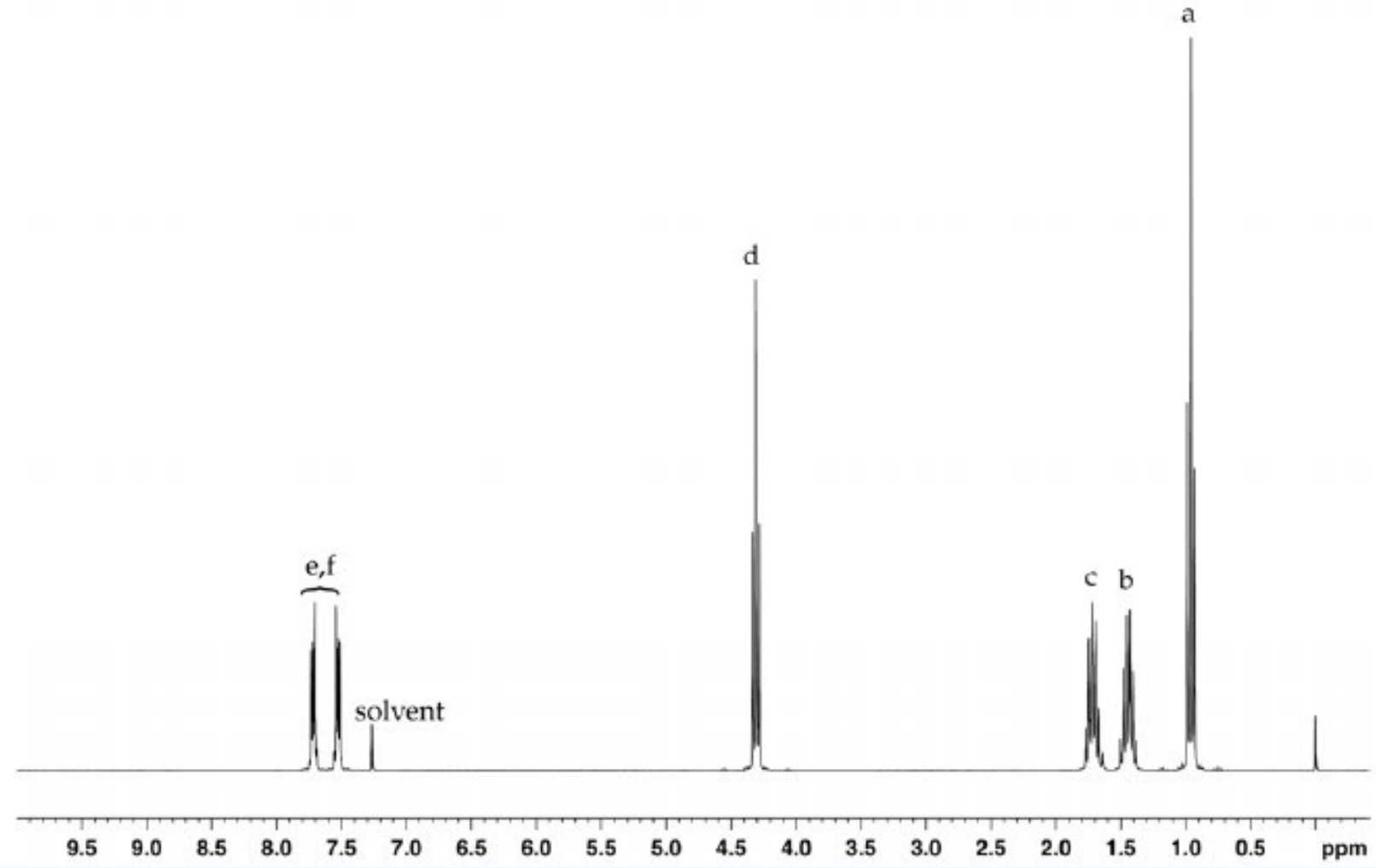

Figure A-2. ${ }^{1}$ H NMR Spectrum of Sample of Di- $n$-butyl Phthalate (Lot MKBB8432)

Reference spectra: Sigma-Aldrich Product No. 524980, http://www.sigmaaldrich.com/spectra/fnmr/FNMR001553.PDF (accessed Dec 22, 2009). 


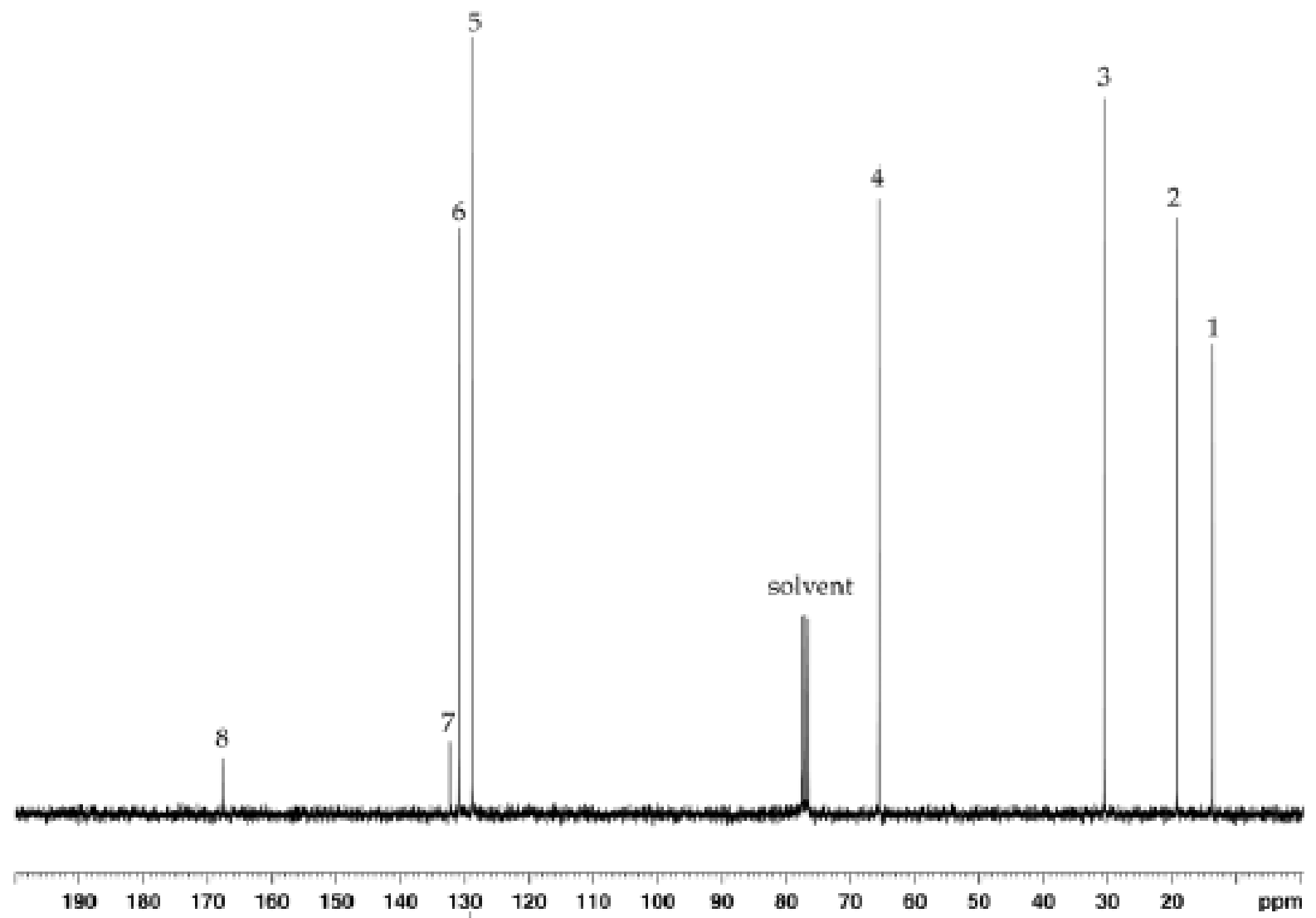

Figure A-3. ${ }^{13}$ C NMR Spectrum of Sample of Di- $n$-butyl Phthalate (Lot MKBB8432)

Sigma-Aldrich Product No. 524980, http://www.sigmaaldrich.com/spectra/fnmm/FNMR001553.PDF (accessed Dec 22, 2009). 


\section{Appendix B. Ingredients, Nutrient Composition, and Contaminant Levels in NIH-07 and NTP-2000 Rat and Mouse Ration}

\section{Tables}

Table B-1. Ingredients of NIH-07 Rat Ration B-2

Table B-2. Vitamins and Minerals in NIH-07 Rat Ration B-2

Table B-3. Nutrient Composition of NIH-07 Rat Ration B-3

Table B-4. Contaminant Levels in NIH-07 Rat Ration B-4

Table B-5. Ingredients of NTP-2000 Rat and Mouse Ration B-6

Table B-6. Vitamins and Minerals in NTP-2000 Rat and Mouse Ration B-7

Table B-7. Nutrient Composition of NTP-2000 Rat and Mouse Ration B-7

Table B-8. Contaminant Levels in NTP-2000 Rat and Mouse Ration 
Table B-1. Ingredients of NIH-07 Rat Ration

\begin{tabular}{|c|c|c|}
\hline Ingredients & & Percent by Weight \\
\hline Ground Hard Winter Wheat & & 23.00 \\
\hline Ground \#2 Yellow Shelled Corn & & 24.25 \\
\hline Wheat Middlings & & 10.0 \\
\hline Oat Hulls & & 0.0 \\
\hline Alfalfa Meal (Dehydrated, $17 \%$ Protein) & & 4.0 \\
\hline Purified Cellulose & & 0.0 \\
\hline Soybean Meal (47\% Protein) & & 12.0 \\
\hline Fish Meal (62\% Protein) & & 10.0 \\
\hline Corn Oil (without Preservatives) & & 0.0 \\
\hline Soy Oil (without Preservatives) & & 2.5 \\
\hline Dried Brewer's Yeast & & 2.0 \\
\hline Calcium Carbonate (USP) & & 0.5 \\
\hline Vitamin Premix ${ }^{\mathrm{a}}$ & & 0.25 \\
\hline Mineral Premix ${ }^{b}$ & & 0.15 \\
\hline Calcium Phosphate, Dibasic (USP) & & 1.25 \\
\hline Sodium Chloride & & 0.5 \\
\hline Choline Chloride ( $70 \%$ Choline) & & 0.10 \\
\hline Dried Skim Milk & & 5.00 \\
\hline Dried Molasses & & 1.50 \\
\hline Corn Gluten Meal (60\% Protein) & & 3.00 \\
\hline Methionine & & 0.00 \\
\hline \multicolumn{3}{|l|}{$\begin{array}{l}\text { USP = United States Pharmacopeia. } \\
\text { aWheat middlings as carrier. } \\
\text { aW } \\
{ }^{b} \text { Calcium carbonate as carrier. }\end{array}$} \\
\hline & Amount $\mathbf{A}^{\mathrm{a}}$ & Source \\
\hline \multicolumn{3}{|l|}{ Vitamins } \\
\hline Vitamin A & $6,062 \mathrm{IU}$ & Stabilized vitamin A palmitate or acetate \\
\hline Vitamin D & $5,070 \mathrm{IU}$ & D-activated animal sterol \\
\hline Vitamin $\mathrm{K}$ & $3.1 \mathrm{mg}$ & Menadione sodium bisulfite complex \\
\hline Vitamin E & $22 \mathrm{IU}$ & $\alpha$-Tocopheryl acetate \\
\hline Niacin & $33 \mathrm{mg}$ & \\
\hline Folic Acid & $2.4 \mathrm{mg}$ & \\
\hline d-Pantothenic Acid & $19.8 \mathrm{mg}$ & d-Calcium pantothenate \\
\hline Riboflavin & $3.8 \mathrm{mg}$ & \\
\hline
\end{tabular}


Di- $n$-butyl Phthalate, NTP TR 600

\begin{tabular}{lcl}
\hline & Amount & \multicolumn{1}{c}{ Source } \\
\hline Thiamine & $11 \mathrm{mg}$ & Thiamine mononitrate \\
$\mathrm{B}_{12}$ & $50 \mu \mathrm{g}$ & \\
Pyridoxine & $6.5 \mathrm{mg}$ & Pyridoxine hydrochloride \\
Biotin & $0.15 \mathrm{mg}$ & d-Biotin \\
Minerals & & \\
Iron & $132 \mathrm{mg}$ & Iron sulfate \\
Zinc & $18 \mathrm{mg}$ & Zinc oxide \\
Manganese & $66 \mathrm{mg}$ & Manganese oxide \\
Copper & $4.4 \mathrm{mg}$ & Copper sulfate \\
Iodine & $2.0 \mathrm{mg}$ & Calcium iodate \\
Cobalt & $0.44 \mathrm{mg}$ & Cobalt carbonate \\
aPer kg of finished diet. & &
\end{tabular}

Table B-3. Nutrient Composition of NIH-07 Rat Ration

\begin{tabular}{lccc}
\hline \multicolumn{1}{c}{ Nutrient } & $\begin{array}{c}\text { Mean } \pm \text { Standard } \\
\text { Deviation }\end{array}$ & Range & Number of Samples \\
\hline Protein (\% by Weight) & $24.25 \pm 1.485$ & $23.2-25.3$ & 2 \\
Crude Fat (\% by Weight) & $5.5 \pm 0.424$ & $5.2-5.8$ & 2 \\
Crude Fiber (\% by Weight) & $3.515 \pm 0.191$ & $3.38-3.65$ & 2 \\
Ash (\% by Weight) & $6.135 \pm 0.021$ & $6.12-6.15$ & 2 \\
Amino Acids (\% of Total Diet) & & & 10 \\
Arginine & $1.380 \pm 0.06$ & $1.3-1.49$ & 10 \\
Cystine & $0.322 \pm 0.031$ & $0.274-0.372$ & 10 \\
Glycine & $1.150 \pm 0.070$ & $1.06-1.31$ & 10 \\
Histidine & $0.518 \pm 0.024$ & $0.497-0.553$ & 10 \\
Isoleucine & $0.984 \pm 0.024$ & $0.952-1.03$ & 10 \\
Leucine & $2.018 \pm 0.067$ & $1.93-2.13$ & 10 \\
Lysine & $1.243 \pm 0.051$ & $1.13-1.32$ & 10 \\
Methionine & $0.488 \pm 0.016$ & $0.468-0.515$ & 10 \\
Phenylalanine & $1.097 \pm 0.022$ & $1.07-1.12$ & 10 \\
Threonine & $0.918 \pm 0.031$ & $0.883-0.961$ & 10 \\
Tryptophan & $0.277 \pm 0.020$ & $0.265-0.326$ & 10 \\
Tyrosine & $0.860 \pm 0.037$ & $0.785-0.894$ & 10 \\
Valine & $1.134 \pm 0.025$ & $1.11-1.17$ & \\
Essential Fatty Acids (\% of Total Diet) & & & \\
Linoleic & $2.30 \pm 0.219$ & $1.99-2.59$ & $0.217-0.296$ \\
Linolenic & $0.25 \pm 0.275$ & & \\
\hline
\end{tabular}




\begin{tabular}{|c|c|c|c|}
\hline Nutrient & $\begin{array}{c}\text { Mean } \pm \text { Standard } \\
\text { Deviation }\end{array}$ & Range & Number of Samples \\
\hline \multicolumn{4}{|l|}{ Vitamins } \\
\hline Vitamin A (IU/kg) & $4,085 \pm 161.9$ & $2,940-5,230$ & 2 \\
\hline$\alpha$-Tocopherol (ppm) & $6,704 \pm 21,045$ & $40.3-66,600$ & 10 \\
\hline Thiamine $(\mathrm{ppm})^{\mathrm{a}}$ & $10.6 \pm 0.283$ & $10.4-10.8$ & 2 \\
\hline Riboflavin (ppm) & $14.47 \pm 3.352$ & $10.0-19.8$ & 10 \\
\hline Niacin (ppm) & $99.33 \pm 8.235$ & $87.0-112.0$ & 10 \\
\hline Pantothenic Acid (ppm) & $44.38 \pm 3.806$ & $38.2-51.1$ & 10 \\
\hline Pyridoxine $(\mathrm{ppm})^{\mathrm{a}}$ & $12.876 \pm 3.171$ & $9.63-19.7$ & 10 \\
\hline Folic Acid (ppm) & $2.482 \pm 0.487$ & $1.68-3.09$ & 10 \\
\hline Biotin (ppm) & $0.3283 \pm 0.172$ & $0.0-0.638$ & 10 \\
\hline $\mathrm{B}_{12}(\mathrm{ppb})$ & $49.4 \pm 6.83$ & $41.8-61.6$ & 10 \\
\hline Choline (as Chloride) (ppm) & $1,821 \pm 197.5$ & $1,570-2,200$ & 10 \\
\hline \multicolumn{4}{|l|}{ Minerals } \\
\hline Calcium (\%) & $1.140 \pm 0.014$ & $1.13-1.15$ & 2 \\
\hline Phosphorus (\%) & $0.955 \pm 0.006$ & $0.951-0.959$ & 2 \\
\hline Potassium (\%) & $0.830 \pm 0.036$ & $0.769-0.88$ & 10 \\
\hline Chloride (\%) & $0.652 \pm 0.106$ & $0.441-0.8$ & 10 \\
\hline Sodium (\%) & $0.378 \pm 0.46$ & $0.318-0.469$ & 10 \\
\hline Magnesium (\%) & $0.187 \pm 0.014$ & $0.17-0.218$ & 10 \\
\hline Iron (ppm) & $385.1 \pm 54.9$ & $276.0-469.0$ & 10 \\
\hline Manganese (ppm) & $90.81 \pm 7.566$ & $80.7-104.0$ & 10 \\
\hline Zinc (ppm) & $64.15 \pm 10.07$ & $52.4-89.2$ & 10 \\
\hline Copper (ppm) & $14.13 \pm 2.57$ & $11.9-21.1$ & 10 \\
\hline Iodine (ppm) & $1.811 \pm 0.992$ & $0.54-3.45$ & 10 \\
\hline Chromium (ppm) & $3.946 \pm 0.036$ & $3.89-4.0$ & 8 \\
\hline Cobalt (ppm) & $0.5155 \pm 0.267$ & $0.01-0.963$ & 10 \\
\hline \multicolumn{4}{|l|}{ as hydrochloride. } \\
\hline \multicolumn{4}{|c|}{ Table B-4. Contaminant Levels in NIH-07 Rat Ration } \\
\hline & $\begin{array}{c}\text { Mean } \pm \text { Standard } \\
\text { Deviation }\end{array}$ & Range & Number of Samples \\
\hline \multicolumn{4}{|l|}{ Contaminants } \\
\hline Arsenic (ppm) & $0.355 \pm 0.010$ & $0.348-0.362$ & 2 \\
\hline Cadmium (ppm) & $0.0445 \pm 0.005$ & $0.041-0.048$ & 2 \\
\hline Lead (ppm) & $0.0885 \pm 0.018$ & $0.076-0.101$ & 2 \\
\hline Mercury (ppm) & $0.022 \pm 0.001$ & $0.021-0.023$ & 2 \\
\hline
\end{tabular}


Di-n-butyl Phthalate, NTP TR 600

\begin{tabular}{|c|c|c|c|}
\hline & $\begin{array}{c}\text { Mean } \pm \text { Standard } \\
\text { Deviation }\end{array}$ & Range & Number of Samples \\
\hline Selenium (ppm) & $0.5125 \pm 0.046$ & $0.48-0.545$ & 2 \\
\hline Aflatoxins (ppb) ${ }^{\mathrm{a}}$ & 5 & - & 2 \\
\hline Nitrate Nitrogen $(\mathrm{ppm})^{\mathrm{b}}$ & $15 \pm 3.677$ & $12.4-17.6$ & 2 \\
\hline Nitrite Nitrogen $(\mathrm{ppm})^{\mathrm{a}, \mathrm{b}}$ & $<0.61$ & - & 2 \\
\hline BHA $(p p m)^{\mathrm{a}, \mathrm{c}}$ & $<1.0$ & - & 2 \\
\hline BHT (ppm) $)^{\mathrm{a}, \mathrm{c}}$ & $<1.0$ & - & 2 \\
\hline Aerobic Plate Count (CFU/gm) & $<10$ & - & 2 \\
\hline Coliform (MPN/gm) & $<3$ & - & 2 \\
\hline Escherichia coli (MPN/gm) & $<10$ & - & 2 \\
\hline Salmonella (MPN/gm) & Negative & - & 2 \\
\hline Total Nitrosamines $(\mathrm{ppb})^{\mathrm{d}}$ & $1.8 \pm 2.546$ & $0.0-3.6$ & 2 \\
\hline N-Nitrosodimethylamine (ppb) ${ }^{\mathrm{d}}$ & $1.8 \pm 2.546$ & $0.0-3.6$ & 2 \\
\hline N-Nitrosopyrrolidine $(p p b)^{d}$ & 0 & - & 2 \\
\hline \multicolumn{4}{|l|}{ Pesticides (ppm) } \\
\hline$\alpha-\mathrm{BHC}^{\mathrm{a}}$ & $<0.01$ & - & 2 \\
\hline$\beta-\mathrm{BHC}^{\mathrm{a}}$ & $<0.02$ & - & 2 \\
\hline$\gamma-\mathrm{BHC}^{\mathrm{a}}$ & $<0.01$ & - & 2 \\
\hline$\delta-\mathrm{BHC}^{\mathrm{a}}$ & $<0.01$ & - & 2 \\
\hline Heptachlor $^{\mathrm{a}}$ & $<0.01$ & - & 2 \\
\hline Aldrin $^{\mathrm{a}}$ & $<0.01$ & - & 2 \\
\hline Heptachlor Epoxide ${ }^{a}$ & $<0.01$ & - & 2 \\
\hline $\mathrm{DDE}^{\mathrm{a}}$ & $<0.01$ & - & 2 \\
\hline $\mathrm{DDD}^{\mathrm{a}}$ & $<0.01$ & - & 2 \\
\hline $\mathrm{DDT}^{\mathrm{a}}$ & $<0.01$ & - & 2 \\
\hline $\mathrm{HCB}^{\mathrm{a}}$ & $<0.01$ & - & 2 \\
\hline Mirex $^{a}$ & $<0.01$ & - & 2 \\
\hline Methoxychlor ${ }^{\mathrm{a}}$ & $<0.05$ & - & 2 \\
\hline Dieldrin $^{\mathrm{a}}$ & $<0.01$ & - & 2 \\
\hline Endrin $^{\mathrm{a}}$ & $<0.01$ & - & 2 \\
\hline Telodrin $^{\mathrm{a}}$ & $<0.01$ & - & 2 \\
\hline Chlordane $^{\mathrm{a}}$ & $<0.05$ & - & 2 \\
\hline Toxaphene $^{\mathrm{a}}$ & $<0.10$ & - & 2 \\
\hline Estimated $\mathrm{PCBs}^{\mathrm{a}}$ & $<0.20$ & - & 2 \\
\hline Ronnel $^{\mathrm{a}}$ & $<0.01$ & - & 2 \\
\hline Ethion $^{\mathrm{a}}$ & $<0.02$ & - & 2 \\
\hline
\end{tabular}


Di- $n$-butyl Phthalate, NTP TR 600

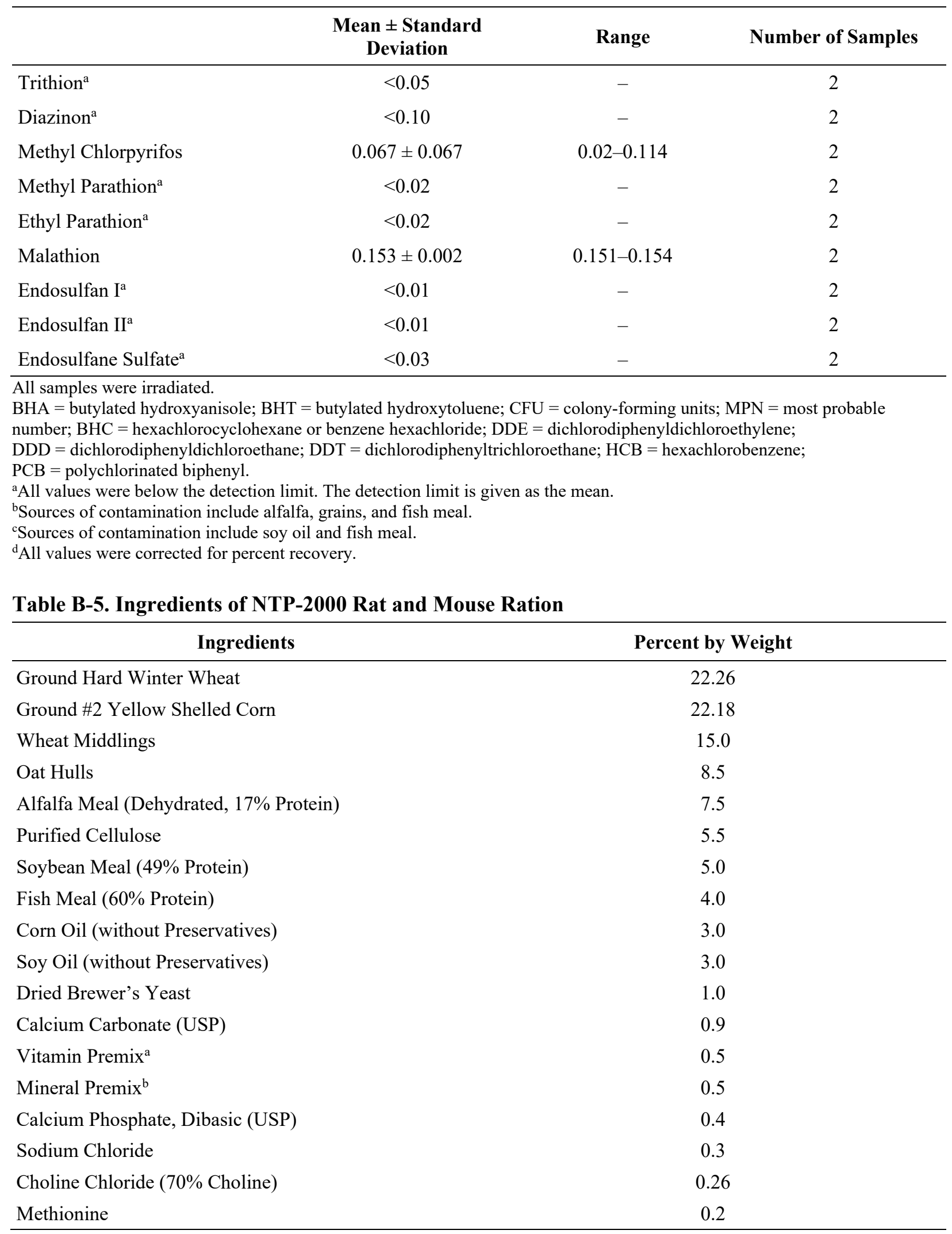

USP $=$ United States Pharmacopeia.

${ }^{a}$ Wheat middlings as carrier.

${ }^{b}$ Calcium carbonate as carrier. 
Table B-6. Vitamins and Minerals in NTP-2000 Rat and Mouse Ration

\begin{tabular}{|c|c|c|}
\hline & Amount $^{\mathrm{a}}$ & Source \\
\hline \multicolumn{3}{|l|}{ Vitamins } \\
\hline Vitamin A & $4,000 \mathrm{IU}$ & Stabilized vitamin A palmitate or acetate \\
\hline Vitamin D & $1,000 \mathrm{IU}$ & D-activated animal sterol \\
\hline Vitamin K & $1.0 \mathrm{mg}$ & Menadione sodium bisulfite complex \\
\hline$\alpha$-Tocopheryl Acetate & $100 \mathrm{IU}$ & - \\
\hline Niacin & $23 \mathrm{mg}$ & - \\
\hline Folic Acid & $1.1 \mathrm{mg}$ & - \\
\hline d-Pantothenic Acid & $10 \mathrm{mg}$ & d-Calcium pantothenate \\
\hline Riboflavin & $3.3 \mathrm{mg}$ & - \\
\hline Thiamine & $4 \mathrm{mg}$ & Thiamine mononitrate \\
\hline $\mathrm{B}_{12}$ & $52 \mu \mathrm{g}$ & - \\
\hline Pyridoxine & $6.3 \mathrm{mg}$ & Pyridoxine hydrochloride \\
\hline Biotin & $0.2 \mathrm{mg}$ & d-Biotin \\
\hline \multicolumn{3}{|l|}{ Minerals } \\
\hline Magnesium & $514 \mathrm{mg}$ & Magnesium oxide \\
\hline Iron & $35 \mathrm{mg}$ & Iron sulfate \\
\hline Zinc & $12 \mathrm{mg}$ & Zinc oxide \\
\hline Manganese & $10 \mathrm{mg}$ & Manganese oxide \\
\hline Copper & $2.0 \mathrm{mg}$ & Copper sulfate \\
\hline Iodine & $0.2 \mathrm{mg}$ & Calcium iodate \\
\hline Chromium & $0.2 \mathrm{mg}$ & Chromium acetate \\
\hline
\end{tabular}

aer kg of finished product.

Table B-7. Nutrient Composition of NTP-2000 Rat and Mouse Ration

\begin{tabular}{lccc}
\hline \multicolumn{1}{c}{ Nutrient } & $\begin{array}{c}\text { Mean } \pm \text { Standard } \\
\text { Deviation }\end{array}$ & Range & Number of Samples \\
\hline Protein (\% by Weight) & $14.81 \pm 0.544$ & $14.2-16.8$ & 25 \\
Crude Fat (\% by Weight) & $8.72 \pm 0.367$ & $8.0-9.7$ & 25 \\
Crude Fiber (\% by Weight) & $9.38 \pm 0.442$ & $8.34-10.1$ & 25 \\
Ash (\% by Weight) & $5.3 \pm 0.187$ & $4.6-14.2$ & 25 \\
Amino Acids (\% of Total Diet) & & & \\
Arginine & $0.805 \pm 0.075$ & $0.67-0.97$ & 29 \\
Cystine & $0.220 \pm 0.021$ & $0.15-0.025$ & 29 \\
Glycine & $0.702 \pm 0.038$ & $0.62-0.80$ & 29 \\
Histidine & $0.342 \pm 0.070$ & $0.27-0.68$ & 29 \\
Isoleucine & $0.549 \pm 0.040$ & $0.43-0.66$ & 29 \\
Leucine & $1.100 \pm 0.063$ & $0.96-1.24$ & 29 \\
\hline
\end{tabular}




\begin{tabular}{|c|c|c|c|}
\hline Nutrient & $\begin{array}{c}\text { Mean } \pm \text { Standard } \\
\text { Deviation }\end{array}$ & Range & Number of Samples \\
\hline Lysine & $0.700 \pm 0.104$ & $0.31-0.86$ & 29 \\
\hline Methionine & $0.409 \pm 0.042$ & $0.26-0.49$ & 29 \\
\hline Phenylalanine & $0.623 \pm 0.047$ & $0.471-0.72$ & 29 \\
\hline Threonine & $0.513 \pm 0.041$ & $0.43-0.61$ & 29 \\
\hline Tryptophan & $0.155 \pm 0.027$ & $0.11-0.2$ & 29 \\
\hline Tyrosine & $0.422 \pm 0.066$ & $0.28-0.54$ & 29 \\
\hline Valine & $0.666 \pm 0.040$ & $0.55-0.73$ & 29 \\
\hline \multicolumn{4}{|c|}{ Essential Fatty Acids (\% of Total Diet) } \\
\hline Linoleic & $3.94 \pm 0.235$ & $3.49-4.55$ & 29 \\
\hline Linolenic & $0.30 \pm 0.064$ & $0.005-0.368$ & 29 \\
\hline \multicolumn{4}{|l|}{ Vitamins } \\
\hline Vitamin A (IU/kg) & $3,821 \pm 80.2$ & $2,030-5,290$ & 25 \\
\hline$\alpha$-Tocopherol (ppm) & $2,456 \pm 12,817$ & $13.6-69,100$ & 29 \\
\hline Thiamine $(\mathrm{ppm})^{\mathrm{a}}$ & $8.47 \pm 1.958$ & $3.9-12.5$ & 25 \\
\hline Riboflavin (ppm) & $8.17 \pm 2.841$ & $4.2-17.5$ & 29 \\
\hline Niacin (ppm) & $78.66 \pm 8.11$ & $66.4-98.2$ & 29 \\
\hline Pantothenic Acid (ppm) & $26.42 \pm 11.05$ & $17.4-81.0$ & 29 \\
\hline Pyridoxine $(\mathrm{ppm})^{\mathrm{a}}$ & $9.75 \pm 2.045$ & $6.44-14.3$ & 29 \\
\hline Folic Acid (ppm) & $1.58 \pm 0.43$ & $1.15-3.27$ & 29 \\
\hline Biotin (ppm) & $0.323 \pm 0.093$ & $0.2-0.704$ & 29 \\
\hline $\mathrm{B}_{12}(\mathrm{ppb})$ & $50.41 \pm 34.89$ & $18.3-174$ & 29 \\
\hline Choline (as Chloride) (ppm) & $2,593 \pm 633.8$ & $1,160-3,790$ & 29 \\
\hline \multicolumn{4}{|l|}{ Minerals } \\
\hline Calcium (\%) & $0.911 \pm 0.046$ & $0.831-1.03$ & 25 \\
\hline Phosphorus (\%) & $0.547 \pm 0.105$ & $0.0531-0.613$ & 25 \\
\hline Potassium (\%) & $0.668 \pm 0.029$ & $0.626-0.733$ & 29 \\
\hline Chloride (\%) & $0.392 \pm 0.044$ & $0.3-0.517$ & 29 \\
\hline Sodium $(\%)$ & $0.195 \pm 0.027$ & $0.16-0.283$ & 29 \\
\hline Magnesium (\%) & $0.217 \pm 0.054$ & $0.185-0.49$ & 29 \\
\hline Iron (ppm) & $191.6 \pm 36.18$ & $135-311$ & 29 \\
\hline Manganese (ppm) & $50.11 \pm 9.42$ & $21-73.1$ & 29 \\
\hline Zinc (ppm) & $57.3 \pm 25.54$ & $43.3-184$ & 29 \\
\hline Copper (ppm) & $7.57 \pm 2.49$ & $3.21-16.3$ & 29 \\
\hline Iodine (ppm) & $0.513 \pm 0.221$ & $0-0.972$ & 29 \\
\hline Chromium (ppm) & $1.02 \pm 1.04$ & $0.33-3.97$ & 28 \\
\hline Cobalt (ppm) & $0.222 \pm 0.152$ & $0.0857-0.864$ & 27 \\
\hline
\end{tabular}


Di- $n$-butyl Phthalate, NTP TR 600

Table B-8. Contaminant Levels in NTP-2000 Rat and Mouse Ration

\begin{tabular}{|c|c|c|c|}
\hline & $\begin{array}{c}\text { Mean } \pm \text { Standard } \\
\text { Deviation }\end{array}$ & Range & Number of Samples \\
\hline \multicolumn{4}{|l|}{ Contaminants } \\
\hline Arsenic (ppm) & $0.22 \pm 0.066$ & $0.149-0.385$ & 25 \\
\hline Cadmium (ppm) & $0.054 \pm 0.013$ & $0.038-0.094$ & 25 \\
\hline Lead (ppm) & $0.132 \pm 0.104$ & $0.064-0.474$ & 25 \\
\hline Mercury (ppm) & $0.014 \pm 0.009$ & $0.01-0.049$ & 25 \\
\hline Selenium (ppm) & $0.16 \pm 0.031$ & $0.029-0.209$ & 25 \\
\hline Aflatoxins $(\mathrm{ppb})^{\mathrm{a}}$ & $<5.0$ & - & 25 \\
\hline Nitrate Nitrogen $(\mathrm{ppm})^{\mathrm{b}}$ & $15.04 \pm 4.97$ & $10.0-28.1$ & 25 \\
\hline Nitrite Nitrogen (ppm) $)^{\mathrm{a}, \mathrm{b}}$ & $<0.61$ & - & 25 \\
\hline BHA (ppm) $)^{\mathrm{a}, \mathrm{c}}$ & $<1.00$ & - & 25 \\
\hline BHT $(\mathrm{ppm})^{\mathrm{c}}$ & $1.09 \pm 0.428$ & $1.0-3.14$ & 25 \\
\hline Aerobic Plate Count (CFU/gm) & $<10.0$ & - & 25 \\
\hline Coliform (MPN/gm) & $<3$ & - & 25 \\
\hline Escherichia coli (MPN/gm) & $<10.0$ & - & 25 \\
\hline Salmonella (MPN/gm) & Negative & - & 25 \\
\hline Total Nitrosamines (ppb) ${ }^{\mathrm{d}}$ & $11.7 \pm 5.58$ & $3.2-24.5$ & 25 \\
\hline N-Ndimethylamine $(\mathrm{ppb})^{\mathrm{d}}$ & $2.6 \pm 1.66$ & $1.0-6.8$ & 25 \\
\hline N-Npyrrolidine $(\mathrm{ppb})^{\mathrm{d}}$ & $9.2 \pm 5.16$ & $2.1-20.0$ & 25 \\
\hline \multicolumn{4}{|l|}{ Pesticides (ppm) } \\
\hline$\alpha-\mathrm{BHC}^{\mathrm{a}}$ & $<0.01$ & - & 25 \\
\hline$\beta-\mathrm{BHC}^{\mathrm{a}}$ & $<0.02$ & - & 25 \\
\hline$\gamma-\mathrm{BHC}^{\mathrm{a}}$ & $<0.01$ & - & 25 \\
\hline$\delta-\mathrm{BHC}^{\mathrm{a}}$ & $<0.01$ & - & 25 \\
\hline Heptachlor $^{\mathrm{a}}$ & $<0.01$ & - & 25 \\
\hline Aldrin $^{\mathrm{a}}$ & $<0.01$ & - & 25 \\
\hline Heptachlor Epoxide ${ }^{a}$ & $<0.01$ & - & 25 \\
\hline $\mathrm{DDE}^{\mathrm{a}}$ & $<0.01$ & - & 25 \\
\hline $\mathrm{DDD}^{\mathrm{a}}$ & $<0.01$ & - & 25 \\
\hline $\mathrm{DDT}^{\mathrm{a}}$ & $<0.01$ & - & 25 \\
\hline $\mathrm{HCB}^{\mathrm{a}}$ & $<0.01$ & - & 25 \\
\hline Mirex $^{a}$ & $<0.01$ & - & 25 \\
\hline Methoxychlor $^{\mathrm{a}}$ & $<0.05$ & - & 25 \\
\hline Dieldrin $^{\mathrm{a}}$ & $<0.01$ & - & 25 \\
\hline Endrin $^{\mathrm{a}}$ & $<0.01$ & - & 25 \\
\hline
\end{tabular}




\begin{tabular}{|c|c|c|c|}
\hline & $\begin{array}{c}\text { Mean } \pm \text { Standard } \\
\text { Deviation }\end{array}$ & Range & Number of Samples \\
\hline Telodrin $^{\mathrm{a}}$ & $<0.01$ & - & 25 \\
\hline Chlordane $^{\mathrm{a}}$ & $<0.05$ & - & 25 \\
\hline Toxaphene $^{\mathrm{a}}$ & $<0.10$ & - & 25 \\
\hline Estimated PCBs ${ }^{\mathrm{a}}$ & $<0.20$ & - & 25 \\
\hline Ronnel $^{\mathrm{a}}$ & $<0.01$ & - & 25 \\
\hline Ethion $^{\mathrm{a}}$ & $<0.02$ & - & 25 \\
\hline Trithion $^{\mathrm{a}}$ & $<0.05$ & - & 25 \\
\hline Diazinon $^{\mathrm{a}}$ & $<0.10$ & - & 25 \\
\hline Methyl Chlorpyrifos & $0.09 \pm 0.073$ & $0.02-0.315$ & 25 \\
\hline Methyl Parathion ${ }^{\mathrm{a}}$ & $<0.02$ & - & 25 \\
\hline Ethyl Parathion ${ }^{\mathrm{a}}$ & $<0.02$ & - & 25 \\
\hline Malathion & $0.094 \pm 0.09$ & $0.02-0.355$ & 25 \\
\hline Endosulfan I ${ }^{\mathrm{a}}$ & $<0.01$ & - & 25 \\
\hline Endosulfan $\mathrm{II}^{\mathrm{a}}$ & $<0.01$ & - & 25 \\
\hline Endosulfane Sulfate ${ }^{a}$ & $<0.03$ & - & 25 \\
\hline
\end{tabular}

All samples were irradiated.

$\mathrm{BHA}=$ butylated hydroxyanisole; $\mathrm{BHT}=$ butylated hydroxytoluene $\mathrm{CFU}=$ colony-forming units; MPN = most probable number; $\mathrm{BHC}=$ hexachlorocyclohexane or benzene hexachloride; DDE = dichlorodiphenyldichloroethylene;

$\mathrm{DDD}=$ dichlorodiphenyldichloroethane; DDT = dichlorodiphenyltrichloroethane; HCB = hexachlorobenzene;

$\mathrm{PCB}=$ polychlorinated biphenyl.

${ }^{a}$ All values were below the detection limit. The detection limit is given as the mean.

bources of contamination include alfalfa, grains, and fish meal.

${ }^{\mathrm{c} S}$ Sources of contamination include soy oil and fish meal.

${ }^{\mathrm{d} A l l}$ values were corrected for percent recovery. 


\section{Appendix C. Sentinel Animal Program \\ Table of Contents}

C.1. Methods

C-2

C.2. Results

C-2

\section{Tables}

Table C-1. Methods and Results for Sentinel Animal Testing in Male and Female Rats ...........C-2

Table C-2. Methods and Results for Sentinel Animal Testing in Male and Female Mice 


\section{C.1. Methods}

Rodents used in the National Toxicology Program are produced in optimally clean facilities to eliminate potential pathogens that might affect study results. The Sentinel Animal Program is part of the periodic monitoring of animal health that occurs during the toxicological evaluation of test compounds. Under this program, the disease state of the rodents is monitored via sera or feces from extra (sentinel) or exposed animals in the study rooms. The sentinel animals and the study animals are subject to identical environmental conditions. Furthermore, the sentinel animals come from the same production source and weanling groups as the animals used for the studies of test compounds.

For these toxicology and carcinogenesis studies, blood samples were collected from each sentinel animal, allowed to clot, and the serum was separated. Additionally, fecal samples were collected and tested for endoparasites and Helicobacter species. All samples were processed appropriately with serology testing sent to IDEXX BioResearch (formerly Rodent Animal Diagnostic Laboratory [RADIL], University of Missouri), Columbia, MO, for determination of the presence of pathogens. Evaluation for endo- and ectoparasites was performed in-house by the testing laboratory.

The laboratory methods and agents for which testing was performed are tabulated in Table C-1 and Table C-2 below; the times at which samples were collected during the studies are also listed.

\section{C.2. Results}

Rats: Positive for endoparasites, pinworms (Syphacia spp.). All other test results were negative.

Mice: All test results were negative.

Table C-1. Methods and Results for Sentinel Animal Testing in Male and Female Rats

\begin{tabular}{|c|c|c|c|c|c|c|c|}
\hline Collection Time Points & Quarantine $^{a}$ & Perinatal $^{\mathrm{b}}$ & $\begin{array}{c}6 \\
\text { Months }\end{array}$ & $\begin{array}{c}12 \\
\text { Months }\end{array}$ & $\begin{array}{c}17 \\
\text { Months }\end{array}$ & $\begin{array}{c}18 \\
\text { Months }\end{array}$ & $\begin{array}{l}\text { End of } \\
\text { Study }\end{array}$ \\
\hline Number Examined (Males/Females) & $0 / 10$ & $0 / 10$ & $5 / 5$ & $5 / 5$ & $0 / 1$ & $5 / 5$ & $5 / 5$ \\
\hline \multicolumn{8}{|l|}{ Method/Test } \\
\hline \multicolumn{8}{|c|}{ Multiplex Fluorescent Immunoassay (MFI) } \\
\hline Kilham rat virus (KRV) & - & - & - & - & NT & - & - \\
\hline Mycoplasma pulmonis & - & - & - & - & NT & - & - \\
\hline Pneumonia virus of mice (PVM) & - & - & - & - & NT & - & - \\
\hline $\begin{array}{l}\text { Rat coronavirus/sialodacryoadenitis } \\
\text { virus (RCV/SDA) }\end{array}$ & - & - & - & - & NT & - & - \\
\hline Rat minute virus (RMV) & - & - & - & - & NT & - & - \\
\hline Rat parvo virus (RPV) & - & - & - & - & NT & - & - \\
\hline Rat theilovirus (RTV) & - & - & - & - & NT & - & - \\
\hline Sendai & - & - & - & - & NT & - & - \\
\hline
\end{tabular}




\begin{tabular}{|c|c|c|c|c|c|c|c|}
\hline Collection Time Points & Quarantine $^{\mathrm{a}}$ & Perinatal $^{b}$ & $\begin{array}{c}6 \\
\text { Months }\end{array}$ & $\begin{array}{c}12 \\
\text { Months }\end{array}$ & $\begin{array}{c}17 \\
\text { Months }\end{array}$ & $\begin{array}{c}18 \\
\text { Months }\end{array}$ & $\begin{array}{l}\text { End of } \\
\text { Study }\end{array}$ \\
\hline $\begin{array}{l}\text { Theiler's murine encephalomyelitis } \\
\text { virus (TMEV) }\end{array}$ & - & - & - & - & NT & - & - \\
\hline Toolan's H-1 & - & - & - & - & NT & - & - \\
\hline \multicolumn{8}{|l|}{ In-house Evaluation } \\
\hline $\begin{array}{l}\text { Endoparasites (evaluation of cecal } \\
\text { content) }\end{array}$ & NT & NT & NT & NT & + & + & NT \\
\hline $\begin{array}{l}\text { Ectoparasites (evaluation of } \\
\text { perianal surface) }\end{array}$ & NT & NT & NT & NT & + & + & NT \\
\hline \multicolumn{8}{|c|}{$\begin{array}{l}-=\text { negative; }+=\text { positive; } \mathrm{NT}=\text { not tested. } \\
\text { aAge matched nonpregnant females. } \\
\text { bTime-mated females that did not have a litter; } 3.5 \text { weeks after arrival. }\end{array}$} \\
\hline Collection Time Points & 1 Month & 6 Months & $12 \mathrm{Mo}$ & onths & 18 Months & End & of Study \\
\hline Number Examined (Males/Females) & $5 / 5$ & $5 / 5$ & $5 / 5$ & & $5 / 5$ & & $5 / 5$ \\
\hline \multicolumn{8}{|l|}{ Method/Test } \\
\hline \multicolumn{8}{|l|}{ Multiplex Fluorescent Immunoassay (MFI) } \\
\hline Ectromelia virus & - & - & - & & - & & - \\
\hline $\begin{array}{l}\text { Epizootic diarrhea of infant mice } \\
\text { (EDIM) }\end{array}$ & - & - & - & & - & & - \\
\hline $\begin{array}{l}\text { Lymphocytic choriomeningitis virus } \\
\text { (LCMV) }\end{array}$ & - & - & - & & - & & - \\
\hline Mycoplasma pulmonis & - & - & - & & - & & - \\
\hline Mouse hepatitis virus (MHV) & - & - & - & & - & & - \\
\hline Mouse norovirus (MNV) & - & - & - & & - & & - \\
\hline Mouse parvovirus (MPV) & - & - & - & & - & & - \\
\hline Minute virus of mice (MVM) & - & - & - & & - & & - \\
\hline Pneumonia virus of mice (PVM) & - & - & - & & - & & - \\
\hline Reovirus (REO3) & - & - & - & & - & & - \\
\hline Sendai & - & - & - & & - & & - \\
\hline $\begin{array}{l}\text { Theiler's murine encephalomyelitis } \\
\text { virus (TMEV) GDVII }\end{array}$ & - & - & - & & - & & - \\
\hline \multicolumn{8}{|l|}{ Immunofluorescence Assay (IFA) } \\
\hline $\begin{array}{l}\text { Epizootic diarrhea of infant mice } \\
\text { (EDIM) }\end{array}$ & NT & NT & - & & NT & & NT \\
\hline Ectromelia virus & NT & NT & - & & NT & & NT \\
\hline \multicolumn{8}{|l|}{ Polymerase Chain Reaction (PCR) } \\
\hline Helicobacter species & NT & NT & $\mathrm{N} 7$ & & - & & NT \\
\hline
\end{tabular}




\section{Appendix D. Peer-review Report}

\section{Table of Contents}

D.1. Attendees

D-2

D.2. Peer Review of the Draft NTP Technical Reports on the Toxicology and

Carcinogenesis Studies of Sodium Tungstate Dihydrate, Di- $n$-butyl Phthalate, and Di(2-ethylhexyl) Phthalate. 
The National Toxicology Program (NTP) virtually convened the NTP Technical Reports PeerReview Panel ("the Panel") on April 2, 2021, to peer review the Draft NTP Technical Reports on the Toxicology and Carcinogenesis Studies of Sodium Tungstate Dihydrate, Di-n-butyl Phthalate, and Di(2-ethylhexyl) Phthalate. Meeting information, including the draft reports, actions, and presentations is currently archived with NTP.

The panel peer reviewed the draft reports and provided its opinion on NTP's preliminary conclusions regarding the level of evidence of carcinogenic activity of sodium tungstate dihydrate, di-n-butyl phthalate, and di(2-ethylhexyl) phthalate. The panel's comments for the Draft NTP Technical Report on the Toxicology and Carcinogenesis Studies of Di-n-butyl Phthalate (CASRN 84-74-2) Administered in Feed to Sprague Dawley (Hsd:Sprague Dawley ${ }^{\circledR}$ $\left.S D^{\circledR}\right)$ Rats and B6C3F1/N Mice begin at Section D.2.3. The panel's recommendations do not necessarily represent NTP's opinion.

\section{D.1. Attendees ${ }^{1}$}

\section{Peer-Review Panel}

Chair: Gabriele Ludewig, University of Iowa

Tracie E. Bunton, Eicarte, LLC

Michael R. Elwell, Apex Toxpath, LLC

Charles R. Mahrt, Retired, formerly with Flagship Biosciences

Daniel J. Spade, Brown University

John Pierce Wise, University of Louisville

National Toxicology Program Board of Scientific Counselors Liaison

Susan Felter, Procter \& Gamble

\section{National Institute of Environmental Health Sciences Staff}

Mamta Behl

Chad Blystone

Mark Cesta

Sheba Churchill

Helen Cunny

Susan Elmore

Dori Germolec

Michelle Hooth

Madelyn (Mimi) Huang

Angela King-Herbert

Barry McIntyre

Georgia Roberts

Sheena Scruggs, Designated Federal Official

Kelly Shipkowski

Keith Shockley

Robert Sills

Stephanie Smith-Roe

Suramya Waidyanatha

${ }^{1}$ The meeting was held via webcast. Individuals who viewed the webcast are not listed except as noted. 
Nigel Walker

Mary Wolfe

Other Federal Agency Staff

Shirisha Chittiboyina, National Institute for Occupational Safety and Health

Gonçalo Gamboa da Costa, U.S. Food and Drug Administration

Contract Support Staff

Amy Brix, EPL, Inc.

Canden Byrd, ICF

Lindsey Green, ICF

Shawn Harris, Social \& Scientific Systems, a DLH Company

Elizabeth Maull, Kelly Government Services

Megan Rooney, ICF

Alessandria Schumacher, ICF

Cynthia Willson, Integrated Laboratory Systems, LLC

\section{D.2. Peer Review of the Draft NTP Technical Reports on the Toxicology and Carcinogenesis Studies of Sodium Tungstate Dihydrate, Di-n-butyl Phthalate, and Di(2-ethylhexyl) Phthalate}

\section{D.2.1. Introductions and Welcome}

The National Toxicology Program (NTP) convened a peer-review panel for the Draft NTP Technical Reports on the Toxicology and Carcinogenesis Studies of Sodium Tungstate Dihydrate, Di-n-butyl Phthalate, and Di(2-ethylhexyl) Phthalate on April 2, 2021 via webcast.

- Dr. Gabriele Ludewig, panel chair, called the meeting to order at 10:00 a.m. and welcomed everyone to the meeting. She asked all attendees to introduce themselves, and reviewed the peer-review meeting format for the panel and audience.

- Dr. Mary Wolfe, Acting Deputy Director for Policy \& Communication, welcomed all participants to the meeting.

- Dr. Sheena Scruggs read the conflict-of-interest policy statement and briefed the attendees on meeting logistics.

- Dr. Susan Felter attended as the liaison to the NTP Board of Scientific Counselors.

- Dr. Shirisha Chittiboyina attended as the liaison for the National Institute for Occupational Safety and Health.

- Dr. Gonçalo Gamboa da Costa attended as the liaison for the U.S. Food and Drug Administration.

\section{D.2.2. Background and Charge to the Panel}

Dr. Chad Blystone briefly presented the NTP draft technical report objectives, including a review of the levels of evidence for the potential carcinogenic activity and factors considered for tested chemicals. He also described how NTP collects historical control data ${ }^{2}$ on neoplastic lesions and

${ }^{2}$ https://ntp.niehs.nih.gov/results/dbsearch/historical 
how these are utilized to provide context to report findings. Dr. Blystone provided the charge for the individual peer reviews:

- Review and evaluate the scientific and technical elements of the study and its presentation.

- Determine whether the study's experimental design, conduct, and findings support NTP's conclusions under the conditions of this study.

The peer-review meeting materials can be found on the NTP website.

\section{D.2.3. Toxicology and Carcinogenesis Studies of Sodium Tungstate Dihydrate}

\section{D.2.3.1. Presentation and Clarifying Questions}

Dr. Mamta Behl summarized the studies and conclusions reported in the Draft NTP Technical Report on the Toxicology and Carcinogenesis Studies of Sodium Tungstate Dihydrate (CASRN 10213-10-2) in Sprague Dawley (Hsd:Sprague Dawley ${ }^{\circledR} S D^{\circledR}$ ) Rats and B6C3F1/N Mice (Drinking Water Studies).

Tungsten occurs naturally in the environment and can enter waterways through the weathering of rocks and soil. It was nominated for study due to concerns about potential widespread human exposure via contaminated drinking water. Sodium tungstate dihydrate was selected because it is a naturally occurring, water-soluble form of tungsten. Drinking water was selected as the most likely route of exposure for the general population.

Dr. Behl first presented a summary of results from the perinatal and postweaning toxicity/carcinogenicity study in Hsd:Sprague Dawley ${ }^{\circledR} \mathrm{SD}^{\circledR}$ rats. NTP exposed time-mated female rats to $0,250,500$, or $1,000 \mathrm{mg} / \mathrm{L}$ sodium tungstate dihydrate in drinking water from gestational day (GD) 6 through postnatal day (PND) 21. NTP provided the $\mathrm{F}_{1}$ generation rats with the same respective sodium tungstate dihydrate concentrations as their dam for 2 years ( $n=50 /$ sex/concentration). In addition, $F_{1}$ generation rats were provided dosed drinking water or the vehicle control for $3,6,12$, or 18 months for interim evaluations ( $n=40 /$ sex/concentration).

Dr. Behl then presented a summary of results from the chronic toxicity/carcinogenicity study in B6C3F1/N mice. NTP exposed mice to $0,500,1,000$, or $2,000 \mathrm{mg} / \mathrm{L}$ sodium tungstate dihydrate in drinking water for 2 years $(n=50 / \mathrm{sex} /$ concentration $)$. An additional $40 \mathrm{mice} / \mathrm{sex} /$ concentration were included for interim evaluations at 3, 6, 12, and 18 months.

Under the conditions of these 2-year studies, NTP's draft conclusions were:

- No evidence of carcinogenic activity in male Hsd:Sprague Dawley ${ }^{\circledR} \mathrm{SD}^{\circledR}$ rats at 250 , 500 , and $1,000 \mathrm{mg} / \mathrm{L}$.

- Exposure to sodium tungstate dihydrate in drinking water caused increased incidences of nonneoplastic lesions in the kidney of male rats.

- Equivocal evidence of carcinogenic activity in female Hsd:Sprague Dawley ${ }^{\circledR} \mathrm{SD}^{\circledR}$ rats based on increased incidences of C-cell adenoma or carcinoma (combined) of the thyroid gland.

- Exposure to sodium tungstate dihydrate in drinking water caused increased incidences of nonneoplastic lesions in the kidney and uterus of female rats. 
- Equivocal evidence of carcinogenic activity in male $\mathrm{B} 6 \mathrm{C} 3 \mathrm{~F} 1 / \mathrm{N}$ mice based on the occurrences of renal tubule adenoma or carcinoma (combined) in exposed animals.

- Exposure to sodium tungstate dihydrate in drinking water caused increased incidences of nonneoplastic lesions in the kidney, testes, and bone marrow of male mice.

- No evidence of carcinogenic activity in female B6C3F1/N mice at 500, 1,000, and 2,000 mg/L sodium tungstate dihydrate.

- Exposure to sodium tungstate dihydrate in drinking water caused increased incidences of nonneoplastic lesions in the kidney and spleen of female mice.

There were no clarifying questions or comments about the presentation.

\section{D.2.3.2. Public Comments}

Dr. Ludewig acknowledged the receipt of one written public comment from Dr. Ranulfo Lemus on behalf of the International Tungsten Industry Association. Dr. Ludewig noted that the panel did not receive requests for oral public comments on the draft technical report.

\section{D.2.3.3. Peer-Review Comments and Panel Discussion}

\section{D.2.3.3.1. First Reviewer - Dr. Michael Elwell}

- Dr. Elwell indicated that the dose selection was appropriate, the studies were wellconducted, the results were discussed clearly, and the rationale was clearly presented for neoplastic findings of equivocal evidence and several nonneoplastic effects. The important sodium tungstate-related findings were well-described and represented by quality pathology images in the report.

- Dr. Elwell noted some inconsistencies across report sections on the relationship of atypical hyperplasia in the uterus of female rats to sodium tungstate dihydrate exposure. Text on page 104 of the draft report indicates that the relationship is unknown; however, text in the abstract, summary, and conclusions states that atypical hyperplasia in the uterus is a nonneoplastic effect caused by sodium tungstate dihydrate.

- Dr. Amy Brix stated that the sentence in the discussion about the unknown relationship to atypical hyperplasia was a typo and NTP may consider removing it. She stated that NTP believes that the effects were related to exposure and would consider make those edits.

- Dr. Elwell noted that on page 69 under "other tissues" for rats, several nonneoplastic findings were mentioned and considered to be of unknown biological significance. However, a significant decrease in fibroadenomas in the mammary gland was mentioned with no comment regarding biological significance or relationship to sodium tungstate dihydrate exposure. The fibroadenomas occurred in female rats with decreased body weights. He recommended that the report discuss the potential relevance of decreased body weight in relation to the tumors given that the effect of lower body weight on occurrence of this tumor has been noted in earlier NTP reports and in published studies.

- Dr. Brix said that information about the mammary gland would be considered by NTP along with citing Dr. Haseman's article that compares body weight 
changes to certain tumor incidences. For the nonneoplastic findings in other tissues, NTP can make it clear that they do not consider them toxicologically significant, treatment-related, or biologically significant.

- Dr. Elwell questioned the rationale for including two of the effects listed in the abstract, specifically increased spleen hematopoiesis and bone marrow hyperplasia. For both findings, the increased incidences occurred in the low and mid-exposure groups with no significant effect in the high-exposure group, and the average severity was similar across exposure groups. Given that the histopathology section states that the biological significance for the bone marrow and spleen is unknown, Dr. Elwell asked if there were other effects (e.g., inflammatory, hematologic, or hematopoietic) that supported listing these as effects in the abstract? As a point of reference, Dr. Elwell noted that NTP concluded that the kidney pigment findings, which were significantly higher in the high-exposure group, were of questionable toxicologic importance and therefore not brought into the abstract.

- Dr. Behl agreed with Dr. Elwell's comment on the spleen and explained that NTP noted an effect in bone marrow hyperplasia in males and hematopoietic cell proliferation in females at both low and mid doses. NTP is open to discussion about whether to bring these effects forward into the abstract. Dr. Behl asked if the panel recommended including spleen effects in the abstract.

- Dr. Elwell commented that the other effects in the abstract were doseor target organ-related; the spleen effects were weaker than what might be expected for a finding listed in the abstract.

- Dr. Brix noted that for the spleen and bone marrow, the incidences were two to three times higher in the low and mid-dose groups, but agreed that it is a weak connection and that NTP may be open to removing them from the abstract based on the panel discussion.

\section{D.2.3.3.2. Second Reviewer - Dr. John Pierce Wise}

- Dr. Wise concurred with Dr. Elwell. The report was well-written, and the study was well-designed.

- Given the pressure to evaluate environmentally relevant concentrations, Dr. Wise recommended that NTP provide language on dose selection rationale to help readers unfamiliar with the NTP approach.

- Dr. Behl noted that the comment on dose selection rationale was well-taken. She explained how NTP selected the concentrations and indicated that they have been criticized in the past for doses that failed to challenge the animals. The concentrations used in this study allowed NTP to state that tungstate at high levels does not result in overt toxicity. The effects observed in the kidney were common with this strain and species.

- Dr. Wise clarified that it was not that NTP should use different doses. Rather, he recommended that NTP specify that their intention is to determine whether a substance causes cancer, not to define whether a substance causes cancer at the most environmentally relevant dose. It 
would help to add that context for a reader who does not understand that approach.

- Dr. Behl said that NTP can add some clarifying language in the report.

- Dr. Wise recommended that NTP provide clarifying language to address the occurrence of pinworms in the rats for reader unfamiliar with rat use.

- Dr. Behl explained that the rats were positive for pinworms for the duration of the study, and they did not receive medication for elimination. At study termination, the incidences of pinworms were similar between the exposed groups. Based on histological sections, the pinworms were not associated with morphological changes in the large intestine and no inflammatory response was noted. NTP can clarify that point.

○ Dr. Wise indicated it would be helpful to include that no medication was administered.

- Dr. Wise recommended that NTP add a second parameter in the table when presenting comet assay results, since it is standard to show two different measures such as tail length, olive moment, or tail moment.

- Dr. Stephanie Smith-Roe noted that NTP uses percent tail DNA, which is the OECD guideline for comet assay. Some comet assays report more than one measure, with those measures usually based on tail length. As there is variability in electrophoretic conditions that can influence tail length, NTP has found that percent tail DNA is a more reliable measure.

- Dr. Ludewig commented that she was unsure of how to interpret the significant comet effects even at the lowest concentration given the lack of pathology in the liver and other published positive comet assay results in the liver and other tissues.

- Dr. Smith-Roe replied that the results suggest that sodium tungstate may be capable of damaging DNA, but the liver was not a target organ for neoplastic effects.

\section{D.2.3.3.3. Third Reviewer - Dr. Charles Mahrt}

- Dr. Mahrt commented that the studies were well-designed, well-conducted, and the report was clear. However, he suggested NTP clarify whether the progression in rats from uterine atypical hyperplasia to adenocarcinomas (noted in Table 31) also included an increase in uterine adenomas.

- Dr. Brix agreed that it was unclear and indicated that NTP will consider adding language regarding the progression. From experience, adenomas are less common and NTP often sees a direct progression from atypical hyperplasia to adenocarcinomas.

\section{D.2.3.3.4. Panel Discussion}

Dr. Daniel Spade indicated he had no additional comments that were not already addressed by the other reviewers. 
Dr. Ludewig noted that the comet assay should be brought forward into the abstract since DNA damage was observed in the liver, despite no associated pathology.

Dr. Tracie Bunton asked about the justification for the large number of interim sacrifices and questioned whether NTP could have obtained information on tungsten accumulation using fewer sacrifices.

- Dr. Behl explained that the study was started several years ago when there were no data in the literature on the accumulation of tungsten in tissues following repeat dosing. Because the kidney is a target, NTP included multiple time points to determine if accumulation continued over the course of the study or if saturation eventually occurred. In addition, a question of sex differences required that NTP use males and females.

Dr. Bunton agreed with Dr. Mahrt's comment about Table 31 and thought the discussion was sufficient. She asked why Table 31 did not include incidence and statistics.

- Dr. Brix clarified that the adenocarcinomas and adenomas were included in Table 31 to show that the incidences were not significantly increased and that there was no progression from atypical hyperplasia. There were no statistics included because they were all negative.

Dr. Bunton noted that for female mice, there was a significant increase in the incidence of hepatocellular adenomas and carcinomas in the $500 \mathrm{mg} / \mathrm{L}$ group and that they were included in the "other tissues" groups. She asked why that was lumped into the "other tissues" category rather than brought into the tumor category.

- Dr. Brix stated that hepatocellular tumors are a common background lesion in this strain of mice, so it is not uncommon to have a dose group with significant differences due to biological variation. However, there was no dose response or reason to consider these treatments related.

Dr. Bunton asked for additional language or reorganization to be added in the discussion to explain how NTP came to an equivocal conclusion for female rats. NTP stated that the conclusion was based on increased incidences of C-cell adenoma and carcinoma (combined) of the thyroid gland, but the statement is incomplete as written because that same rationale could apply for a carcinogenic conclusion.

- Dr. Brix said that NTP could look at the discussion and clarify.

Dr. Ludewig asked if NTP had any information about adipose tissue or lipid content in the liver, given that absolute liver weight decreased, there were positive comet assay results in the males, and the text mentions that sodium tungstate dihydrate is an antidiabetic agent.

- Dr. Nigel Walker said that NTP does not have these data.

\section{D.2.3.4. Vote on NTP Conclusions}

\section{D.2.3.4.1. Male Hsd:Sprague Dawley ${ }^{\circledR} S D^{\circledR}$ rats}

Dr. Ludewig called for a motion from the panel to approve the conclusions as written. Dr. Wise so moved, and Dr. Mahrt seconded the motion. The panel voted unanimously ( 5 yes, 0 no, 0 abstentions) to approve the conclusions as written. 


\section{D.2.3.4.2. Female Hsd:Sprague Dawley ${ }^{\circledR} S D^{\circledR}$ rats}

Dr. Ludewig called for a motion from the panel to approve the conclusions as written. Dr. Wise so moved, and Dr. Elwell seconded the motion. The panel voted unanimously ( 5 yes, 0 no, 0 abstentions) to approve the conclusions as written.

\section{D.2.3.4.3. Male B6C3F1/N mice}

Dr. Ludewig called for a motion from the panel to approve the conclusions as written. Dr. Wise so moved, and Dr. Elwell seconded the motion. The panel voted unanimously ( 5 yes, 0 no, 0 abstentions) to approve the conclusions as written.

\section{D.2.3.4.4. Female B6C3F1/N mice}

Dr. Ludewig called for a motion from the panel to approve the conclusions as written. Dr. Wise so moved, and Dr. Mahrt seconded the motion. The panel voted unanimously ( 5 yes, 0 no, 0 abstentions) to approve the conclusions as written.

\section{D.2.4. Toxicology and Carcinogenesis Studies of Di-n-butyl Phthalate}

\section{D.2.4.1. Presentation and Clarifying Questions}

Dr. Madelyn (Mimi) Huang summarized the studies and conclusions reported in the Draft NTP Technical Report on the Toxicology and Carcinogenesis Studies of Di-n-butyl Phthalate (CASRN 84-74-2) Administered in Feed to Sprague Dawley (Hsd:Sprague Dawley ${ }^{\circledR} S D^{\circledR}$ ) Rats and B6C3F1/N Mice.

Di-n-butyl phthalate (DBP) is commonly used as a plasticizer and is found in a variety of consumer products, such as vinyl fabrics and flooring, personal care products, pharmaceuticals, and food packaging. Human exposure primarily occurs through ingestion of food packaged in materials containing DBP; some inhalation and dermal exposure occurs as well, but to a lesser extent. In the gut, DBP is rapidly metabolized to mono-n-butyl phthalate (MBP) and undergoes broad distribution throughout the body.

Dr. Huang presented a summary of results from the perinatal and postweaning toxicity and carcinogenicity study in Hsd:Sprague Dawley ${ }^{\circledR} \mathrm{SD}^{\circledR}$ rats. Time-mated female rats were fed diets containing $0,300,1,000,3,000$, or 10,000 ppm DBP from gestation day (GD) 6 through postnatal day (PND) 21. NTP provided F1 generation rats with the same respective DBP concentrations in feed as their dam for 2 years (generally two/sex/litter). In addition, select dams and their litters were removed on GD 18 and lactation day (LD) 4 to quantify the internal concentration of MBP.

Dr. Huang then presented a summary of results from the chronic toxicity and carcinogenicity study in B6C3F1/N mice. Mice were fed diets containing 0, 1,000, 3,000, or 10,000 ppm DBP for 2 years $(n=50 /$ sex/group).

Under the conditions of these 2-year studies, NTP's draft conclusions were:

- Equivocal evidence of carcinogenic activity in male Hsd:Sprague Dawley ${ }^{\circledR} \mathrm{SD}^{\circledR}$ rats based on marginal increases in the incidence of pancreatic acinus adenomas. 
- Exposure to DBP resulted in increased incidences of gross lesions of the male reproductive system and nonneoplastic lesions of the male reproductive system, liver, and pituitary gland pars distalis in male rats.

- No evidence of carcinogenic activity in female Hsd:Sprague Dawley ${ }^{\circledR} \mathrm{SD}^{\circledR}$ rats at $300,1,000,3,000$, or 10,000 ppm.

- Exposure to DBP resulted in increased incidences of nonneoplastic lesions of the liver in female rats.

- No evidence of carcinogenic activity in male B6C3F1/N mice at 1,000, 3,000, or 10,000 ppm.

- Exposure to DBP increased incidences of nonneoplastic lesions of the male reproductive system and liver in male mice.

- No evidence of carcinogenic activity in female B6C3F1/N mice at 1,000, 3,000, or $10,000 \mathrm{ppm}$.

- Exposure to DBP increased incidences of nonneoplastic lesions of the liver and kidney in female mice.

There were no clarifying questions or comments about the presentation.

\section{D.2.4.2. Public Comments}

Dr. Gabriele Ludewig acknowledged that there were no written public comments on the draft technical report. She also noted that the panel did not receive requests for oral public comments on the draft technical report.

\section{D.2.4.3. Peer-Review Comments and Panel Discussion}

\section{D.2.4.3.1. First Reviewer - Dr. Tracie Bunton}

- Dr. Bunton said the presentation of the rationale, methods, and results was clear and concise.

- She commented that she liked the introduction and found it helpful in getting up to speed on the properties, uses, and reduction in use of DBP. The rationale for the overall significance of the study is solid, especially given that perinatal exposure is a knowledge gap.

- She indicated that all the information about stability, homogeneity, dose selection, and number of animals per dose group is appropriate for the design of the study.

- Dr. Bunton suggested including the word "microscopic" or eliminate the word "gross" in the conclusion statement of the report as it currently specifies gross lesions in the male reproductive system but does not specify that the nonneoplastic lesions are not gross lesions.

○ Dr. Huang indicated that NTP is open to adding in the word "microscopic" to differentiate from gross lesions.

- Dr. Bunton noted that the findings to support the "equivocal" decision included an increased incidence in pancreatic acinar adenomas compared to controls, without a concurrent increase in hyperplasia, and a significant positive trend. 
- She stated the lesion in the liver was compatible with effects of other phthalates, namely increased cytoplasmic alteration. This was an important point that was noted in the pathology review and in the discussion.

- She also agreed that the findings fit into the "equivocal" category.

\section{D.2.4.3.2. Second Reviewer - Dr. Charles Mahrt}

- Dr. Mahrt agreed with Dr. Bunton's comments and noted that the report was welldesigned, conducted, and written.

- He appreciated the references to the literature to put the findings in perspective, especially the possibility of lesions related to peroxisome proliferation.

\section{D.2.4.3.3. Third Reviewer-Dr. Daniel Spade}

- Dr. Spade indicated that the study was well-conducted, and the report was clearly written.

- He noted that in the abstract, lines 39 to 40 indicate that there were fewer and less severe reproductive lesions in mice than in rats. He agreed with that conclusion, though suggested qualifying it by acknowledging the limits of cross-species comparison given that rats had perinatal exposure and mice did not.

- Dr. Huang agreed that it was important to qualify the rat versus mouse comparison and said NTP could clarify those statements.

- Dr. Nigel Walker explained that when NTP started adding the perinatal component to rat studies, people were trying to understand why the study design changed. With rat studies as perinatal and mouse studies as adults only, NTP has started to address that in the mid-2000s. In addition, it is difficult to do perinatal exposure on $\mathrm{F}_{1}$ generation $\mathrm{B} 6 \mathrm{C} 3 \mathrm{~F} 1 / \mathrm{N}$ mice.

- Dr. Spade built on Dr. Bunton's comment about the equivocal conclusion for pancreatic acinar adenomas and asked if there was a significant trend test but not pairwise test.

○ Dr. Huang stated the affirmative.

- Dr. Spade appreciated the response and agreed with the conclusion.

- He also asked why images were not included in some cases.

- Dr. Huang clarified that NTP does not generally include images for common lesions or when the conclusion is equivocal.

- Dr. Spade appreciated the response and agreed with the approach.

\section{D.2.4.3.4. Panel Discussion}

Dr. Michael Elwell noted that the last line of the discussion mentions that 2,4dichlorophenoxyacetic acid and DBP did not produce hepatic lesions typical of peroxisome proliferators. DBP did result in hepatic lesions but did not produce hepatic neoplasms.

- Dr. Huang agreed that the last line should reference neoplasms instead of lesions, as Dr. Elwell suggested. 
Regarding voting, Dr. Elwell noted that the original draft report mentions hypertrophy in the pituitary and hyperplasia, but that it was not mentioned in the oral presentation. He asked if hypertrophy was included in the pituitary findings.

- Dr. Mark Cesta explained that NTP relooked at the data about the pituitary and hyperplasia. Hyperplasia often occurs with hypertrophy lesions, so they wanted to explain the observed hyperplasia. However, after a closer look, NTP could not make that conclusion and decided to remove it from the abstract.

Dr. Ludewig noted that page 78 of the draft report explains the concentrations found in the amniotic fluid. When humans and rats both take up $1 \mathrm{mg} / \mathrm{kg} / \mathrm{day}$, a historic report showed that there were $22 \mathrm{ng} / \mathrm{mL}$ of the metabolite in the amniotic fluid of humans. However, NTP only found $5 \mathrm{ng} / \mathrm{mL}$ in rats. Dr. Ludewig said she was initially surprised until she noticed that NTP did not measure the glucuronic acid conjugate. She wondered if that would also cross the placenta or if conjugation would protect the fetus. She suggested adding a statement that the gluconate conjugate was not measured.

- Dr. Huang agreed that there are differences in distribution and metabolism between rodents and humans. She was unsure if glucuronidation affects its ability to cross the placenta and said that was something NTP would look into.

\section{D.2.4.4. Vote on NTP Conclusions}

\section{D.2.4.4.1. Male Hsd:Sprague Dawley ${ }^{\circledR} S D^{\circledR}$ rats}

Dr. Ludewig called for a motion from the panel to approve the conclusions as written. Dr. Bunton so moved, and Dr. Mahrt seconded the motion. The panel voted unanimously (5 yes, 0 no, 0 abstentions) to approve the conclusions as written.

D.2.4.4.2. Female Hsd:Sprague Dawley ${ }^{\circledR} S D^{\circledR}$ rats

Dr. Ludewig called for a motion from the panel to approve the conclusions as written. Dr. John Pierce Wise so moved, and Dr. Elwell seconded the motion. The panel voted unanimously (5 yes, 0 no, 0 abstentions) to approve the conclusions as written.

\section{D.2.4.4.3. Male B6C3F1/N mice}

Dr. Ludewig called for a motion from the panel to approve the conclusions as written. Dr. Bunton so moved, and Dr. Wise seconded the motion. The panel voted unanimously ( 5 yes, 0 no, 0 abstentions) to approve the conclusions as written.

\section{D.2.4.4.4. Female B6C3F1/N mice}

Dr. Ludewig called for a motion from the panel to approve the conclusions as written. Dr. Wise so moved, and Dr. Bunton seconded the motion. The panel voted unanimously ( 5 yes, 0 no, 0 abstentions) to approve the conclusions as written.

\section{D.2.5. Toxicology and Carcinogenesis Studies of Di(2-ethylhexyl) Phthalate}

\section{D.2.5.1. Presentation and Clarifying Questions}

Dr. Chad Blystone summarized the studies and conclusions reported in the Draft NTP Technical Report on the Toxicology and Carcinogenesis Studies of Di(2-ethylhexyl) Phthalate (CASRN 117-81-7) Administered in Feed to Sprague Dawley (Hsd:Sprague Dawley ${ }^{\circledR} S D^{\circledR}$ ) Rats. 
Di(2-ethylhexyl) phthalate (DEHP) is a phthalate ester that was widely used in manufacturing of PVC polymers and corresponding products, such as cosmetics and toys. Over the years DEHP use has declined due to toxicity concerns, but chronic exposure throughout multiple life stages still occurs. The literature suggests that exposure to DEHP during an early life stage may result in chronic or carcinogenic health outcomes. However, previous DEHP chronic rodent studies did not include exposure during the gestational period up to weaning in rodents. To address this, NTP conducted two comparative DEHP carcinogenesis studies in rats to determine if including early life exposure would alter chronic toxicity or carcinogenicity outcomes.

Dr. Blystone presented a summary of results from the perinatal and postweaning toxicity/carcinogenicity study in Hsd:Sprague Dawley ${ }^{\circledR} \mathrm{SD}^{\circledR}$ rats. In the perinatal and postweaning study, time-mated female rats were fed diets containing $0,300,1,000,3,000$, or 10,000 ppm DEHP from gestational day (GD) 6 through postnatal day (PND) 21 ( $\mathrm{n}=45 /$ group). Select dams were removed on GD 18 to quantify internal concentrations of a metabolite of DEHP, mono(2-ethylhexyl) phthalate, in plasma and tissue samples. NTP provided $\mathrm{F}_{1}$ generation rats with the same respective DEHP concentration in feed as their dam for 2 years ( $\mathrm{n}=2 / \mathrm{sex} /$ litter; $\mathrm{n}=50$ total/sex/group).

Dr. Blystone then presented a summary of results from the postweaning toxicity/carcinogenicity study in Hsd:Sprague Dawley ${ }^{\circledR} \mathrm{SD}^{\circledR}$ rats. In the postweaning-only study, rats were fed diets containing $0,300,1,000,3,000$, or 10,000 ppm DEHP for 2 years ( $\mathrm{n}=50 / \mathrm{sex} /$ group).

Under the conditions of these 2-year studies, NTP's draft conclusions were:

- Perinatal and Postweaning Feed Study:

- Clear evidence of carcinogenic activity in male Hsd:Sprague Dawley ${ }^{\circledR} \mathrm{SD}^{\circledR}$ rats based on the increased incidences of hepatocellular adenoma or carcinoma (combined) and acinar adenoma or carcinoma (combined) neoplasms (predominantly adenomas) of the pancreas.

- Exposure to DEHP resulted in increased incidences of nonneoplastic lesions in the liver, heart, pituitary gland, testis, and epididymis and increased incidences of gross lesions of the reproductive tract, bone marrow, and kidney in male rats.

- Clear evidence of carcinogenic activity in female Hsd:Sprague Dawley ${ }^{\circledR} \mathrm{SD}^{\circledR}$ rats based on the increased incidence of hepatocellular adenoma or carcinoma (combined).

- The occurrence of pancreatic acinar adenoma or carcinoma (combined) was considered to be related to exposure. (Some evidence)

- The occurrence of uterine (including cervix) adenoma, adenocarcinoma, squamous cell carcinoma, or squamous cell papilloma (combined) in female rats may have been related to exposure. (Equivocal evidence)

- Exposure to DEHP resulted in increased incidences of nonneoplastic lesions in the liver and increased incidences of gross lesions of the kidney in female rats.

- Postweaning-only Feed Study 
- Clear evidence of carcinogenic activity in male Hsd:Sprague Dawley ${ }^{\circledR} \mathrm{SD}^{\circledR}$ rats based on the increased incidences of hepatocellular adenoma or carcinoma (combined) and increased incidences of acinar adenoma or carcinoma (combined) neoplasms (predominantly adenomas) of the pancreas.

- The occurrence of testicular interstitial cell adenoma in male rats may have been related to exposure. (Equivocal evidence)

- Exposure to DEHP resulted in increased incidences of nonneoplastic lesions in the liver, pancreas, bone marrow, heart, pituitary gland, testis, and epididymis.

- Clear evidence of carcinogenic activity in female Hsd:Sprague Dawley ${ }^{\circledR} \mathrm{SD}^{\circledR}$ rats based on the incidences of hepatocellular adenoma or carcinoma (combined) and uterine (including cervix) adenoma, adenocarcinoma, squamous cell carcinoma, or squamous cell papilloma (combined).

- The occurrence of pancreatic acinar adenoma or carcinoma (combined) in female rats was considered to be related to exposure. (Some evidence)

- Exposure to DEHP resulted in increased incidences of nonneoplastic lesions in the liver, pancreas, bone marrow, and uterus in female rats.

- Comparative Carcinogenic Benchmark Dose Analyses

- No consistent pattern indicating that perinatal and postweaning exposure was more sensitive compared to postweaning-only exposure and modeled responses were within threefold of each other.

- However, there was a stronger carcinogenic response in the reproductive organs (uterus and testis) in the postweaning-only exposure study compared to the perinatal and postweaning exposure study.

Dr. Gabriele Ludewig asked a clarifying question about a shift in male to female fetus ratios that was not mentioned during Dr. Blystone's talk. Dr. Blystone responded that female fetuses were lost at the highest concentration. The reduction in litter size was due to this but was inconsistent and not considered related to DEHP exposure.

\section{D.2.5.2. Public Comments}

Dr. Ludewig acknowledged that there were no written public comments submitted on the draft technical report. She noted that the panel also did not receive requests for oral public comments on the draft technical report.

\section{D.2.5.3. Peer-Review Comments and Panel Discussion}

\section{D.2.5.3.1. First Reviewer - Dr. John Pierce Wise}

- Dr. Wise indicated that the study was well-designed, well-conducted, and clear in its data presentation.

- He suggested that NTP clarify that pinworm infections were not treated with medication.

○ Dr. Blystone said that NTP can add this clarification. 
- Dr. Wise also reiterated his comment from sodium tungstate dihydrate that NTP should explain that the choice of dose was deliberate and not intended to test the most environmentally relevant level of exposure, but rather to test whether the substance is carcinogenic.

- Dr. Blystone agreed that the point of these studies is hazard characterization and noted that NTP can clarify that in the report and include it in the lay summary.

- Dr. Wise suggested that NTP could add this in a dose selection rationale section.

○ Dr. Blystone responded that the reports have a section covering the technical aspects of the exposure concentration selection and that a sentence can be added to highlight rationale for exposure concentrations.

\section{D.2.5.3.2. Second Reviewer-Dr. Daniel Spade}

- Dr. Spade stated that the report was thorough and clear; it makes a massive amount of work easily understandable.

- He asked for clarification in how the reduction in litter size was presented, and asked whether there was an effort to address post-implantation loss as part of the reduced litter size. Reduced litter size could not be due to exposure related pre-implantation loss since the dosing window did not begin before implantation. However, Dr. Spade argued that with exposures beginning on GD 6, this overlaps with organogenesis and poses a risk for post-implantation loss which has been reported in the phthalate literature.

- Dr. Blystone said that NTP only evaluated post-implantation loss in females which did not deliver, so there are no more data available on postimplantation loss and litter size.

- Dr. Spade asked why pup survival data for PND 1-4 and PND 5-21 on page 29 of the draft report were analyzed separately. Dr. Spade thought that there could have been a trend in mortality if PND 1-21 were analyzed together.

$\circ$ Dr. Blystone explained that NTP typically standardizes the litter size on PND 4, so the analysis looks at early (PND 1-4) and later (PND 5-21) mortality. Dr. Blystone acknowledged that based on Dr. Spade's written comment NTP reanalyzed the data after combining the two periods and there was still no significant trend or pairwise comparison.

- Dr. Spade also noted that it was unclear why some lesions of unknown biological significance on page 61 of the draft report were classified as such. Of note were the adrenal gland lesions, because of the known antiandrogenic effect of DEHP. Also, he questioned the ovarian atrophy as classified as unknown biological significance, because published data from academic studies indicate that phthalates change the rates of follicle maturation which could be related.

- Dr. Blystone indicated that NTP can clarify the language and focus more on toxicological significance. 
- Dr. Spade commented that 24 months is reproductively aged, so for certain findings such as seminiferous epithelium degeneration, the control levels are very high which makes it less likely that there will be a significant pairwise test. This limits the ability to know with certainty what the dose response would look like for an endpoint such as epithelial degeneration. If 4-month-old males were tested, you might see a significant response at lower levels. The study supports the conclusions within the constraints of the study, but this is a limitation.

- Dr. Blystone agreed that at this age, the model is not very sensitive. NTP can add a statement about that to the report.

- Dr. Spade noted that for gestational transfer, as discussed on page 33 of the draft report, one limitation is that DEHP has many secondary metabolites. He noted that without measuring these secondary metabolites it is difficult to determine the total transfer.

- Dr. Blystone agreed and said that NTP can clarify that metabolites can be transferred at different rates.

Dr. Ludewig stated that it was interesting that mono(2-ethylhexyl) phthalate was found in the amniotic fluid and the fetus of the control animals, but nothing in the serum of dams.

- Dr. Blystone agreed that this was unusual and noted that sometimes sample preparations can lead to irregularities.

- Dr. Suramya Waidyanatha said NTP concluded it was probably due to contamination of samples during collection or preparation and that this is likely due to the small volume of these samples.

\section{D.2.5.3.3. Third Reviewer - Dr. Michael Elwell}

- Dr. Elwell agreed with previous reviewers that the results are clearly presented and discussed.

- He noted that at the highest dose, body weights were reduced by approximately $30 \%$ in the perinatal postweaning and approximately $20 \%$ in the postweaning study. Although this did not affect survival, the decreased incidence of several neoplastic and nonneoplastic findings (especially for the high dose group of each study) might be attributable to significantly lower body weights. In the report (pages 61 and 77) these are indicated to be of unknown biological significance. If these findings are due to lower body weight, they should be addressed as such rather than reported as unknown significance. For example, neoplasms including the c-cell, pituitary, and mammary gland tumors can be affected by body weight. In females, a single pituitary gland neoplasm reported at the high dose is unexpected and notable in comparison to the control group where 16 animals were reported to have this tumor. The decreased incidence of the nonneoplastic lesions of testis polyarteritis and parathyroid hyperplasia could also be related to the lowered severity of chronic progressive nephropathy (CPN). In both studies, CPN was decreased in severity at the high dose in both studies and indicated as the cause of death in 0 and 1 animal while 16-18 animals in the control groups list CPN as the cause of death. This report cites other DEHP studies that attribute an increase in CPN to DEHP while this report suggests the opposite effect on CPN. This may be because the highest doses in this study were 
lower, the decreased body weight, or that the NTP 2000 diet was not used in earlier studies.

- Dr. Blystone indicated that NTP can clarify biological significance versus toxicological significance. Dr. Blystone agreed that some of the effects could be related to decreased body weight and stated that NTP can clarify.

- Dr. Elwell asked if page 87 of the draft report should state that it is unclear if any difference corresponded to developmental mechanisms when comparing the two studies, or if it is a typo. It appeared the kidney was affected by a developmental mechanism and DEHP was presumed to interfere with proper development.

- Dr. Blystone stated that NTP can fix the typo.

- Dr. Elwell noted that for the nonneoplastic conclusions, there are dozens of neoplastic and nonneoplastic findings clearly related to DEHP. He questioned why the acute inflammation in the uterus in the perinatal/postnatal study was considered an effect. He also asked why the bone marrow in females in the postweaning-only study was included as a finding and if it was possibly a false positive.

- Dr. Blystone said that although the response was not strong, NTP considered the bone marrow lesion exposure related since it was observed in males and females. The acute inflammation in the uterus was considered exposure related. NTP can review this and clarify.

- Dr. Susan Elmore stated that she can see Dr. Elwell's point about the acute inflammation of the uterus possibly not being related to exposure, but that this was something NTP would need to discuss further.

\section{D.2.5.3.4. Panel Discussion}

Dr. Tracie Bunton said she wanted to see the presentation of the benchmark dose analysis, but beyond that, just had minor edits submitted in writing.

Dr. Spade asked if Dr. Elwell's comments about bone marrow and uterus related to one of the conclusions on which the panel would vote. He wondered if it was about including it in the abstract rather than the conclusion that there was a finding.

- Dr. Elwell said while the other findings listed in the abstract were convincing effects, the rationale to include the non-dose-related difference of acute uterus inflammation in the perinatal-post weaning study was not clear although there may have been reason to include it as chronic uterus inflammation was increased in the postweaningonly study. The question on including the bone marrow finding in females from the postweaning-only study in the abstract was based on very small group differences in incidence with no apparent effect on severity.

Dr. Bunton noted that a number of genetic toxicity tests were conducted and asked if they were related to this particular report or conducted over time.

- Dr. Blystone said they were not related to this report itself. They were accumulated over time and not published previously, so they were published with this report. 


\section{D.2.5.4. Vote on NTP Conclusions}

\section{D.2.5.4.1. Male Hsd:Sprague Dawley ${ }^{\circledR} S D^{\circledR}$ rats (perinatal and postweaning feed study)}

Dr. Ludewig called for a motion from the panel to approve the conclusions as written. Dr. Bunton so moved, and Dr. Wise seconded the motion. The panel voted unanimously ( 5 yes, 0 no, 0 abstentions) to approve the conclusions as written.

\section{D.2.5.4.2. Female Hsd:Sprague Dawle ${ }^{\circledR} S D^{\circledR}$ rats (perinatal and postweaning feed study)}

Dr. Ludewig called for a motion from the panel to approve the conclusions as written. Dr. Wise so moved, and Dr. Elwell seconded the motion. Dr. Elwell asked to amend the motion to vote and moved that NTP delete "and increased incidences of gross lesions of the" from the conclusion and add "and uterus." Dr. Wise motioned to accepted revisions to the conclusion and Dr. Spade seconded the motion. The panel voted unanimously ( 5 yes, 0 no, 0 abstentions) to approve the new conclusion.

In a second round of revisions, Dr. Blystone noted that the end of a sentence was cut off. He added "and gross observations in the female reproductive tract" to the end of the final conclusion. Dr. Ludewig called for a motion from the panel to approve the second round of revised conclusions. Dr. Wise so moved, and Dr. Elwell seconded the motion. The panel voted unanimously ( 5 yes, 0 no, 0 abstentions) to approve the new conclusion, below.

Revised Conclusion:

- Clear evidence of carcinogenic activity

○ Increased incidence of hepatocellular adenoma or carcinoma (combined).

- The occurrence of pancreatic acinar adenoma or carcinoma (combined) was considered to be related to exposure. (Some evidence)

- The occurrence of uterine (including cervix) adenoma, adenocarcinoma, squamous cell carcinoma, or squamous cell papilloma (combined) in female rats may have been related to exposure. (Equivocal evidence)

- Exposure to DEHP resulted in increased incidences of nonneoplastic lesions in the liver, and increased incidences of gross lesions of the kidney, and uterus in female rats and gross observations in the female reproductive tract.

D.2.5.4.3. Male Hsd:Sprague Dawley ${ }^{\circledR} S D^{\circledR}$ rats (postweaning-only study)

Dr. Ludewig called for a motion from the panel to approve the conclusions as written. Dr. Wise so moved, and Dr. Elwell seconded the motion. The panel voted unanimously ( 5 yes, 0 no, 0 abstentions) to approve the conclusions as written.

\section{D.2.5.4.4. Female Hsd:Sprague Dawley ${ }^{\circledR} S D^{\circledR}$ rats (postweaning-only study)}

Dr. Ludewig called for a motion from the panel to approve the conclusions as written. The panel did not offer a motion. Dr. Elwell moved that NTP delete the reference to increased incidences of nonneoplastic lesions in the bone marrow from the conclusion. Dr. Wise seconded the motion. The panel voted unanimously ( 5 yes, 0 no, 0 abstentions) to approve the new conclusion, below. 
Revised Conclusion:

- Clear evidence of carcinogenic activity

- Increased incidences of hepatocellular adenoma or carcinoma (combined) and uterine (including cervix) adenoma, adenocarcinoma, squamous cell carcinoma, or squamous cell papilloma (combined).

- The occurrence of pancreatic acinar adenoma or carcinoma (combined) in female rats was considered to be related to exposure. (Some evidence)

- Exposure to DEHP resulted in increased incidences of nonneoplastic lesions in the liver, pancreas, bone marrow, and uterus in female rats.

\section{D.2.5.4.5. Hsd:Sprague Dawley ${ }^{\circledR} S D^{\circledR}$ rats (comparative benchmark dose analyses)}

Dr. Ludewig called for a motion from the panel to approve the conclusions as written. Dr. Wise so moved, and Dr. Elwell seconded the motion. The panel voted unanimously ( 5 yes, 0 no, 0 abstentions) to approve the conclusions as written.

\section{D.2.5.5. Final Conclusions}

Because revisions were proposed and approved during the meeting, the final approved conclusions are presented below:

- Perinatal and Postweaning Feed Study:

- Clear evidence of carcinogenic activity in male Hsd:Sprague Dawley ${ }^{\circledR} \mathrm{SD}^{\circledR}$ rats based on the increased incidences of hepatocellular adenoma or carcinoma (combined) and acinar adenoma or carcinoma (combined) neoplasms (predominantly adenomas) of the pancreas.

- Exposure to DEHP resulted in increased incidences of nonneoplastic lesions in the liver, kidney, bone marrow, heart, pituitary gland, testis, and epididymis and increased incidences of gross lesions of the reproductive tract

○ Clear evidence of carcinogenic activity in female Hsd:Sprague Dawley ${ }^{\circledR} \mathrm{SD}^{\circledR}$ rats based on the increased incidence of hepatocellular adenoma or carcinoma (combined).

- The occurrence of pancreatic acinar adenoma or carcinoma (combined) was considered to be related to exposure. (Some evidence)

- The occurrence of uterine (including cervix) adenoma, adenocarcinoma, squamous cell carcinoma, or squamous cell papilloma (combined) in female rats may have been related to exposure. (Equivocal evidence)

- Exposure to DEHP resulted in increased incidences of nonneoplastic lesions in the liver, kidney, and uterus in female rats and gross observations in the female reproductive tract.

- Postweaning-only Feed Study

- Clear evidence of carcinogenic activity in male Hsd:Sprague Dawley ${ }^{\circledR} \mathrm{SD}^{\circledR}$ rats based on the increased incidences of hepatocellular adenoma or carcinoma (combined) and increased incidences of acinar adenoma or carcinoma (combined) neoplasms (predominantly adenomas) of the pancreas. 
- The occurrence of testicular interstitial cell adenoma in male rats may have been related to exposure. (Equivocal evidence)

- Exposure to DEHP resulted in increased incidences of nonneoplastic lesions in the liver, pancreas, bone marrow, heart, pituitary gland, testis, and epididymis.

- Clear evidence of carcinogenic activity in female Hsd:Sprague Dawley ${ }^{\circledR} \mathrm{SD}^{\circledR}$ rats based on the increased incidences of hepatocellular adenoma or carcinoma (combined) and uterine (including cervix) adenoma, adenocarcinoma, squamous cell carcinoma, or squamous cell papilloma (combined).

- The occurrence of pancreatic acinar adenoma or carcinoma (combined) in female rats was considered to be related to exposure. (Some evidence)

- Exposure to DEHP resulted in increased incidences of nonneoplastic lesions in the liver, pancreas, and uterus in female rats.

- Comparative Carcinogenic Benchmark Dose Analyses

$\circ$ No consistent pattern indicating that perinatal and postweaning exposure was more sensitive compared to postweaning-only exposure and modeled responses were within threefold of each other.

- However, there was a stronger carcinogenic response in the reproductive organs (uterus and testis) in the postweaning-only exposure study compared to the perinatal and postweaning exposure study.

\section{D.2.6. Closing Remarks on the Draft Reports}

Dr. Gabriele Ludewig welcomed additional panel comments on the draft report. There were no additional comments.

Closing the meeting, Dr. Sheena Scruggs thanked all the peer-review panelists.

Dr. Ludewig added her thanks to the NTP staff and the panel members for their efforts.

Dr. Ludewig adjourned the meeting at 2:00 p.m. EDT on April 2, 2021. 


\section{Appendix E. Supplemental Data}

Tables with supplemental data can be found here: https://doi.org/10.22427/NTP-DATA-TR$\underline{600 .} .^{145}$

\section{E.1. Perinatal and Two-year Study in Rats}

E01 - Animal Removal Summary by Treatment Group

1098701_E01_Animal_Removal_Summary_by_Treatment_Group.pdf

E02 - Animals Removed from Experiment

1098701_E02_Animals_Removed_from_Experiment.pdf

E03 - Growth Curves

1098701_E03_Growth_Curves.pdf

E04 - Mean Body Weights and Survival Table

1098701_E04_Mean_Body_Weights_and_Survival_Table.pdf

E05 - Clinical Observations Summary

1098701_E05_Clinical_Observations_Summary.pdf

E08 - Feed Water and Compound Consumption Table

1098701_E08_Feed_Water_and_Compound_Consumption_Table.pdf

Gestational Body Weights

1098701_Gestational_Body_Weights.pdf

Gestational Food Consumption

1098701_Gestational_Food_Consumption.pdf

Gestational and Lactational Chemical Consumption

C1098701_Gestational_and_Lactational_Chemical_Consumption.pdf

\section{Lactational Body Weights}

1098701_Lactational_Body_Weights.pdf

Lactational Food Consumption

C1098701_Lactational_Food_Consumption.pdf

P03 - Incidence Rates of Non-Neoplastic Lesions by Anatomic Site

1098701_P03_Incidence_Rates_of_Non-Neoplastic_Lesions_by_Anatomic_Site.pdf

P04 - Neoplasms by Individual Animal

1098701_P04_Neoplasms_by_Individual_Animal.pdf

P05 - Incidence Rates of Neoplasms by Anatomic Site (Systemic Lesions Abridged)

1098701_P05_Incidence_Rates_of_Neoplasms_by_Anatomic_Site_(Systemic_Lesions_Abridge d).pdf 
P08 - Statistical Analysis of Primary Tumors

1098701_P08_Statistical_Analysis_of_Primary_Tumors.pdf

P09 - Non-Neoplastic Lesions by Individual Animal

1098701_P09_Non-Neoplastic_Lesions_by_Individual_Animal.pdf

P10 - Statistical Analysis of Non-Neoplastic Lesions

1098701_P10_Statistical_Analysis_of_Non-Neoplastic_Lesions.pdf

P11 - Statistical Analysis of Survival Data

1098701_P11_Statistical_Analysis_of_Survival_Data.pdf

P14 - Individual Animal Pathology Data

1098701_P14_Individual_Animal_Pathology_Data.pdf

P17 - Neoplasms by Individual Animal (Systemic Lesions Abridged)

1098701_P17_Neoplasms_By_Individual_Animal_(Systemic_Lesions_Abridged).pdf

P18 - Incidence Rates of Non-Neoplastic Lesions by Anatomic Site with Average Severity

Grades

1098701_P18_Incidence_Rates_of_Non-

Neoplastic_Lesions_by_Anatomic_Site_with_Average_Severity_Grades.pdf

P22 - Cause of Death Summary

1098701_P22_Cause_of_Death_Summary.pdf

P40 - Survival Curves

1098701_P40_Survival_Curves.pdf

PA46R - Summary of Gross Pathology with Litter Incidence

C1098701_PA46R_Summary_of_Gross_Pathology_with_Litter_Incidence.pdf

PA48 - Summary of Tissue Concentration

1098701_PA48_Summary_of_Tissue_Concentration.pdf

PND 1 Litter Data

1098701_PND_1_Litter_Data.pdf

PND 4 and 21 Live Litter Size and Survival

1098701_PND_4_and_21_Live_Litter_Size_and_Survival.pdf

Pup Body Weights

1098701_Pup_Body_Weights.pdf

R02 - Reproductive Performance Summary

1098701_R02_Reproductive_Performance_Summary.pdf

R23 - Gubernaculum Length Summary

C1098701_R23_Gubernaculum_Length_Summary.pdf 


\section{E.2. Individual Animal Data for Perinatal and Two-year Study in Rats}

Female Individual Animal Body Weight Data All Animals

1098701_Female_Individual_Animal_Body_Weight_Data_All_Animals.xls

Female Individual Animal Pathology Data Neoplastic

1098701_Female_Individual_Animal_Pathology_Data_Neoplastic.xls

Female Individual Animal Pathology Data Non-Neoplastic

1098701_Female_Individual_Animal_Pathology_Data_Non-Neoplastic.xls

Female Individual Animal Survival Data

1098701_Female_Individual_Animal_Survival_Data.xls

Female Individual Animal Terminal Body Weight Data

1098701_Female_Individual_Animal_Terminal_Body_Weight_Data.xls

Female Individual Clinical Observations

1098701_Female_Individual_Animal_Clinical_Observations.xls

Male Individual Animal Body Weight Data All Animals

1098701_Male_Individual_Animal_Body_Weight_Data_All_Animals.xls

Male Individual Animal Clinical Observations

1098701_Male_Individual_Animal_Clinical_Observations.xls

Male Individual Animal Neoplastic Pathology Data

1098701_Male_Individual_Animal_Neoplastic_Pathology_Data.xls

Male Individual Animal Organ Weight Data

1098701_Male_Individual_Animal_Organ_Weight_Data.xls

Male Individual Animal Non-Neoplastic Pathology Data

1098701_Male_Individual_Animal_Pathology_Data_Non-Neoplastic.xls

Male Individual Animal Survival Data

1098701_Male_Individual_Animal_Survival_Data.xls

Gubernaculum and Urogenital Findings Data

1098701_Gubernaculum_and_Urogenital_Findings_Data.xls

Individual Animal DamID and PupID Data

1098701_Individual_Animal_DamID_and_PupID_Data.xlsx

Individual Animal Reproductive Performance Data

1098701_Individual_Animal_Reproductive_Performance_Data.xlsx

Individual Animal Tissue Concentration Data

1098701_Individual_Animal_Tissue_Concentration_Data.xlsx 


\section{E.3. Two-year Study in Mice}

E01 - Animal Removal Summary by Treatment Group 1098702_E01_Animal_Removal_Summary_by_Treatment_Group.pdf

E02 - Animals Removed from Experiment

1098702_E02_Animals_Removed_from_Experiment.pdf

E03 - Growth Curves

1098702_E03_Growth_Curves.pdf

E04 - Mean Body Weights and Survival Table

1098702_E04_Mean_Body_Weights_and_Survival_Table.pdf

E05 - Clinical Observations Summary

1098702_E05_Clinical_Observations_Summary.pdf

E08 - Feed Water and Compound Consumption Table

1098702_E08_Feed_Water_and_Compound_Consumption_Table.pdf

P03 - Incidence Rates of Non-Neoplastic Lesions by Anatomic Site

1098702_P03_Incidence_Rates_of_Non-Neoplastic_Lesions_by_Anatomic_Site.pdf

P04 - Neoplasms by Individual Animal

1098702_P04_Neoplasms_by_Individual_Animal.pdf

P05 - Incidence Rates of Neoplasms by Anatomic Site (Systemic Lesions Abridged)

1098702_P05_Incidence_Rates_of_Neoplasms_by_Anatomic_Site_(Systemic_Lesions_Abridge

d).pdf

P08 - Statistical Analysis of Primary Tumors

1098702_P08_Statistical_Analysis_of_Primary_Tumors.pdf

P09 - Non-Neoplastic Lesions by Individual Animal

1098702_P09_Non-Neoplastic_Lesions_by_Individual_Animal.pdf

P10 - Statistical Analysis of Non-Neoplastic Lesions

1098702_P10_Statistical_Analysis_of_Non-Neoplastic_Lesions.pdf

P11 - Statistical Analysis of Survival Data

1098702_P11_Statistical_Analysis_of_Survival_Data.pdf

P14 - Individual Animal Pathology Data

1098702_P14_Individual_Animal_Pathology_Data.pdf

P17 - Neoplasms by Individual Animal (Systemic Lesions Abridged)

1098702_P17_Neoplasms_By_Individual_Animal_(Systemic_Lesions_Abridged).pdf 
P18 - Incidence Rates of Non-Neoplastic Lesions by Anatomic Site with Average Severity Grades 1098702 P18 Incidence Rates of Non-

Neoplastic_Lesions_by_Ānatomic_Site_with_Average_Severity_Grades.pdf

P22 - Cause of Death Summary

1098702_P22_Cause_of_Death_Summary.pdf

P40 - Survival Curves

1098702_P40_Survival_Curves.pdf

\section{E.4. Individual Data for Two-year Study in Mice}

Female Individual Animal Body Weight Data

1098702_Female_Individual_Animal_Body_Weight_Data.xls

Female Individual Animal Clinical Observations

1098702_Female_Individual_Animal_Clinical_Observations.xls

Female Individual Animal Organ Weight Data

1098702_Female_Individual_Animal_Organ_Weight_Data.xls

Female Individual Animal Pathology Data Neoplastic

1098702_Female_Individual_Animal_Pathology_Data_Neoplastic.xls

Female Individual Animal Pathology Data Non-Neoplastic

1098702_Female_Individual_Animal_Pathology_Data_NonNeoplastic.xls

Female Individual Animal Survival Data

1098702_Female_Individual_Animal_Survival_Data.xls

Male Individual Animal Body Weight Data

1098702_Male_Individual_Animal_Body_Weight_Data.xls

Male Individual Animal Clinical Observations

1098702_Male_Individual_Animal_Clinical_Observations.xls

Male Individual Animal Organ Weight Data

1098702_Male_Individual_Animal_Organ_Weight_Data.xls

Male Individual Animal Pathology Data Neoplastic

1098702_Male_Individual_Animal_Pathology_Data_Neoplastic.xls

Male Individual Animal Pathology Data Non-Neoplastic

1098702_Male_Individual_Animal_Pathology_Data_NonNeoplastic.xls

Male Individual Animal Survival Data

1098702_Male_Individual_Animal_Survival_Data.xls 


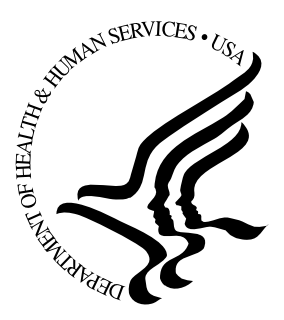

National Toxicology Program

National Institute of Environmental Health Sciences

National Institutes of Health

P.O. Box 12233, MD K2-05

Durham, NC 27709

Tel: 984-287-3211

ntpwebrequest@niehs.nih.gov 